\title{
REFLEXÕES SOBRE PRÁTICA ASSISTENCIAL INOVADORA E DE \\ QUALIDADE DA GRAVIDEZ AO NASCIMENTO
}

ORGANIZADORAS CATIANE RAQUEL SOUSA FERNANDES RAQUEL VILANOVA ARAÚJO MÁRCIA TELES DE OLIVEIRA GOUVEIA 
2021 - Editora Amplla

Copyright (C) Editora Amplla

Editor Chefe: Leonardo Pereira Tavares

Design da Capa: Editora Amplla

Diagramação: Yáscara Maia Araújo de Brito

Projeto Gráfico: Higor Costa de Brito

Reflexões sobre a prática assistencial inovadora e de qualidade da gravidez ao nascimento está licenciado sob CC BY 4.0.

\begin{abstract}
(c) (†) Esta licença exige que as reutilizações deem crédito ao criador. Ele permite que os reutilizadores distribuam, remixem, adaptem e construam o material em qualquer meio ou formato, mesmo para fins comerciais.

O conteúdo da obra e seus dados em sua forma, correção e confiabilidade são de responsabilidade exclusiva dos autores, não representando a posição oficial da Editora Amplla. É permitido o download da obra e o compartilhamento desde que sejam atribuídos créditos aos autores. Todos os direitos para esta edição foram cedidos à Editora Amplla.
\end{abstract}

ISBN: 978-65-88332-91-7

DOI: 10.51859/amplla.esp917.1121-0

Editora Amplla

Campina Grande - PB - Brasil contato@ampllaeditora.com.br www.ampllaeditora.com.br

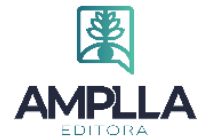




\section{CONSELHO EDITORIAL}

Andréa Cátia Leal Badaró - Universidade Tecnológica Federal do Paraná

Andréia Monique Lermen - Universidade Federal do Rio Grande do Sul

Antoniele Silvana de Melo Souza - Universidade Estadual do Ceará

Bergson Rodrigo Siqueira de Melo - Universidade Estadual do Ceará

Bruna Beatriz da Rocha - Instituto Federal do Sudeste de Minas Gerais

Caio César Costa Santos - Universidade Federal de Sergipe

Carina Alexandra Rondini - Universidade Estadual Paulista

Carla Caroline Alves Carvalho - Universidade Federal de Campina Grande

Carlos Augusto Trojaner - Prefeitura de Venâncio Aires

Carolina Carbonell Demori - Universidade Federal de Pelotas

Cícero Batista do Nascimento Filho - Universidade Federal do Ceará

Clécio Danilo Dias da Silva - Universidade Federal do Rio Grande do Norte

Daniela de Freitas Lima - Universidade Federal de Campina Grande

Denise Barguil Nepomuceno - Universidade Federal de Minas Gerais

Dylan Ávila Alves - Instituto Federal Goiano

Edson Lourenço da Silva - Instituto Federal de Educação, Ciência e Tecnologia do Piauí

Elane da Silva Barbosa - Universidade Estadual do Ceará

Érica Rios de Carvalho - Universidade Católica do Salvador

Gilberto de Melo Junior - Instituto Federal do Pará

Higor Costa de Brito - Universidade Federal de Campina Grande

Italan Carneiro Bezerra - Instituto Federal da Paraíba

Ivo Batista Conde - Universidade Estadual do Ceará

Jaqueline Rocha Borges dos Santos - Universidade Federal Rural do Rio de Janeiro

Jessica Wanderley Souza do Nascimento - Instituto de Especialização do Amazonas

João Henriques de Sousa Júnior - Universidade Federal de Santa Catarina

João Manoel Da Silva - Universidade Federal de Alagoas

João Vitor Andrade - Universidade de São Paulo

Joilson Silva de Sousa - Instituto Federal do Rio Grande do Norte

José Cândido Rodrigues Neto - Universidade Estadual da Paraíba

Jose Henrique de Lacerda Furtado - Instituto Federal do Rio de Janeiro

Josenita Luiz da Silva - Faculdade Frassinetti do Recife

Josiney Farias de Araújo - Universidade Federal do Pará

Karina de Araújo Dias - SME/Prefeitura Municipal de Florianópolis

Laíze Lantyer Luz - Universidade Católica do Salvador

Lindon Johnson Pontes Portela - Universidade Federal do Oeste do Pará

Lucas Capita Quarto - Universidade Federal do Oeste do Pará

Lúcia Magnólia Albuquerque Soares de Camargo - Unifacisa Centro Universitário

Luciana de Jesus Botelho Sodré dos Santos - Universidade Estadual do Maranhão

Luís Paulo Souza e Souza - Universidade Federal do Amazonas

Luiza Catarina Sobreira de Souza - Faculdade de Ciências Humanas do Sertão Central

Manoel Mariano Neto da Silva - Universidade Federal de Campina Grande

Marcelo Alves Pereira Eufrasio - Centro Universitário Unifacisa

Marcelo Williams Oliveira de Souza - Universidade Federal do Pará

Marcos Pereira dos Santos - Faculdade Rachel de Queiroz

Marcus Vinicius Peralva Santos - Universidade Federal da Bahia

Marina Magalhães de Morais - Universidade Federal de Campina Grande

Nadja Maria Mourão - Universidade do Estado de Minas Gerais

Natan Galves Santana - Universidade Paranaense

Nathalia Bezerra da Silva Ferreira - Universidade do Estado do Rio Grande do Norte

Neide Kazue Sakugawa Shinohara - Universidade Federal Rural de Pernambuco

Neudson Johnson Martinho - Faculdade de Medicina da Universidade Federal de Mato Grosso

Patrícia Appelt - Universidade Tecnológica Federal do Paraná

Paulo Henrique Matos de Jesus - Universidade Federal do Maranhão

Rafael Rodrigues Gomides - Faculdade de Quatro Marcos

Reângela Cíntia Rodrigues de Oliveira Lima - Universidade Federal do Ceará

Rebeca Freitas Ivanicska - Universidade Federal de Lavras 
Renan Monteiro do Nascimento - Universidade de Brasília Ricardo Leoni Gonçalves Bastos - Universidade Federal do Ceará Rodrigo da Rosa Pereira - Universidade Federal do Rio Grande Sabrynna Brito Oliveira - Universidade Federal de Minas Gerais Samuel Miranda Mattos - Universidade Estadual do Ceará Shirley Santos Nascimento - Universidade Estadual Do Sudoeste Da Bahia Silvana Carloto Andres - Universidade Federal de Santa Maria Silvio de Almeida Junior - Universidade de Franca Tatiana Paschoalette Rodrigues Bachur - Universidade Estadual do Ceará Telma Regina Stroparo - Universidade Estadual do Centro-Oeste Thayla Amorim Santino - Universidade Federal do Rio Grande do Norte Virgínia Maia de Araújo Oliveira - Instituto Federal da Paraíba Virginia Tomaz Machado - Faculdade Santa Maria de Cajazeiras Walmir Fernandes Pereira - Miami University of Science and Technology Wanessa Dunga de Assis - Universidade Federal de Campina Grande Wellington Alves Silva - Universidade Estadual de Roraima Yáscara Maia Araújo de Brito - Universidade Federal de Campina Grande Yasmin da Silva Santos - Fundação Oswaldo Cruz

Yuciara Barbosa Costa Ferreira - Universidade Federal de Campina Grande 
2021 - Editora Amplla

Copyright (C) Editora Amplla

Editor Chefe: Leonardo Pereira Tavares

Design da Capa: Editora Amplla

Diagramação: Yáscara Maia Araújo de Brito

Projeto Gráfico: Higor Costa de Brito

\section{Dados Internacionais de Catalogação na Publicação (CIP)}

Reflexões sobre a prática assistencial inovadora e de qualidade da gravidez ao nascimento [livro eletrônico] / Catiane Raquel Sousa Fernandes, Raquel Vilanova Araújo, Márcia Teles de Oliveira Gouveia. -Campina Grande : Editora Amplla, 2021.

247 p.

Formato: PDF

ISBN : $978-65-88332-91-7$

1. Enfermagem. 2. Gravidez. 3. Obstetrícia I. Fernandes, Catiane Raquel Sousa. II. Araújo, Raquel Vilanova. III. Gouveia, Márcia Teles de Oliveira. IV. Título.

Sueli Costa - Bibliotecária - CRB-8/5213

(SC Assessoria Editorial, SP, Brasil)

Índices para catálogo sistemático:

1. Enfermagem : Gravidez 610.7

Editora Amplla

Campina Grande - PB - Brasil contato@ampllaeditora.com.br www.ampllaeditora.com.br

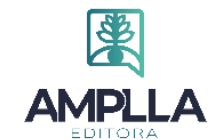




\section{PREFÁCIO}

A apresentação deste livro que traz importantes reflexões sobre prática assistencial inovadora e de qualidade da gravidez ao nascimento organizado pelo Núcleo de Estudos, Pesquisa e Extensão em Cuidado Humano de Enfermagem (NEPECHE).

É uma obra de grande impacto quando se propõe a refletir como está sendo realizada a assistência e quais as repercussões geradas na vida das mulheres, famílias e crianças no transcorrer desse período tão importante.

Ao longo da publicação o leitor poderá apreciar trabalhos com diversas abordagens que são de fundamental relevância para o correto manejo e condução do binômio mãe-filho durante a gestação, parto e pós-parto, inclusive em relação ao processo de abortamento e relativas ao período de Pandemia em que vivemos.

No período gravídico será discutida a importância da inclusão da família no pré-natal, a avaliação da Atenção Primária à Saúde na perspectiva de mulheres segundo a situação gestacional, além de um aprofundamento sobre a assistência de Enfermagem às gestantes com insuficiência renal.

A incidência de sífilis é outro aspecto abordado que afeta bastante as gestações, podendo voltar a tornar-se um problema de Saúde Pública, também teve destaque nos estudos aqui apresentados abordando a prevalência de sífilis congênita em uma capital do nordeste, a implementação do protocolo de investigação de transmissão vertical da sífilis em uma maternidade e um estudo epidemiológico sobre as notificações de sífilis em gestantes.

Sobre o momento do parto, a forma de condução e os cuidados recebidos são trazidas excelentes abordagens em relação à percepção da mulher sobre a violência do contexto do parto, modalidades de posição materna durante o processo de parturição, a percepção de acadêmicos de Enfermagem sobre a violência obstétrica, práticas obstétricas humanizadoras realizadas pela equipe de Enfermagem e a evolução das políticas públicas para humanização do parto e nascimento no Brasil.

Em relação ao período de Pandemia pelo qual estamos passando serão apresentados estudos sobre a assistência ao recém-nascido de mãe suspeita ou confirmada para covid-19 e os cuidados da equipe de saúde ao aleitamento materno em tempos de covid-19. Também se incluiu um olhar especial para as mulheres em 
processo de abortamento com um capítulo dedicado à revisão integrativa da assistência de Enfermagem oferecida a essas mulheres e suas implicações.

Dessa forma, apresentamos aqui uma obra primorosa pois traz em seu escopo 16 capítulos que abordam aspectos muito relevantes da prática assistencial em todo o transcurso da gravidez ao nascimento que servirão tanto de embasamento científico para melhoria da assistência como de descrição do cenário atual dos serviços de atenção à saúde.

A produção é composta por estudos desenvolvidos por discentes dos cursos de graduação em enfermagem, discentes da pós graduação (especialização, residência em enfermagem obstétrica, mestrado e doutorado), enfermeiros assistenciais que atuam na obstetrícia, pediatria e neonatologia e professores experts nas respectivas áreas.

A ideia foi produzir um livro focando em áreas especificas da obstetrícia, bem como divulgar estudos riquíssimos desenvolvidos pelos autores convidados e pesquisadores do núcleo.

Desejamos a todos uma excelente leitura e muita aprendizagem.

Profa. Ma. Livia Maria Melo Viana Profa. Dra. Raquel Vilanova Profa. Marcia Teles 


\section{SUMÁRIO}

CAPÍTULO I - A IMPORTÂNCIA DA INCLUSÃO DA FAMÍLIA NO PRÉ-NATAL 10

DOI: 10.51859/AMPLLA.ESP917.1121-1

CAPÍTULO II - AVALIAÇÃO DA ATENÇÃO PRIMÁRIA À SAÚDE NA PERSPECTIVA DE MULHERES SEGUNDO A SITUAÇÃO GESTACIONAL EM UMA CAPITAL DO NORDESTE

DOI: 10.51859/AMPLLA.ESP917.1121-2

CAPÍTULO III - GESTANTES COM INSUFICIÊNCIA RENAL: CONSIDERAÇ̃̃ES SOBRE A ASSISTÊNCIA DE ENFERMAGEM 38

DOI: $10.51859 /$ AMPLLA.ESP917.1121-3

CAPÍTULO IV - PREVALÊNCIA DE SÍFILIS CONGÊNITA EM UMA CAPITAL DO NORDESTE NO PERIODO DE 2007 A 2017. 50

DOI: $10.51859 /$ AMPLLA.ESP917.1121-4

CAPÍTULO V - PERCEPÇÃO DE ACADÊMICOS DE ENFERMAGEM SOBRE A VIOLÊNCIA OBSTÉTRICA. 62

DOI: $10.51859 / A M P L L A . E S P 917.1121-5$

CAPÍTULO VI - IMPLEMENTAÇÃO DO PROTOCOLO DE INVESTIGAÇÃO DE TRANSMISSÃO VERTICAL DA SíFILIS EM UMA MATERNIDADE MUNICIPAL DO PIAUI

. .81

DOI: 10.51859/AMPLLA.ESP917.1121-6

CAPÍTULO VII - A PERCEPÇÃO DA MULHER SOBRE A VIOLÊNCIA NO CONTEXTO DO PARTO 90

DOI: 10.51859/AMPLLA.ESP917.1121-7

CAPÍTULO VIII - POSIÇÕES ALTERNATIVAS: MODALIDADES DE POSIÇÃO MATERNA DURANTE O PROCESSO DE PARTURIÇÃO.. 107 DOI: $10.51859 /$ AMPLLA.ESP917.1121-8

CAPÍTULO IX - MODALIDADES DE POSIÇÃO MATERNA DURANTE O TRABALHO DE PARTO E PARTO NORMAL .124

DOI: 10.51859/AMPLLA.ESP917.1121-9

CAPÍTULO X - CUIDADOS DA EQUIPE DE SAÚDE AO ALEITAMENTO MATERNO EM TEMPOS DE COVID-19: REVISÃO DE ESCOPO .137

DOI: 10.51859/AMPLLA.ESP917.1121-10

CAPÍTULO XI - ASSISTÊNCIA AO RECÉM-NASCIDO DE MÃE SUSPEITA OU CONFIRMADA PARA COVID-19: REVISÃO DE ESCOPO 
CAPÍTULO XII - PRÁTICAS OBSTÉTRICAS HUMANIZADORAS REALIZADAS PELA EQUIPE DE ENFERMAGEM

DOI: 10.51859/AMPLLA.ESP917.1121-12

CAPÍTULO XIII - SÍFILIS EM GESTANTES: ESTUDO EPIDEMIOLÓGICO SOBRE AS NOTIFICAÇ̃̃ES DO NORDESTE BRASILEIRO E DO ESTADO DO PIAUÍ. .186 DOI: 10.51859/AMPLLA.ESP917.1121-13

CAPÍTULO XIV - EVOLUÇÃO DAS POLÍTICAS PÚBLICAS PARA HUMANIZAÇÃO DO PARTO E NASCIMENTO NO BRASIL .202

DOI: 10.51859/AMPLLA.ESP917.1121-14

CAPÍTULO XV - ASSISTÊNCIA DE ENFERMAGEM ÀS MULHERES NO PROCESSO DE ABORTAMENTO: REVISÃO INTEGRATIVA....218 DOI: 10.51859/AMPLLA.ESP917.1121-15

CAPÍTULO XVI - IMPLANTAÇÃO DA CONSULTA DE ENFERMAGEM NO SEGUIMENTO DO PREMATURO DE RISCO. .235

DOI: 10.51859/AMPLLA.ESP917.1121-16 


\title{
CAPITULOI
}

\section{A IMPORTÂNCIA DA INCLUSÃO DA FAMIILA NO PRÉ- NATAL}

미: 10.51859/amplla.esp917.1121-1

\author{
Millena Daniella Soares Quixabeira Santos ${ }^{1}$ \\ Soraia da Silva Aires ${ }^{2}$ \\ Sara Machado Miranda Leal Barbosa ${ }^{3}$ \\ Deisiane da Silva Mesquita ${ }^{4}$ \\ Marilene de Sousa Oliveira ${ }^{5}$ \\ Maria Regivania Da Silva Santos 6
}

\footnotetext{
${ }^{1}$ Pós graduanda do curso de Enfermagem obstétrica pela Faculdade Instituto de Ensino Superior Múltiplo IESM

${ }^{2}$ Graduanda do curso de Enfermagem pela Faculdade Instituto de Ensino Superior Múltiplo - IESM

3 Enfermeira Dra em Saúde Pública(UFMA), CCIH HU ufpi, HUT. Teresina Piaúi.

${ }^{4}$ Enfermeira Mestra. Epidemiologista da secretaria de Saúde do Pará.

${ }^{5}$ Enfermeira. Mestra em Saúde e comunidade(UFPI). Responsável Técnica pelo Programa de Hepatites Virais /toxoplasmose. SESAPI.

${ }^{6}$ Enfermeiro, Mestre em Enfermagem pela UFPI. Especialista em Saúde da Família -UFPI, Enfermeiro da Estratégia Saúde da Família - Teresina.
}

\section{RESUMO}

Objetivou-se com essa pesquisa analisar a importância da inclusão da família nas consultas pré-natal. Trata-se de uma revisão de literatura integrativa realizada na base de dados da Biblioteca Virtual em Saúde (BVS); Scientific Eletronic Library Online (Scielo) e Google Shcolar. Incluíram-se estudos publicados em português no período de 2016 a 2021 e disponíveis na íntegra. A amostra foi constituída por 18 artigos. Com a análise de dados pode-se perceber que à família são atribuídos diversos significados apresentando-se como agente transformador da sociedade a partir do meio onde está inserida. A gestação traz muitas transformações para a mulher, transformações estas que contemplam os campos emocional, físico e social tornando-se fase de autoconhecimento e de muitas dúvidas. Dúvidas estas que passam a serem supridas nas consultas pré-natais. 0 pré-natal é o momento onde a gestante pode ter apoio por parte dos profissionais que oferecem informações acerca do período que abrange desde a descoberta da gravidez até o parto e puerpério. Contudo, as orientações fornecidas devem ser passadas também para o acompanhante da mulher que pode ser de livre escolha da mesma. Este acompanhante geralmente é o homem/pai que fornece suporte emocional e ativa sua paternidade criando vínculos com o bebê desde a gravidez. Além do pai, a mãe da gestante também é um dos principais sujeitos que está presente no acompanhamento pré-natal.

Palavras-chave: Gestação; Família; Cuidados; Pré-Natal. 
A família é uma construção sócio-histórica que tem sofrido transformações quanto aos seus significados e estrutura. Sendo as relações definidas por ela e a partir dela, a família tem como função aplicar as primeiras noções de sociabilidade aos indivíduos assim que nascem sendo o primeiro contato do ser humano com o mundo. Portanto, tem-se na família o instrumento primário de formação de um novo ser. É nela que a gestante encontra suporte para a nova fase da vida que ela irá passar: a gravidez (PRADO, 2017).

Tendo em vista os novos arranjos familiares, os dispositivos legais afirmam que o auxílio de um acompanhante é importante para que a mulher grávida tenha auxílio e se sinta bem durante todo o processo de gravidez tendo em vista a dimensão de promoção à saúde e os cuidados humanizados à gestação estabelecidos pelo Programa de Humanização (BRASIL, 2001).

Desta forma, na família podem estar incluídos pais, avós, tios, amigos próximos, dentre outros que estão inclusos nas relações não somente de sangue, mas também nas relações afetivas que funcionam como rede de apoio a gestante desde a descoberta da gravidez até o parto (CAMPOS e NUNES, 2017).

0 pré-natal mostra-se como momento importante no processo de maternidade dado que é neste período que a mulher pode sanar dúvidas em torno do nascimento da criança e das transformações fisiológicas bem como encontrar suporte emocional para entender o andamento da gravidez. Para isso, o apoio de um acompanhante apresenta-se como direito para que esse processo ocorra da melhor maneira possível (GUEDES, 2019).

Portanto, o acompanhamento pré-natal é alvo deste trabalho apontando para a importância da inclusão de membros da família nesse momento de mudanças na vida da mulher e como rede de apoio. Tem-se como objetivo elucidar sobre essa importância assim como entender em que medida ocorre a influência desse acompanhamento. 
O presente trabalho trata-se de uma revisão integrativa tendo em vista que a revisão integrativa tem como proposta a análise de resultados de maneira sistemática, ordenada e abrangente. Fornece informações mais amplas sobre um tema com fontes de origem secundária através de levantamento de dados. Com rigor metodológico conciso e criterioso, a pesquisa aumenta a credibilidade na apresentação de resultados para estudos posteriores.

Nesse estudo optou-se por bases de dados conhecidas no meio acadêmico, foram estas: Biblioteca Virtual de Saúde (BVS), Scientific Electronic Library Online (SciELO) e Google Scholar com os descritores "família”, "pré-natal”, "cuidados" e "gestação". Realizando o cruzamento dos descritores com o operador boleano "AND". Com o cruzamento dos descritores obteve-se um resultado de 22.629 artigos científicos. Foi determinada a amostra final após a inserção dos critérios de inclusão e exclusão definidos para creditar a pesquisa de maneira minuciosa.

A coleta dos dados ocorreu no mês de abril de 2021 somente por meio eletrônico. Os critérios para inclusão e exclusão foram: trabalhos publicados em língua portuguesa; disponíveis na íntegra, gratuitos e publicados no período de 2016 a 2021. O recorte temporal se justifica para manter-se a atualidade dos trabalhos que contemplam essa temática. Com destaque para os dispositivos legais que foram utilizados o ano em que entraram em vigor. Exemplificando, o Programa de Parto, Aborto e Puérperio: assistência humanizada à mulher.

A seleção se deu por meio da leitura dos títulos e resumos, após a adequação com o tema proposto, prosseguiu-se para a leitura na íntegra de estudos que atenderam o objetivo da pesquisa. Comparando os resultados encontrados nas bases de dados, houveram repetições entre todas as bases de dados, excluindo os mesmos do refinamento final.

Após a leitura dos artigos na íntegra, 17 trabalhos foram selecionados e categorizados por temas centrais: a gestação, família e seus significados, a importância do pré-natal, a importância da família no pré-natal e envolvimento do pai no pré-natal. 
Como resultado da pesquisa bibliográfica, do total de 17 trabalhos, incluindose artigos e livros, foram encontrados 8 artigos com enfoque no pai como acompanhante e sujeito ativo no processo do pré-natal, 4 relacionados a construção do conceito de família e 5 relacionados a mulher e o significado da gestação. Apesar dos temas divergirem, os artigos mostraram-se complementares trazendo ao levantamento de dados interlocuções e diversidade a pesquisa.

\section{DISCUSSÕES}

\subsection{A FAMILLIA E SEUS SIGNIFICADOS}

Os conceitos utilizados para definir família são oriundos de aspectos sociais e culturais, sendo assim, mutáveis. Ainda que não exista um conceito único de família, é importante dizer que o conceito ocidental é o mais comumente utilizado no Brasil. 0 modelo nuclear: pai, mãe e filhos, é o modelo mais privilegiado no que tange o modelo historicamente construído, que remete a família tradicional burguesa pondo significados explícitos sobre a mulher (mãe/cuidadora) e o homem (pai/provedor) (SEGUIN et al., 2016).

A instituição família se adequa as mudanças temporais e das relações interpessoais como produto do meio ao qual está inserida. Sendo sujeita a aspectos sociais, vale salientar que como construção social tem influência crucial em sua composição. Citando-se um exemplo, famílias de baixa renda possuem uma rede de apoio ampla contando com membros que estão fora do ambiente residencial privilegiando os laços de afetividade. Não excludente, as famílias com rendas elevadas têm seu núcleo em relações de consanguinidade reproduzindo o conceito de família nuclear (OLIVEIRA, 2017).

Portanto, a família é ambiente de sociabilidade, da afetividade e do bem estar físico dos indivíduos. Alvo de políticas e basilar na sociedade, a família é tema de estudo para vários autores. Para estes estudiosos, as famílias são agentes transformadores da sociedade e elas são capazes de definir os costumes e princípios de acordo com o tempo e local, estando assim para além de um fenômeno natural constituindo-se também de interações sociais (PRADO, 2017). 
Desse modo, família envolve a reprodução biológica e social dos homens, considerando o espaço da casa assim como as redes de relações familiares que estão para além do ambiente doméstico constituindo-se, dessa maneira, por vínculos de afetividade, de aliança e de adoção que extrapolam as questões de sangue prezando os vínculos afetivos e de cuidado mútuo (CAMPOS e NUNES, 2017).

No Brasil, com a Constituição de 1988, a família passa a ter função essencial na sociedade em todas as Políticas Públicas, inclusive na Política de Saúde constituinte do tripé da Seguridade Social no Brasil, preconizada pela vigente Carta Magna. A família se torna parte significativa na construção do ser social começando dos primeiros passos com a chegada do recém-nascido e até mesmo antes com o processo do pré-natal (XAVIER, 2016).

\subsection{A GESTAÇÃO E O PRÉ-NATAL}

A gestação vem acompanhada de muitas transformações na vida da mulher que abarcam os campos emocional, social e fisiológico da mesma. As alterações corporais são visíveis, mas a partir do momento da descoberta da gravidez ela passa por diversos tipos de emoções que se intensificam e podem causar confusão e ambivalências tendo em vista que esse período de mudanças ao mesmo tempo em que pode trazer alegrias também traz inseguranças, medos e dúvidas (FERREIRA et al., 2017).

A maternidade, nova fase que a mulher passa a vivenciar, também é período de significativas alterações que afetam a saúde da mulher, do bebê e os cuidados maternos com a criança ao mesmo tempo em que representa adaptações e reorganização da vida para a chegada de um novo indivíduo à família. Sendo assim, não somente a mulher, mas toda a rede de apoio na qual ela está inserida passa por essas modificações considerando que o ser humano é ser social e encontra-se envolvido em uma rede de apoio na sociedade (MAGALHÃES et al., 2018).

A gestação exige um acompanhamento e é neste momento que se deve buscar atendimento especializado com o pré-natal. A atenção pré-natal deve ser humanizada e qualificada por meio dos serviços de saúde básico, médio e de alta complexidade se necessário for envolvendo ações de promoção, prevenção e assistência em saúde à gestante e à criança (BALICA e AGUIAR, 2019).

Para o bom andamento da gestação, a adequada assistência pré-natal é crucial para o processo de parturição e puerpério, visto que como preconiza a 
Programa de Humanização, o direito de livre escolha do acompanhante, a ambiência e as boas práticas na assistência fazem parte dos fatores que condicionam a qualidade da assistência ao parto (SANTOS et al., 2019).

De acordo com o Programa de Humanização no Pré-Natal e Nascimento, o incentivo a assistência pré-natal, humanizando o parto, preconiza o preparo adequado para o momento do nascimento, processo este iniciado com o pré-natal. Um atendimento acolhedor deve ser oferecido tanto a gestante quanto ao seu acompanhante que poderá estar ao seu lado durante o pré-natal, durante o trabalho de parto e parto, vivenciando junto à mulher a experiência do nascimento (BRASIL, 2001).

O acompanhante pode ser algum membro da família. Destaca-se que, orientações em torno do processo gestacional, mudanças corporais e emocionais durante a gravidez, trabalho de parto, parto e puerpério, cuidados com o recémnascido e amamentação, devem ser informados tanto a gestante quanto ao seu acompanhante, pois os dois sujeitos estão incluídos na participação da vida e cuidados com o recém-nascido. Daí a importância de inclusão do acompanhante (família) neste processo (BRASIL, 2001).

É necessário destacar que, a gestante é o foco principal desse processo, mas junto com ela incluir a família é primordial. Desta forma, a família se mostra de extrema importância para o bom andamento do pré-natal uma vez que, esta mesma rede pode fornecer à gestante apoio emocional e material para o binômio mulherbebê (MAGALHÃES et al., 2018).

\subsection{A IMPORTÂNCIA DA FAMILIA NO ACOMPANHAMENTO PRÉ-NATAL}

Pesquisas realizadas constatam que o papel do acompanhante é essencial para a mulher. Os motivos aos quais levam as mulheres a escolher os acompanhantes são diversos, sendo a principal escolha do pai/companheiro para vivenciar o momento da gestação no pré-natal, tendo em vista que, fortalece os vínculos entre o casal e a construção da paternidade participativa e afetiva, pois o homem/pai inicia um vínculo com a criança desde antes do parto estabelecendo melhor preparo para este homem para a paternidade. (AMORIM et al., 2020)

Entretanto, ainda que o homem/pai seja uma das escolhas mais constantes não é a única e também não exclui a possibilidade de haverem outros membros da família como acompanhantes. As mães da gestante também exercem papel 
importante nessa fase, seja pela indisponibilidade do companheiro/pai ocasionados por motivos de trabalho ou por possuir um vínculo afetivo e de confiança maior com a mulher/mãe (AMORIM et al., 2020).

Antes de passarem pelo pré-natal, a gestante e sua família chegam com muitas dúvidas, curiosidades e medos. Portanto, durante esse período são fornecidas informações em torno do processo ao qual a gestante irá passar, informações estas que favorecem a gestante e suas necessidades normalizando o período gestacional (GUEDES, 2019).

Ainda que a gestante possa contar com uma rede de apoio familiar, o papel do pai ainda é muito importante no que tange ao acompanhamento pré-natal. Alvo da maioria das pesquisas, o pai (homem) passa a ser desmitificado e incentivado a ocupar um espaço maior no que diz respeito aos cuidados com a gestante e seu filho (GOMES e SILVA, 2019).

O homem vive a paternidade principalmente como provedor material responsável pela manutenção financeira da família. É uma construção social que data desde os primórdios da existência humana. 0 homem estereotipado como desprovido de interesse e de cuidados passa incitado a participação em todo o processo gravídico puerperal. (LIMA, 2014)

Os serviços de saúde incentivam cada vez mais a inclusão do pai nas consultas e palestras pré-natal. O Ministério da Saúde o incluiu oficialmente no contexto da Política Nacional de Atenção Integral à Saúde do Homem (PNAISH) tornando-o sujeito ativo no pré-natal dotado de necessidades emocionais e físicas. Com isto, o homem/pai pode fornecer apoio à mulher/mãe a auxiliando com suporte afetivo e favorecendo, assim, maior facilidade no parto (PETITO et al., 2017).

Historicamente, os homens têm sido considerados desnecessários no processo de pré-natal. Entretanto, a literatura evidencia que os homens fornecem contribuições únicas nessa fase que influenciam o crescimento e desenvolvimento da criança. A presença do homem nas consultas de pré-natal além de demonstrar suporte para a mulher também pode desencadear processo de conforto através de elogios, conversas e ajuda nas tarefas domésticas demonstrando compreensão e proatividade. Somando-se a isso, o pai também dinamiza as consultas tornando-as participativas ao mesmo tempo em que, proporciona a gestante maior facilidade 
durante o parto. Alguns homens acreditam que sua presença pode causar desconforto para a mulher (SILVA et al., 2021).

\section{CONSIDERAÇOEES FINAIS}

Ainda que a mulher seja protagonista durante o período pré-natal não torna excludente a necessidade de acompanhante durante as consultas. Considerando que a busca por uma assistência humanizada preconiza a presença de alguém em todo esse processo. Os benefícios advindos da presença de um acompanhante são atestados e dentre eles estão segurança, confiabilidade e tranquilidade que são oferecidos às mulheres que acarretam em diminuição de intervenções desnecessárias bem como oportunizar um processo singular, natural e fisiológico aliado ao protagonismo da mulher.

O período pré-natal está para além do espaço de tempo entre a descoberta da gravidez e o parto. Portanto, significa o momento em que a gestante tem a oportunidade de tirar suas dúvidas com relação a gravidez e outros aspectos que acometem a mulher nessa nova fase. 0 acompanhamento pré-natal deve agregar a família da gestante tendo em vista que é direito garantido pelos dispositivos legais contar com a rede de apoio para suporte emocional.

A participação do pai no pré-natal é campo de discussões e investimentos visto que ainda é campo pouco explorado pelas políticas de saúde. Apesar dos avanços neste sentido, pode-se notar que ainda são lentos resultando na ausência do pai no acompanhamento da gestação. Contudo, os estudos demonstram que o acompanhamento do homem nas consultas pré-natal promove apoio à mulher, o que acarreta tranquilidade a mesma durante o processo de gestação.

O pai como principal sujeito nessa rede de apoio familiar, não anula a escolha da gestante por outros membros da família para fazer parte das consultas pré-natal sendo também solicitada a presença da mãe dessa gestante. Com isso, a livre escolha da gestante também conta na hora do oferecimento desse suporte. 
AMORIM, T.; AGUIAR, L. A. de A.; PEREIRA, M. de A. C.; MARCATTO, J. de O. Critérios para escolha do acompanhante durante o trabalho de parto. Revista Baiana de Enfermagem, Salvador, v. 34, n. 1, p. 1-8, nov. 2020. Disponível em: http://www.revenf.bvs.br/scielo.php?script=sci_arttext\&pid=S217886502020000100342. Acesso em: 26 abr. 2021.

BALICA, L. O.; AGUIAR, R. S. Percepções paternas no acompanhamento do prénatal. Revista Atenção À Saúde, São Caetano do Sul, v. 17, n. 615934, p. 114$126.2019 . \quad$ Disponível em: https://seer.uscs.edu.br/index.php/revista_ciencias_saude/article/view/59 34. Acesso em: 26 abr. 2021.

BRASIL. Ministério da Saúde. Parto, aborto e puerpério: assistência humanizada à mulher. Brasília: Ministério da Saúde, 2001. Disponível em: https://bvsms.saude.gov.br/bvs/publicacoes/cd04_13.pdf. Acesso em: 26 abr. 2021.

CAMPOS, M. S. de; NUNES, I. de O. Família: conceitos, preceitos e construção. conceitos, preceitos e construção. 2017. Disponível em: https://eventosacademicos.ufmt.br/index.php/seminarioichs/seminarioich s2017/paper/viewFile/5554/1529. Acesso em: 26 abr. 2021.

FERREIRA, T. N. et al. A importância da participação paterna durante o pré-natal: percepção da gestante e do pai no município de Cáceres-MT. Revista Eletrônica Gestão \& Saúde, Mato Grosso, v. 5, n. 02, p. 337-345, ago. 2017. Disponível em: https://periodicos.unb.br/index.php/rgs/article/view/432. Acesso em: 26 abr. 2021.

GOMES, E. M. da S.; SILVA, R. A. M. da. Pré-natal masculino: as dificuldades da inclusão paterna no ciclo gravídico. 2019. 24 f. TCC (Graduação) - Curso de Enfermagem, Faculdade Cesmac do Sertão, Palmeira dos Índios, 2019. Disponível em: https://ri.cesmac.edu.br/handle/tede/572. Acesso em: 26 abr. 2021.

GUEDES, R. K. O. Pré-natal masculino nas estratégias de saúde da família: realidade ou utopia. 2019. 32 f. TCC (Graduação) - Curso de Enfermagem, Universidade Federal de Campina Grande, Cuité, 2019. Disponível em: https://t.me/c/1432836968/233. Acesso em: 26 abr. 2021.

LIMA, F. L. A. Construção da identidade paterna: repercussões no pré-natal masculino. 2014. 238 f. Tese (Doutorado) - Curso de Psicologia, Universidade Federal da Paraíba, João Pessoa, 2014. Disponível em: https://repositorio.ufpb.br/jspui/bitstream/tede/7644/2/arquivototal.pdf . Acesso em: 26 abr. 2021. 
MAGALHÃES, S. Q. C.; FRACOLLI, L. A.; SIQUEIRA, L. D.; CHIESA, A. M.; RETICENA, K. de 0 . Contribuições do pré-natal para o autocuidado de mulheres assistidas por equipes de saúde da família. 2018. Disponível em: https://periodicos.uem.br/ojs/index.php/CiencCuidSaude/article/view/39 994. Acesso em: 26 abr. 2021.

OLIVEIRA, A. C. de. Famílias, cuidados e políticas públicas no Brasil contemporâneo. Arquivo Nacional, Rio de Janeiro, v. 30, n. 1, p. 195-208, jan. 2017.

em: http://revista.arquivonacional.gov.br/index.php/revistaacervo/article/vie w/780/791. Acesso em: 26 abr. 2021.

PRADO, D. 0 que é família? Tatuapé: Brasiliense, 2017. 74 p. Disponível em: https://books.google.com.br/books?hl=pt-

BR\&lr=lang_pt\&id=bmkvDwAAQBAJ\&oi=fnd\&pg=PT4\&dq=o+que+\%C3\%A 9+familia\&ots=s3ROZewKfW\&sig=kZ5PyVEAwh8poeT9bfxoOC7P36M\#v=o nepage \&q\&f=false. Acesso em: 26 abr. 2021.

PETITO, A. D. de C.; CÂNDIDO, A. C. F.; RIBEIRO, L. O.; PETITO, G. A importância da participação do pai no ciclo gravídico puerperal: uma revisão bibliográfica. 2017. Disponível em: http://periodicos.unievangelica.edu.br/index.php/refacer/article/view/33 67/2367. Acesso em: 26 abr. 2021.

SANTOS, D. S. S. dos; ROSÁRIO, C. R. do; BRITO, H. do E. S. de; SOARES, T. M.; BISPO, T. C. F. Importância da participação paterna no pré-natal para compreensão do parto e puerpério: uma revisão sistemática. Revista Brasileira de Saúde Funcional: Promoção da saúde e prevenção de agravos à saúde em diversos contextos, Cachoeira, v. 5, n. 2, p. 55-68, set. 2018. Disponível em: https://seer-adventista.com.br/ojs3/index.php/RBSF/article/view/972. Acesso em: 26 abr. 2021.

SEGUIN, É.; ARAÚJO, L. M de; NETO, M. dos R. C. Uma nova família: a multiespécie. Revista de Direito Ambiental, São Paulo, v. 82, n. 1, p. 01-09, abr. 2016. Disponível em: https://dspace.almg.gov.br/handle/11037/21807. Acesso em: 26 abr. 2021.

SILVA, C.; PINTO, C.; MARTINS, C. Transição para a paternidade no período prénatal: um estudo qualitativo. Ciência \& Saúde Coletiva, Rio de Janeiro, v. 26, n. 1 , p. 01-10, fev. 2021. Disponível em: https://www.scielo.br/j/csc/a/cNfcnJXBhkm39yN7YxTMffd/?lang=pt. Acesso em: 26 abr. 2021.

SILVA, P. S. da; MARTEllO, J. M. dos S.; RUFFONI, L. D. G.; ANDRADE, J. C. de; STRADA, C. F. de O. Participação dos pais no programa pré-natal masculino na cidade de Santa Terezinha de Itaipu-PR. Varia Scientia: Ciências da Saúde, Cascavel, v. 3, n. 2, p. 173-180, set. 2017. Disponível em: http://erevista.unioeste.br/index.php/variasaude/article/view/17677. Acesso em: 26 abr. 2021.

XAVIER, L. B. e. A família brasileira em face da História e do Direito. Revista Científica Fagoc Jurídica, Ubá, v. 1, n. 1, p. 39-52, set. 2016. Disponível em: 
https://revista.fagoc.br/index.php/juridico/article/view/55. Acesso em: 26 abr. 2021. 


\title{
CAPITULO $\|$
}

\section{AUALACC̄̃O DA ATENCÃO PRIMÁRIA À SAÚDENA PERSPECTIUA DEMULHERES SEGUNDO A SITUACÃO GESTACIONAL EM UMA CAPITALDO NORDESTE}

DDI: 10.51859/amplla.esp917.1121-2

\author{
Lívia Maria Mello Viana ${ }^{1}$ \\ Inez Sampaio Nery ${ }^{2}$ \\ Francidalma Soares Sousa Carvalho Filha ${ }^{3}$ \\ Iel Marciano de Moraes Filho ${ }^{4}$
}

\footnotetext{
${ }^{1}$ Mestre em Enfermagem. Discente de Bacharelado em Estatística da Universidade Federal do Piauí (UFPI). Enfermeira da Fundação Municipal de Saúde (FMS) de Teresina.

${ }^{2}$ Pós-Doutora em Enfermagem. Docente da UFPI.

${ }^{3}$ Doutora em Saúde Pública. Doutoranda do PPGEnf (UFPI). Docente da Universidade Estadual do Maranhão (UEMA).

${ }^{4}$ Mestre em Ciências Ambientais e Saúde. Doutorando em Sociedade, Tecnologia e Meio Ambiente. Docente da Universidade Paulista (UNIP).
}

\section{RESUMO}

Atenção Primária à Saúde (APS) representa o primeiro contato na rede assistencial dentro do sistema de saúde, caracterizando-se, principalmente, pela continuidade e integralidade da atenção, além da coordenação da assistência no sistema, atenção centrada na família, orientação e participação comunitária e competência cultural dos profissionais. Objetivouse avaliar a APS segundo a situação gestacional das usuárias por meio da aplicação do PCATool. Trata-se de um estudo exploratório, descritivo de corte transversal. A população foi composta por usuárias adultas atendidas pelas equipes de Saúde da Família da zona urbana de Teresina com utilização de amostragem aleatória simples por conglomerado. A moldura da amostragem compôs-se de 146 equipes com um total de 1098 usuárias. As usuárias eram adultos jovens com média de 29,35 anos com baixo nível socioeconômico. Na resolução da gestação em parto normal avaliaram como de baixo escore geral da APS $(0,51$; $\mathrm{p}<0,01$ ), onde quanto maior o número de gestações e parto normal pior é a avaliação em relação ao serviço de saúde. Na realização de pré-natal em gestações anteriores observa-se que, entre as que não estavam grávidas ou que estavam na primeira gestação e não tinham experiência com assistência pré-natal, $50 \%(\mathrm{p}=0,035)$ considera a APS como de baixo escore geral. Porém ressalta-se que as que fizeram o pré-natal completo classificam como alto escore geral da APS $(\geq 6,6)$. Assim, faz-se importante estudar os atributos da APS uma vez que esta vem sendo apontada como um dos principais pilares para a efetivação de uma assistência de qualidade.

Palavras-chave: Atenção Primária à Saúde. Avaliação de Programas e Projetos de Saúde. 
A Constituição Federal Brasileira de 1988 marca a consolidação do Sistema Único de Saúde (SUS) como sistema de saúde vigente no país, com intuito de garantia de acesso universal aos serviços e estabelece a saúde como direito do cidadão. Este processo permitiu uma nova configuração dos serviços de saúde, priorizando ações de caráter coletivo e preventivo em substituição às ações individuais e curativas, até então, predominantes (NASCIMENTO; NASCIMENTO, 2005; CARNEIRO et.al., 2008; SANTOS et. al., 2008).

Em busca do fortalecimento dos princípios do SUS, o Ministério da Saúde (MS) baseou-se nas experiências de países como Inglaterra, Canadá, Espanha e Cuba para implementar mudanças na assistência ambulatorial nacional. Esses países organizaram seus sistemas de saúde dando prioridade à atenção de acesso universal, continuada e integral junto à comunidade, isto é, desenvolveram sistemas orientados para Atenção Primária à Saúde (APS) (OLIVEIRA, 2007).

A APS representa um complexo conjunto de conhecimentos e procedimentos e demanda uma intervenção ampla em diversos aspectos para que se possa ter efeito positivo sobre a qualidade de vida da população. Na definição já clássica de Starfield (2004), APS representa o primeiro contato na rede assistencial dentro do sistema de saúde, caracterizando-se, principalmente, pela continuidade e integralidade da atenção, além da coordenação da assistência dentro do próprio sistema, da atenção centrada na família, da orientação e participação comunitária e da competência cultural dos profissionais.

Assim, para uma melhor assistência na APS faz-se necessário o cumprimento das diretrizes e princípios do SUS, particularmente do atendimento integral ao usuário, tendo em vista sua implicação numa prática de qualidade, que desenvolva capacidade de análise crítica de contextos. A ação integral pressupõe mudanças nas relações de poder entre os profissionais de saúde e entre o profissional e a gestante (PINHEIRO, 2007).

Mendes (2002) afirma que a APS deve cumprir, nas redes de atenção à saúde, três funções: resolução, coordenação e responsabilização para que todo sistema funcione de forma eficiente. A função de resolução, intrínseca à sua instrumentalidade como ponto de atenção à saúde, consiste em solucionar a grande 
e maioria dos problemas de saúde; a função de coordenação, relacionada ao desempenho do papel de centro de comunicação, consiste em organizar os fluxos e contrafluxos das pessoas e objetos pelos diversos pontos de atenção à saúde da rede; e a função de responsabilização consiste em co-responsabilizar-se pela saúde dos usuários em quaisquer pontos de atenção em que sejam atendidos.

Dessa forma, a APS pode ser definida como: um conjunto de valores - direito ao mais alto nível de saúde, solidariedade e equidade - um conjunto de princípios responsabilidade governamental, sustentabilidade, intersetorialidade, participação social, entre outros - e como um conjunto indissociável de elementos estruturantes - atributos - do sistema de serviços de saúde: acesso de primeiro contato, integralidade, longitudinalidade, coordenação, orientação familiar e comunitária e competência cultural (BRASIL, 2010).

Starfield (1992) define a APS como o primeiro nível de assistência dentro do sistema, caracterizando-se, principalmente, pela continuidade e integralidade da atenção, além da coordenação da assistência dentro do próprio sistema, da atenção centrada na família, da orientação comunitária das ações e da competência cultural dos profissionais. Assim, define os quatro atributos essenciais da APS: o acesso de primeiro contato do indivíduo com o sistema de saúde, a continuidade e a integralidade da atenção e a coordenação da atenção dentro do sistema; enfatiza a presença de outras três características, chamadas atributos derivados: orientação familiar, orientação comunitária e competência cultural (Figura 01).

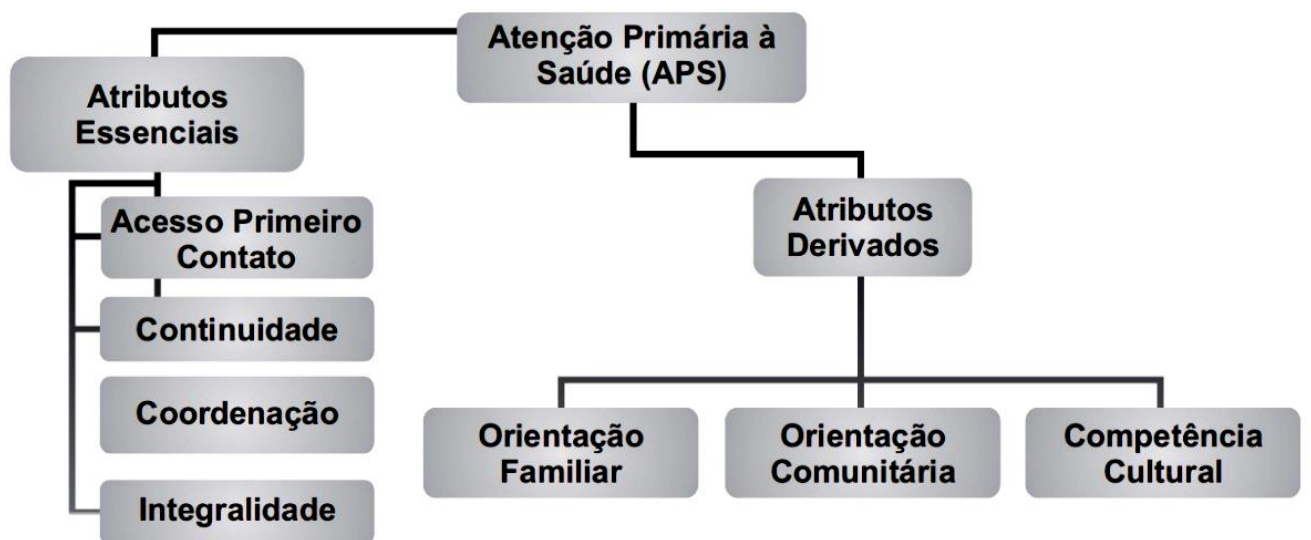

Figura 01 - Atributos essenciais e derivados da atenção primária à saúde. Fonte: Criado a partir de Starfield (1992)/ Adaptado por Harzheim, Stein e Álvarez-Dardet (2004).

Esses atributos podem ser avaliados separadamente, apesar de se apresentarem intimamente inter-relacionados na prática assistencial, individual ou 
coletiva, dos serviços de APS. Assim, um serviço de atenção básica dirigido à população geral pode ser considerado provedor de atenção primária quando apresenta os quatro atributos essenciais, aumentando seu poder de interação com os indivíduos e com a comunidade ao apresentar também os atributos derivados. Nessa perspectiva, a eSF é uma oportunidade de requalificação do trabalho em saúde para uma defesa do SUS. Dentre as inovações trazidas pela eSF, destaca-se o vínculo da população a uma equipe básica de saúde, composta por 01 médico generalista, 01 enfermeira1, 01 auxiliar de enfermagem e 04 a 06 agentes comunitários de saúde (ACS). A participação do Enfermeiro nas equipes da eSF tem sido de fundamental importância para o fortalecimento deste modelo assistencial, no entanto, também é notório que este papel vem sendo submetido a impasses e desafios (BENIGNA; NASCIMENTO; MARTINS, 2004).

Os serviços de Atenção Primária devem responder às necessidades de saúde da população e estar organizados em uma estrutura hierarquizada, de forma que, caso haja necessidade, possa ter garantida a atenção em um nível de maior complexidade (ALVES, 2005). Portanto, a avaliação da presença dos atributos da APS e do funcionamento da eSF em consonância com os princípios do SUS, deve ser uma atividade a acontecer no âmbito nacional, regional e local, com vistas a fornecer subsídios para as adequações necessárias, principalmente por se tratar de um processo em implantação e tendência a universalização.

Para viabilizar o desenvolvimento do estudo, elegeu-se a atenção as usuárias das Unidades Básicas de Saúde de Teresina - PI como condição traçadora da atenção. A opção pela atenção as usuárias basearam-se nos seguintes quesitos: constituem a população adulta que mais procura os serviços de saúde no Brasil; a maioria das políticas públicas implementadas na $\mathrm{AB}$ são voltadas ou relacionadas à população feminina; o atendimento adequado a tal grupo requer a existência de um vínculo longitudinal com a equipe de APS.

Assim sendo, o presente estudo objetivou avaliar a Atenção Primária à Saúde segundo a situação gestacional das usuárias das Unidades Básicas de Saúde de Teresina - PI por meio da aplicação do PCATool.

1 Em função de a Enfermagem ser uma profissão composta predominantemente por mulheres, decidiu-se manter a nomenclatura no feminino. 
Trata-se de um estudo de natureza exploratória, descritivo de corte transversal com abordagem quantitativa, realizado com as usuárias da eSF do município de Teresina, capital do Piauí. Teresina possuía uma densidade demográfica de 584,95 hab/ $\mathrm{Km}^{2}$, com população estimada em $2011 \mathrm{de}$ 822.364 pessoas (IBGE, 2011). O município apresenta 229 Equipes da eSF, sob coordenação de três regionais de Saúde: Sul, Leste-Sudeste e Centro-Norte.

A Fundação Municipal de Saúde (FMS), órgão de gestão da Atenção Básica do município de Teresina, possui 73 Unidades Básicas de Saúde (UBS) onde, em alguns casos, mais de uma equipe funciona em uma mesma Unidade. Foram selecionadas usuárias de forma proporcional às equipes da eSF distribuídas nas três regionais: 294 (26,8\%) da Regional Leste-Sudeste, 354 (32,2\%) da Sul e 450 (41\%) da CentroNorte.

Utilizou-se amostragem aleatória simples por conglomerado por não se dispor de um cadastro único da população feminina usuária do serviço de saúde e por motivos de ordem prática e econômica, onde se divide uma população em pequenos grupos e sorteia-se um número suficiente desses pequenos grupos (conglomerados), cujos elementos constituirão a amostra (VIEIRA, 2003). A unidade amostral foi cada equipe da eSF do município de Teresina. A unidade elementar 1 ou de análise 1 foi a eSF, e a unidade 2 foi a usuária.

A moldura da amostragem, trouxe a listagem da unidade amostral enumerada segundo a tabela da FMS sobre o Consolidado da População Coberta pela eSF até dezembro de 2009, a qual traz um total de 229 Equipes de Saúde da Família (ESF) na zona urbana. Essa listagem teve a enumeração de 1 a 229 (N) para efeito de sorteio. Foram sorteadas 146 equipes. Este tamanho de amostra (n) permitiu estimar o parâmetro com margem de erro tolerável de 5\% e nível de confiança de $95 \%$.

Assim, para efeito de sorteio da unidade amostral foi utilizada a planilha Microsoft Excel para gerar $\mathbf{n}$ números aleatórios entre a 1aㅡ e a 229a equipe da eSF listada na moldura da amostragem. Em cada uma das 146 equipes sorteadas foi previamente levantado o dia da rotina da Unidade em que se fazem as consultas prénatais e agendou-se a coleta de dados para o mesmo dia, onde participaram da 
pesquisa todas as gestantes e/ou usuárias adultas atendidas que se fizeram presentes na Unidade de Saúde no momento de realização da coleta, atenderam os critérios de inclusão e aceitaram participar da pesquisa, com uma média de 5 usuárias por equipe, com tamanho fixo de 730 usuárias.

Considerando que as usuárias não estavam distribuídas uniformemente nas UBS (conglomerados), adotou-se o sorteio em 2 estágios, com probabilidade proporcional ao tamanho dos conglomerados. Utilizou-se o estimador deff (efeito de delineamento) como estratégia de ajuste para o desenho amostral. Após a correção compôs-se um total geral de 1098 participantes.

A priori a população do estudo era o conjunto de gestantes cadastradas e acompanhadas pelas equipes da eSF do município no período de realização da pesquisa, desde que se enquadrassem nos critérios pré-estabelecidos de inclusão: a paciente estar gestante, ser cadastrada no programa de acompanhamento pré-natal (SISPRENATAL) e estar presente à consulta no dia estabelecido para coleta de dados.

Objetivava-se dessa forma, dentro do contexto da APS, a avaliação da integralidade na perspectiva da usuária gestante. Porém durante o pré-teste e na aplicação dos primeiros questionários ocorreram algumas dificuldades em relação à localização da amostra.

A eSF em Teresina funciona, como na maioria de outros municípios, com demanda programada, havendo assim um dia específico para o atendimento aos grupos populacionais, inclusive às gestantes. Quando da idealização dessa pesquisa essa realidade era conhecida e esperava-se que na data agendada fosse encontrado o mínimo de 05 gestantes por Unidade, conforme cálculo amostral. Porém, encontrou-se uma realidade espantosa, pois a assistência mostrou-se fragmentada, descontínua e desorganizada, apesar de demanda programada.

Essa mesma realidade foi percebida nos relatórios de campo de todos os coletores de dados, onde passaram a referir os mesmos problemas, a saber: equipes de saúde que não atendem pré-natal, pois funcionam em unidades com mais de uma equipe e o pré-natal fica restrito somente a uma equipe; ausência dos profissionais no dia das consultas (reuniões, faltas, férias, licenças, etc.); consultas pré-natal agendadas apenas uma vez por mês; vínculo diminuído evidenciado pela ausência da gestante na unidade de saúde no dia da consulta. 
Houve também resistência das gestantes em participar da pesquisa em função do tamanho do questionário, o qual necessita de uma maior disponibilidade de tempo para ser respondido; incompatível com a espera para a consulta. Assim esses fatores implicaram em maior período despendido para coleta, necessidade de várias visitas a unidade e mudanças no processo de coleta dos dados. Dessa forma, optou-se por tornar mais ampla a pesquisa e alterar os critérios de inclusão na mesma para: qualquer usuária adulta que estivesse na unidade de saúde no momento da coleta, que tivesse experiência prévia com a APS, ou seja, mais de um episódio de utilização do serviço de saúde e que aceitasse participar da pesquisa.

Decidiu-se incluir somente usuárias na tentativa de formar um grupo homogêneo, uma vez que, a busca por assistência de saúde é mais constante entre mulheres. 0 que resultou na formação de amostra constituída por dois grupos diferentes: mulheres gestantes e mulheres não gestantes; para que em função dos problemas apresentados, fosse possível comparar a avaliação da assistência entre os grupos em relação aos escores atribuídos por eles para os atributos essenciais e derivados da atenção primária.

Os dados desse estudo foram coletados por meio de entrevista com utilização do instrumento de avaliação da capacidade e desempenho dos serviços de atenção primária (PCATool) versão Adulto traduzido e validado pelo MS, acrescido de questões referentes ao perfil social, econômico e obstétrico. A versão adulto do Instrumento de Avaliação da Atenção Primária PCATool-Brasil é composta por blocos de perguntas que correspondem aos atributos essenciais, derivados e o grau de afiliação ao serviço de saúde, definido como a força da relação entre o usuário e o serviço/profissional de saúde (STARFIELD, 2004). São considerados serviços com Alto Escore de APS aqueles que obtiverem valor maior ou igual a 6,6 (tercil superior do escore). 0 escore final de cada um destes atributos é dado pela média das respostas de seus itens.

0 instrumento foi submetido a um pré-teste piloto realizado por meio de entrevistas com 35 usuárias de 5 equipes da eSF que não compuseram a amostra. Os dados desse estudo foram coletados no período de maio a julho de 2011 mediante a aplicação do PCATool-Brasil para coleta de dados nas UBS, nos horários de funcionamento das mesmas, de forma a coincidir o dia da coleta dos dados com a rotina de atendimento da unidade. 
O primeiro contato com as usuárias foi realizado na sala de espera dos consultórios das UBS onde, considerando os critérios de inclusão, estas eram esclarecidas quanto aos objetivos do estudo e convidadas a participar do mesmo; caso concordassem, assinavam o Termo de Consentimento Livre e Esclarecido de acordo com a Resolução 196/96. Todas as entrevistas ocorreram após a realização do atendimento que a usuária procurou na UBS, em uma sala reservada com condições adequadas de conforto e privacidade, de forma espontânea, permitindoa refletir sobre as questões que eram feitas.

Após a coleta, os dados foram digitados no programa Microsoft Excel e, após as correções, os dados foram exportadas para o Banco de Dados no programa Statistical Package for the Social Sciences (SPSS) versão 18.0 for Windows. Todos estes procedimentos foram realizados concomitantemente por digitação dupla.

Os dados foram tabulados e consolidados utilizando as técnicas de estatísticas descritivas, calculados os desvios-padrão, a distribuição de frequências e as médias de algumas variáveis. Utilizou-se o teste t de Student para comparação das médias e o teste Qui-quadrado de Pearson para as proporções com significância estatística definida com um nível de 5\%, ou seja, $\mathrm{p} \leq 0,05$ para verificar as possíveis associações entre as variáveis. 0 projeto foi submetido à autorização do Comitê de Ética e Pesquisa (CEP) da UFPI com CAAE: 0027.0.045.000-11, e à Secretaria Municipal de Saúde do município de Teresina, na qual as Unidades de Saúde a serem estudadas encontram-se inseridas.

\section{RESULTADOS}

\subsection{CARACTERÍSTICAS DA AMOSTRA E RELACIONADAS AO ALTO E baIXO ESCORE GERAL DA APS}

Participaram deste estudo 1098 mulheres do município de Teresina, com idade de 16 a 60 anos, média de 29,35 anos e desvio padrão de 9,64 anos. Em relação à classificação em alto e baixo escore associada aos aspectos sociodemográficos percebe-se que, segundo a Tabela 1, a maioria dos aspectos está estatisticamente associado a um baixo escore geral da APS $(<6,6)$, a exceção de membro da família de que a usuária depende financeiramente, número de abortos e cesarianas, uma vez 
que estes são aspectos que não estão diretamente relacionados a utilização da atenção básica por essas usuárias.

Em relação ao estado civil a maioria era casada (53\%), sendo que 23,5\% relatou viver em união estável com o companheiro. Os níveis de escolaridade predominantes foram o ensino médio incompleto com $31,1 \%$ das usuárias tendo informado este nível e o ensino médio completo com 29\%; chama atenção o fato de apenas 4,9\% referir possuir ensino superior (completo ou incompleto). Quanto à ocupação, a maioria das entrevistadas referiu se dedicar as atividades domésticas $(50,8 \%)$.

Nas características econômicas das entrevistadas a maioria apresentava renda familiar em torno de 1 a 2 salários mínimos (de $\mathrm{R} \$ 206,01$ a $\mathrm{R} \$ 824,00$ ). Em função da baixa escolaridade e renda familiar mais de $80 \%$ das entrevistadas referiram possuir dependência financeira (total ou parcial) de terceiros, sendo o companheiro apontado por $65 \%$ delas como o responsável pelo sustento.

Nos aspectos gestacionais a amostra se mostrou proporcional, com $43,2 \%$ de usuárias não gestantes no momento da coleta e 56,8\% de usuárias gestantes em qualquer trimestre gestacional. As usuárias foram arguidas em relação à realização de consultas pré-natal anteriormente, sendo que 57,4\% não estavam gestantes ou estavam na primeira gestação o que impossibilitaria haver esse histórico. Daquelas que estavam na segunda ou mais gestações, 37,2\% referiu ter feito pré-natal completo na última gestação.

Os achados relacionados ao perfil sociodemográfico assemelham-se aos encontrados no estudo de Leão, Caldeira e Oliveira (2011) em que os cuidadores das crianças que utilizavam a eSF como fonte regular de atenção sinalizam para uma maior vulnerabilidade social e econômica, onde os estratos mais pobres da população utilizam mais os referidos serviços da ESF como fonte regular de assistência à saúde. 
Tabela 1. Características sociodemográficas, econômicas e obstétricas das usuárias adscritas aos serviços de APS classificados como Alto e Baixo Escore Geral de APS. Teresina (PI), maio a julho, 2011 ( $\mathrm{n}=1098)$.

\begin{tabular}{|c|c|c|c|}
\hline \multirow[t]{2}{*}{ Características } & $\begin{array}{c}\text { Alto Escore } \\
\text { Geral da } \\
\operatorname{APS}(\geq 6,6)\end{array}$ & $\begin{array}{l}\text { Baixo Escore Geral } \\
\text { da } \operatorname{APS}(<6,6)\end{array}$ & \multirow[t]{2}{*}{ valor-p } \\
\hline & $\begin{array}{c}\text { n/média(\%/IC9 } \\
\mathbf{5 \% )}\end{array}$ & n/média(\%/IC95\%) & \\
\hline Idade** & $\begin{array}{c}28,84(28,23- \\
29,45)\end{array}$ & $32,68(31,15-34,22)$ & $<0,01$ \\
\hline Estado Civil/Situação Conjugal* & & & $<0,01$ \\
\hline Solteira/Viúva & $23(2,1 \%)$ & $235(21,4 \%)$ & \\
\hline Casada/União Estável & $94(8,5 \%)$ & $746(68 \%)$ & \\
\hline Escolaridade* & & & $<0,01$ \\
\hline Não alfabetizada & $0(0 \%)$ & $12(1,1 \%)$ & \\
\hline Ensino fundamental & $64(5,8 \%)$ & $308(28,1 \%)$ & \\
\hline Ensino médio & $53(4,8 \%)$ & $607(55,3 \%)$ & \\
\hline Ensino superior & $0(0 \%)$ & $54(4,9 \%)$ & \\
\hline Ocupação* & & & 0,024 \\
\hline Estudante & $11(1 \%)$ & $139(12,7 \%)$ & \\
\hline Do lar & $76(6,9 \%)$ & $482(43,9 \%)$ & \\
\hline Outras & $30(2,7 \%)$ & $360(32,8 \%)$ & \\
\hline Renda Familiar (SM)* & & & $<0,01$ \\
\hline$<1$ & $36(3,2 \%)$ & $408(37,2 \%)$ & \\
\hline 1 a 2 & $70(6,4 \%)$ & $374(44,5 \%)$ & \\
\hline $3 \mathrm{ou}+$ & $11(1 \%)$ & $85(7,7 \%)$ & \\
\hline Dependência Financeira* & & & $<0,01$ \\
\hline Sim, parcialmente & $53(4,8 \%)$ & $301(27,4 \%)$ & \\
\hline Sim, totalmente & $40(3,6 \%)$ & $536(48,8 \%)$ & \\
\hline Não depende & $24(2,2 \%)$ & $144(13,1 \%)$ & \\
\hline De quem & & & \\
\hline financeiramente * & & & 0,088 \\
\hline Companheiro & $76(6,9 \%)$ & $638(58,1 \%)$ & \\
\hline Seus pais & $11(1 \%)$ & $157(14,3 \%)$ & \\
\hline Outros & $6(0,5 \%)$ & $42(3,8 \%)$ & \\
\hline Não se aplica (não depende) & $24(2,2 \%)$ & $144(13,1 \%)$ & \\
\hline \multicolumn{4}{|l|}{ Estado de Gestação } \\
\hline IG atual** & $\begin{array}{c}10,90(8,29- \\
13,51)\end{array}$ & $13,52(12,67-14,37)$ & 0,049 \\
\hline Número de Gestação** & $1,12(0,84-1,40)$ & $1,53(1,43-1,63)$ & 0,007 \\
\hline Número de Partos** & $0,46(0,32-0,60)$ & $0,72(0,66-0,79)$ & 0,01 \\
\hline Número de Abortos** & $0,26(0,16-0,36)$ & $0,23(0,19-0,26)$ & 0,598 \\
\hline Parto Normal** & $0,15(0,07-0,24)$ & $0,51(0,45-0,57)$ & $<0,01$ \\
\hline Parto Cesário** & $0,31(0,20-0,41)$ & $0,21(0,17-0,24)$ & 0,083 \\
\hline Fez pré-natal antes* & & & 0,035 \\
\hline Sim, completo & $30(2,7 \%)$ & $378(34,4 \%)$ & \\
\hline Sim, incompleto & $6(0,5 \%)$ & $48(4,4 \%)$ & \\
\hline Não & $0(0 \%)$ & $6(0,5 \%)$ & \\
\hline $\begin{array}{l}\text { Não se aplica (não gestante ou } \\
\text { primípara) }\end{array}$ & $81(7,4 \%)$ & $549(50 \%)$ & \\
\hline
\end{tabular}

Legenda: Salário Mínimo (SM), Idade Gestacional (IG). * teste qui-quadrado de Pearson para as proporções. ${ }^{* *}$ teste $t$ de Student para as médias. 
Assim como a maioria das usuárias eram casadas (53\%), essa proporção se manteve em relação a classificação em alto e baixo escore geral da APS, onde $45 \%$ $(\mathrm{p}<0,01)$ das usuárias atribuem um baixo escore geral e a maioria vivia com companheiro, conforme estudo de Prado (2005). O baixo escore geral da APS está estatisticamente associado ao nível de escolaridade ficando concentrado entre ensino médio incompleto (29\%) e ensino médio completo (26,3\%). Assim observase um baixo nível de escolaridade entre as usuárias, semelhante ao apresentado nos estudos de Trindade (2007) e Sala et al. (2011).

A ocupação mais referida pelas pesquisadas foi dona de casa, apresentando relação estatisticamente significativa $(p=0,024)$ com a classificação em baixo escore geral da APS $(<6,6)$; uma vez que, em função desta ocupação teriam mais facilidade em frequentar o serviço. Também, em outros estudos, a maioria das usuárias entrevistadas declarou ocupação do lar (RIBEIRO; ROCHA, RAMOS-JORGE, 2010; VIEIRA; GAZZINELLI, 2010).

A renda familiar mensal per capita média da população estudada concentrouse em até 02 salários mínimos, atentando-se para o fato de apenas $1 \%(\mathrm{p}<0,01)$ da população que ganha acima de 2 salários mínimos ter classificado como alto escore geral da APS $(\geq 6,6)$. Assemelhando-se a outros estudos nacionais onde com relação à classe socioeconômica, encontram-se na classe $\mathrm{C}$ e a renda per capita das famílias é menor que 02 salários mínimos (ZILS et al., 2009; RIBEIRO; ROCHA, RAMOSJORGE, 2010; VIEIRA; GAZZINELLI, 2010).

Em função de a população em estudo possuir uma renda baixa, explica-se o fato da alta proporção de dependência financeira, seja parcialmente $(27,4 \%)$ ou totalmente $(48,8 \%)$, onde as duas formas estão associadas $(\mathrm{p}<0,01)$ ao baixo escore geral da APS. Porém destaca-se o fato da significativa quantidade de usuárias que não referem dependência financeira e classificam a APS como de alto escore, o que pode estar relacionado com a maior independência destas, inclusive no que diz respeito a procurar outros serviços de atenção à saúde o qual considerem como mais efetivo.

Ao compor uma linha do tempo em relação à história obstétrica das usuárias ter-se-ia: gestação atual/número de gestação/número de partos/partos normal. Conforme evolui nessa linha, a usuária que, teoricamente, passa a utilizar mais o serviço tende a aumentar a classificação da APS como baixo escore geral. No aspecto 
de gestação atual, por não termos avaliado em função do trimestre gestacional, os valores de alto e baixo escore encontram-se próximos e quase sem nível de significância $(\mathrm{p}=0,049)$, porém ainda apresenta maior inclinação para baixo escore.

Quanto ao número de gestações $(1,53 ; p=0,007)$ observa-se uma avaliação negativa, da mesma forma que associado ao número de partos $(0,72 ; p=0,01)$. Quando se trata da resolução da gestação em forma de parto normal observa-se o aumento da proporção de baixo escore geral da APS $(0,51 ; \mathrm{p}<0,01)$, sendo que quanto maior o número de gestações e finalização em forma de parto normal pior é a avaliação em relação ao serviço de saúde.

Quanto ao número de aborto e cesarianas, apesar de não apresentarem significado estatístico ( $p=0,598$ e p=0,083, respectivamente) em função da pequena proporção em relação a amostra, traz a avaliação das usuárias como de alto escore da APS o que reflete a tendência de melhor classificação aos serviços de resolução cirúrgica, de maneira mais rápida e em ambiente hospitalar.

De acordo com a realização de pré-natal em gestações anteriores observa-se que, entre as que não estavam grávidas ou que estavam na primeira gestação e não tinham experiência com assistência pré-natal, 50\% considera a APS como de baixo escore geral com uma associação estatisticamente significante $(\mathrm{p}=0,035)$. Aquelas que realizaram pré-natal, completo e/ou incompleto, também a classificam como de baixo escore geral. Demonstrando que o pré-natal, da maneira que é realizado, não gera impacto positivo na avaliação do serviço.

Porém deve-se ressaltar que, entre aquelas que classificam como alto escore geral da APS $(\geq 6,6)$, observa-se um maior percentual àquelas que fizeram o prénatal completo e nenhuma usuária que, em gestações anteriores não fez pré-natal avaliou a APS como de alto escore, o que retrata que a oferta e a qualidade da assistência pré-natal possui interferência direta na avaliação das usuárias em relação ao serviço prestado pela eSF.

\subsection{ASSOCIAÇÃO DA SITUAÇÃO GESTACIONAL AOS ESCORES DA APS}

Ao associar a situação gestacional da usuária e a classificação que ela faz observa-se que a maioria avaliou a APS com baixo escore $(<6,6)$, com diferença estatística significante $(\mathrm{p}<0,01)$ conforme descrito na Tabela 3. Chama-se atenção para o fato de que, entre aquelas que atribuíram alto escore da $\operatorname{APS}(\geq 6,6)$, a maioria 
$(14,8 \%)$ não estava gestante no momento da coleta, o que pode estar associado ao tipo de assistência oferecida.

Apesar das dificuldades de coleta já mencionadas na metodologia, procurouse também associar o Escore Geral classificado como Alto e Baixo a cada atributo da APS em relação à situação gestacional das usuárias, a qual foi: não gestante (não se aplica $-43,2 \%)$ ou gestante $(56,8 \%)$ em algum trimestre gestacional $\left(13,1 \%\right.$ no $1^{\circ}$ trimestre, $18 \%$ no $2^{\circ}$ e $25,7 \%$ no $3^{\circ}$ ). Optou-se também por utilizar as frequências e os percentuais para facilitar o entendimento, uma vez que, os escores já foram apresentados anteriormente.

Tabela 3. Comparação dos escores em Alto e Baixo Escore Geral de APS segundo a situação gestacional. Teresina (PI), maio a julho, 2011 ( $\mathrm{n}=1098)$.

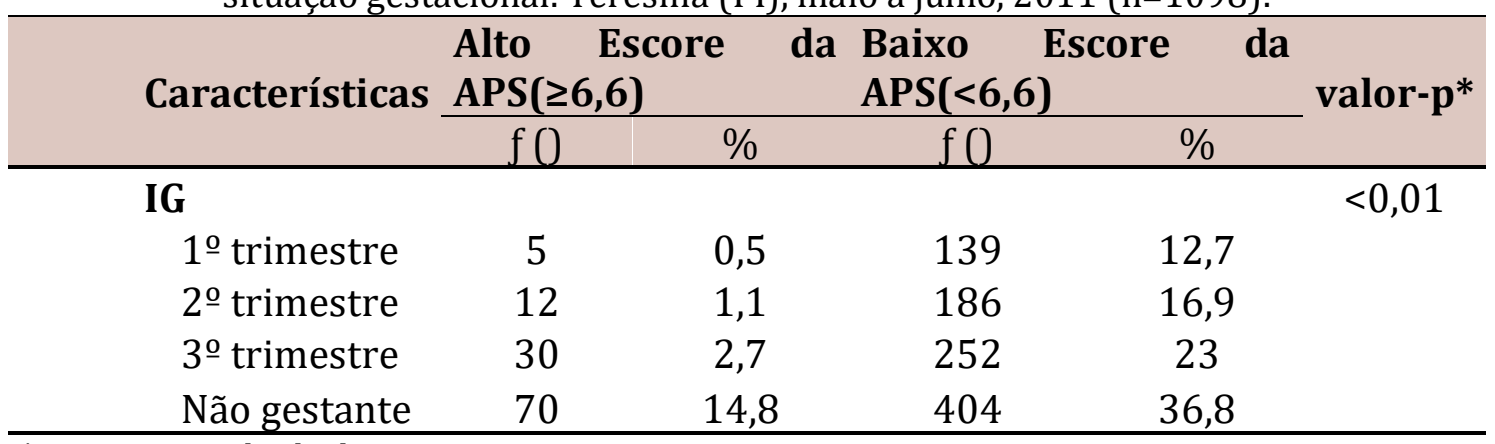

* teste qui quadrado de Pearson para proporção

Ao longo dos últimos anos, a APS foi gradualmente se fortalecendo como condição necessária para a estruturação dos sistemas locais de saúde e para a efetiva consolidação dos princípios e diretrizes do SUS. Corroborando com a baixa avaliação das usuárias gestantes, Rehem e Egry (2011) identificaram que as internações por doenças relacionadas ao pré-natal e ao parto apresentaram aumento, mesmo considerando que são diagnósticos que historicamente fazem parte da abordagem e do cuidado da atenção primária e, portanto, seria de se esperar que ocupassem outra posição neste panorama.

A avaliação da $A B$ mediante a utilização de um instrumento padronizado tem, assim, a justificativa de contribuir para o conhecimento dessa rede de serviços e também para sua definição tecnológica a partir da consideração de que a valorização da cultura avaliativa e a orientação a partir do processo de trabalho favorecem repensar e propor mudanças (CASTANHEIRA et al., 2011). Nesse sentido, pode-se afirmar que os incentivos governamentais para a implantação de equipes da eSF, sem dúvida, promoveram ampliação da oferta de APS na maioria dos municípios. No 
entanto, em Teresina, apesar da ampla cobertura da eSF, as usuárias gestantes (consideradas como grupo vulnerável) atribuem baixo escore geral à APS.

Assim torna-se pertinente, investigar se existe por parte da população adscrita o reconhecimento das unidades da eSF como fonte regular de cuidados ou se a utilização da unidade é simplesmente pela restrição de opções, o que poderia implicar a não adesão às recomendações terapêuticas, e ainda a busca de serviços de emergência para tratamento de agravos passíveis de intervenção pela equipe de APS (CUNHA; GIOVANELLA, 2011).

Diferentemente do encontrado em Teresina, em outro estudo especificamente em relação ao atendimento pré-natal, foram verificadas diferenças estatisticamente significantes entre os modelos de assistência, onde todas as diferenças apontadas foram em favor da eSF (CALDEIRA; OLIVEIRA; RODRIGUES, 2010). Assim, confirma-se a existência de uma oferta de serviços de forma fragmentada, não planejada e que não atende as necessidades da população o que culmina em uma assistência não integral, que não privilegia todas as abordagens possíveis nem a percepção e o discurso do usuário.

\section{CONSIDERAÇÕES FINAIS}

Este foi o primeiro estudo que se tem conhecimento a avaliar a Estratégia Saúde da Família em um município do Nordeste do Brasil quanto ao grau de orientação do serviço em relação aos atributos da Atenção Primária à Saúde. Esperase, com isso, apresentar uma realidade até então desconhecida.

As usuárias participantes da pesquisa são, em sua maioria, adultos jovens com média de idade de 29,35 anos, casadas, com baixa escolaridade, católicas, se dedicam as atividades domésticas, com uma renda familiar de até dois salários mínimos e apresentarem dependência financeira (total ou parcial) de terceiros, e apresentam características sociodemográficas semelhantes à de outros estudos da APS no Brasil. Nos aspectos gestacionais a amostra se mostrou proporcional, com 43,2\% de usuárias não gestantes no momento da coleta e 56,8\% de usuárias gestantes em qualquer trimestre gestacional, sendo que a maioria referiu ter feito pré-natal completo $(37,2 \%)$ na última gestação. 
Um aspecto a se considerar se deve ao fato de que os atributos da APS foram avaliados segundo a percepção das usuárias, e estas tendem a avaliar os serviços de saúde de maneira menos favorável do que quando são avaliados pelos profissionais ou gestores que atuam no serviço; assim sendo é possível que uma abordagem ampliada do processo avaliativo dos atributos da APS registre melhores escores com a inserção de outros atores sociais.

Ao associar-se a história obstétrica da usuária e a classificação que ela faz as APS observa-se que a maioria avaliou a APS com baixo escore $(<6,6)$, com diferença estatística significante. Chama-se atenção para o fato de que, entre aquelas que atribuíram alto escore da APS $(\geq 6,6)$, a maioria não estava gestante no momento da coleta, o que pode estar associado ao tipo de assistência oferecida. Faz-se relevante notar que os resultados deste estudo apontam para a necessidade de melhoria de alguns atributos da prática assistencial. Essa melhoria implica em reformulações de aspectos da estrutura e processo para que futuramente possa ser oferecida uma APS de qualidade.

Assim, faz-se importante estudar os atributos da APS uma vez que esta vem sendo apontada como um dos principais pilares para a efetivação de uma assistência de qualidade. Dessa forma, este estudo certamente irá contribuir para uma análise da repercussão da assistência oferecida pela APS em Teresina. Servirá também como subsídio para os gestores e profissionais de saúde envolvidos, favorecendo o planejamento de ações nesta área, de modo a minimizar as principais falhas encontradas.

\section{REFERÊNCIAS}

ALVES, V. S. Um modelo de educação em saúde para o Programa Saúde da Família: pela integralidade da atenção e reorientação do modelo assistencial. Interface - Comunic, Saúde, Educ, v. 9, n.16, p. 39-52, 2005.

BENIGNA, M. J. C.; NASCIMENTO, W. G.; MARTINS, J. L. Pré-natal no Programa Saúde da Família (PSF): com a palavra, os enfermeiros. Cogitare Enferm. v. 9, n. 2, p. 23-31, jul./dez., 2004

BRASIL. Ministério da Saúde. Secretaria da Atenção à Saúde, Departamento de Atenção Básica. Manual do instrumento de avaliação da atenção primária à saúde: primary care assessment tool pcatool - Brasil. Brasília: Ministério da Saúde; 2010. 80p. 
CALDEIRA, A. P.; OLIVEIRA, R. M.; RODRIGUES, O. A. Qualidade da assistência materno-infantil em diferentes modelos de Atenção Primária. Ciênc. saúde coletiva [online], Rio de Janeiro, v.15, suppl. 2, p. 3139-3147, 2010.

CARNEIRO, A. D.; et. al. Prescrição de medicamentos e solicitação de exames por enfermeiros no PSF: aspectos, éticos e legais. Revista Eletrônica de Enfermagem. v. 10, n. 3, p. 756-65, 2008.

CASTANHEIRA, E. R. L. et al. QualiAB: desenvolvimento e validação de uma metodologia de avaliação de serviços de atenção básica. Saude soc. [online], São Paulo, v. 20, n. 4, dez. p. 935-947, 2011.

CUNHA, E. M.; GIOVANELLA, L. Longitudinalidade/continuidade do cuidado: identificando dimensões e variáveis para a avaliação da Atenção Primária no contexto do sistema público de saúde brasileiro. Ciênc. saúde coletiva [online], Rio de Janeiro. v.16, n. suppl.1, p. 1029-42, 2011.

HARZHEIM, E.; STEIN, A. T.; ÁLVAREZ-DARDET, C. A efetividade dos atributos da atenção primária sobre a saúde infantil. Bol Saúde. v. 18, n. 1, p. 23-40, 2004.

IBGE, Diretoria de Pesquisas - DPE. Coordenação de População e Indicadores Sociais - COPIS. NOTA: Estimativas da população residente com data de referência $1^{\circ}$ de julho de 2011.

LEAO, C. D. A.; CALDEIRA, A. P.; OLIVEIRA, M. M. C. Atributos da atenção primária na assistência à saúde da criança: avaliação dos cuidadores. Rev. Bras. Saude Mater. Infant. [online]. v.11, n.3, p. 323-334, 2011.

MENDES, E. V. A Atenção Primária à Saúde no SUS. Fortaleza: Escola de Saúde Pública do Ceará; 2002.

NASCIMENTO, M. S.; NASCIMENTO, M. A. A. Prática da enfermeira no programa de saúde da família: a interface da vigilância em saúde versus as ações programáticas em saúde. Ciência \& Saúde Coletiva. v. 10, n. 2, p. 333-45, 2005.

OLIVEIRA, M. M. C. Presença e extensão dos atributos da Atenção Primária à Saúde entre os serviços de Atenção Primária à Saúde em Porto Alegre: uma análise agregada. 2007. 118 p. Dissertação (Mestrado em Epidemiologia), Universidade de Caxias do Sul, Rio Grande do Sul, 2007.

PINHEIRO, R. Cuidado como um valor: um ensaio sobre o (re) pensar e a ação na construção de práticas eficazes de integralidade em saúde. In: PINHEIRO, R.; MATTOS, R.; A. (orgs). Razões Públicas para a integralidade em saúde: o cuidado como valor. Rio de janeiro: IMS/UERJ: CEPESC: ABRASCO, 2007, p. 5-28.

PRADO, S. R. L. A. Integralidade: um estudo a partir da atenção básica à saúde da criança em modelos assistenciais distintos [tese]. São Paulo (SP): EEUSP/Programa de Pós-Graduação em Enfermagem; 2005. 
REHEM, T. C. M. S. B.; EGRY, E. Y. Internações por condições sensíveis à atenção primária no estado de São Paulo. Ciênc. saúde coletiva [online], Rio de Janeiro, v. 16, n. 12, p. 4755-66, dez., 2011.

RIBEIRO, L. C. C.; ROCHA, R. L; RAMOS-JORGE, M. L. Acolhimento às crianças na atenção primária à saúde: um estudo sobre a postura dos profissionais das equipes de saúde da família. Cad. Saúde Pública, Rio de Janeiro, v. 26, n. 12, p. 2316-22, dez., 2010.

SALA, A.; et al. Integralidade e Atenção Primária à Saúde: avaliação na perspectiva dos usuários de unidades de saúde do município de São Paulo. Saude soc. [online]. v. 20, n. 4, p. 948-960, 2011.

SANTOS, S. M. R. ; et. al. A consulta de enfermagem no contexto da atenção básica de saúde, Juiz de Fora, Minas Gerais. Revista Texto e Contexto Enfermagem. Florianópolis, v. 17, n. 1, p. 124-30, jan./mar., 2008.

STARFIELD, B. Primary Care: concept, evaluation and policy. New York: Oxford University Press, 1992.

STARFIELD. Atenção Primária: equilíbrio entre necessidades de saúde, serviços e tecnologia. Brasília: UNESCO. Brasil, Ministério da Saúde, 2004.

TRINDADE, T. G. Associação entre extensão dos atributos de atenção primária e qualidade do manejo da hipertensão arterial em adultos adscritos à rede de atenção primária à saúde de Porto Alegre. 2007. 145 p. Dissertação (Mestrado em Epidemiologia), Faculdade de Medicina Universidade Federal do Rio Grande do Sul, Rio Grande do Sul, 2007.

VIEIRA, S. Princípios de Estatística. 1. ${ }^{\mathrm{a}}$ reimpr. da 1a ed. São Paulo: Editora Pioneira Thomson Learning, 2003.

VIEIRA, E. W. R.; GAZZINELLI, A. Acesso e utilização dos serviços de saúde de atenção primária em população rural do Município de Jequitinhonha, Minas Gerais. 2010. Dissertação (Mestrado). Universidade Federal de Minas Gerais - UFMG, Belo Horizonte, 2010.

ZILS, A. A.; et al. Satisfação dos usuários da rede de Atenção Primária de Porto Alegre. Rev Bras Med Fam e Com - RBMFC. Rio de Janeiro, v. 4, n. 16, p. 270-6, jan./mar., 2009. 


\section{GESTANTES COM INSUAICIENCIA RENAL: CONSIDERAÇOEES SOBREA A ASISTÊNCIA DE ENFERMAGEM}

DDI: 10.51859/amplla.esp917.1121-3

Aline Lima de Almeida ${ }^{1}$ Irene Arêa Soares da Silva ${ }^{1}$ Maria Clara Barradas Leão ${ }^{1}$ Marília Feitosa de Freitas ${ }^{1}$ Yanka Delmondes Campelo ${ }^{1}$

Raquel Vilanova Araujo ${ }^{2}$

${ }^{1}$ Graduando do curso de Enfermagem. Centro Universitário Santo Agostinho

${ }^{2}$ Doutora em enfermagem -UFPI, Docente Centro Universitário Santo Agostinho

\section{RESUMO}

Mulheres com insuficiência renal, seja aguda ou crônica, que engravidam, em geral são classificadas como gravidez de alto risco, e necessitam de assistência especializada e qualificada em virtude do risco de complicações associadas ao aumento da morbimortalidade materna e perinatal. Deste modo, neste capítulo, pretende-se trazer considerações acerca da assistência de enfermagem às gestantes com insuficiência renal. Neste cenário destaca-se a importância da assistência a ser prestada por uma equipe especializada, qualificada e apta a reconhecer precocemente as situações de riscos e agir prontamente diante destas situações e, portanto, prevenir reduzir a ocorrência dos desfechos indesejáveis.

Palavras-chave: Insuficiência renal. Gestantes. Assistência de enfermagem.

\section{INTRODUÇÃO}

A insuficiência renal é uma doença insidiosa, e considerado um problema de saúde público em virtude dos altos índices de morbimortalidade em todo o mundo 
e com aumento no número de pessoas acometidas pela doença a cada ano. (BRASIL, 2019). Nos casos em quem os rins, órgãos vitais do corpo humano que contribuem para a homeostase metabólica e hidroeletrolítica do organismo, apresentam alterações em suas funções, como consequência tem-se um desequilíbrio ou deficiência nas funções básicas dos rins, este pode ser comprometido de maneira parcial ou total, e, portanto, desenvolver a insuficiência renal aguda ou crônica (BRASIL, 2020).

A insuficiência renal aguda (IRA) é uma condição em que os rins perdem suas funções excretoras, reguladoras e endócrinas de maneira rápida e súbita, levando assim o sistema renal a perder a sua homeostase hidroeletrolítica em questões de dias ou semanas (GUEDES et al 2017).

O diagnóstico da IRA se dar pela diminuição da filtração glomerular, anúria ou oligúria e o aumento dos níveis séricos da ureia e creatinina observados pela dosagem sanguínea, como também, através de exames de imagem ou em alguns casos por meio de biopsias renais (SOUZA et al., 2017).

Faz- se necessário o diagnóstico precoce da doença, afim de diminuir ou minimizar os danos causa dos pela patologia, mas para isto é fundamental o acesso da população aos serviços de saúdes, porém, tem-se observado que a realidade de muitos países subdesenvolvidos e em desenvolvimento, muitas pessoas apresentam o quadro agudo da doença, e bem como elevado risco de morte (RIBEIRO; SILVA, 2020).

A respeito do tratamento da insuficiência renal os pacientes que são diagnosticados com IRA ou IRC são encaminhados para as terapias dialíticas que consistem na substituição de algumas funções dos rins doentes, seja por meio da hemodiálise, diálise peritoneal ou transplante renal. No caso da IRC o tratamento pode ser classificado como contínuo e paliativo. No entanto, as mudanças no estilo de vida, são cruciais, e fazem parte do tratamento, dentre estas, as principais são as restrições hídricas e alimentares (BOSCARINO et al., 2021).

Estima-se que no Brasil há cerca de dez milhões de pessoas diagnosticada e pelo menos 90 mil destes indivíduos estão dependentes de tratamentos dialíticos (BRASIL, 2019).

Dentre esses indivíduos, tem-se a realidade das pacientes gestantes acometidas pela insuficiência renal, seja ela aguda ou crônica. Neste caso, em geral 
a gestante é classificada como gravidez de alto risco, em decorrência da possibilidade de complicações, que na maioria das vezes são relacionadas ao aumento da morbimortalidade materna e perinatal. Neste contexto, é válido ressaltar que os avanços no tratamento da doença têm possibilitado um melhor prognóstico de mulheres com insuficiência renal dependente do tratamento dialítico que engravidam (RIBEIRO; SILVA, 2020).

A gestação é um período de grandes mudanças na mulher, sejam elas físicas, hormonais e mesmo psicológicas. Já na mulher com Insuficiência Renal, estas alterações são mais intensas tendo em vista a possibilidade de um maior risco durante a gestação relacionadas a própria doença e/ou tratamento. A respeito das complicações, em gestantes com insuficiência renal, estas podem acometer tanto a própria gestante como o feto. Nesta situação, as gestantes têm o risco aumentado de apresentar um agravamento da doença e o feto, grande possibilidade de nascer com prematuridade (OLIVEIRA, T. L; DE MEDONÇA, J. M. G; DE SENA, R.R, 2007).

No entanto, é importante ressaltar que a maioria destas complicações podem ser prevenidas, para isto é essencial que a gestante seja assistida por profissionais qualificados e experientes, além disso, outro aspecto fundamental é planejamento da gravidez e início precoce da assistência pré-natal, afim de diminuir as possíveis implicações da doença e/ou do tratamento na gestante bem como no feto, de modo a garantir uma gestação segura (RIBEIRO; SILVA, 2020)

Assim sendo, é válido salientar que os cuidados de enfermagem são fundamentais e indispensáveis para assistência humanizada, sistematizado prestada por profissionais qualificados e capacitados para prestar uma assistência livre de danos e complicações, de modo a reduzir os desfechos desfavoráveis para mãe-feto.

\section{ASSISTÊNCIA DE ENFERMAGEM À GESTANTE COM INSUFICIÊNCIA}

\section{RENAL}

A mulher com insuficiência renal, a partir do momento que expressa o desejo de engravidar, a assistência a mesma deve ser iniciada antes de engravidar, pois nesta condição a equipe de enfermagem e demais profissionais da equipe interdisciplinar tem possibilidade de avaliar o atual estado de saúde da mulher, de 
identificar a necessidade de alterações na terapêutica instituída, auxiliar no planejamento familiar, bem como acompanhar com mais segurança a mulher durante o percurso da gestação, parto e puerpério (ASSIS et al., 2018).

0 pré-natal ainda se constitui o método mais eficaz para evitar ou minimizar desfechos desfavoráveis para mães e bebês. No entanto, no Brasil, ainda persiste um grande índice de morbimortalidades em decorrência de complicações no período gravídico, devido uma cobertura deficiente na realização do pré-natal. A literatura aponta que mulheres afetadas por patologias renais são integrantes do grupo de alto risco materno e, por isso, a terapêutica instituída deve ser realizada com o monitoramento de profissionais habilitados (BERLATO, COSTENARO, BENEDETTI., 2016).

Berlato, Costenaro, Benedetti (2016), explicam que embora até há um algum tempo atras a ocorrência da gravidez em mulheres com insuficiência renal sob tratamento dialítico não fosse comum, o número crescente de situações como esta, fez com que novos métodos de tratamento dialítico fosse introduzidos, dentre estes, a dialise de alto fluxo, diálise peritoneal ambulatorial contínua, de fármacos como a eritropoetina, indicada para o tratamento da anemia e de anti-hipertensivos

Em virtude do aumento dos riscos de complicações relacionadas à insuficiência renal em gestantes a gestante, destaca-se a importância de um acompanhamento destas mulheres de modo mais atencioso e vigilante. Em situações como esta é recomendado, o início precoce do pré-natal, maior frequência no intervalo entre consultas de pré-natal e o acompanhamento destas gestantes pela equipe do pré-natal de alto risco (LIMA et al., 2020).

A gestação pode ser considerada de alto risco quando é identificado alguma patologia e/ou problemas de saúde na mãe durante o ciclo gravídico ou agravamento de uma situação que já existia, que põe em risco tanto a saúde da mãe quanto a do feto, podem ser de caráter patológico ou psicossocial (TELES et al., 2019). Das situações consideradas de grande risco em gestantes com insuficiência renal, tem-se a hipertensão arterial, pré-eclâmpsia, bem como as complicações da função renal por conta do estresse e ansiedade (BOSCARINO et al., 2021).

De acordo com Lima et al. (2020) as consultas de pré-natal devem ser realizadas a cada 15 dias até a 28ํㅗ semana, semanalmente até a $34^{\circ}$ semana e a partir desse período, recomenda-se que a gestante seja internada em um Centro 
especializado de referência para monitoramento contínuo pela equipe multidisciplinar materno e fetal (LIMA et al., 2020).

Neste cenário, a enfermagem também atua no sentido de proporcionar todas as condições necessária para o percurso de uma gravidez até o seu final de maneira saudável e sem intercorrências. Para isto, é fundamental que a assistência seja prestada por profissionais experientes e gabaritados, embasada nas evidencias cientificas, e alicerçada nos protocolos assistenciais (BOSCARINO et al., 2021). Os autores explicam que em situações como esta é fundamental a solicitação e avaliação constante de exames, monitoramento da pressão arterial e demais sinais vitais, bem como o aumento na frequência das sessões de hemodiálise, devendo a dialise ser evitada em decorrência do risco de aborto espontâneo relacionado a inserção do cateter de diálise.

Outrossim, a enfermagem, também, imprimi em sua rotina uma assistência acolhedora e humanizada à estas gestantes, com escuta qualificada, bem como construção e fortalecimento de vínculo, de forma a ajudá-la no processo de enfrentamento de medos, anseios e insegurança decorrente da situação de risco que vivencia no momento na gestação, bem como o suporte a família e/ou companheiro(a), no sentido de oferecer apoio, orientações, bem como incentivar a participação no cuidado à gestante para que essa se sinta mais acolhida e segura (SILVA; ARRAIS, 2018).

\subsection{DIAGNÓSTICOS E INTERVENÇÕES DE ENFERMAGEM ÀS GESTANTES COM INSUFICIÊNCIA RENAL}

A gestante com insuficiência renal requer de uma assistência prestada por profissionais qualificados e capacitados, a fim de reduzir o risco de complicações (BOSCARINO et al., 2021). Diante desta conjuntura, a enfermagem tem buscado se aperfeiçoar em seu campo de atuação, e portanto prestando assistência baseado em metodologia científica, como a Sistematização da Assistência de Enfermagem (SAE), que contribui para organizar o processo de trabalho de enfermagem e o processo de enfermagem, um instrumento de assistência da prática profissional que deve ser aplicado em toda atividade de enfermagem (SARTORI et al., 2018).

A resolução do Conselho Federal de Enfermagem (COFEN) 358/2009 que dispõe sobre a SAE e sobre a implementação do processo de enfermagem em todos os ambientes em que se é desenvolvido o cuidado profissional de enfermagem, 
registra que a SAE é um instrumento imprescindível para garantir a organização do serviço em todos os seus aspectos e proporcionar a sua realização conforme o estabelecido por lei, ressaltando que o profissional enfermeiro, líder da equipe de enfermagem, tem responsabilidade privativa pelos diagnósticos e prescrições de enfermagem (BRASIL, 2009).

De acordo com Tannure (2011) são cinco as etapas do processo de enfermagem, sendo estas interrelacionadas e interdependes: a primeira, diz respeito à implementação da assistência de enfermagem, envolve a anamnese, exame físico, bem como o levantamento e definição de problemas. Os autores explicam que esta etapa é fundamental para a elaboração do plano de cuidados. Nesta etapa situações de risco como: história reprodutiva, antecedente obstétricos, dados da gestação atual, características individuais, condições sociodemográficas, condições clínicas prévias e outros fatores de risco devem ser investigados (TELES et al., 2019).

Na segunda etapa tem-se os Diagnósticos de Enfermagem (DE), esta envolve a avaliação realizada sobre a resposta dos indivíduos aos problemas de saúde, e nortear as intervenções de enfermagem, bem como direcionar o cuidado e estimular o paciente a participar do seu tratamento, e, portanto, alcançar os resultados esperados (TANNURE, 2011). A Taxonomia de diagnóstico de enfermagem mais utilizada no Brasil para padronizar a prática profissional é a proposta pela North American Nursing Diagnosis Association (NANDA). (SARTORI et al., 2018).

As evidencias cientificas apontam que os Diagnósticos de Enfermagem têm contribuído para qualificar a assistência de enfermagem, conceder mais autonomia à equipe de enfermagem, bem como maior segurança ao paciente e (SARTORI et al., 2018). Para gestantes de alto risco vários diagnósticos de enfermagem podem ser levantados, sendo de suma importância a identificação dos mesmos para as intervenções de enfermagem sejam selecionadas e, portanto, garantir uma assistência de qualidade e com menor risco de complicações (TELES et al., 2019).

\subsection{DIAGNÓSTICOS DE ENFERMAGEM RELACIONADOS A GESTANTES COM INSUFICIENCIA RENAL}

- Manutenção ineficaz da saúde, caracterizada pela incapacidade de assumir a responsabilidade de atender a práticas básicas de saúde, relacionada com estratégias de enfrentamento ineficazes. 
- Estilo de vida sedentário, caracterizado por falta de condicionamento físico, relacionada com motivação insuficiente para a atividade física.

- Risco de desequilíbrio eletrolítico, relacionado com o volume de líquidos deficientes, associados a disfunção renal.

- Risco de função hepática prejudicada

- Risco de glicemia instável, relacionado com o ganho de peso excessivo, associado a gravidez.

- Eliminação urinária prejudicada, caraterizada por noctúria.

- Risco de constipação, relacionada com alterações nos hábitos alimentares, associada a gravidez.

- Risco de função cardiovascular prejudicada

- Insônia, caracterizada por alterações no padrão do sono, relacionada com ansiedade.

- Fadiga, caracterizada por cansaço, relacionada com ansiedade.

- Risco de perfusão renal ineficaz

- Risco de baixa autoestima situacional, relacionada com a alteração da imagem corporal, associada a prejuízo funcional.

- Risco de maternidade prejudicada, relacionada a baixa autoestima, associada a condição incapacitante.

- Risco de binômio mãe-feto perturbado, relacionada com cuidado pré-natal inadequado, associado com complicações gestacional.

- Ansiedade, caracterizada por preocupações em razão de mudanças em eventos da vida, relacionada a ameaça à condição atual.

- Resiliência prejudicada, relacionada a múltiplas situações adversas coexistentes.

- Sobrecarga de estresse, caracterizada por estresse excessivo, relacionado com estressores.

- Risco de infecção, relacionado com alteração na integridade da pele, associada com procedimento invasivo.

- Risco de sangramento, relacionada com conhecimento insuficiente sobre precauções de sangramento, associada a função hepática prejudicada. 
- Integridade da pele prejudicada, caracterizada por alteração na integridade da pele, relacionada com alteração no volume de líquidos.

- Risco de queda, relacionada com a mobilidade prejudicada, associado a doença aguda.

- Conforto prejudicado, caracterizado por ansiedade, relacionada com controle situacional insuficiente, associado ao regime de tratamento.

- Dor aguda, caracterizada por alteração no parâmetro fisiológico, relacionado com agente físico lesivo.

- Náuseas, caracterizada por ânsia de vômito, relacionada ao medo, associado a gravidez.

Diante disso, é importante que os profissionais de enfermagem tenham uma visão geral das principais necessidades da gestante com insuficiência renal, de modo a melhorar a qualidade da assistência prestada (TELES et al., 2019).

Dos principais cuidados de enfermagem, descritos no plano de cuidado a gestantes com insuficiência renal tem-se:

- Acolher a gestante e seu familiar/parceiro em todas as consultas de pré-natal

- Orientar quanto ao repouso por pelo menos 15 minutos antes de verificar sinais vitais.

- Encaminhar a gestante ao toalhete para esvaziar a bexiga antes da aferição da pressão arterial

- Orientar a gestante quanto ao posicionamento correto para aferição da pressão arterial

- Aferir a pressão arterial e demais sinais vitais. Anotar os valores em impresso próprio e acompanhar a evolução em todas as consultas.

- Oferecer apoio emocional e/ou psicológico a gestante e sua família e/ou parceiro(a)

- Orientar quanto a realização dos exames. Resultado e possíveis alterações

- informar quanto aos sinais de alerta (dor epigástrica, cefaleia, vômitos incoercíveis, sangramentos, etc.)

- Orientar sobre os serviços de urgência de referencia

- Promover ações de educação em saúde

- Incentivar o autocuidado 
- Orientar quanto o uso de medicamentos prescritos, atividade física, repouso e atividade de trabalho

- Orientar quanto os cuidados com alimentação e incentivar alimentação saudável.

- Encaminhar a nutricionista para planejamento de dieta caso seja necessário.

- Avaliar a pele e orientar quanto os cuidados para manter a integridade da pele,

- Orientar quanto o uso de roupas e calçados adequados

- Orientar quanto o risco de queda

- Orientar quanto os cuidados com a pele, uso de filtro solar, repelentes e meias compressivas

- Orientar quanto a importância das estratégias para regulação das emoções (meditação, terapia em grupo, terapia individual, musicoterapia, técnicas de relaxamento, etc.)

- Compreender a individualidade e abordar a gestante da melhor forma possível.

- Detectar os movimentos e apresentação fetal

- Esclarecer dúvidas

- Reduzir os medos

O diagnóstico conforto prejudicado é exemplificado por ambientes desfavoráveis às gestantes e podendo até ser psicossociais tendo exemplo da ansiedade, irritabilidade, estresse e relato de desconforto da paciente. Já o diagnóstico risco de infecção ocorre possivelmente por falta de conhecimento sobre a educação em saúde para evitar esse tipo de risco como exemplo a falta de vacinas tomadas pela a grávida sendo útil a orientação do enfermeiro com o intuito de aumentar as vacinações (TELES et al., 2019). Além disso, o diagnóstico fadiga pode estar relacionado ao posicionamento errado o que pode causar certo desconforto e fadiga, dessa forma, necessário a presença constante da equipe de enfermagem com uma assistência continua que possa evitar esses desconfortos a paciente e que possam impedir o surgimento de intercorrências (MEDEIROS et al., 2016). 
A insuficiência renal por si só é uma patologia grave, e quando em gestantes, os riscos de complicações são maiores, e com possibilidade de causar danos irreversíveis a gestante e/ou feto. Deste modo, percebe-se que é fundamental a assistência de enfermagem prestada por profissionais qualificados e preparados para prestar um cuidado integral, holístico, humanizado e segura, de modo a manter vigilância e identificar precocemente as situações de risco e intervir prontamente a fim de prevenir desfechos indesejáveis. Ressalta-se a importância da sistematização da assistência, e das ações com foco no incentivo ao autocuidado e assiduidade às consultas de pré-natal.

Por fim destaca-se a importância das pesquisas e discussões acerca desta temática no sentido de compreender os aspectos relacionados a doença, os riscos, complicações, e ações para prevenção e atuação diante das possíveis complicações, no sentido de prestar uma assistência de excelência e manter a integridade do binômio mãe-filho.

\section{REFERÊNCIAS}

BERLATO, Luciane Pereira; COSTENARO, Regina Gema Santini; BENEDETTI, Franceliane Jobim. Gestação na paciente renal crônica em hemodiálise. Disciplinarum Scientia| Saúde, v. 17, n. 1, p. 171-180, 2016. Disponível em: https://periodicos.ufn.edu.br/index.php/disciplinarumS/article/view/191 8/1818. Acesso em: 13 jul. 2021.

BOSCARINO, Juliana de Cassia Reis; et al; SILVA, Marcela Bruna da; OLIVEIRA, Letícia Loss de; SOUZA, Rodrigo Rocha de. Gravidez na paciente portadora de insuficiência renal crônica. Global Academic Nursing Journal, [s. l.], v. 2, n. 1, 2021. Disponível em: https://www.globalacademicnursing.com/index.php/globacadnurs/article /view/139/205. Acesso em: 13 jul. 2021.

BRASIL. Hemodiálise. Ministério da Saúde - Biblioteca Virtual em Saúde, 2019. Disponível em: http://bvsms.saude.gov.br/dicas-em-saude/2988hemodialise. Acesso em: 26 jul de 2021.

_. Resolução № 358, DE 15 DE OUTUBRO DE 2009. Dispõe sobre a Sistematização da Assistência de Enfermagem e a implementação do Processo de Enfermagem em ambientes, públicos ou privados, em que ocorre o cuidado 
profissional de Enfermagem, e dá outras providências. 0 Conselho Federal de Enfermagem (COFEN), no uso de suas atribuições legais que lhe são conferidas pela Lei no 5.905, de 12 de julho de 1973, e pelo Regimento da Autarquia, aprovado pela Resolução COFEN no 242, de 31 de agosto de 2000. Conselho Federal de Enfermagem, [2009]. Disponível em: http://www.cofen.gov.br/resoluo-cofen-3582009_4384.html. Acesso em: 30 jul. 2021.

DA SOUZA, Nauã Rodrigues da; et al. Caracterização dos pacientes com insuficiência renal aguda de uma unidade de terapia intensiva submetidos à hemodiálise. Veredas Favip-Revista Eletrônica de Ciências, v. 10, n. 2, p. 51-64, 2018. Disponível

em: http://veredas.favip.edu.br/ojs/index.php/veredas1/article/view/489/pdf . Acesso em 30 jul. 2021.

DE ASSIS, Bruno Majevski de; et al. Desejo da maternidade entre mulheres com insuficiência renal crônica dialítica. Revista Científica de Enfermagem, São Paulo, v. 8, n. 24, p. 78-88, 2018. Disponível em: https://recien.com.br/index.php/Recien/article/view/273/pdf_1. Acesso em: 13 jul. 2021.

GOMES, Ryanne Carolynne Marques; et al. Análise do conceito "binômio mãe-feto" da taxonomia da NANDA-I em gestantes de alto risco. Revista Brasileira de Enfermagem. 73 (suppl 4). 2020. Disponível em: https://www.scielo.br/j/reben/a/DqbGLLzLM4NqdNphpwBsfZz/?lang=pt. Acesso em: 25 jun. 2021.

GUEDES, Jailza da Rocha; et al. Incidência e fatores predisponentes de insuficiência renal aguda em unidade de terapia intensiva. Cogitare Enfermagem, vol. 22, núm. 2, e49035, $2017 \quad$ Disponível em: https://www.redalyc.org/jatsRepo/4836/483654815021/483654815021. pdf. Acesso em: 30 jul.2021.

LIMA, Janielle Ferreira de Brito; et al. Complicações e desfechos de gestações durante o tratamento hemodialítico. Revista Científica de Enfermagem, São Paulo, v. 11, n. 33, p. 46-52, 2020. Disponível em: https://recien.com.br/index.php/Recien/article/view/470/pdf. Acesso em: 13 jul. 2021.

MEDEIROS, Ana Lúcia de; et al. Avaliando diagnósticos e intervenções de enfermagem no trabalho de parto e na gestação de risco. Revista Gaúcha Enfermagem. 2016 set;37(3):e55316. Disponível em: https://www.scielo.br/j/rgenf/a/9dZwkv3VJjm9Fv8V39bfkKC/?lang=pt\&f ormat=pdf. Acesso em: 25 jun. 2021.

OLIVEIRA, Thatiane Lopes; DE MENDONÇA, José Márcio Girardi; DE SENA, Roseni Rosangela. Insuficiência renal crônica e gestação: desejos e possibilidades. Revista Mineira de Enfermagem, v. 11, n. 3, p. 258-264, 
2007. Disponível em: https://www.reme.org.br/artigo/detalhes/344. Acesso em: 13 jul. 2021.

RIBEIRO, Catarina Isabel; SILVA, Natália. Gravidez e diálise. Braz. J. Nephrol., v. 42, n. 3, p. 349-356, ago. 2020. Disponível em: https://www.scielo.br/j/jbn/a/RFk3D8wWHXdSVYShvbgnXHP/?lang=pt\&f ormat=pdf. Acesso em: 13 jul. 2021.

SARTORI, Angela Antonia et al. Diagnósticos de enfermagem no setor de hemodinâmica: uma perspectiva adaptativa. Revista da Escola de Enfermagem da USP, v. 52, 2018. Disponível em: https://www.scielo.br/j/reeusp/a/Xr4SmxC7rynHqs7cZBdv8dm/abstract/ ?lang=pt. Acesso em: 13 jul. 2021.

SILVA, Carmen Lúcia Lucas da; ARRAIS, Alessandra Rocha. Vivências de uma gestante em tratamento de hemodiálise no SUS. Revista de Pesquisa Cuidado é Fundamental on line, [s. l.], p. 53-57, 2018. Disponível em: https://pesquisa.bvsalud.org/portal/resource/pt/biblio-905347. Acesso em: 13 jul. 2021.

SOCIEDADE BRASILEIRA DE NEFROLOGIA, 2020. Gestação em pacientes em Diálise, 2020. Disponível em: https://www.sbn.org.br/profissional/sbncientifico/blog-cientifico/single-cientifica/news/gestacao-em-pacientesem-dialise/. Acesso em: 13 jul. 2021.

TEIXEIRA, Gracimary Alves; et al. Sistematização da assistência de enfermagem a pessoa em situação de rua. Revista de enfermagem UFPE on line. Recife, 9(3):7169-74, mar. 2015. Disponível em: https://periodicos.ufpe.br/revistas/revistaenfermagem/article/view/1044 8. Acesso em: 25 jun. 2021.

TELES, Priscila Alvarenga; et al. Diagnósticos de enfermagem mais prevalentes em gestantes de alto risco. Enfermagem. em Foco 2019; 10 (3): 119-125. Disponível em: http://revista.cofen.gov.br/index.php/enfermagem/article/view/1937. Acesso em: 25 jun. 2021.

TANNURE, Meire Chucre; PINHEIRO, Ana Maria. SAE: Sistematização da Assistência de Enfermagem: guia prático. 2.ed. Rio de Janeiro: Guanabara Koogan, 2011. p. 298-298. Disponível em: https://pesquisa.bvsalud.org/portal/resource/pt/sms-10492. Acesso em: 11 ago. 2021. 


\section{CAPITULOIV}

\section{PREUALÊNCIA DE SIFILIS CONGÊNITA EM UMA CAPITAL DO NORDESTE NO PERIODO DE 2007 A 2017}

DDI: 10.51859/amplla.esp917.1121-4

Fabrício bezerra Alves ${ }^{1}$

Janaína Araújo Silva ${ }^{1}$

José Francisco Ribeiro ${ }^{1}$

Raquel Vilanova Araujo ${ }^{1}$

Regina Célia Vilanova Campelo ${ }^{1}$

\footnotetext{
${ }^{1}$ Graduada em Enfermagem. Centro Universitário Santo Agostinho - UNIFSA; Pós-Graduada em Circulação Extracorpórea (Perfusão) - Asgard Cursos, Goiânia - GO.

${ }^{2}$ Graduada em Enfermagem. Centro Universitário Santo Agostinho - UNIFSA

${ }^{3}$ Doutor em Enfermagem UFpi, coordenadora de curso de pós graduação, docente UNIFSA
}

\section{RESUMO}

Tendo em vista que a Sífilis Congênita é uma doença de notificação compulsória que trás sérios problemas de saúde para o binômio mãe-filho se o tratamento não for feito de maneira correta com o esquema de tratamento recomendado pelo Ministério da Saúde, por isso pesquisa-se sobre o tema de prevalência na capital do Piauí, a fim de analisar os casos de Sífilis Congênita em Teresina - PI conforme banco de dados do Sistema de Informação de Agravos de Notificação no período de 2007 a 2017. Para tanto, é necessário traçar o perfil socioepidemiológico da Sífilis Congênita em Teresina no período de 2007 a 2017, determinar a classificação conforme tratamento da Sífilis congênita em Teresina no período estudado e Avaliar o tratamento da Sífilis Congênita em Teresina no período de 2007 a 2017. Realiza-se, então, uma pesquisa quantitativa, de caráter descritivo e exploratório. Diante disso verifica-se que as características sociodemográficas mais significativas foram: faixa etária de 20 a $39(69,5 \%)$ anos; raça/cor parda $(71,9 \%)$; ensino fundamental $(49,15 \%)$, que as características diagnósticas mais significativas foram: estágio clínico latente $(48,42 \%)$; teste não treponêmico reativo $(91,46 \%)$; teste treponêmico $(55,90 \%)$, que quanto à caracterização obstétrica, os dados mais relevantes foram: a maioria das gestantes realizou o pré-natal $(81,32 \%)$; o diagnóstico e o tratamento foram iniciados durante o pré-natal $(51,94 \%)$; os parceiros não foram tratados $(61,90 \%)$; a classificação final foi a recente (82,42\%); a evolução dos casos foi de RN's vivos $(95,95 \%)$, o que impõe a constatação de que Frente aos achados do presente estudo, verificou-se que Teresina apresenta uma alta taxa de notificação da doença, o que aponta a necessidade de políticas públicas para o enfrentamento ao agente infeccioso. Aliado a isto se deve também capacitar os profissionais de saúde para estarem aptos a utilizar as ferramentas disponíveis no combate a doença.

Palavras-chave: Sífilis. Sífilis Congênita. Prevalência. Tratamento. Nordeste. 
Bearing in mind that Syphilis Congenital is compulsory notification disease that brings serious health problems to the binominal (mother-child) if the treatment is not done correctly with the treatment scheme recommended by the Ministry of Health, that is why research on the topic of prevalence in capital of Piauí, in order to analyze the cases of congenital syphilis in Teresina - Piauí according to the database of the Information System for Notification Diseases in the period from 2001 to 2017. Therefore, it is necessary to trace the socio-epidemiological profile of congenital syphilis in Teresina from 2007 to 2017, determine the classification according to the treatment of congenital syphilis in Teresina in the period studied and evaluate the treatment of congenital syphilis in Teresina in the same period. Then, a quantitative research of a descriptive and exploratory nature is carried out. Therefore, it appears that the most significant social-demographic characteristics were: age group 20 to $29(69,25 \%)$ years old, race/brow color $(71,9 \%)$; elementary education $(49$, $15 \%)$, that the most significant diagnostic characteristics were: latent clinical stage (48, $42 \%)$; reactive non-treponemic test $(91,46 \%)$; treponemic test $(55,90 \%)$, that regarding obstetric characterization, the most relevant data were: the majority of pregnant women performed prenatal care $(81,32 \%)$; diagnosis and treatment started during prenatal care $(51,94 \%)$, partners were not treated $(61,90 \%)$; the final to recent classification $(81,42 \%)$; the evolution of the cases was of live NB's $(95,95 \%)$, which imposes the observation that, considering the findings of the present study, it was found that Teresina has a high rate of notification of the disease, which points to the need for policies public to confront the infectious agent. In addition to this, health professionals should also be trained to be able to use the tools available to fight the disease.

Keywords: Syphilis. Syphilis Congenital. Prevalence. Treatment. Northeast.

\section{INTRODUÇÃOO}

A Sífilis é um relevante agravo em saúde pública, uma vez que se trata de uma doença infectocontagiosa e com capacidade de acometer o organismo de maneira severa quando não tratada, aumentando significativamente o risco de contração da infecção pelo HIV, devido à presença das lesões sifilíticas que facilitam a entrada do vírus. Além disso, a Sífilis Congênita é responsável por altas taxas de morbidade e mortalidade, podendo chegar a $40 \%$ a taxa de abortamento, óbito fetal e morte neonatal (BRASIL, 2016).

Os treponemas patogênicos originam sífilis venérea, bouba, sífilis endêmica e pinta em múltiplos estágios. Ainda que semelhantes, essas infeções podem ser diferenciadas com base em critérios clínicos, epidemiológicos e geográficos. A sífilis venérea é transmitida por atividade sexual. Eles toleram mal a dessecação, a 
temperatura elevada e a tensão de oxigênio no ambiente, características que explicam por que a transmissão eficiente exige contato pessoal próximo (RADOLF, et al; 2016)

Em 2016, foram notificados 87.593 casos de Sífilis adquirida, 37.436 casos de Sífilis em gestantes e 20.474 casos de Sífilis Congênita - dentre eles, 185 óbitos - no Brasil. A maior proporção dos casos foi notificada na região Sudeste. Destacando-se as elevadas taxas de Sífilis em gestantes encontradas no Espírito Santo, Rio de Janeiro, Rio Grande do Sul e Mato Grosso do Sul. Em relação à Sífilis congênita, os três primeiros estados supracitados permanecem em evidência, ao lado do estado de Pernambuco (BRASIL, 2017).

No período de 1998 a junho de 2017, foram notificados no Sinan 159.890 casos de sífilis congênita em menores de um ano de idade, dos quais 70.558(44,1\%) eram residente na Região Sudeste, 49.585 (31,0\%) no Nordeste, 17.257 (10,8\%) no Sul, 13.625 (8,5\%) no Norte e 8.865 (5,5\%) no Centro-Oeste. No ano de 2016, notificaram-se 20.474 casos, a maioria dos quais $(41,5 \%)$ residia na Região Sudeste, seguidos pelo Nordeste $(28,9 \%)$, Sul $(15,4 \%)$, Norte $(8,4 \%)$ e Centro-Oeste $(5,8 \%)$. De 2015 para 2016, houve incremento de 4,7\% no número de notificações no Brasil (BRASIL, 2017).

Segundo a Secretaria de Estado do Piauí 2018, o município de Teresina apresentou em um intervalo de 2013 a 2018, o maior número de casos de Sífilis Congênita e de Sífilis em gestantes no estado sendo um total de 188 casos no ano de 218 e de 927 casos também no ano de 218, respectivamente.

A Sífilis Congênita é uma doença de notificação compulsória verticalmente transmissível da mãe para o concepto, que trás sérios problemas de saúde para o recém-nascido e que pode leva ao óbito da criança se a mãe não for tratada corretamente com o esquema de tratamento recomendado pelo Ministério da Saúde. Apesar da evolução do tratamento da sífilis, a quantidade de casos continua a persistir em alta. No Piauí os casos de Sífilis Congênita pouco diminuíram em praticamente todos os municípios do estado, sendo o de Teresina o de maior evolução, tendo um total de 188 casos no ano de 2018 apresentando uma diferença de 146 casos do segundo colocado, Parnaíba, que apontou apenas 42 casos em 2018.

Nesse contexto, faz-se necessário analisar os casos de Sífilis Congênita em Teresina - PI no período de 2007 a 2017. 


\section{METODOLOGIA}

Trata-se de uma pesquisa exploratória, descritiva, com abordagem quantitativa, realizada através da coleta dos dados fornecidos pela Vigilância Epidemiológica da Secretaria Municipal de Saúde do município de Teresina (PI), com as informações provenientes do Sistema de Informação de Agravos de Notificação (SINAN) no período de 2007-2017. Foram incluídos apenas os registros referentes a classificação estatística internacional de doenças e problemas relacionados à saúde na categoria CID10 A50 - A53 (Sífilis congênita).

Para a investigação da sífilis congênita foram analisadas as seguintes características referentes à mãe: idade, raça/cor, escolaridade. Considerados os seguintes dados clínicos: classificação clínica da doença, se fez ou não teste treponêmico, realização do pré-natal, momento do diagnóstico da sífilis materna, adequação do tratamento para a sífilis materna e o tratamento do parceiro da gestante, evolução dos casos.

Utilizando-se os dados do período em que foi iniciado o registro dos casos da doença no Sistema de Informação de Agravos de Notificação. O Para a investigação da sífilis congênita foram analisadas as seguintes características referentes à mãe: idade, raça/cor, escolaridade, endereço residencial, realização do pré-natal, momento do diagnóstico da sífilis materna, adequação do tratamento para a sífilis materna e o tratamento do parceiro da gestante.

Para descrição dos casos de Sífilis Congênita confirmados através das variáveis utilizadas para a pesquisa, utilizamos o programa estatístico Startistical Product Service Solucions (SPSS) - versão 20.0, realizaram-se os cálculos referentes à estatística descritiva, com a elaboração das frequências absolutas, que, em seguida, foram organizadas em tabelas.

\section{RESULTADOS}

Foram registrados 832 casos de sífilis no período de 2007 a 2017 em Teresina-Piaui, observa-se maior prevalência de gestantes com idade entre 20 a 39 
anos $(69,5 \%)$, raca/cor parda $(71,9 \%)$ e com ensino fundamental $(49,15 \%)$. A tabela 1 apresenta as características sociodemográficas das gestantes.

Tabela 1. Características sociodemográficas de gestantes diagnosticadas com Sífilis de acordo com Sistema de Informação de Agravos de Notificação (SINAN) no período de 2007

\begin{tabular}{|c|c|c|}
\hline Características & $\mathbf{n}$ & $\%$ \\
\hline \multicolumn{3}{|l|}{ Faixa Etária } \\
\hline $10-14$ anos & 10 & 1,21 \\
\hline 15 - 19 anos & 229 & 27,52 \\
\hline $20-39$ anos & 578 & 69,47 \\
\hline $40-59$ anos & 15 & 1,80 \\
\hline \multicolumn{3}{|l|}{ Raça/cor } \\
\hline Parda & 598 & 71,87 \\
\hline Preta & 122 & 14,66 \\
\hline Branca & 65 & 7,81 \\
\hline Amarela & 13 & 1,56 \\
\hline Indígena & 3 & 0,38 \\
\hline Não informado & 31 & 3,72 \\
\hline \multicolumn{3}{|l|}{ Escolaridade } \\
\hline Ensino fundamental & 409 & 49,15 \\
\hline Ensino médio & 301 & 36,17 \\
\hline Ensino Superior & 17 & 2,04 \\
\hline Analfabeto & 8 & 0,99 \\
\hline Não informado & 97 & 11,65 \\
\hline
\end{tabular}

Está ilustrado na Tabela 2 as características do diagnóstico de sífilis em mulheres no período de 2007 a 2017 em Teresina. Em relação à classificação clínica da sífilis a mais frequente foi no estágio latente (48,42\%); teste não treponêmico reativo $(91,46 \%)$; teste treponêmico $(55,90 \%)$. 
Tabela 2. Características do diagnóstico de sífilis em gestantes no período de 2007 - 2017 em Teresina, Piauí -Brasil

\begin{tabular}{llc}
\hline Características & $\mathrm{n}$ & $\%$ \\
\hline Classificação clinica & & \\
Primária & 115 & 15,09 \\
Secundária & 57 & 7,49 \\
Terciária & 146 & 19,16 \\
Latente & 369 & 48,42 \\
Não informado & 75 & 9,84 \\
Teste não Treponêmicos segundo Evolução & & \\
Reativo & 697 & 91,46 \\
Não reativo & 27 & 3,54 \\
Não realizado & 25 & 3,28 \\
Não informado & 13 & 1,72 \\
Teste Treponêmicos segundo Evolução & & \\
Reativo & 426 & 55,90 \\
Não reativo & 21 & 2,77 \\
Não realizado & 288 & 37,79 \\
Não informado & 27 & 3,54 \\
\hline
\end{tabular}

Fonte: DATASUS/SINAN, 2019.

O número de mulheres acometidas por sífilis durante a gestação quee tiveram o diagnóstico e o tratamento da sífilis iniciados durante o pré-natal $(51,94 \%)$.

Tabela 3. Dados da assistência pré-natal, diagnostico/tratamento, classificação e evolução dos casos de sífilis no período de 2007 - 2017 em Teresina-Piauí - Brasil

\begin{tabular}{lll}
\hline Características & n & \% \\
\hline Realizou Pré-natal & & \\
Sim & 775 & 81,32 \\
Não & 171 & 17,94 \\
Não informado & 7 & 0,74
\end{tabular}

Diagnostico/tratamento 


\begin{tabular}{lll}
\hline Características & $\mathbf{n}$ & $\mathbf{\%}$ \\
\hline Durante pré-natal & 495 & 51,94 \\
No momento do parto/curetagem & 348 & 36,51 \\
No pós-parto & 91 & 9,54 \\
Não realizado & 9 & 0,97 \\
Não informado & 10 & 1,04 \\
Tratamento do(s) parceiros das & & \\
gestantes & & \\
Sim & 306 & 32,10 \\
Não & 590 & 61,90 \\
Não informado & 57 & 6,00 \\
Classificação final & & \\
Sífilis congênita recente & 783 & 82,42 \\
Natimorto/Aborto por Sífilis & 42 & 4,42 \\
Descartados & 42 & 4,42 \\
Não informados & 83 & 8,74 \\
Evolução dos casos & & \\
Vivo & 830 & 95,95 \\
Óbito pelo agravo notificado & 13 & 1,50 \\
Óbito por outra causa & 15 & 1,73 \\
Não informado & 7 & 0,82 \\
\hline
\end{tabular}

\section{DISCUSSÃO}

Estatísticas oficiais mostram que, entre 1998 e junho de 2016, apenas 12,7\% dos parceiros de gestantes soropositivas para sífilis foram tratados. Este fato enfatiza a importância dos esforços para melhorar o tratamento oportuno e adequado para mulheres grávidas e seus parceiros (Rocha; AFB, 2019).

Em um estudo realizado no período entre janeiro de 2016 a dezembro de 2017 em hospitais universitários de Pelotas, os autores encontraram variáveis correspondente a 21 a 30 anos, o que corrobora com o encontrado nesse estudo (LOPES; ALBERNAZ, 2019). 
Em um estudo realizado em Guarapuava / PR, os autores relataram que a caracterização socioeconômica das gestantes com diagnóstico de sífilis descritos na literatura nacional e internacional, refere que esta é mais comum entre mulheres jovem, com baixa escolaridade e trabalho não remunerado (SOARES, Larissa Gramazio, et al; 2017).

Embora não seja uma doença atrelada ás classes de baixa renda, estes marcadores podem sublinhar que esta parcela da população tem acesso restrito aos serviços de saúde e, com isso, uma assistência pré-natal ineficaz, favorecendo o aumento da Transmissão Vertical ás gestantes (ARAUJO, Cinthia Lociks de et al; 2012).

O fato da escolaridade ser apontada como fator para a apreensão de conhecimentos, vários estudos realizados mundialmente relatam que a educação está fortemente relacionada com os fatores socioeconômicos dessas gestantes, situação esta que reflete para o binômio. Tal evento alerta as autoridades e os profissionais da saúde para buscar uma melhor estratégia para minimizar o problema (JESUS, Tales Bruno da Silva de et al, 2019).

Identificou-se predomínio da raça/cor parda, porém as características encontradas mostram que a ocorrência da sífilis não apresenta um perfil definido da população e varia conforme a região do Brasil (SIGNOR, Mariane et al; 2019). No estado do Piauí devido ao processo de miscigenação, a raça/cor mais predominante é a parda (IBGE; 2017).

Os testes treponêmicos e não treponêmicos confirma a sífilis em seu estado latente uma vez que os testes de anticorpos específicos como ELISA (treponêmicos) e os testes de prova reagínicas como VDRL e RPR (não treponêmicos) se fazem reativos com maior incidência.

No estudo "Nascer no Brasil" os autores revelaram que a o teste VDRL foi maior nas capitais. Enquanto que em uma pesquisa nacional, a solicitação do primeiro VDRL atingiu 89,1\% no período entre 2011-2012, seguida do segundo teste mais tardiamente na gravidez representando apenas $41,1 \%$ dos casos registrados (DOMINGUES; LEAL, 2016).

Diante da classificação clínica, o que chama a atenção é que a sífilis latente se mostra mais evidente, onde a gestante tem o teste treponêmico reativo, mas não apresenta sinais e sintomas clínicos da doença. Em consequência a isso, a sífilis 
terciária se apresenta como a principal causa de infecção nas gestantes, pois apresenta um espaço de tempo mais amplo para aparecimento ( 2 a 40 anos).

Podemos perceber com essa tabela, a falha na atenção primária se analisarmos o número de testes treponêmicos não realizados. Essa não realização dificulta processo do parto, pois não se sabe em qual estágio está à sífilis, com isso, a intervenção medicamentosa pode não ser eficaz.

Enfatize-se que o tratamento do parceiro se torna um determinante para a cura eficaz da mãe, assim como, para o fim do agravo, através da inclusão do tratamento do parceiro na problemática abordada como um possível agravante para a prevalência da doença (De Oliveira; D. R., 2011).

A maioria das gestantes realizou acompanhamento pré-natal, no entanto, o fato não inibiu o aumento de casos da doença, isso sugere que a qualidade do prénatal carece de ações estratégicas e educativas para qualificação do tratamento e melhores resultados. Ainda existe o fato de que há a omissão das subnotificações, o que pode sugerir taxas ainda maiores da doença. (HOLZTRATTNER, Jéssica Strube et al, 2019).

No estudo realizado em Palmas, Tocantins, no período entre 2007 á 2014, observou-se que a maioria do tratamento dos parceiros foi ignorada. Das mães que realizaram o pré-natal, 83,0\% não tiveram seus parceiros tratados. (CAVALCANTE, PEREIRA, CASTRO; 2017).

Um estudo realizado para avaliar o manejo de parceiros sexuais de gestantes com sífilis na atenção primária à saúde no nordeste do Brasil, em 2014, na cidade de Fortaleza, realizando observação de seis centros de atenção básica, mostrou que estes não aderiram a nenhuma das estratégias preconizadas pelo Ministério da Saúde para notificação de parceiros. Isso mostra que não há uma busca efetiva aos parceiros (Rocha; 2019).

Segundo "BRASIL, 2006", para a sífilis recente, o período de negativação dos testes de cardiolipina após tratamento eficaz é tanto mais tardio quanto maior a duração da infecção ou mais altos forem os títulos no início do tratamento. Com isso, o estagio recente da sífilis se torna mais relevante, como foi encontrado nesse estudo.

Nesse contexto de atenção primária, como o profissional de enfermagem tem um maior contato com a população de um modo geral, deve-se apropriar do vínculo 
que é feito com a gestante e com o parceiro, e aproveitar para reforçar as ações de prevenção e diagnóstico o mais precoce possível, especialmente no pré-natal, além de informar as gestantes o direito que elas têm de realizar os testes que detectam a sífilis e quantas vezes forem necessários no período gestacional.

\section{CONCLUSÃO}

Diante do estudo feito, pode-se observar mais a fundo a Sífilis Congênita, como se dá a infecção, como são suas manifestações clínicas, seu diagnóstico e tratamento, visto que esta é uma doença que acomete milhões de pessoas ao redor do mundo.

Pôde-se ver que, apesar do diagnóstico e do tratamento poder ser feito na unidade primária e de forma gratuita, o índice de notificação ainda é alto, e que existem gestantes que são diagnosticadas no momento do parto. 0 estudo também mostrou que, um dos principais fatores para a não eficácia total do tratamento preconizado pelo Ministério da Saúde com a Penicila, é a não aderência dos parceiros no tratamento.

Outro dado importante verificado, foi o fato de que a faixa etária que corresponde á 15 - 19 anos, foi a segunda maior dentro o fator Idade, isso mostra que a atividade sexual nos adolescentes está começando cada vez mais cedo, sendo um risco para esses jovens que tendem a fazer sexo sem preservativo.

Frente aos achados do presente estudo, verificou-se que Teresina apresenta uma alta taxa de notificação da doença, o que aponta a necessidade de políticas públicas para o enfrentamento ao agente infeccioso. Aliado a isto se deve também capacitar os profissionais de saúde para serem aptos a utilizar as ferramentas disponíveis no combate à doença.

\section{REFERENCIA}

ARAUJO, Cinthia Lociks de et al . Incidência da sífilis congênita no Brasil e sua relação com a Estratégia Saúde da Família. Rev. Saúde Pública, São Paulo , v. 46, n. 3, p. 479-486, jun. 2012 . Disponível em: <http://www.scielo.br/scielo.php?script=sci_arttext\&pid=S0034$89102012000300010 \& \operatorname{lng}=$ pt\&nrm=iso>. em 04 mar. 2020. https://doi.org/10.1590/S0034-89102012000300010. 
BRASIL. Ministério da Saúde. Secretaria de Vigilância em Saúde Programa Nacional de Dst e Aids. MANUAL TÉCNICO PARA DIAGNÓSTICO DA SÍFILIS. Brasília: Ministério da Saúde, 2016.54 p.

BRASIL, Ministério da Saúde. Diretrizes para o controle da Sífilis Congênita Manual de Bolso. 2006. Disponível em: <http://bvsms.saude.gov.br/bvs/publicacoes/manual_sifilis_bolso.pdf>. Acesso em: 05 mar. 2020.

BRASIL, 2017A. Ministério da Saúde. Secretaria de Vigilância em Saúde (Org.). Boletim Epidemiológico Sífilis 2017. 48. ed. Brasília, 2017. 44 p. Disponível em: <http://portalarquivos.saude.gov.br/images/pdf/2017/novembro/13/BE2017-038-Boletim-Sifilis-11-2017-publicacao-.pdf>. Acesso em: 17 out. 2018.

CAVALCANTE, Patrícia Alves de Mendonça; PEREIRA, Ruth Bernardes de Lima; CASTRO, José Gerley Diaz. Sífilis gestacional e congênita em Palmas, Tocantins, 2007-2014 *. Epidemiologia e Serviços de Saúde, [s.l.], v. 26, n. 2, p.255-264, mar. 2017. Instituto Evandro Chagas. Disponível em: http://dx.doi.org/10.5123/s1679-49742017000200003.

DE OLIVEIRA, D. R.. Abordagem conceitual sobre a sífilis na gestação e o tratamento de parceiros sexuais Enfermagem em Foco 2011; 2(2):108$111 . \quad$ Disponível em: http://revista.cofen.gov.br/index.php/enfermagem/article/download/106 /88

DOMINGUES, Rosa Maria Madeira Soares Madeira; LEAL, Maria do Carmo. Incidência de sífilis congênita e fatores associados à transmissão vertical da sífilis: dados do estudo Nascer no Brasil: Incidence of congenital syphilis and factors associated with vertical transmission: data from the Birth in Brazil study. 2016. Cad. Saúde Pública vol.32 no.6 Rio de Janeiro. Disponível em: <http://dx.doi.org/10.1590/0102-311X00082415>.

HOLZTRATTNER, Jéssica Strubeet al. SÍFILIS CONGÊNITA: REALIZAÇÃO DO PRÉNATAL E TRATAMENTO DA GESTANTE E DE SEU PARCEIRO. Cogitare Enfermagem, [s.l.], v. 24, p.1-11, 29 abr. 2019. Universidade Federal do Parana. Disponível em: http://dx.doi.org/10.5380/ce.v24i0.59316.

IBGE. Instituto Brasileiro de Geografia e Estatística. Censo 2013 - Guarapuava. [acesso em $22 \quad$ fev 2017]. Disponível em: http://www.cidades.ibge.gov.br/xtras/perfil.php?lang=\&codmun=410 $940 \&$ search=parana|guarapuava

JESUS, Tales Bruno da Silva de et al. Sífilis em gestante e congênita: casos notificados de um município do Noroeste Paulista. Revista Nursing, S.l, v. 250, n. 22, p.2766-2771, fev. 2019.

LOPES, Carolina Damé Osório; ALBERNAZ, Elaine Pinto. Sífilis congênita: prevalência e fatores associados em hospitais universitários de 
pelotas. Ciência \& Saúde, [S.L.], v. 12, n. 3, p. 1-8, 6 dez. 2019. EDIPUCRS. http://dx.doi.org/10.15448/1983-652x.2019.3.33415.

RADOLF JD, DEKA RK, ANAND A, ŠMAJS D, NORGARD MV, YANG XF. Treponema pallidum, a espiroqueta da sífilis: ganhar a vida como um patógeno furtivo. Nat RevMicrobiol.2016; 14 (12): 744-759. Disponível em: doi: 10.1038 / nrmicro.2016.141

Rocha AFB, Araújo MAL, Miranda AE, Leon RGP, Silva Junior GB, Vasconcelos LDPG. Manejo de parceiros sexuais de gestantes com sífilis no nordeste do Brasil - um estudo qualitativo. BMC Health Serv Res.2019; 19 (1): 65. Publicado em 24 de janeiro de 2019. Disponível em: doi: 10.1186 / s12913-019-3910-y

SESAPI 2018. Nota técica dia Nacional da Sífilis - out. 2018.pdf. Disponível em: http://www.saude.pi.gov.br/uploads/warning_document/file/357/NOTA_ T\%C3\%89CNICA_DIA_NACIONAL_DA_S\%C3\%8DFILIS_out_2018.pdf

SOARES, Larissa Gramazio et al . Gestational and congenital syphilis: maternal, neonatal characteristics and outcome of cases. Rev. Bras. Saude Mater. Infant., Recife , v. 17, n. 4, p. 781-789, Dec. 2017 . Available from <http://www.scielo.br/scielo.php?script=sci_arttext\&pid=S1519$38292017000400781 \& \operatorname{lng}=e n \& n r m=i s o>$. access on 04 Mar. 2020. Disponível em: https://doi.org/10.1590/180693042017000400010 . 


\section{CAPITULO V}

\section{PERCEPCÃO DEACADÊMICOS DEENFERMAGEM SOBRE A VIOLÊNCIA OBSTÉTRICA}

DDI: 10.51859/amplla.esp917.1121-5

Fabyanna Lucena Costa Medeiros ${ }^{1}$

Hiêda Maria Porto Cintra ${ }^{2}$

Francisco Honeidy Carvalho Azevedo ${ }^{3}$

\footnotetext{
${ }^{1}$ Graduada em Enfermagem. Centro Universitário Santo Agostinho - UNIFSA; Pós-Graduada em Circulação Extracorpórea (Perfusão) - Asgard Cursos, Goiânia - GO.

${ }^{2}$ Graduada em Enfermagem. Centro Universitário Santo Agostinho - UNIFSA

${ }^{3}$ Doutor em Biologia Celular e Molecular Aplicada à Saúde pela Universidade Luterana do Brasil - ULBRA.
}

\section{RESUMO}

O parto é um momento ímpar na vida de uma mulher, dependendo de como ela está em seu estado físico e psicológico. A violência contra a mulher apresenta-se em distintas expressões e uma delas tem sido muito presente e não identificada: a violência obstétrica, que se caracteriza também pela imposição de intervenções danosas à integridade física e emocional das mulheres nas instituições em que são atendidas, bem como o desrespeito à sua autonomia que ocorre quando o profissional impõe o uso de medicações para acelerar o processo de expulsão do feto. Trata-se de um estudo descritivo, exploratório, com abordagem qualitativa. Para instrumentalização da produção de dados foram realizadas 20 entrevistas no período de março de 2017, com acadêmicos de enfermagem de uma Instituição de Ensino Superior privada, localizada na zona sul da cidade de Teresina - PI, por meio de roteiro de entrevista semiestruturado, em que os depoimentos foram gravados através do celular (com o consentimento dos participantes) e transcritos na íntegra, com a finalidade de reproduzir, de maneira fidedigna, suas falas durante o diálogo. A forma de violência obstétrica com maior grau de conhecimento foi a violência psicológica, seguida de manobras sobre o abdômen da mulher, impedimento da entrada de acompanhante, episiotomia de rotina, ocitocina e rompimento da bolsa amniótica. Eles também relataram outras formas de violência como gravação de partos sem o consentimento das mulheres, toques vaginais constantes, falta de informação e negligência. Dentre os meios para combater a violência obstétrica destacaram-se humanizar a assistência e informar às mulheres sobre os seus direitos. Diante disso, na contemporaneidade são notórios a presença e o crescimento acentuado das mídias sociais como forma de divulgar trabalhos, operações, casos clínicos e outras demandas que permitem a conexão e o envolvimento de muitas pessoas e sociedades. Isso acontece porque o ciberativismo está dando vez e voz aos cidadãos, que possuem a liberdade de expor suas opiniões em suas contas pessoais e as empresas em contas comerciais, fortalecendo sua autonomia e liberdade de expressão. Um exemplo desse ciberativismo é o aplicativo "Salve Maria", que permite que qualquer pessoa denuncie abusos de forma rápida e precisa, por meio de um canal direto com a Polícia Militar (PM). Portanto, faz-se necessário dar continuidade a estudos que investiguem a percepção de acadêmicos sobre a violência obstétrica em outras áreas da saúde que atuam no momento do trabalho de parto, servindo como incentivo ao aprimoramento dos conhecimentos a respeito desta violência.

Palavras-chave: Violência contra a Mulher. Enfermagem em Saúde Comunitária. Ética em Enfermagem. 
O parto é um momento ímpar na vida de uma mulher, dependendo de como ela está em seu estado físico e psicológico. Para manter esse momento agradável, os profissionais precisam respeitar e entender que este é um processo natural e é diferente dos demais casos de internação hospitalar, que necessitam de medicações e outras intercorrências. Segundo Biscegli et al. (2015), o trabalho de parto, mesmo sendo um estado fisiológico, pode e é influenciado por muitos fatores, como o estado emocional, fatores ambientais, valores culturais e pelos próprios antecedentes da mulher. Entretanto, muitas mulheres são vítimas de violência no parto, o que pode transformar um acontecimento tão único e satisfatório num momento traumático, acarretando prejuízos não só para a mãe e o bebê, como também para toda a estrutura familiar.

A violência é conhecida como um triste e grave fenômeno social que está sofrendo grande aumento em todas as suas formas, principalmente contra a mulher e, ao longo da história vem ganhando destaque em todos os países do mundo seja de forma social, racial, etária, religiosa, sexual e doméstica. A violência contra a mulher apresenta-se em distintas expressões, e uma delas tem sido muito presente e não identificada: a violência obstétrica (ANDRADE; AGGIO, 2014). De acordo com as autoras, entende-se por violência obstétrica qualquer ato exercido por profissionais da saúde no que diz respeito ao corpo e aos processos reprodutivos das mulheres, expresso através de uma atenção desumanizada, abuso de ações intervencionistas, medicações e a transformação do processo de parto fisiológico em patológico. Este tipo de violência caracteriza-se também, pela imposição de intervenções danosas à integridade física e emocional das mulheres nas instituições em que são atendidas, bem como o desrespeito à sua autonomia, que ocorre quando o profissional impõe o uso de medicações para acelerar o processo de expulsão do feto. A violência obstétrica pode ocorrer antes, durante ou depois do parto (SILVA et al., 2015). Diante disso, faz-se necessária a atribuição da atenção humanizada que engloba conhecimentos, práticas e atitudes que têm como objetivo garantir o parto e nascimento saudáveis, levando em consideração a prevenção da morbimortalidade materna e perinatal (BRASIL, 2001). 
Para Silva et al. (2015), a humanização faz com que o momento do parto deixe de ser objeto de medo e tensões e siga a ordem natural dos acontecimentos, obedecendo ao ritmo e às necessidades específicas do corpo de cada mulher em trabalho de parto, e os profissionais de saúde interferindo o mínimo possível no processo do nascimento da criança. Por isso, é necessário, que no desenvolvimento de atividades de prevenção e acolhimento às mulheres em situação de violência obstétrica, o enfermeiro concentre suas ações de cuidado às necessidades assistenciais da mulher, respeitando sempre sua autonomia no trabalho de parto (ASSUMPÇÃO et al., 2014).

Diante disso, o presente trabalho tem como objetivo investigar o conhecimento dos acadêmicos de enfermagem sobre a violência obstétrica e os meios para combatê-la. É através deste estudo que a sociedade saberá o que caracteriza uma violência obstétrica, sendo instigada a combatê-la e a lutar também pelos seus direitos. Além disso, a pesquisa poderá dar mais otimismo à população, no que diz respeito à luta por um atendimento mais digno e que respeite a vida de quem necessita dele.

\section{REVISÃO BIBLIOGRÁFICA}

\subsection{O INICIO DAS PRÁTICAS DO PARTO E SUA CONTEUTUALIZAÇÃO}

No Brasil, o parto é considerado um evento histórico, que tem apresentado grandes mudanças culturais ao longo dos anos. Uma das principais mudanças envolve o trabalho das parteiras, fruto de uma prática de solidariedade feminina, desenvolvido durante um longo período, cujo era conduzido o parto como um evento natural e fisiológico dentro das comunidades, uma experiência corporal e emocional que levava as mulheres a se sentirem valorizadas e significava poder, prestígio e competência para as parteiras (WOLF; WALDOW, 2008).

Segundo Wolf e Waldow (2008), a prática da assistência ao parto, mesmo ainda contando com a participação das parteiras, passou a ser vista como ato privativo do médico e, no século XX, predominou o parto hospitalar. Essa prática foi ampliada logo após a Segunda Guerra Mundial, visto que houve a intensificação do desenvolvimento industrial. Com a institucionalização do parto, a mulher passou a 
ser medicada e a sofrer intervenções cirúrgicas que muitas vezes poderiam ser evitadas.

Assim, a assistência à saúde da mulher parturiente foi se masculinizando nos últimos dois séculos, sendo realizada cada vez mais dentro do hospital, que desde sua criação no século XVIII, vem se constituindo num espaço onde predomina o controle médico e, consequentemente, no controle de corpos. O que se pode observar é que, de acordo com o desenvolvimento de novas práticas na área da medicina, o tradicionalismo feminista nas práticas do parto foi sendo substituído por novas tecnologias, dando aos homens um poder maior de decisão sobre onde e como seria realizado o parto das mulheres (BARBOZA; MOTA, 2016).

Em contrapartida, as políticas públicas na área da saúde da mulher modificaram-se ao longo dos tempos, impulsionadas pelas transformações históricas, políticas, econômicas e sociais. A partir da década de 80, no campo obstétrico brasileiro, os reflexos desta luta foram percebidos quando o modelo medicalizado, que considera a gravidez um risco e o parto um ato médico, começou a ser questionado, devido ao fato de ser defendida a ideia de que a autonomia da mulher, tanto no processo de gestar quanto no de parir são fenômenos prazerosos e únicos. Nasceu assim, o parto com um modelo humanizado (BARBOZA; MOTA, 2016).

\subsection{A VIOLÊNCIA OBSTÉTRICA NO PRÉ-PARTO}

Os principais tipos de violência no pré-parto identificam-se como uma informação e comunicação ineficiente, a mistificação, objetificação e a desqualificação, presentes na relação dos médicos e sua equipe e as usuárias. Por ser uma violência silenciosa e institucionalizada, os maus tratos às mulheres antes do parto, expressos através da violência psicológica, provocam grande sofrimento para elas. No momento em que o que se espera é acolhimento e cuidado à mãe, o que se observa é o exercício do poder e uma assistência violenta, com uma prática discriminatória quanto ao gênero, classe e etnia (BARBOZA; MOTA, 2016).

Este tipo de violência engloba desde a negligência na assistência, discriminação social, violência verbal, como tratamento grosseiro, ameaças, gritos, humilhação intencional, violência física, que inclui a não utilização de medicação analgésica quando indicada, e até mesmo o abuso sexual. No ambiente hospitalar, as mulheres são frequentemente destratadas e desrespeitadas. A dor e o sofrimento 
transformam-se, quase, em algo que todas as mulheres precisarão passar e suportar como preço pelo prazer sentido no ato sexual que deu origem àquela gestação (BARBOZA; MOTA, 2016).

\subsection{A VIOLÊNCIA OBSTÉTRICA DURANTE O PARTO}

Para Andrade e Aggio (2014), a mulher e seu corpo são vistos como uma máquina, onde o profissional que a coordena é o médico que negligencia informações, emoções, sentimentos, percepções e direitos da mulher, tanto na gestação quanto no parto, impedindo-a de ter a presença de acompanhante, de decidir a posição que prefere para ter o seu bebê e de expressar aquilo que está sentindo. Isso contraria a Política Nacional de Humanização e muda o foco que antes era a mulher e passa a ser o procedimento, deixando-a mais vulnerável a esse tipo de violência, qual, na maioria das vezes, é silenciado pelos profissionais e pela própria mulher em trabalho de parto. Porém, a amarga vivência e o trauma acompanham durante muito tempo após o ocorrido.

O estudo das autoras supracitadas revela, ainda, que muitas mulheres, ao serem submetidas ao trabalho de parto, relatam críticas sobre xingamentos, gritos, brutalidade, pouca tolerância e incompreensão por parte do obstetra, negligenciando lhes informações sobre seu estado geral e dos bebês prematuros que são levados para a UTI neonatal, além do desrespeito ao seu limiar à dor da contração, fazendo com que as mulheres se sintam ofendidas, desvalorizadas, desrespeitadas, descontentes e traumatizadas com o parto normal.

Além da negligência a informações, outra característica da violência obstétrica durante o parto é a prática de ações intervencionistas sem o consentimento das mulheres, como o uso de ocitocina (hormônio utilizado para acelerar as contrações), amniotomia (rompimento da bolsa amniótica), episiotomia, manobras de Kristeller (manobras sobre o abdômen das mulheres com o objetivo de expulsar o feto o mais rápido possível). Muitas vezes, isso acontece pelo fato do médico ter pouco tempo, ou mesmo pouca paciência para dar atenção às mulheres em trabalho de parto, tirando a autonomia destas no momento em que deveriam ser as protagonistas (BRASIL, 2001). 


\subsection{A VIOLÊMCIA OBSTÉTRICA NO PÓS-PARTO}

Relatos de mulheres que sofreram algum tipo de violência obstétrica, antes ou durante o trabalho de parto, revelam que essas mulheres também sofreram violência após o trabalho de parto. Esses tipos de violência se exemplam em deixar a paciente sozinha na sala de parto, evitar o contato da mãe e do bebê, além da falta de amamentação na primeira hora de vida, usar a mãe como um "objeto" e fazer xingamentos ao bebê, julgando-o ser feio ou com cara de uma coisa ou outra (PÉREZ; OLIVEIRA; LAGO, 2015).

Toda violência que a mulher sofre antes e durante o parto, como as frustações, dores, desejos não concedidos e estresse, podem acarretar ainda mais problemas no pós-parto, tanto para parturiente quanto para o recém-nascido. Devido ao fato de a mulher sofrer todas essas manifestações, isso pode causar alterações de humor, levando a uma depressão pós-parto, tornando aquele momento que deveria ser prazeroso num momento difícil por conta dos traumas que acometem a mulher (SOUZA et al., 2013).

Isso evidencia que, embora haja leis e políticas que assegurem os direitos da mulher em relação ao parto e puerpério, ainda existem muitas transgressões que reprimem essas leis e que levam as mulheres a passar por constrangimentos na hora de terem seus bebês, quando precisaria haver apenas momentos bons e prazerosos.

\section{METODOLOGIA}

Trata-se de uma pesquisa descritiva, exploratória, com abordagem qualitativa. Na pesquisa descritiva, os fatos são analisados, observados, registrados, classificados e interpretados sem que o pesquisador interfira sobre eles, ou seja, os resultados não são manipulados pelo pesquisador (PRODANOV; FREITAS, 2013). 0 método exploratório visa à descoberta, o achado, à elucidação de fenômenos ou à explicação daqueles que não eram aceitos apesar de evidentes (GONÇALVES, 2014).

A pesquisa foi desenvolvida numa Instituição de Ensino Superior (IES), localizada no bairro São Pedro, zona sul na cidade de Teresina - PI, e os participantes do estudo foram os acadêmicos de enfermagem que estudam nos períodos da man hã e da tarde na IES escolhida como local da pesquisa, que já estagiaram ou estagiam 
em hospitais com serviço de maternidade, sendo respeitados seus limites e ocupações.

\section{RESULTADOS E DISCUSSÃO}

\subsection{CONHECIMENTO DOS ACADÊMICOS DE ENFERMAGEM SOBRE A VIOLÊNCIA OBSTÉTRICA}

De acordo com os dados coletados, os participantes souberam como caracterizar uma violência obstétrica tanto na teoria quanto na prática, além de perceber e identificar quando algum episódio é caracterizado como violência. Para eles, o trabalho de parto é um momento exclusivo na vida da mulher e, muitas vezes, os profissionais de saúde ignoram a fisiologia dos processos reprodutivos e a autonomia da mãe, transformando o parto num momento de transtornos, devido aos procedimentos realizados desnecessariamente. Isso está relatado nos depoimentos abaixo:

"[...] Infelizmente, a violência obstétrica é muito comum ainda, mesmo com todos os tipos de estudo, com todos os tipos de análises, todos os tipos de prevenção e ensinamento que os acadêmicos têm na graduação para levarem para assistência, mesmo assim continua um índice muito alto de violência obstétrica [...]" (Depoente $\mathrm{n}^{\circ}$ 03)

"[...] Acho que a gente deveria quebrar esses paradigmas, porque é uma coisa totalmente antiética e fora do nosso século e que não deveria existir [...]" (Depoente ${ }^{\circ}$ 18)

De acordo com Soares, M. (2015), estar gestante e ter um bebê saído de seu ventre são algo ímpar na vida de uma mulher, e elas trazem consigo várias alterações sejam físicas ou emocionais, as quais manifestam seus valores e crenças a respeito do parto, além de muitas expectativas e também preocupações associadas àquele momento. As mulheres sofrem vários tipos de violência na sociedade e a violência obstétrica é mais uma pela qual elas passam, pelo fato de que apenas esse gênero é capaz de gestar e parir. Deste modo, não pode ser considerada comum. Esse termo é utilizado para referir tanto a assistência ao parto que utiliza medicações excessivas até atos de violência física contra a mulher no momento do nascimento do filho (OLIVEIRA, 2016). 
Segundo os depoentes, sofrer uma violência obstétrica causa transtornos para as mulheres, gerando sofrimento e a perda do desejo de viver uma nova gestação. Eles consideram a violência um desrespeito para com as mulheres pelo fato de elas esperarem muito tempo para viver o momento do nascimento do filho, e acabarem obtendo uma experiência desagradável e desconfortante.

"[...] Acho que a gestação em si é um momento único para uma mulher, e o parto também é aquele momento de maior alegria daquele ser que ela estava trazendo consigo durante nove meses e é para ser uma experiência boa, única, saudável de ser relembrada, então a violência obstétrica vem para acabar com isso [...]" (Depoente $\mathrm{n}^{\circ}$ 06)

"[...] É um tipo de violência que não deveria existir, pois é um momento muito especial na vida de uma mulher e dependendo da forma como ela é tratada acaba se tornando um momento constrangedor e que pode desenvolver problemas psicológicos na paciente, além de ser um desrespeito com a pessoa humana e família que tanto espera pelo momento do nascimento do bebê [...]" (Depoente $n^{\circ}$ 09)

Antigamente, parir era algo subjetivo, e apenas a mulher e sua família vivenciavam aquele momento. Devido às mudanças no contexto histórico envolvendo o parto, este passou a ser vivenciado no âmbito hospitalar, coberto de normas e procedimentos que manipulam os corpos femininos, tirando sua autonomia e fazendo daquele momento algo desgastante e traumático (FUJITA; NASCIMENTO; SHIMO, 2015). Nesse sentido, as satisfações físicas e psicológicas das mulheres no momento do parto não são levadas em conta, tornando-se de pouca relevância para a saúde delas. Além disso, não há o interesse em procurar saber se as mulheres têm satisfação em parir pois, infelizmente, vivemos num momento em que a quantidade supera a qualidade dos serviços (SILVA et al., 2016).

\subsection{AS FORMAS DE VIOLÊNCIA OBSTÉTRICA CONHECIDAS PELOS PARTICIPANTES}

Ao serem questionados sobre as formas de violência obstétrica das quais tinham conhecimento e que constavam no segundo eixo do roteiro de entrevista semiestruturado, os depoentes demonstraram que conheciam tanto as formas citadas, quanto outras formas de violência obstétrica que não foram contempladas pela entrevista, como demostra a figura 1. 


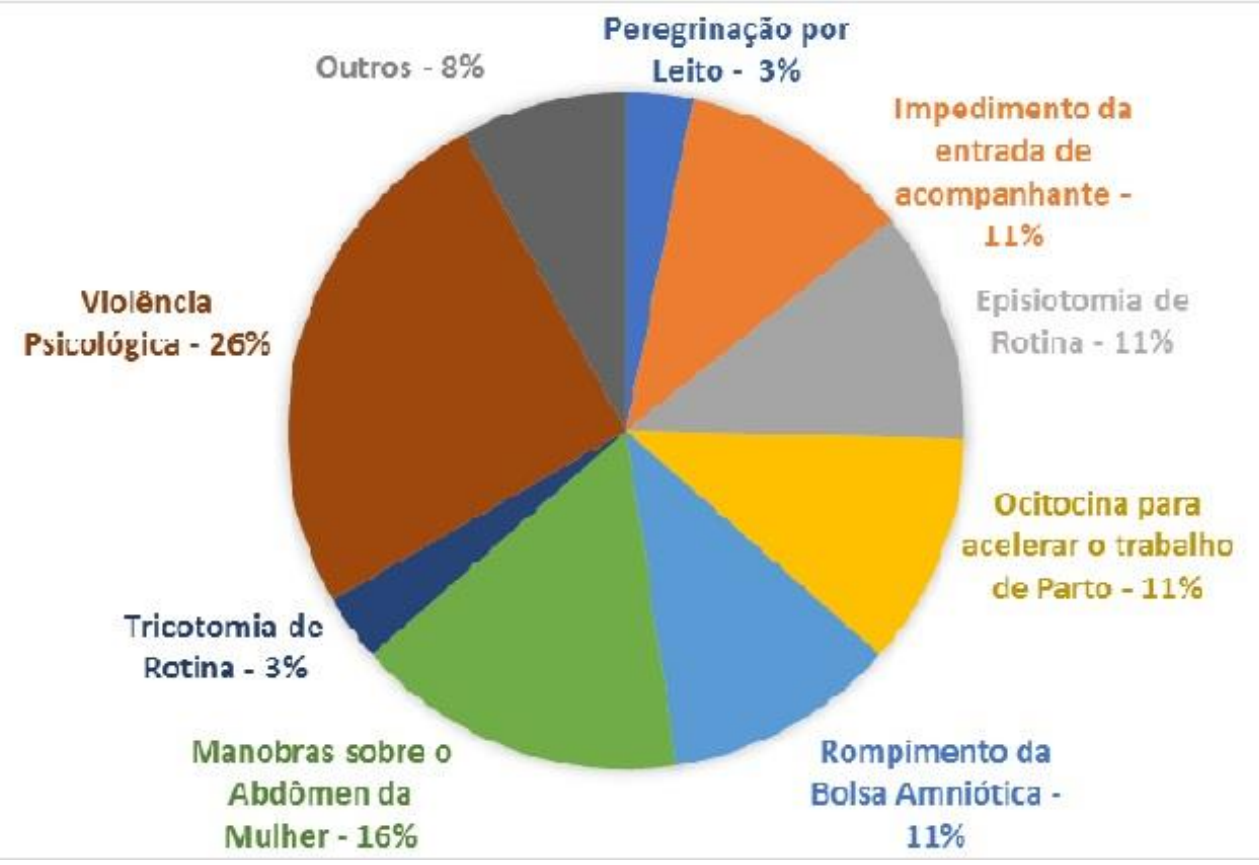

Figura 1 - Conhecimento dos acadêmicos de enfermagem sobre as formas de violência obstétrica

Fonte: Dados coletados pelas pesquisadoras, Março - 2017.

De acordo com a figura 1, a forma de violência obstétrica com maior grau de conhecimento foi a violência psicológica, seguida de manobras sobre o abdômen da mulher, impedimento da entrada de acompanhante, episiotomia de rotina, ocitocina para acelerar o trabalho de parto e rompimento da bolsa amniótica, atos que, segundo alguns depoentes, são corriqueiros nas maternidades, principalmente nas cidades pequenas.

"[...] Todas essas formas de violência obstétrica como colocar ocitocina, rompimento da bolsa amniótica, são procedimentos que não têm necessidade nenhuma de ser feitos, e hoje em dia isso acontece porque muitos profissionais fazem isso simplesmente porque eles querem que esse parto seja o mais rápido possível [...]" (Depoente $n^{\circ}$ 04)

No parto vaginal não humanizado, observa-se a realização de procedimentos que não têm sua eficácia garantida por dados científicos, mas, ainda assim, são praticados rotineiramente nas maternidades de todo o país. Esses procedimentos, em sua maioria, são realizados sem que a gestante permita, deixando a equipe com o livre controle sobre o corpo da mulher (OLIVEIRA, 2016). Encaixam-se no conceito de violência obstétrica aqueles atos que são praticados sobre o corpo da mulher sem o consentimento dela, como a episiotomia e as manobras de Kristeller, uso da 
ocitocina, do fórceps, o jejum prolongado, exames de toque frequentes, o rompimento artificial da bolsa amniótica e a posição supina da mulher (MARIANI; NASCIMENTO NETO, 2016).

Em relação às formas de violência obstétrica menos conhecidas, peregrinação por leitos e tricotomia de rotina, os depoentes não relataram nenhuma opinião, podendo interpretar que eles enxergam a tricotomia como algo que precisa fazer parte da higienização das pacientes, e a peregrinação por leitos pode ser justificada por questões de desorganização institucional.

Ao serem questionados se conheciam outras formas de violência obstétrica que não foram citadas no roteiro de entrevista, alguns depoentes exemplificaram a 1- gravação do parto sem o consentimento das mulheres, 2- toques vaginais constantes por vários profissionais diferentes e, 3- a negligência por parte dos profissionais. Isso é comprovado nos relatos a seguir:

"[...] Acho que outra forma de violência é gravar o parto das mulheres sem que elas permitam [...]" (Depoente no 01)

"[...] Eu acho que a negligência é uma forma de violência, principalmente no parto cesáreo. Eu conheço um caso em que por causa da negligência dos profissionais, eles deixaram uma compressa dentro de uma paciente [...]" (Depoente no 06)

"[...] No hospital que eu estagiei, um professor nem pediu permissão para a paciente para os alunos poderem avaliar ela. Aí ele já foi fazendo um monte de toque na paciente e depois deixou os alunos também fazerem. Isso deixou a paciente numa situação constrangedora [...]" (Depoente no 18)

Também é considerada violência obstétrica todos os tipos de intervenções, cujo objetivo principal é usar o corpo da mulher para ensinar aos estudantes e residentes a como realizar os procedimentos, e é nessa hora que muitos desrespeitam o direito de imagem e de ser humano da mulher, executando atividades sem o consentimento das mesmas e expondo, de certa forma, sua intimidade. Os exames de toque são feitos sem aviso prévio e sem o consentimento da mulher, causando dor e incômodo, no sentido de que elas terão seu órgão genital exposto a profissionais que sequer se apresentaram ou informaram o objetivo do procedimento. Em alguns casos, durante o exame de toque ocorrem comentários agressivos e desrespeitosos para com as mulheres (OLIVEIRA, 2016). 
Além das formas de violência supracitadas, alguns depoentes consideram o parto cesáreo como um exemplo de violência obstétrica, pois julgam que o parto deve seguir o seu curso normal, visto que a mulher tem condições fisiológicas para esperar o tempo do bebê e ter um parto livre de intervenções ou procedimentos invasivos.

"[...] Eu acho que o próprio parto cesáreo é uma forma de violência obstétrica [...]" (Depoente $\left.n^{\circ} 11\right)$

"[...] Sou contra a violência, porque acho que tudo tem seu tempo, né? Porque é um mecanismo e tudo vai ocorrer de forma normal, só precisa esperar e vai dar tudo certo [...]" (Depoente $\left.{ }^{\circ} 12\right)$

Vale destacar que nem sempre o parto segue o seu ritmo normal sem a necessidade de intercorrências. Segundo Costa et al. (2013), cerca de 15\% das gestantes podem apresentar alguma complicação que pode levar ao óbito do bebê, fazendo-se necessária uma assistência de qualidade e, até mesmo, uma intervenção obstétrica eficiente para que possa assegurar tanto a vida da mãe quanto do bebê, como é o caso do parto cesáreo.

\subsection{COMBATE À VIOLÊNCIA OBSTÉTRICA SOB A ÓTICA DOS ACADÊMICOS DE ENFERMAGEM}

Segundo os relatos dos depoentes, a violência obstétrica é algo que ainda ocorre nas maternidades e que não deveria acontecer por conta dos avanços tecnológicos que existem e das informações que precisam ser repassadas tanto para as mulheres, para as famílias e para os próprios profissionais. Dentre os meios para combater a violência obstétrica destacaram-se a humanizar a assistência e informar as mulheres sobre os seus direitos.

\subsubsection{HUMANIZAR A ASSISTENMCIA}

Questionados sobre a capacidade de atuar contra a violência obstétrica, os participantes relataram que atitudes como respeito à autonomia da mulher, à sua fisiologia e ao tempo de nascer do bebê são cruciais para proporcionar às parturientes um momento mágico, livre de experiências traumáticas e dar a elas o poder de escolher a quais procedimentos querem ser submetidas. Eles destacam que é importante iniciar a humanização desde o pré-natal, visto que muitas mães 
apresentam dificuldades e dúvidas a respeito da gestação, do local onde vão parir e qual a posição adequada para ganhar o bebê.

"[...] Por não gostar do que eu vi, pretendo lutar contra isso humanizando cada vez mais o parto [...]" (Depoente $\left.n^{\circ} 02\right)$

“[...] Eu me sinto capaz. Acredito que durante o pré-natal é possível passar todas essas informações, explicar para a gestante o que é a violência obstétrica e explicar todos os passos que acontecem no prénatal, porque se vim acontecer um caso de violência obstétrica, ela sabe os seus direitos e não permite que isso seja feito [...]" (Depoente $n^{\circ}$ 04)

"[...] Me sinto capaz de atuar sempre respeitando, ajudando a gestante no seu pré-natal, visto que a mesma precisa de enfermeiros capacitados e que tenham ética para recebê-la adequadamente como ela merece para que se sinta bem acolhida [...]" (Depoente $\left.n^{\circ} 07\right)$

A política de humanização existe desde o ano 2000. Instituída pelo Ministério da Saúde (MS), está inserida no Programa de Humanização do Parto e Nascimento (PHPN), que se caracteriza por uma série de normas e portarias que contam com incentivos financeiros específicos, visando oferecer um número mínimo de consultas durante o período do pré-natal bem como um atendimento qualificado no momento do parto (BRASIL, 2000).

A assistência pré-natal tem o objetivo de identificar de forma adequada, e o mais rapidamente possível aquelas gestantes com maior possibilidade de apresentar dificuldades durante a gestação e no momento do parto, além de acolher a mulher desde a primeira consulta, buscando ouvi-la, favorecendo um sentimento de confiança, para que a mulher tenha autonomia durante toda a gestação e trabalho de parto (COSTA et al., 2013).

Felizmente, segundo Fujita, Nascimento e Shimo (2015), o Brasil tem investido em políticas públicas que resgatem a autonomia da mulher durante sua gestação e parto. Isso demonstra que, aos poucos, a satisfação com tudo que permeia o nascimento do filho e que foi retirado da mulher com a evolução do parto medicado vem sendo resgatada e trazendo novamente o prazer em gestar e parir. Entretanto, na visão de Rodrigues (2013), mesmo o Ministério da Saúde desenvolvendo medidas que torne mais humanizado o atendimento nos serviços de saúde, os programas que são ofertados não garantem que os serviços sejam efetivos. 
Os participantes evidenciaram, ainda, que a humanização precisa iniciar-se na graduação, etapa em que eles estão aprendendo a desenvolver a melhor forma de dar assistência. Assim, a partir das experiências adquiridas durante o período da graduação, poderão desenvolver um senso crítico de realidade e atuar da maneira como desejam ser atendidos por outros profissionais.

"[...] A gente tem que começar a combater durante a graduação mesmo, começar a explicar como que tem que tratar. E como profissional o que eu posso fazer para combater é não praticar a violência e dizer, esclarecer, falar para aquelas mulheres os direitos que elas têm né? Como de escolher a via de parto, de se recusar a fazer o toque repetidamente, de escolher o acompanhante, essas coisas [...]" (Depoente $\left.n^{\circ} 06\right)$

\subsubsection{INFORMAR AS MULLERES SOBRE OS SEUS DIREITOS}

Os participantes da pesquisa declararam que a mulher precisa conhecer seus direitos, sendo importante que informações como essas sejam repassadas desde o pré-natal porque, a partir do momento em que ela adquire conhecimento sobre aquilo que lhe respalda, isso vai evitar certos procedimentos que poderiam ser usados sem o seu consentimento, garantindo-lhe a prevalência da sua autonomia na decisão sobre o parto.

"[...] Eu acredito que durante o pré-natal é possível repassar todas essas informações, através de folhetins que explicam os direitos que ela tem, e outra forma também são as formas de conversa com pessoas que já passaram por uma violência obstétrica e podem estar relatando [...]” (Depoente nº 04)

"[...] Acho que a primeira coisa que deve ser repassada é a informação para gestantes e famílias. Antigamente eu não tinha conhecimento sobre o que era a violência obstétrica, assim como a maioria das pessoas pensam que esses procedimentos que os médicos fazem são normais. Então eu acho que a primeira coisa que deve ser trabalhada deve ser com as gestantes, com os familiares e com os profissionais de saúde, ressaltando sobre a violência que não deve ser feita [...]" (Depoente $\left.n^{\circ} 10\right)$

Segundo Soares (2015), é importante que sejam esclarecidas dúvidas sobre os direitos sexuais e reprodutivos durante a assistência pré-natal, como forma de educar com qualidade sobre as vantagens e desvantagens que envolvem as práticas assistenciais relacionadas ao parto e nascimento. A maioria das mulheres 
desconhece seus direitos em relação ao trabalho de parto, e acabam julgando normais algumas atitudes dos profissionais em relação a elas neste momento, fazendo-se, portanto, necessária uma série de explicações a respeito do que é considerado ou não uma violência obstétrica.

Tão importante quanto informar é fazer com que a violência contra a mulher seja cada vez mais debatida e tornada públicas para que haja um esforço conjunto em detê-la, bem como denunciar os atos de violência obstétrica aos órgãos competentes para que haja a criação de políticas públicas que respaldem a saúde das mulheres. Neste sentido, alguns estados brasileiros, como Santa Catarina e Distrito Federal, estão adotando medidas para combater a violência obstétrica em seus territórios, devido a muitas denúncias de abusos cometidos pela equipe de saúde (ARSIE, 2015).

Portanto, fornecer informações pertinentes aos direitos da mulher garante que ela tenha autonomia para decidir o que quer ter no momento do parto, tendo a ciência de que seus valores, sua cultura e, principalmente, o seu querer estarão em primeiro lugar no momento em que tudo é muito complexo e novo, pois ela tem que decidir por si e pelo filho que está a caminho (RODRIGUES, 2013).

\subsection{O USO DAS MIDIAS SOCIAIS NO ENFRENTAMENTO DA VIOLÊNCIA OBSTÉTRICA}

Historicamente, alguns movimentos feministas que defendem os direitos humanos e reprodutivos das mulheres incluíram em suas atividades, entre as décadas de 1980 e 1990, começaram a promover discussões a respeito de violência obstétrica, bem como enfatizaram as formas para combater este mal que assola as mulheres. Estes movimentos passaram a ganhar forças na década de 1990 e anos 2000, chegando a construir mais campos de investigação sobre o tema no país (DINIZ et al, 2015).

Esses movimentos sociais enfatizam a humanização do parto e o protagonismo da mulher durante o processo do trabalho de parto, respeitando seus direitos e emoções. Vale ressaltar que mesmo sendo considerado um tema novo, a violência obstétrica é registrada em diferentes épocas e em muitos países, como Estados Unidos e Reino Unido. Alguns exemplos desses maus tratos eram o uso de algemas para conter a parturiente no leito, sedações profundas e o uso de fórceps 
como rotina em mulheres desacordadas. Além disso, muitos profissionais atuavam com agressividade e intimidação para com as usuárias (SENA; TESSER, 2017).

Diante disso, os movimentos sociais foram ganhando forças e destaque em jornais e revistas de grande circulação, fazendo com que as autoridades adquirissem o conhecimento a respeito dos casos e iniciasse o processo de julgamento dessas ações. No Brasil, foi criado o Programa de Atenção Integral à Saúde da Mulher (PAISM), em 1980. Também foram promovidos cursos de atualização sobre o tema por entidades específicas aos direitos das mulheres (SOUZA; MICHALISZYN; CUNHA, 1992).

Apesar de muitos serem os trabalhos envolvidos no que diz respeito a conceitos, ideias, relatos de experiência e denúncias, ainda existem muitos casos isolados, em que as vítimas ficam caladas por medo da opressão, preconceito ou trauma em ter que relatar o que as acometeu. A violência obstétrica ainda se faz muito presente em nossa sociedade, principalmente em locais onde a assistência não é de qualidade e possui profissionais mal remunerados, exaustos e desacreditados na profissão.

Muitas já foram as estratégias adotadas pelos grandes centros especializados em saúde da mulher, bem como de universidades em relação à formação de profissionais que sejam capazes de atuar contra a violência obstétrica e proporcionem à mulher e ao seu filho um momento único e prazeroso. Porém, fica o seguinte questionamento: apesar de tantas estratégias, por que ainda vemos tantos relatos de violência, e por que muitos crimes ainda ficam impunes? 0 que ainda falta para tornar a mulher a protagonista do momento de trabalho de parto?

Diante disso, falaremos sobre algo que revolucionou a forma de comunicação da população nos últimos tempos. Na contemporaneidade são notórios a presença e o crescimento acentuado das mídias sociais como forma de divulgar trabalhos, operações, casos clínicos e outras demandas que permitem a conexão e o envolvimento de muitas pessoas e sociedades. Muitas vezes, o fato de ser muito divulgado algum produto faz com que seja efetuado o consumo do mesmo, apesar de nem sempre este ser de interesse em primeiro momento.

De acordo com Sena e Tesser (2017), dois fatores fazem da internet um meio estratégico para as mais diversas ações: a facilidade de acesso à conexão e, ao mesmo tempo, uma forma violenta de repassar informações. Essas características 
têm feito governos, empresas e a sociedade em geral, desenvolverem formas inovadoras de abordar os vários tipos de violência presentes na sociedade, principalmente no que diz respeito à violência contra a mulher. Isso acontece porque o ciberativismo está dando vez e voz aos cidadãos, que possuem a liberdade de expor suas opiniões em suas contas pessoais e as empresas em contas comerciais, fortalecendo sua autonomia e liberdade de expressão.

Ainda de acordo com os autores, essa liberdade de expressão ganha ainda mais relevância quando essas pessoas fazem parte de grupos tradicionalmente reprimidos, como mulheres e homossexuais, e através dessas plataformas digitais estão tendo a oportunidade de ver seus direitos sendo, de fato, concretizados, devido à grande visibilidade que se tem quando se está inserido no meio de mídias sociais.

Um exemplo desse ciberativismo é o aplicativo "Salve Maria", criado como estratégia de enfrentamento da violência contra a mulher, divulgada pelas mídias digitais. Desenvolvido pelo Portal da Prefeitura de Uberlândia - PRODAUB, tem como objetivo facilitar a denúncia de violência contra a mulher. A ferramenta "Salve Maria" permite que qualquer pessoa denuncie abusos de forma rápida e precisa, por meio de um canal direto com a Polícia Militar (PM) (MENEGON; SILVA, 2020).

\section{REFERÊNCIAS}

ANDRADE, B. P.; AGGIO, C. M. Violência obstétrica: a dor que cala. Anais do III Simpósio Gênero e Políticas Públicas. Universidade Estadual de Londrina, p.1-7, Maio, 2014. Disponível em: <http://www.uel.br/eventos/gpp/pages/arquivos/GT3_Briena\%20Padilha \%20Andrade.pdf>. Acesso em: 16 de agosto de 2016.

ARSIE, J. G. Violência Obstétrica: Uma Violação Aos Direitos Fundamentais Da Mulher. 2015. 96p. Monografia (Graduação em Direito). Centro de Ciências Jurídicas da Universidade Federal de Santa Catarina. Florianópolis, 2015. Disponível em: <https://repositorio.ufsc.br/xmlui/bitstream/handle/123456789/166562 /Monografia\%20Jaqueline\%20Gon\%C3\%A7alves\%20Arsie.pdf?sequence= 1\&amp;isAllowed=y>. Acesso em: 28 de Março de 2017.

ASSUMPÇÃO, T. A. et al. A Produção Científica Brasileira Sobre A Violência Obstétrica: Uma Revisão Integrativa. Vi Conclave Dos Depoentes De Enfermagem Da Universidade Positivo (CONAENF). Universidade Positivo, p.48-55, out, 2014. Disponível em: 
<http://www.up.edu.br/CmsPositivo/uploads/imagens/galeria2753/VI_C ONAENFanais_finalizados.pdf\#page=48>. Acesso em: 16 de agosto de 2016 .

BARBOZA, L. P.; MOTA, A. Violência Obstétrica: vivências de sofrimento entre gestantes do Brasil. Revista Psicologia, Diversidade e Saúde. Salvador, v.5, n.1, p.119-129, 2016. Disponível em: <https://www5.bahiana.edu.br/index.php/psicologia/article/view/847>. Acesso em: 16 de agosto de 2016.

BISCEGLI, T.S. et al. Violência Obstétrica: Perfil Assistencial De Uma Maternidade Escola Do Interior Do Estado De São Paulo. Revista Cuidar Enfermagem. Catanduva, v.9, n.1. p.18-25, jan/jun, 2015. Disponível em: <http://bases.bireme.br/cgibin/wxislind.exe/iah/online/?IsisScript=iah/ia h.xis\&src=google\&base=BDENF\&lang=p\&nextAction=lnk\&exprSearch=269 51\&indexSearch=ID>. Acesso em: 16 de agosto de 2016.

BRASIL. Ministério da Saúde. Portaria n.ำ 569/GM, de 01 de junho de 2000: institui o Programa de Humanização no Pré-Natal e Nascimento, no âmbito do Sistema Único de Saúde. Diário Oficial da União, seção 1, p. 4. Brasília, Ministério da Saúde, 2000.

Ministério da Saúde. Secretaria de Políticas de Saúde. Área Técnica de Saúde da Mulher. Parto, aborto e puerpério: assistência humanizada à mulher/Ministério da Saúde, Secretaria de Políticas de Saúde, Área Técnica da Mulher. Brasília, Ministério da Saúde, 2001.

COSTA, K. F. et al. Percepção das gestantes sobre a assistência prestada pelo enfermeiro durante o pré-natal. R. Interd. v.6, n.4, p.86-94, out-dez. 2013. Disponível em: Disponível em: <http://revistainterdisciplinar.uninovafapi.edu.br/index.php/revinter/arti cle/view/118/pdf_70>. Acesso em: 28 de março de 2017.

FUJITA, J. A. L. M.; NASCIMENTO, P. L.; SHIMO, A. K. K. O Enfrentamento Da Violência Obstétrica E Suas Repercussões Na Prática De Enfermeiras Obstetras. Rev enferm UFPE. Recife, v.9, n.12, p.1360-1369. Dez, 2015. Disponível em: $<$ https://periodicos.ufpe.br/revistas/revistaenfermagem/article/view/108 45/12056>. Acesso em: 28 de março de 2017.

GONÇALVES, H. A. Manual de Metodologia da Pesquisa Científica. 2ed, Sergipe: Avercamp, $2014 . \quad$ Disponível em: <https://pt.scribt.com/doc/144229707/Manual-demetodologia-dapesquisa-cientifica>. Acesso em: 01 de setembro de 2016.

MARIANI, A. C.; NASCIMENTO NETO, J. O. Violência Obstétrica Como Violência De Gênero E Violência Institucionalizada: Breves Considerações A Partir Dos Direitos Humanos E Do Respeito Às Mulheres. Cad. Esc. Dir. Rel. Int. (UNIBRASIL), Curitiba, v.2, n.25, p.48-60, Jul/Dez, 2016. Disponível em: <http://revistas.unibrasil.com.br/cadernosdireito/index.php/direito/articl e/view/865/822>. Acesso em: 28 de março de 2017. 
MENEGON, V.G.S; SILVA, T.H.J. Feminicídio no Maranhão e Covid-19: o que diz a imprensa. Revista Espaço Acadêmico. v.20, n.224. 2020. Disponível em: $<$ https://periodicos.uem.br/ojs/index.php/EspacoAcademico/article/view /55021>. Acesso em: 21 de Julho de 2021.

OLIVEIRA, A. L. Violência Obstétrica: Uma Análise De Suas Dimensões Nas Normativas Brasileiras. 2016. 69p. Monografia (Graduação em Direito). Universidade de Brasília. Brasília, 2016. Disponível em: <http://bdm.unb.br/bitstream/10483/15883/1/2016_AmandaLimadeOliv eira_tcc.pdf>. Acesso em: 28 de março de 2017.

PEREZ, B. A. G.; OLIVEIRA, E. V.; LAGO, M. S. Percepções De Puérperas Vítimas De Violência Institucional Durante O Trabalho De Parto E Parto: Revisão Integrativa. Revista Enfermagem Contemporânea. v.4, n.1, p.66-77, jan./Jun., $2015 . \quad$ Disponível em: <https://www5.bahiana.edu.br/index.php/enfermagem/article/view/472 >. Acesso em: 16 de agosto de 2016.

PRODANOV, C. C.; FREITAS, E. C. Metodologia do trabalho científico: métodos e técnicas de pesquisa e do trabalho acadêmico. 2ed. Novo Hamburgo, Freevale, $2013 . \quad$ Disponível em: <http://www.feevale.br/Comum/midias/8807f05a-14d0-4d5b-b1ad1538f3aef538/Ebook\%20Metodologia\%20do\%20Trabalho\%20Cientifico.pdf>. Acesso em: 01 de setembro de 2016.

RODRIGUES, R. R. N. O parto é nosso: Autonomia, poder simbólico e violência no parto humanizado sob a perspectiva de médicos humanistas em Florianópolis, SC. 2013. 143p. Monografia (Graduação em Ciências Sociais). Universidade Federal De Santa Catarina. Florianópolis, 2013. Disponível em: <https://repositorio.ufsc.br/bitstream/handle/123456789/105117/TCC\% 20Raphaela\%20R\%20_a5_pdf?sequence=1\&amp;isAllowed=y>. Acesso em: 29 de março de 2017.

SENA, L.G; TESSER, C.D. Violência obstétrica no Brasil e o ciberativismo de mulheres mães: relato de duas experiências. REVISTA INTERFACE. v. 21, n. 60, p. 209$220.2017 . \quad$ Disponível em: <https://www.scielo.br/j/icse/a/5yYdGTkjmkRqRXnFJX6xfpk/>. Acesso em: 21 de Julho de 2021.

SILVA, A. A. et al. Violência Obstétrica: Perspectiva Da Enfermagem. Revista Rede de Cuidados em Saúde.v.9, n.2, p.1-4, 2015. Disponível em: $<$ http://publicacoes.unigranrio.br/index.php/rcs/article/view/2686/1318 >. Acesso em: 16 de agosto de 2016.

SILVA, R. L. et al. Violência Obstétrica Sob O Olhar Das Usuárias. Rev enferm UFPE. Recife, Dez, v.10, n.12. p.4474-4480, 2016. Disponível em: 
<https://periodicos.ufpe.br/revistas/revistaenfermagem/article/view/115 12/13392>. Acesso em: 30 de novembro de 2016.

SOARES, B. P. et al. Violência obstétrica e suas implicações. Revista Norte Mineira de Enfermagem. v. 4, p.93-94, 2015. Disponível em: <http://www.renome.unimontes.br/index.php/renome/article/view/47>. Acesso em: 16 de agosto de 2016.

SOARES, M. L. A Participação Da Mulher No Processo Decisório De Seu Parto. 2015. 30p. Monografia (Graduação em Enfermagem). Faculdade de Ciências da Saúde da Universidade de Brasília. Brasília, 2015. Disponível em: <http://bdm.unb.br/bitstream/10483/10701/1/2015_MarianneLourencoS oares.pdf>. Acesso em: 28 de março de 2017.

SOUZA, E.M; MICHALISZYN, P.R; CUNHA, M.F.O. Por detrás da violência: um olhar sobre a cidade, violência nas açöes de saúde. Cadernos Cefor. 1992;209. DINIZ, S.G; et al. Violência Obstétrica Como Questão Para A Saúde Pública No Brasil: Origens, Definições, Tipologia, Impactos Sobre A Saúde Materna, E Propostas Para Sua Prevenção. Journal of Human Growth and Development. v.25, n. 3, p. 377-376. 2015. Disponível em: <http://pepsic.bvsalud.org/pdf/rbcdh/v25n3/pt_19.pdf>. Acesso em: $21 \mathrm{de}$ Julho de 2021.

SOUZA, G. N. et al. Métodos de indução do trabalho de parto. FEMINA, São Paulo, v.41, n.1, p.47-54, Jan/Fev, 2013. Disponível em: <https://files..bvs.br/upload/S/0100-7254/2013/v41n1/a3781.pdf>. Acesso em: 03 de setembro de 2016.

WOLFF, L. R.; WALDOW, V. R. Violência Consentida: mulheres em trabalho de parto e parto. Saúde Soc. São Paulo, v.17, n.3, p.138-151, 2008. Disponível em: <http://www.scielo.br/pdf/sausoc/v17n3/14>. Acesso em: 16 de agosto de 2016. 


\title{
IMPLEMENTAÇÃO DO PROTOCOLO DE INUESTIGAÇÃO DETRANSMISSÃO VERTICAL DA SIFILIS EM UMA MATERNIDADEMUNICIPALDO PIAUI
}

\author{
DDI: 10.51859/amplla.esp917.1121-6
}

Mônica da Silva Pinto Cronemberger ${ }^{1}$

Márcia Teles de Oliveira Gouveia ${ }^{2}$ Ivanilda Sepúlveda Gomes ${ }^{3}$

Priscilla Cavalcante Lima ${ }^{4}$

\footnotetext{
${ }^{1}$ Especialista em Obstetrícia e Epidemiologia. Maternidade Olavo Mendes Carvalho - MOMC PIAUI

${ }^{2}$ Doutora em Ciências. Docente da Universidade Federal do Piauí - UFPI

${ }^{3}$ Mestre em Enfermagem. Eii2 Universidade Federal do Piauí - UFPI

${ }^{4}$ Doutoranda em Enfermagem. Universidade Federal do Piauí - UFPI
}

\section{RESUMO}

Introdução: Estados e municípios devem acompanhar os dados epidemiológicos de casos de transmissão vertical da Sífilis e proceder com a investigação. Objetivo: Implementar o Protocolo de Investigação de Transmissão Vertical da Sífilis em Neonatos. Métodos: Estudo de vigilância descritivo, realizado em uma maternidade municipal de Teresina-PI com casos de Sífilis Congênita em Neonatos. Foram analisadas as fichas de investigação/notificação e aplicado um questionário às mães dos neonatos. Resultados: Implementação do Protocolo de Investigação de Transmissão Vertical em Neonatos nascidos na Maternidade. Conclusão: O projeto de intervenção proposto é de significante importância pois a Implantação do Protocolo e do Comitê de Vigilância permitirá o mapeamento dos problemas focais.

Palavras-chave: Sífilis Congênita. Transmissão Vertical de doença infecciosa. Epidemiologia. Protocolos. Enfermagem.

\section{INTRODUÇÃO}

Dentre as várias doenças que podem ser adquiridas durante o período gravídico-puerperal, a sífilis é a que possui as maiores taxas de transmissão (LIMA,2013 p 499). A transmissão vertical da sífilis pode alcançar taxas entre $70 \%$ e 100\% em gestantes não tratadas, através das espiroquetas que atingem a placenta 
e causam endarterite (aumento da resistência das artérias uterinas e umbilicais) e, consequentemente abortos tardios, prematuridade, óbito fetal e sífilis neonatal congênita (PAZ,2005 p 12). A sífilis congênita apresenta elevada mortalidade, podendo chegar a 40\% das crianças infectadas (SAUDE,2014). Mesmo com instrumentos diagnósticos (teste VDRL) e terapêuticos (penicilina benzatina) eficazes, baratos e de execução simples, a doença continua sendo um problema de saúde pública mundial, inclusive no Brasil (RAMOS,2001 P 3). Devido à elevada frequência de desfechos graves, tanto para a gestação quanto para a criança, a via congênita é o meio de transmissão de maior impacto para a saúde pública (SOUZA,2013 p 59). A maioria dos casos acontece porque a mãe não foi testada para sífilis durante o pre-natal ou porque recebeu tratamento não adequado para sífilis antes ou durante a gestação (BRASIL,2019).

Em 2018 foram notificados no SINAN 26.219 casos de sífilis congênita (taxa de incidência de 9,0/1.000 nascidos vivos); e 241 óbitos por sífilis congênita (taxa de mortalidade de 8,2/100.000 nascidos vivos)(SAÚDE,2019). O Piauí teve em 2014, 175 casos confirmados de Sífilis Congênita enquanto que em 2018, teve 696 casos (PIAUÍ,2019).

Em Teresina observou-se uma situação ainda mais alarmante, o elevadíssimo crescimento de casos de Sífilis Congênita em Residentes em Teresina, onde a Fundação Municipal de Saúde registrou em 2012 um total de 45 casos, 2013= 79 casos, $2014=98$ casos, $2015=242$ casos, $2016=240$ casos, $2017=236$ casos e 2018= 285 casos de sífilis congênita residentes em Teresina (TERESINA,2015).

Com tudo isso, a transmissão vertical, passou a ser um problema cada vez mais importante na saúde pública.

\section{REVISÃO BIBLIOGRÁFICA}

O Pacto pela Saúde, aprovado pelo Conselho Nacional de Saúde (CNS) em fevereiro de 2006 fortalece a gestão compartilhada entre os diversos níveis de governo e, segundo o pacto, cabe aos estados e municípios o desenvolvimento de ações necessárias para o cumprimento das metas de acordo com a realidade local, de maneira que as prioridades estaduais e municipais também possam ser agregadas à agenda nacional (BRASIL,2006). 
Um dos três eixos do Pacto pela Saúde é o Pacto pela Vida, em que a redução da mortalidade materna e infantil é uma das prioridades básicas (BRASIL,2006). Um dos componentes para a execução desta prioridade é a redução das taxas de transmissão vertical (TV) do HIV e da sífilis estabelecido pela Organização Mundial de Saúde - OMS (PAZ,2005 p 12).

Em 2011, foi instituída a Rede Cegonha, que visa assegurar à mulher uma rede de cuidados (planejamento reprodutivo e atenção humanizada à gravidez, ao parto e ao puerpério) e à criança o direito ao nascimento seguro e ao crescimento e desenvolvimento saudável (PORTARIA,2011). Entre as ações do componente prénatal da Rede Cegonha se encontram a prevenção e tratamento das IST's, HIV/Aids e hepatites virais, com disponibilização de testes rápidos de sífilis e HIV(PORTARIA,2011).

O Departamento de IST- Aids e Hepatites Virais do Ministério da Saúde, vem adotando estratégias para a redução da transmissão vertical do HIV e da sífilis desde 2000, como a notificação da gestante com HIV e da gestante com sífilis (SAÚDE,2014). Essas ações possibilitam a captação e notificação das gestantes com sorologias reagentes para a sífilis e/ou HIV. Diante desse contexto, estados e municípios devem observar dados epidemiológicos de casos de transmissão vertical da Sífilis e verificar a necessidade de sua investigação, para identificar as causas e possibilidades de atuação em todos os níveis do Sistema (SAÚDE,2014).

Com intuito de viabilizar a coleta das informações, um instrumento de investigação será utilizado, o Protocolo de investigação de Transmissão Vertical de Sífilis Congênita Precoce que permitirá identificar as possíveis falhas que ocasionaram a transmissão vertical e poderá contribuir no aprimoramento das ações assistenciais e de vigilância epidemiológica e permitir a qualificação de políticas públicas voltadas para a redução da Transmissão Vertical, visando sua eliminação (SAÚDE,2014).

O comitê de investigação de Transmissão Vertical da Sífilis, por sua vez deverá propor medidas para redução dos casos de Transmissão Vertical da Sífilis, visando a melhoria da qualidade da vigilância, assistência e da gestão (BRASIL,2009). A criação de comitês permite mapear os problemas e propor soluções a partir de um Protocolo de Investigação pré-estabelecido(BRASIL,2009). Os comitês são organismos de natureza intrainstitucional, interinstitucional, 
multiprofissional, que visam analisar eventos relacionados a agravos evitáveis, e apontar medidas de intervenção para a sua redução no local de abrangência (BRASIL,2009), por isso a necessidade de instituir o protocolo juntamente com o comitê visando a avaliação dos casos. 0 comitê contribuirá ainda para a melhoria da informação, permitindo avaliar os resultados da assistência prestada à gestante durante o parto e identificar possíveis falhas considerando-se ainda a necessidade de diminuir a incidência da transmissão vertical da Sífilis Congênita, é importante que os profissionais de saúde e gestores tenham acesso às informações demonstrativas da magnitude do problema em cada nível local, com base na situação epidemiológica, e assim disponham de subsídios para o planejamento e monitoramento das intervenções a serem empreendidas. Enquanto Enfermeira Obstetra tenho o dever de resguardar a saúde da mãe e de seu filho ou filha, bem como proteger dando condições para que essa mãe e essa criança estejam num ambiente seguro, independente das condições financeiras e sociais dessa mãe. A proteção à maternidade contribui para a consecução de três Objetivos de Desenvolvimento do Milênio (ODM), adotados pelos países-membros das Nações Unidas: ODM 3, sobre a promoção da igualdade de gênero e a autonomia das mulheres; ODM 4, relativo à redução da mortalidade infantil; e ODM 5, relativo a melhorias na saúde materna(OIT,2015).

\subsection{OBJETIVO GERAL}

O objetivo geral do estudo foi Implementar o Protocolo de Investigação da Transmissão Vertical da Sífilis, visando a melhoria da qualidade da assistência e gestão e o aprimoramento da vigilância da sífilis e consequentemente a redução deste agravo, juntamente com o Comitê de Vigilância do Óbito Infantil e Fetal e Agravos para analisar os dados e propor medidas que possam corrigir falhas na prevenção, assistência e vigilância da transmissão vertical da sífilis no parto. Para implementar o Protocolo de Investigação de Transmissão Vertical da Sífilis foi necessário adequar e otimizar os protocolos já existentes, já que na realidade atual as informações são dispersas e não surtem efeito na prática. Para isso houve a implantação do Comitê de Vigilância do Óbito Infantil e Fetal e Agravos, de forma gradativa, através de oficinas com os profissionais para socialização do instrumento de trabalho a ser seguido, obedecendo um cronograma previsto, contando com a participação ativa dos gestores locais. 0 monitoramento da implantação do Comitê 
de Vigilância e implementação do Protocolo, aconteceu de forma sistemática e teve como ponto de partida a análise de alguns dos indicadores de Saúde na base local. São eles: número de casos de sífilis congênita em menores de 1 ano e número de gestantes testadas para sífilis, o que fortalece a idéia de que centralizando essas informações elas serão melhor aproveitadas para a tomada de decisão. Nossa intenção foi proporcionar melhorias na qualidade da assistência como um todo, estabelecendo pontos de atenção que precisam ser melhorados, como o encaminhamento correto dessas pacientes com posterior tratamento, ou seja, a conduta correta avaliando se há alguma barreira impeditiva ocasionando a não adesão ao tratamento e permitir uma análise específica de cada caso para obtenção de um melhor resultado, visando o favorecimento adequado das necessidades de cada um para uma maior adesão ao tratamento adequado e controle do agravo.

\subsection{METODOLOGIA}

Foi realizado estudo de vigilância, do tipo descritivo, com abordagem qualitativa em uma maternidade publica localizada em Teresina, Piauí. Trata-se de uma maternidade municipal, possui um total de 20 leitos obstétricos para alojamento conjunto, 04 leitos em sala de parto, 07 leitos neonatais, 02 leitos UCINco, além de duas salas cirúrgicas. A população do estudo foi constituída pelos casos de Sífilis Congênita de Neonatos, óbitos e natimortos nascidos na maternidade. Foram analisadas as informações maternas e dos recém-nascidos e as fichas de investigação/notificação registradas no SINAN, e aplicado um questionário específico estruturado com perguntas abertas e fechadas com informações relacionadas à mãe, ao parto e ao recém nascido. A coleta de dados foi realizada pelo Enfermeiro (a) do Núcleo Hospitalar de Epidemiologia - NHE. Foram abordados na entrevista dados gerais das pacientes e outros de interesse para a vigilância tais como: o entendimento das mães sobre Sífilis Congênita, o modo de transmissão e o que é a transmissão vertical, realização do teste para SífILIS, se houve no momento das consultas, esclarecimento sobre a transmissão da SÍFILIS da mãe para o bebê, e entendimento da gestante em relação à Sífilis agora. As informações foram coletadas na enfermaria de internação da paciente, o instrumento de foi preenchido manualmente através de questionário impresso e houve gravação das respostas. A pesquisa teve início em março de 2017 e finalizada em abril de 2018. Posteriormente os dados obtidos com o auxílio dos instrumentos foram discutidos 
e analisados pelo Comitê de Vigilância do Óbito Infantil e Fetal e Agravos e a pesquisadora, onde foram destacados os pontos mais relevantes e propostas medidas de intervenção para prevenção de novos casos. Como estratégia principal da Investigação de Transmissão Vertical da Sífilis, obteve-se a produção de dados que subsidiarão as ações futuras do referido comitê. O Protocolo de Investigação da Transmissão Vertical de Sífilis Congênita foi utilizado como instrumento de coleta de dados e análise diagnóstico-situacional. $O$ instrumento é composto dos seguintes itens: Registro da Notificação, Dados de Identificação da criança, Dados da mãe, Prénatal, Parto, Puerpério e conclusão da investigação. Para execução do Projeto, no primeiro momento foi realizada uma sensibilização dos gestores e profissionais apresentando dados epidemiológicos da sífilis congênita e indicadores do parto expondo a situação epidemiológica da sífilis congênita na maternidade e enfatizando a necessidade de mudanças no serviço para melhor servir a população em questão. No segundo momento foi apresentada a proposta do Protocolo de Investigação de Transmissão Vertical da Sífilis, sendo utilizado como base o Protocolo proposto pelo Ministério da Saúde, fazendo as adequações inerentes ao serviço, sensibilizando os profissionais enfermeiros da maternidade e permitindo sugestões no intuito de haver uma melhor aplicabilidade, nesse momento tivemos a participação também dos gestores. E, no terceiro e último momento a aplicação do protocolo por 3 meses como piloto com posterior avaliação para as adequações necessárias que surgiram conforme foi sendo aplicado. Durante essas reuniões também houve a implantação do Comitê de Vigilância, com o intuito de captar os profissionais da maternidade, núcleo hospitalar de epidemiologia e os gestores para compor o comitê, com sugestão de uma reunião mensal para discussão dos casos e análise dos óbitos.

\section{CONSIDERACÕES FINAIS}

As Infecções Sexualmente Transmissíveis (IST) estão entre os problemas de saúde pública mais comuns no Brasil e em todo o mundo, sendo atualmente consideradas o principal fator facilitador da transmissão sexual. Algumas IST's quando não diagnosticadas e tratadas a tempo, podem evoluir para complicações 
graves. A maioria das pessoas infectadas desconhece seu estado de portador (PORTARIA,2010).

A Sífilis é também de extrema importância, pois é mais prevalente do que o HIV nas gestantes, devido sua alta incidência. É possível controlar essa infecção por meio de ações e pelo diagnóstico precoce e terapia adequada da pessoa portadora. Por isso a necessidade de estarmos nos mobilizando para propor ações de controle. Diante da situação enquanto Enfermeira Obstetra plantonista da Maternidade e Coordenadora do Núcleo Hospitalar de Epidemiologia, senti a necessidade de implementar um instrumento que ajudasse no momento da coleta de dados com um embasamento maior e mais eficaz para produção de medidas e ações, além da necessidade da implementação do Comitê de Vigilância do Óbito Infantil e Fetal e Agravos para dar seguimento com a análise dos dados produzidos. Na referida Maternidade os profissionais enfermeiros já realizam a Notificação de Investigação de Óbito Infantil e Fetal (PORTARIA,2010), porém as informações são, na sua maioria, incompletas, como também as mesmas se perdem, pois não há um comitê para avaliação e julgamento dessas informações. Para avaliar é necessário existir informação, sendo que a qualidade da informação determina a qualidade da avaliação, pois sem sistemas de informação e de registros confiáveis a avaliação fica comprometida. A avaliação deste projeto de intervenção em saúde hospitalar, que visa o aprimoramento e a qualidade das informações prestadas acerca dos casos de transmissão vertical de sífilis, foi feita após a sua implementação, tendo por base os objetivos, os indicadores e as metas previamente estabelecidas, é sabido que em relação aos indicadores de resultado a avaliação não pode ser imediata, pois requer tempo para se medir o impacto do projeto. Monitorizações e avaliações parciais foram sistematicamente efetuadas, conforme os parâmetros foram se desenvolvendo, para o mais precocemente detectar falhas e proceder às correções. Ocorreu também a elaboração de um relatório final, com as avaliações de execução e de resultado, bem como dificuldades e limitações e aspectos facilitadores e dificultores e as potencialidades e fragilidades como subsídio para propostas futuras. 
1. LIMA, M. G. et at. Incidência e fatores de risco para sífilis congênita em Belo Horizonte, Minas Gerais, 2001-2008. Ciência \& Saúde Coletiva.V.18, n.2, p.499-506, 2013.

2. PAZ, L.C.et al. Vigilância epidemiológica da sífilis congênita no Brasil: definição de casos, 2004. Boletim Epidemiológico AIDS, v.1, n.1, p.12-17, 2005.

3. SAUDE.Ministério da Saúde. Transmissão Vertical do HIV e Sífilis: Estratégias para redução e Eliminação. Brasília, 2014.

4. RAMOS, M. C. Sífilis congênita, ainda um desafio. DST - J bras Doenças Sex Transm. v.13, n.2, p. 3-4, 2001.

5. SOUZA, B. C.; SANTANA, L. S. As consequências da sífilis congênita no binômio materno-fetal: um estudo de revisão. Interfaces científicas - saúde e ambiente.V.1, N.3, p. 59-67, 2013.

6. BRASIL. Ministério da Saúde. Secretaria de Vigilância em Saúde. Departamento de Doenças de Condições Crônicas e Infecções Sexualmente Transmissíveis. Protocolo Clínico e Diretrizes Terapêuticas para Prevenção da Transmissão Vertical do HIV, Sífilis e Hepatites Virais / Ministério da Saúde, Secretaria de Vigilância em Saúde, Departamento de Doenças de Condições Crônicas e Infecções Sexualmente Transmissíveis. - Brasília : Ministério da Saúde, 2019. 248 p. :il.ISBN 978-85-334-2630-6

7. SAÚDE.Ministério da Saúde. Boletim Epidemiológico Especial Secretaria de Vigilância em Saúde. Número Especial Departamento de Doenças de Condições Crônicas e Infecções Sexualmente Transmissíveis - DCCI | Out. 2019. ISSN 2358-9450.

8. PIAUI. Secretaria de Estado da Saúde do Piauí.Informe Epidemiológico da Sífilis no Piauí, 2019.

9. TERESINA.Prefeitura Municipal de Teresina. Fundação Municipal de Saúde. Unidade de Respostas Rápidas. Casos de Sífilis Congênita em Residentes em Teresina. Teresina, 2015.

10. BRASIL. Ministério da Saúde. Secretaria Executiva. Departamento de Apoio à Descentralização. Coordenação-Geral de Apoio à Gestão Descentralizada. Diretrizes operacionais dos Pactos pela Vida, em Defesa do SUS e de Gestão / Ministério da Saúde, Secretaria Executiva,2006.

11. PORTARIA. PORTARIA № 1.459, DE 24 DE JUNHO DE 2011. Institui, no âmbito do Sistema Único de Saúde - SUS - a Rede Cegonha. 
12. SAÚDE.Ministério da Saúde. Protocolo de Investigação de Transmissão Vertical, 2014.

13. BRASIL. Ministério da Saúde. Secretaria de Atenção à Saúde. Departamento de Ações Programáticas Estratégicas. Manual dos comitês de mortalidade materna / Ministério da Saúde, Secretaria de Atenção à Saúde, Departamento de Ações Programáticas Estratégicas. - 3. ed. - Brasília : Editora do Ministério da Saúde, 2009. 104 p. :il - (Série A. Normas e Manuais Técnicos).

14. OIT.Organização Internacional do Trabalho. Notas da OIT - Trabalho e família.Proteção da Maternidade.Nota 4, 2015.Disponível em: http://www.oit.org.br/sites/default/files/topic/gender/doc/br_nota_4_69 8.pdf . Acesso em 11/11/2015.

15. PORTARIA .PORTARIA № 72, DE 11 DE JANEIRO DE 2010. Estabelece que a vigilância do óbito infantil e fetal é obrigatória nos serviços de saúde (públicos e privados) que integram o Sistema Único de Saúde (SUS). 


\title{
CAPITULO VII
}

\section{A PERCEPÇÃO DA MULHER SOBREA VIOLÊNCIA NO CONTEXTO DO PARTO}

DDI: $10.51859 / a m p l l a . e s p 917.1121-7$

\author{
Hildelane Maria Rodrigues Pereira ${ }^{1}$ \\ Valéria Moreno Oliveira ${ }^{1}$ \\ Leidiane Pereira Rodrigues ${ }^{2}$ \\ Thamires Barbosa dos Santos ${ }^{2}$ \\ Nabilia Abreu da Silva ${ }^{3}$ \\ Dean Douglas Ferreira de Olivindo ${ }^{4}$
}

\footnotetext{
${ }^{1}$ Graduanda do curso de Enfermagem pela Faculdade Instituto de Ensino Superior Múltiplo - IESM

${ }^{1}$ Graduanda do curso de Enfermagem pela Faculdade Instituto de Ensino Superior Múltiplo - IESM

2 Enfermeira. Pós-graduanda em Urgência e Emergência e UTI pela faculdade Ademar Rosado - FAR

2 Enfermeira. Pós-graduanda em saúde da família, saúde pública e docência do ensino superior. Faculdade Adelmar Rosado- FAR

${ }^{3}$ Enfermeira. Pós-graduação em Urgência e Emergência pela Faculdade de Tecnologia e Educação Superior Profissional - FATESP

Enfermeiro, Mestre em Enfermagem pela UFPI. Especialista em Saúde da Família -UFPI, Enfermeiro da Estratégia Saúde da Família - Teresina. Docente do curso de Enfermagem do Centro Universitário Santo Agostinho - UNIFSA
}

A violência no parto é o desrespeito à mulher, invasão do seu corpo e de seus processos reprodutivos, e isso ocorre através de verbalizações inadequadas, intervenções desnecessárias que alteram o processo natural do parto, abuso da medicalização, negando às mulheres a possibilidade de decidir sobre seu corpo e como querem parir. 0 objetivo do estudo foi analisar a percepção das mulheres sobre a violência no contexto do parto. Tratase de um estudo descritivo, exploratório, de abordagem qualitativa. O estudo foi desenvolvido em uma Unidade Básica de Saúde (UBS) da cidade de Teresina - PI. A coleta de dados foi realizada com 20 mulheres a partir de uma entrevista semiestruturada. Os dados foram coletados nos meses de abril e maio do ano de 2019. Após a análise dos dados coletados foi possível construir as seguintes categorias: Mulheres que percebem violência no seu trabalho de parto evidenciando situações de violência nos seus discursos; Mulheres que não perceberam violência, mas seus discursos evidenciam situações de violência durante o trabalho de parto. Foi possível evidenciar no presente estudo que as mulheres reconhecem ações violentas dentro do âmbito hospitalar como violência no parto de forma limitada, pois estão acostumadas a associar o momento do parto a um momento de dor e sofrimento. Os discursos apontam que a falta de conhecimento, por parte das parturientes, as expõem a situações de violência no parto, ocasionando repercussões de caráter físico, psicológico e emocional.

Palavras-chave: Violência; Obstetrícia; Parto. 
Em épocas passadas as mulheres pariam sem assistência ou cuidado vindo de profissionais da saúde, apenas seguiam seus instintos. 0 parto era considerado natural e fisiológico, e feito por parteiras, mulheres que compartilhavam das mesmas experiências e iniciaram um processo de acumulação de saber sobre a parturição, mas sem nenhum saber cientifico, no final do século XIX, os obstetras passaram a transformar o parto em um evento controlado que se efetivou na metade do século XX, fazendo com que o momento privado da mulher se tornasse um evento médico (SANFELICE et al., 2014).

A violência no parto é o desrespeito à mulher, invasão do seu corpo e de seus processos reprodutivos, e isso ocorre através de verbalizações inadequadas, intervenções desnecessárias que alteram o processo natural do parto, abuso da medicalização, negando às mulheres a possibilidade de decidir sobre seu corpo e como querem parir. É considerada violência desde comentários constrangedores sobre sua cor, raça ou idade, até realização de intervenções no corpo da mulher sem que elas sejam explicadas e que haja o consentimento desta, apesar de a Organização Mundial da Saúde (OMS) determinar critérios e cautela para a adoção de procedimentos, médicos fazem a prática de maneira rotineira (ANDRADE, AGGIO, 2014).

A Lei Estadual № 17.097 de 2017, sancionada pelo Governador de Santa Catarina, foi uma das resoluções para o enfrentamento da Violência, que tem como objetivo a implantação de medidas de informação e proteção à gestante e parturiente contra a violência no parto. A MS institui no âmbito do Sistema Único de Saúde - SUS - A Portaria № 1.459, de 24 de junho de 2011 - Rede Cegonha, que assegura às mulheres o direito ao planejamento reprodutivo, a atenção humanizada à gravidez, parto, abortamento e puerpério (BRASIL, 2011).

As crianças: direito ao nascimento seguro, crescimento e desenvolvimento saudável e a Lei Federal no 11.108, de 07 de abril de 2005, mais conhecida como a Lei do Acompanhante, que prevê o direito a, pelo menos, um ou uma acompanhante, escolhido pela gestante, durante o pré-parto, parto e pós-parto imediato (BRASIL, 2005; BRASIL, 2017). 
Para Nicarete e Cortêz (2015), os hospitais brasileiros precisam se adequar aos direitos humanos das mulheres em seu ciclo gravídico puerperal, deixando estruturas tradicionais e ultrapassadas para trás e promovendo ambientes mais favoráveis à atuação holística dos profissionais, garantindo uma assistência mais digna à mulher e ao recém-nascido, melhorando o acolhimento e atenção humanizada preconizada pela OMS.

Para que a parturiente tenha uma assistência de qualidade e humanizada, o profissional de saúde envolvido neste processo da vida da mulher deve dispor de conhecimentos científicos, que sejam direcionados para as necessidades individuais. Mudanças na estrutura física dos hospitais, capacitação profissional e atualização de diretrizes assistenciais, são mudanças indispensáveis, visto que o despreparo institucional representa um dos fatores desencadeantes da violência obstétrica (BOHREN et al., 2015; TESSER et al., 2015).

A humanização da atenção ao parto se torna necessária, pois as mulheres precisam que a vivência do parto seja conforme suas expectativas, de modo que tenham sua autonomia, individualidade e privacidade respeitadas, pois são condições invioláveis e indispensáveis para que aconteça o parto humanizado. Nesse sentido, é preciso que o corpo feminino não seja visto como uma máquina ou um objeto que é operado pelo médico e demais profissionais, negligenciando informações, emoções, sentimentos, percepções e direitos da mulher no gestar o próprio corpo e o próprio parto (CAUS et al., 2012).

Diante desse contexto, o interesse em desenvolver a pesquisa surgiu por ser um tema atual e o por ser realizado com frequência entre os profissionais da área da saúde, que invadem o corpo da mulher, desrespeitando o momento fisiológico do parto e impedindo a mesma de exercer autonomia sobre seu corpo. Além disso, as portarias e leis que protegem a mulher de sofrerem violências não são praticadas por muitos profissionais da saúde. Assim, os objetivos do estudo são analisar a percepção das mulheres sobre a violência no contexto do parto, além de descrever as principais formas de violência vivenciada durante a assistência obstétrica apontada pelas mulheres a partir de suas perspectivas. 
Trata-se de uma pesquisa do tipo exploratória, descritiva com abordagem qualitativa, desenvolvida em uma Unidade Básica de Saúde (UBS) na cidade de Teresina-PI, de referência com um razoável fluxo de atendimentos, atendem as mulheres no acompanhamento pós-parto, e em função desses serem de grande acessibilidade para os pesquisadores.

As participantes da pesquisa foram 20 mulheres assistidas na atenção básica, cujos critérios de inclusão foram ter filhos no último ano, que levaram os filhos para vacinação na UBS, e que estivessem aptos a responder o roteiro de entrevista, mediante a aceitação, por meio de sua assinatura no Termo de Consentimento Livre e Esclarecido (TCLE) (APÊNDICE B). Foram excluídas dessa pesquisa menores de idade e mulheres que não tenham tido filho no último ano.

A coleta de dados foi realizada pelas pesquisadoras, nos dias de vacinação na UBS, onde não interferiu na assistência à saúde prestada ao paciente. A partir de uma entrevista semiestruturada com base no uso de um roteiro de entrevista (APÊNDICE A), composto por perguntas para caracterização das participantes e perguntas referentes à temática, realizada em uma sala reservada na UBS, de forma individual, garantindo sigilo das informações coletadas e mediante autorização prévia do entrevistado por meio da assinatura do TCLE.

Para cada participante destinou-se cerca de 20 minutos, para a entrevista. As falas foram gravadas por meio de aparelho celular. A gravação eletrônica reproduz com precisão as respostas obtidas e é considerada a melhor maneira para preservar o conteúdo da entrevista. Os dados foram coletados nos meses de abril e maio do ano de 2019.

Após a obtenção das informações, as respostas foram transcritas na íntegra. Foi efetuada uma exploração do material para mostrar a análise propriamente dita, sendo que as falas dos participantes passaram por análises e interpretações. Foi elaborado categorias de acordo com a compreensão dos depoimentos prestados pelas mulheres para uma melhor abordagem interpretativa.

Em relação aos aspectos éticos-legais a pesquisa foi submetida à apreciação do Comitê de Ética e Pesquisa do Centro Universitário Santo Agostinho (CEP/UNIFSA), bem como ao Comitê de Ética e Pesquisa da instituição 
coparticipante, onde foi solicitada aos participantes sua participação voluntária, consentida por meio da assinatura do Termo de Consentimento Livre e Esclarecido (TCLE) (APÊNDICE B) de acordo com a Resolução 466/12, tendo respeito ao anonimato dos entrevistados. A pesquisa foi aprovada sob Protocolo $\mathrm{n}$ : : CAAE: 07398219. 4. 0000. 5602 .

\section{RESULTADOS E DISCUSSÃO}

A pesquisa contou com 20 mulheres, que buscavam atendimento em uma Unidade Básica de saúde da atenção básica. As participantes tinham a faixa etária dos 18 aos 33 anos de idade, com união estável (11), a cor predominante foi parda (11), com ensino médio completo (12) e dona de casa, conforme pode ser verificado no Quadro 1.

Quadro 1. Caracterização das mulheres do estudo.

\begin{tabular}{|c|c|c|c|c|c|c|}
\hline MULHER & IDADE & $\begin{array}{l}\text { ESTADO } \\
\text { CIVIL }\end{array}$ & RAÇA & ESCOLARIDADE & OCUPAÇÃO & $\begin{array}{l}\text { CONSILTAS } \\
\text { PRÉ- NATAIS }\end{array}$ \\
\hline M1 & 18 anos & Solteira & Parda & \begin{tabular}{|c|}
$\begin{array}{c}\text { Ensino fundamental } \\
\text { incompleto }\end{array}$ \\
\end{tabular} & Dona de casa & 8 \\
\hline M2 & 26 anos & Uniãoestável & Parda & $\begin{array}{c}\text { Ensino médio } \\
\text { completo }\end{array}$ & Dona de casa & 6 \\
\hline M3 & 20 anos & Solteira & Parda & $\begin{array}{c}\text { Ensino médio } \\
\text { completo }\end{array}$ & Dona de casa & 9 \\
\hline M4 & 27 anos & Uniãoestável & Preta & $\begin{array}{c}\text { Ensino médio } \\
\text { completo }\end{array}$ & Dona de casa & 10 \\
\hline M5 & 18 anos & Uniãoestável & Preta & $\begin{array}{c}\text { Ensino fundamental } \\
\text { incompleto }\end{array}$ & Dona de casa & 9 \\
\hline M6 & 23 anos & Uniãoestável & Preta & $\begin{array}{l}\text { Ensino médio } \\
\text { completo }\end{array}$ & Dona de casa & 10 \\
\hline M7 & 18 anos & Solteira & Parda & $\begin{array}{l}\text { Ensino médio } \\
\text { incompleto }\end{array}$ & Dona de casa & 9 \\
\hline M8 & 26 anos & Uniãoestável & Parda & $\begin{array}{l}\text { Ensino médio } \\
\text { incompleto }\end{array}$ & Dona de casa & 6 \\
\hline M9 & 22 anos & Uniãoestável & Parda & $\begin{array}{l}\text { Ensino médio } \\
\text { incompleto }\end{array}$ & Dona de casa & 8 \\
\hline M10 & 20 anos & Uniãoestável & Parda & $\begin{array}{l}\text { Ensino médio } \\
\text { completo }\end{array}$ & Dona de casa & 6 \\
\hline M11 & 31 anos & Casada & Branca & $\begin{array}{l}\text { Ensino médio } \\
\text { completo }\end{array}$ & Dona de casa & 6 \\
\hline M12 & 22 anos & Uniãoestável & Parda & $\begin{array}{c}\text { Ensino médio } \\
\text { completo }\end{array}$ & Dona de casa & 12 \\
\hline M13 & 33 anos & Uniãoestável & Parda & $\begin{array}{l}\text { Ensino médio } \\
\text { completo }\end{array}$ & Dona de casa & 6 \\
\hline M14 & 22 anos & Uniãoestável & Preta & $\begin{array}{l}\text { Ensino médio } \\
\text { completo }\end{array}$ & Dona de casa & 8 \\
\hline M15 & 31 anos & Casada & Parda & $\begin{array}{l}\text { Ensino médio } \\
\text { completo }\end{array}$ & Dona de casa & 10 \\
\hline
\end{tabular}




\begin{tabular}{|c|c|c|c|c|c|c|}
\hline MULHER & IDADE & $\begin{array}{c}\text { ESTADO } \\
\text { CIVIL }\end{array}$ & RAÇA & ESCOLARIDADE & OCUPAÇÃO & $\begin{array}{c}\text { CONSILTAS } \\
\text { PRÉ- NATAIS }\end{array}$ \\
\hline M16 & 25 anos & Uniãoestável & Parda & $\begin{array}{c}\text { Ensino médio } \\
\text { completo }\end{array}$ & Dona de casa & 6 \\
\hline M17 & 19 anos & Uniãoestável & Parda & $\begin{array}{c}\text { Ensino fundamental } \\
\text { incompleto }\end{array}$ & Dona de casa & 8 \\
\hline M18 & 23 anos & Uniãoestável & Parda & $\begin{array}{c}\text { Ensino médio } \\
\text { completo }\end{array}$ & Dona de casa & 7 \\
\hline M19 & 31 anos & Solteira & Parda & $\begin{array}{c}\text { Ensino médio } \\
\text { completo }\end{array}$ & Dona de casa & 10 \\
\hline M20 & 20 anos & Uniãoestável & Parda & $\begin{array}{c}\text { Ensino fundamental } \\
\text { incompleto }\end{array}$ & Dona de casa & 10 \\
\hline
\end{tabular}

Fonte: Elaborado pelos pesquisadores.

A partir da análise da coleta de dados foi possível construir as seguintes categorias: Mulheres que percebem que sofreram violência e que situações de violência estão presentes nos seus discursos; Mulheres que não perceberam violência, mas que em seus discursos estão presentes situações de violência durante o trabalho de parto; Mulheres que não passaram por nenhum tipo de violência. Para garantir e preservar a identidade das participantes, as falas foram identificadas com um códigoalfanumérico composto pela letra "M" (referente à "Mulher"), seguida de um algarismo arábico, conforme a ordem cronológica de realização das entrevistas. Exemplo: M1 - 1므 entrevistada, M2 - 2ª entrevistada, e assim, sucessivamente.

\subsection{MULHERES QUE PERCEBERAM VIOLÊNCIA EM SEU TRABALHO DE PARTO EVIDENCIANDO SITUAÇÕES DE VIOLÊNCIA NOS SEUS DISCURSOS.}

A construção desta categoria incluiu as expressões que sugerem a violência no parto que as mulheres descrevem em seus relatos, tais como negligência, desrespeito, realização da manobra de Kristeller, comentários ofensivos contra a mulher, impedimento da presença do acompanhante durante o trabalho de parto, assegurada pela Lei federal 11.108 de 2005.

[...] o médico não queria me atender, foi com ignorância falando que se eu tivesse vindo mais cedo eles tinham me atendido, mas como fui tarde eles iriam deixar eu sofrer mais um pouquinho [...] M1.

[...] foi horrível, eles me deixaram na sala sozinha [...] eu sentia muita dor, pedi que me dessem algo para aliviar, mas disseram que eu tinha que aguentar que isso era normal [...] quando já estava parindo meu filho sozinho em cima da cama, as técnicas vieram, e uma delas perguntou se eu era louca, mandou eu me deitar disse que eu ia matar meu filho, tudo porque está de cócoras parindo ele [...] M16. 
Diante dos dados obtidos foi posssível constatar que a maior necessidade para uma mulher em trabalho de parto está no manejo do controle emocional, pois as mulheres mostram como fator decisório para uma experiência de parto positiva a segurança na equipe pelo meio da qual são assistidas e evidenciam a importância de carinho, paciência e calma por parte dos profissionais.

Segundo estudos de Bohren et al. (2015) destaca-se que a forma de violência mais comum e constante nas unidades hospitalares que prestam assistência ao parto é a aplicaçãode atitudes intimidadoras, faltando o respeito e educação com as usuárias do serviço, bem como piadas e comentários constrangedores relacionados ao peso, à condição socioeconômicoe racial.

É reprovável que na hora de dar à luz, o momento mais esperado de uma mulher, o profissional aja com um descaso desse tipo, submetendo a mulher a uma condição humilhante. A negligência trata-se do descuido dos profissionais para com as parturientes, desde a falta de informações necessárias até a privação de assistência.

[...] foi muito doloroso porque eles apertaram bastante a minha barriga e eu via que ele não tinha paciência, ele apertou tanto minha barriga que adquiri uma fissura [...] M3.

Além disso, a manobra de Kristeller é outra violência obstétrica e, em muitos casos as mulheres não percebem este fato. A entrevistada relatou que foi realizada a manobra de Kristeller durante seu parto. Andrade et al. (2016) identificaram nos seus estudos que $9 \%$ das gestantes receberam esse procedimento, o que representa um risco para saúde da mulher e do feto. Além das dores relatadas pela participante, afirmam Moiety e Azzam (2014), que esse procedimento está associado a lacerações pirenéias graves e internação em UTI neonatal parao recém-nascido, motivo pelo qual é uma prática não recomendada.

[...] eu pedi que deixassem minha mãe entrar eles disseram que não podia, fiquei sozinha [...] ouvi até uma técnica dizendo na hora de fazer não é ruim [...] M10.

[...] eles me botaram um soro com uma medicação, que depois comecei a sentir muita dor [...] fizeram toque algumas vezes [...] quando o médico do plantão chegou fez toque novamente e eu já tinha dilatação total, ele estourou minha bolsa, aí senti a dor da morte porque doía muito [...] em nenhum momento fui informada de nada 
que estava acontecendo não tive direito a acompanhante não tive apoio para suporta meu parto [...] M19.

No presente estudo, mulheres relataram que lhe foram negadas o direito a presença do acompanhante de sua escolha. Os estudos de Andrade et al. (2016) afirmaram que várias instituições hospitalares no Brasil privam gestantes da presença do acompanhante e, em seus estudos, encontraram que 5\% das mulheres não tiveram a presença do acompanhante autorizada pela instituição.

Diniz et al. (2014) defende que a presença do acompanhante representa uma forma de proteger a gestante contra toda e qualquer forma de violência no parto. Além disso, Brüggemann et al. (2016) lembram que a presença do acompanhante junto à mulher nas maternidades é um direito estabelecido em lei, e que a presença dessa pessoa favorece a sensação de estar segura, de sentir-se apoiada e bem tratada, o que não pode ser visto no relato das participantes. É importante que os médicos e demais profissionais da saúdeestejam sensibilizados quanto à relevância da presença do acompanhante no decorrer do trabalho de parto.

A ligação profissional de saúde-paciente, usualmente assimétrica, faz com que as mulheres, sentindo-se menos capacitadas para decidir e fazer valer seus desejos, tendo dificuldades em participar da decisão diante das questões técnicas abordadas pelos profissionais de saúde, fato esse que poderia ser solucionado ou pelo menos amenizado com a prática da humanização na assistência ao parto e nascimento, que abrange os cuidados de enfermagem durante o processo gravídico puerperal (FRUTUOSO; BRUGGEMANN, 2016).

\subsection{MULHERES QUE NÃO PERCEBERAM VIOLÊNCIA EM SEU TRABALHO DE PARTO, MAS SEUS DISCURSOS EVIDENCIAM SITUAÇÕES DE VIOLÊNCIA DURANTE O TRABALHO DE PARTO}

Nesta categoria, as mulheres entrevistadas mostram desconhecimento quanto às práticas que caracterizam uma violência no parto. Sendo assim, nos seus relatos evidenciam que a percepção que elas têm do momento do seu parto é de que não foram vitimas de nenhum ato de violência durante o parto.

Toda mulher tem direito a receber informações sobre o seu estado de saúde e sobre os procedimentos indicados, em linguagem clara, de modo respeitoso e compreensível. Por conseguinte, o profissional de saúde tem o dever de explicar a finalidade de cada intervenção ou tratamento, assim como os riscos ou possíveis 
complicações e as alternativas disponíveis. Com base nessas informações, a mulher tem o direito de recusar tratamentos ou procedimentos em seu corpo, o que se chama de direito à recusa informada.

[...] ai me induziram com remédio no soro [...] fizeram o toque, bastante toque, acho que levei toque umas seis vezes, me disseram que estava com $6 \mathrm{~cm}$ de dilatação [...]Não sofre nenhuma violência, foram todos pacientes comigo, foi tudo tranquiloe normal[...] M2.

[...] me injetaram comprimido, para dilatar, só que não conseguia dilatar, me falaramque iam me levar meio dia, só que achei uma falta de respeito, porque eles já tinham me colocado na frente para fazer à cesárea e depois colocaram três pessoas na minhafrente [...] No meu entendimento foi bom, só não gostei da demora em me atender [...] M8.

O uso de ocitocínicos no soro na tentativa de induzir o parto também foi percebido no relato de M9, que destacou o quanto isso tornou o trabalho de parto doloroso. Nos estudos de Andrade et al. (2016), essa prática foi identificada em 41\% dos partos estudados e Diniz et al. (2015), afirmam que a descomodidade desse procedimento para as mulheres é evidente. Asdiretrizes atuais de atendimento ao parto não recomendam o emprego de ocitocínicos como prática rotineira, uma vez que, de maneira isolada, não diminuem a possibilidade de cesariana em mulheres com analgesia peridural e também podem levar ao aumento da atividade uterina com consequente hipóxia fetal (COSTLEY; EAST, 2012).

Por estar focada no nascimento do seu filho, a vítima pode não se abalar tanto com a violência no parto no momento em que a sofre. Há também a violência verbal, que se referem a tratamento rude, ameaças, gritos, humilhação e abuso verbal (QUEIROZ et al., 2018).

[...] eles me deram muitos toques e falaram que o menino já estava para sair, só que eu falei que não, porque todos os meus partos foram cesariano, mas o médico continuou insistindo pra que eu tivesse parto normal. Aí mandei chamar outro médico, esse outro médico fez o toque e falou que já estava passando da hora de nascer, então ele me encaminhou logo para a sala de cirurgia, não gostei do atendimento desse último parto, porque sofri muito com dor, [...] Não acho que sofri violência, só achei um exagero a quantidade de toque que eles fazem [...] M13.

[...] me deram muito toque, tanto o medico como os estagiários, eu não falava nada porque eles tinham que fazer [...] quando estava tendo meu neném eu tentava botar força, toda minha força, mas eles 
não tinham paciência imperaram minha barriga [...] o importante foi que ele nasceu bem [...] acho que não sofre nenhuma violência não [...] M18.

Outra prática de violência no parto que é identificada nos relatos foi à realização indiscriminada do toque vaginal por diferentes profissionais que, além do incômodo relacionado ao procedimento, há a exposição da mulher e de sua intimidade, com repercussões negativas à experiência do parto. Nos estudos de Andrade et al. (2016), 19\% das mulheres de uma amostra de 562 pacientes sofreram toques vaginais repetidos por diferentes profissionais, relatando que se sentiram desconfortáveis e humilhadas com tal situação. Corroborando com esses autores, Tesser et al. (2015) elucidam que a prática repetitiva de toque vaginal, pelo mesmo ou por diferentes profissionais pode ser considerada um abuso físico e uma quebra à humanização do atendimento.

A dor, além de ser um evento biológico, também é uma construção sociocultural, e em relação ao processo do parto a vivência da dor é influenciada pela forma como a sociedade interpreta o ato de parir, pela história de vida da parturiente, pelas experiências prévias de parto desta mulher e de seus familiares, pelo preparo desta mulher e pelo acolhimento no momento do parto (GAYESKI; BRUGGEMANN, 2015).

[...] não fui bem atendida, praticamente tive meu filho sozinha, não tinha nenhum profissional do meu lado, fiquei com a minha acompanhante sozinha cheguei a parirmeu filho sozinha na cama onde eu estava, quando estava parindo pedi para a minha acompanhante chamar o médico, pedi até pelo amor de Deus pra ela vir [..] não acho que sofre violência [..] M11.

[...] não tive assistência foi horrível [...] eles veem a pessoa ali acha que esta só sentindo dor, mas ás vezes não é só dor, eu estava para me sentar no chão porque a dor que eu estava sentido já era dor de colocar minha filha para fora [...] Não sofri nenhuma violência não, porque depois que tive a minha filha foi que vieram aparecer a junta medica [...] M12.

Diante do abandono em que as parturientes são deixadas, os riscos de complicações durante o parto e pós-parto podem aumentar drasticamente. Através de uma pesquisa, evidenciou-se que o atendimento nos hospitais é representado por descaso, abandono e dor, e que estes estão ligados à violência, tanto psicológica quanto física. 
[...] quando tive o bebê não me colocaram pra ver ele [...] Foi tudo normal, fui bem atendida [...] M7.

[...] eles não me deram minha filha pra eu ver na hora que nasceu, e ela nasceu sem nenhum problema, quando olhei em volta tinha uma moça segurando minha filha nos braços e mostrando para as outras pessoas lá dentro [...] Fui bem tratada [...]M9.

[...] durante meu trabalho de parto foi tudo tranquilo, mas quando minha filha nasceuperguntei pra médica como estava minha filha, e a enfermeira pediu que eu me calasse, porque a médica estava cuidando da minha filha [...] não acho que sofri violência, só não gostei que mandassem que eu calasse a boca [...] M20.

Palma e Donelli, (2017) apontam como fator preditor para a vivência de violência no parto a separação entre a mãe e seu bebê logo após o nascimento, sem que nenhum profissional lhe explicasse o que estava acontecendo com ele, ou através do impedimento ou postergação do aleitamento na $1^{\mathfrak{a}}$ hora de vida do bebê, sem motivos para justificar esta atitude.

Apesar do Programa Nacional de Incentivo ao Aleitamento Materno (PNIAM) (SILVA, GALDINO, 2019) ser bastante difundido, muitos serviços não respeitam o desejo da mãe em amamentar seu bebê logo ao nascer, mesmo que não haja nenhum impeditivo clínico para isso. Em algumas maternidades, só é permitido que a mãe permaneça em alojamento conjunto com seu bebê várias horas após o nascimento, ainda que não haja nenhum motivoque justifique a separação mãebebê. Essa demora dificulta o início da amamentação e afeta a duração do aleitamento materno exclusivo.

\subsection{MULHERES QUE NÃO PASSARAM POR NENHUM TIPO DE VIOLÊNCIA E EM SEUS DISCURSOS NÃO ESTÃO PRESENTES SITUAÇÕES DE VIOLÊNCIA DURANTE O TRABALHO DE PARTO.}

Os relatos ilustrados nessa categoria mostram algumas experiências vivenciadas pelas mulheres de forma positiva, pois na descrição podemos perceber a forma de tratamento, o acolhimento e a segurança que alguns profissionais conseguiram passar a essas mulheres. Sabendo acolher de forma diferenciada, e priorizando um atendimento tranquilo e humanizado.

[...] me trataram muito bem; quando o meu filho nasceu eles me deram meu bebe nahora, achei tudo normal gostei do atendimento [...] M4. 
[...] me senti bem, ocorreu tudo bem, fui bem tratada por todos [...] M5.

[...] Meu parto foi bom, me senti segura, o acompanhamento que tive foi excelente, cheguei ao hospital fui bem atendida, queria muito parto normal [...] M6.

[...] meu parto foi muito bom ocorreu tudo bem [...] Não sofri nenhuma violência[...] M14.

[...] Fui encaminhada para a sala de parto, quando cheguei lá me deparei com 4 enfermeira que me explicaram como seria, foram muito atenciosas, fizeram massagem, me mandaram relaxar, me levaram para passear para poder aumentar a dilatação, quando chegou $8 \mathrm{~cm}$ veio outras mulheres para me ajudar, me levaram para tomar banho quente, fizeram massagem [...] Quando chegou nos $10 \mathrm{~cm}$ chamaram a médica, me explicaram o que iriam fazer, e pediram pra eu respirarpelo nariz e soltar pela boca e logo eu tive minha filha, ocorreu tudo bem [...] não sofri nenhuma violência, pelo contrário, elas me ajudaram muito e meu esposo estava do meu lado e observando tudo, porque já tínhamos visto algumas reportagens sobre isso [...] M15.

[...] quando cheguei à maternidade fui examinada pela obstetra plantonista, já estava com $6 \mathrm{~cm}$ de dilatação[...]ela botou musica e me botou pra dançar, também tomei banho de chuveiro, fiquei em uma bola, ela me tratou super bem, sempre me dizendoo que fazer [...] quando meu filho nasceu eu posso dizer que pari sozinha, mas com a ajuda dela, ela tava sempre por perto e foi maravilhoso, pude pegar ele na hora em que nasceu [...] M17.

Podemos perceber que diante dos relatos mencionados, existem ações que caracterizam o atendimento humanizado, podemos observar pontos otimistas com relação à assistência utilizada no parto. Nos relatos das participantes podemos perceber a existência de característica ética de alguns profissionais, quanto ao respeito da autonomia da mulher e o olhar humanizado.

0 profissional que assiste à parturiente deve identificar e compreender os fatores socioculturais, ambientais, assistenciais e a fisiologia envolvida no processo de parturição, tendo em vista identificar fatores que possam causar medo e insegurança às mesmas, com o intuito de proporcionar uma assistência humanizada e integral (LEHUGEUR; STRAPASSON, 2017).

$\mathrm{O}$ acolhimento compreende um momento oportuno para que a equipe de saúde possa oferecer atenção, interesse e disponibilidade, buscando conhecer e entender as expectativas daparturiente e sua família, esclarecendo as dúvidas relacionadas à gestação e ao parto. 0 acolhimento tende a facilitar a relação da 
parturiente com os profissionais, evitando, assim, situações de estresse e angústia para a mulher e sua família (SANTOS; PEREIRA, 2012).

A humanização do parto pressupõe a atenção centrada na mulher, incentivando a substituição de práticas intervencionistas por práticas menos invasivas e direcionando os cuidados a partir de condutas mais humanizadas.

Segundo Possati et al. (2017), As técnicas não farmacológicas para o alívio da dor, como a deambulação e o posicionamento livre, banho de chuveiro e a dança, são práticas que devem ser realizadas no sentido de melhorar a assistência prestada e torná-la humanizada. Pois essas práticas tendem a contribuir para que a parturiente tenha mais liberdade e autonomia, pondera-se que esta é uma prática que favorece a progressão do feto, mas que também segue os desígnios corporais femininos e proporciona maior conforto à parturiente.

Autores como Narchi, Cruz e Gonçalves (2013), destacam que humanizar a assistência do parto e nascimento implica na mudança de atitudes e de condutas, por meio de uma assistência que garanta o respeito e a sensibilidade com o trinômio mulher-criança- família. A humanização precisa ir além de tratar bem as pessoas, envolvendo a valorização dos sujeitos e o respeito às suas singularidades, humanizar o parto e o nascimento envolve a revisão de ações e condutas dos profissionais de saúde.

A empatia e o respeito estão diretamente relacionados ao modo de tratar as pessoas, àforma de abordar, de esclarecer as dúvidas ou de, simplesmente, ouvir as necessidades da paciente e conhecer as demandas que ela traz ao serviço de saúde. Apreende-se, assim, que a humanização surge da tentativa de reforçar os princípios da integralidade, equidade e acessibilidade, preconizados pelo SUS.

Sousa et al. (2016), afirma que atitudes de empatia, sensibilidade e respeito refletem positivamente na resolutividade dos serviços de saúde e no atendimento às demandas dos usuários. Nessa direção, as definições apresentadas pelas depoentes também estão apoiadas nas políticas públicas e recomendações do Ministério da Saúde, que resgatam a humanização do parto e os princípios do SUS. 
Por meio do presente estudo, foi possível perceber que a violência obstétrica é um ato comum durante o processo de parturição, envolvendo diversas dimensões do sujeito. O tema vem sendo amplamente discutido na literatura nacional e internacional, buscando-se reflexões em torno da temática, propostas de soluções de humanização do parto e mudanças na postura dos profissionais de Saúde.

É importante destacar que no presente estudo as mulheres reconhecem ações violentas dentro do âmbito hospitalar como violência no parto de forma limitada, pois estão acostumadas a associar o momento do parto a um momento de dor e sofrimento. Os discursos apontam que a falta de conhecimento, por parte das parturientes, as expõe a situações de violência no parto, ocasionando repercussões de caráter físico, psicológico e emocional.

É necessário que haja uma mudança no paradigma de atenção à saúde da mulher durante a gravidez e o parto. Essa mudança não depende apenas dos profissionais de saúde em assumir uma postura mais humanizada e qualificada para o atendimento, mas principalmente das próprias gestantes em buscar conhecimentos sobre a gravidez, sobre seus direitos a uma atenção integral e, de fato, cobrar dos serviços de saúde e dos profissionais o respeito a esses direitos.

Por meio desse estudo foi percebido, que a violência no parto emergiu nas posturas agressivas e impacientes com as mulheres, emprego ostensivo do toque vaginal, amniotomia, a separação mãe e bebê após o nascimento, manobra de Kristeller e emprego de ocitocínicos no soro. Essas formas de violência foram citadas tanto pelas mulheres que reconheceram as ações como violência no parto, como as que não reconheceram esses atos como sendo uma violência no parto. Por outro lado, houve gestantes que relataram experiências positivas relacionadas ao parto, uma experiência feliz, em que tudo correu bem.

0 respeito à autonomia da paciente e a percepção positiva em torno do atendimento recebido, permitiram às mulheres participantes do estudo classificar o atendimento como bom. Houve aquelas que citaram atenção por parte dos profissionais como ponto positivo do atendimento e, por isso, a experiência de parturição foi considerada boa. Essa situação sugere um avanço nas formas de atendimento, mas o estudo demonstra que ainda há necessidade de melhorias. 
Afirma-se que esta pesquisa se limita a 20 participantes de uma unidade básica de saúde UBS. Apesar disso, trouxe implicações positivas, como a compreensão das ações da violência no parto como uma forma de violência institucional, multifatorial e recorrente. Permitiu expor que não são os lugares, mas sim as pessoas que provocam a violência no parto e as gestantes aceitam, sem ao menos perceber que sofreram um ato violento.

A experiência negativa do parto, associada à dor e ao sofrimento é um fato que impacta negativamente na vida da mulher. A atuação dos profissionais de saúde nas maternidades deve, portanto, ser humanizada, acolhedora, esclarecedora, integral e focada nas questões objetivas e subjetivas relacionadas ao pré-natal, gravidez e parto.

É no pré-natal, juntamente com uma equipe que a atenda de maneira integral, que a mulher poderá construir o conhecimento em torno da gestação, parto e puerpério, possibilitando a chegada dessa mulher à maternidade com atitude empoderada que não permite que violência obstétrica ocorra, ou pelo menos, dificulte a ocorrência dessa violência.

Sugere-se um estudo futuro, com amostra mais representativa, executado dentro da maternidade, na modalidade observacional e por período de tempo suficiente para caracterizar como a violência no parto ocorre. Espera-se que esse estudo sirva de base para provocar a mudança do modelo assistencial no pré-natal, parto e puerpério, promovendo o empoderamento da mulher sobre o ciclo gravídico, para que não permita ser vítima de violência no parto.

\section{AGRADECIMENTOS}

Agradecemos a Deus por ter iluminado nosso caminho, aos nossos familiares pelo apoio, a todos os professores por todo o ensinamento ao longo dessa jornada, e a todos os nossos amigos que nos apoiaram nos momentos mais difíceis.

\section{REFERÊMCIAS}

ANDRADE, B.P, AGGIO, C.M. Violência obstétrica: a dor que cala. Anais do III Simpósio Gênero e Políticas Públicas: Violência contra a Mulher, Londrina (PR), p. 1-7, 2014. Disponível 
em:<http://www.uel.br/eventos/gpp/pages/arquivos/GT3_Briena\%20Pad ilha\%20Andrade.pdf>. Acesso em 15 mar 2018.

ANDRADE et al. Fatores relacionados à saúde da mulher no puerpério e repercussões na saúde da criança. Escola Anna Nery Revista de Enfermagem. São Paulo, v. 19, n. 1, p. 181-186. Jan./mar. 2015. Disponível em: <http://www.scielo.br/pdf/ean/v19n1/1414-8145-ean-19- 010181.pdf $>$. Acessado em 02 de mar. De 2018.

BOHREN, M.A. et al. The Mistreatment of Women during Childbirth in Health Facilities Globally: A Mixed-Methods Systematic Review. PLOS Med., v. 12, n. 6, p. 1-32, jun. 2015. Disponível em:<https://www.ncbi.nlm.nih.gov/pubmed/26126110>. Acesso em $22 \mathrm{de}$ Abril de 2019.

BRASIL. Ministério da Saúde. Portaria no 2.418, de 02 de dezembro de 2005. Regulamenta, em conformidade com o art. 1으 da Lei no 11.108 , de 7 de abril de 2005, a presença de acompanhante para mulheres em trabalho de parto, parto e pós-parto imediato nos hospitais públicos e conveniados com o Sistema Único de Saúde - SUS. Extraído de <http://bvsms.saude.gov. br/bvs/saudelegis/gm/2005/prt2418_02_12_2005.html>. Acesso em 23 de mar. 2018.

BRASIL. Ministério da Saúde. Secretaria de Atenção à Saúde. Manual prático para implementação da Rede Cegonha. Brasília, p. 1-42, jul. 2011. Disponível em:<http://www.

saude.pi.gov.br/ckeditor_assets/attachments/138/DOCUMENTOS_REDE_C EGONHA.pdf>. Acesso em 25 de março de 2018.

BRASIL. Lei no 17.097, de 17 de janeiro de 2017. Lei da Violência Obstétrica. Florianópolis, 17 jan. 2017. Disponível em: <http://leis.alesc.sc.gov.br/html/2017/17097_2017_lei.html>. Acesso em 23 de mar. De 2018.

CAUS E.C.M. et al. O processo de parir assistido pela enfermeira obstétrica no contexto hospitalar: significados para as parturientes. Revista de enfermagem, Brasília, v. 16, n. 1, p. 34-40, mar. 2012. Disponível em:<http://www.scielo.br/pdf/ean/v16n1/v16n1a 05.pdf >. Acesso em 25 de março de 2018.

MATOS G.C. A trajetória histórica das políticas de atenção ao parto no Brasil: uma revisão integrativa. Revista Enfermagem UFPE online. Recife, v. 7, n. 3, p. 870-878, mar. 2013. Disponível em: <http://C:/Users/aluno/Downloads/11552-26852-1-PB.pdf>. Acesso em 25 de abril de 2018.

MARTINELLI, K. G. et al. Adequação do processo da assistência pré-natal segundo os critérios do Programa de Humanização do Pré-natal e Nascimento e Rede Cegonha. Revista. Brasileira de Ginecologia e Obstetrícia, Rio de Janeiro, 
v. 36, n.2, p. 56-64, jan. 2014. Disponível em: <http://www.scielo.br/pdf/rbgo/v36n2/0100-7203-rbgo-36-0200056.pdf $>$. Acesso em: 27 de março de 2018.

NICARETTA, J.C; CORTÊZ, D.T. Centros de parto normal: revisão integrativa. Revista Saúde e Pesquisa. Maringá. v. 8, n. 2, p. 345-353, mai./ago. 2015. Disponível em:

<http://periodicos.unicesumar.edu.br/index.php/saudpesq/article/view/3 852/2640>. Acesso em 10 de abr., de 2018.

PÉREZ,B. A. G, OLIVEIRA ,E. V.; LAGO, M. S. Percepções de puérperas vítimas de violência institucional durante o trabalho de parto e parto. Rev. Enferm. Contemporânea. Bahia. v. 4, n. 1, p. 66-77, jan./jul., 2015. Disponível em: $<$ https://www5.bahiana .edu. index.php/enfermagem/article/view/472/436>. Acesso em: 01 de mai. De 2018.

SANFELICE, C.F. et al. Do parto institucionalizado ao parto domiciliar. Rev Rene. Minas Gerais, v. 15, n. 2, p. 362-370; mar/abr 2014. Disponível em <http://C:/Users /aluno/ Down loads/3170-5930-1-SM.pdf> acesso em: 05 de mar. de 2018.

TESSER, C.D. Violência obstétrica e prevenção quaternária: o que é e o que fazer. Rev. Bras. Med. Fam. Comunidade. Rio de Janeiro, v. 10, n. 35, p. 1-12, 2015. Disponível em: <https://www.rbmfc.org.br/rbmfc/article/view/1013/716>. Acessado em 01 de mai. de 2018. 


\title{
CAPITULO VIII
}

\section{POSIÇOESS ALTERNATIUAS: MODALIDADES DE POSIÇÃO MATERNA DURANTEO PROCESSO DEPARTURIÇÃO}

DDI: 10.51859/amplla.esp917.1121-8

Bruna Maria de Moura Soares ${ }^{1}$

Tatiana Maria Melo Guimarães 2

Fernanda de Moura Soares ${ }^{3}$

Márcia Teles de Oliveira Gouveia ${ }^{3}$

Samila Gomes Ribeiro ${ }^{3}$

Priscilla Cavalcante Lima 4

\author{
${ }^{1}$ Mestranda em Saúde da Mulher. Mestrado Profissional em saúde da mulher - UFPI \\ 2 Docente de enfermagem. Centro Universitário Santo Agostinho - UNIFSA \\ 3 Mestre em Saúde do Adulto e da Criança. Centro Universitários Cristus \\ 3 Docente. Universidade Federal do Piauí - UFPI \\ ${ }^{3}$ Docente. Universidade Federal do Piauí - UFPI \\ ${ }^{4}$ Doutoranda. Programa de Pós- Graduação em Enfermagem - UFPI
}

\section{RESUMO}

O Ministério da Saúde preconiza a assistência humanizada ao parto, de modo que a mulher deve conduzir seu próprio processo de parto, respaldada por orientações fundamentadas em informações confiáveis acerca dos possíveis benefícios, relativos ao bem-estar materno e fetal, das diferentes posições maternas adotadas durante o trabalho de parto e de parto. 0 trabalho objetiva desvelar as diversas modalidades de posição materna vivenciadas durante o trabalho de parto e parto. Trata-se de um estudo de abordagem qualitativa, realizado em uma maternidade pública de Teresina-PI. Foram entrevistadas treze puérperas, cujos relatos foram analisados segundo análise de conteúdo. Os resultados evidenciaram predomínio da posição supina no trabalho de parto e parto anterior, a mulher restrita ao leito. Em relação à vivência atual no trabalho de parto e parto evidenciou-se a mulher exercendo seu papel de protagonista, assumindo sua autonomia e liberdade, ativa no processo, as entrevistadas mostraram-se favoráveis às posições verticais. Ressalta-se as tecnologias não invasivas para o alívio da dor relatadas também como parte do processo de trabalho de parto, foram citadas massagem, banho de aspersão, exercícios respiratórios, uso da bola Suíça, cavalinho, presença do acompanhante, musicoterapia e deambulação. Percebeu-se nos relatos as mais variadas modalidades de posição durante trabalho de parto e parto, as entrevistadas mostraram-se favoráveis às posições verticais, destaque para as tecnologias não invasivas de cuidado, a participação do enfermeiro obstetra envolvido e disposto em oferecer terapias não farmacológicas para o alivio da dor e também atuante ao processo de verticalização, respeitando a fisiologia do parto normal.

Palavras-chave: Parto Humanizado; Modalidades de Posição; Enfermagem Obstétrica. 
Acredita-se que o conhecimento das mulheres acerca do parto normal e da prática de se posicionarem para dar à luz, venha de experiências tradicionais, relacionadas com a cultura e resultante dos conhecimentos passados de geração em geração (SILVEIRA; CARVALHO, 2003). Evidências etnológicas demonstraram que tribos primitivas adotavam diferentes posições para o parto, de acordo com seus instintos. Cerca de quarenta posições foram documentadas, como de cócoras, de joelhos, em pé, inclinadas, quatro apoios; as mulheres assumiam várias posturas em diferentes momentos do trabalho de parto e no parto (BALASKAS, 2014).

A obstetrícia nasce como disciplina científica na França, nos séculos XVII e XVIII, tornando-se uma especialidade da medicina o que viria a desapropriar, paulatinamente, as parteiras do direito de exercício de seu ofício e negar a validade de seu saber, consolidando a entrada dos homens no cenário do parto. Acirram-se os conflitos entre os médicos e as parteiras/obstetrizes e a disputa entre estes dois atores pela assistência ao parto, conflitos, estes, que persistem até os tempos atuais (BRASIL, 2013).

Diante desse cenário, a obstetrícia moderna surge sob a defesa da cirurgia e transformou o parto e o nascimento em um evento medicalizado, descaracterizando a essência original de fenômeno existencial e psicológico, para mãe e filho, e acontecimento social, para o grupo familiar e sociedade. Esse modelo prima pela racionalidade, tecnicismo, mercantilismo e pela carência de princípios humanísticos, em que mãe e filho deixam de ser vistos como pessoas e passam de sujeitos para objetos da assistência (CARON; SILVA, 2002).

$\mathrm{O}$ parto foi institucionalizado no século XX, expressivamente após a Segunda Guerra Mundial, com a finalidade de redução da mortalidade materna e infantil. Assim, ele que era a celebração da vida passa a ser visto prioritariamente pelos riscos à saúde, sendo medicalizado com base na premissa de que a medicina poderia dominar e/ou neutralizar os riscos (BARROS, 2009).

Apesar da hospitalização ter sido, em grande parte, responsável pela queda da mortalidade materna e neonatal, o cenário de nascimento transformou-se rapidamente: simbolicamente, a mulher foi despida de sua individualidade, autonomia e sexualidade, por meio do cerimonial de internação - separação da 
família, remoção de roupas e de objetos pessoais, ritual de limpeza com enema, jejum, não deambular. Ou seja, a atenção foi organizada como uma linha de produção e a mulher transformaram-se em propriedade institucional (NAGAHAMA; SANTIAGO, 2005).

Com a institucionalização do parto, a posição litotômica passou a ser considerada mais adequada para a realização dos procedimentos hospitalares e adotada como clássica para o nascimento; adotou-se o decúbito dorsal, colocando a mulher numa posição antifisiológica, que contribuiu para o uso de tecnologias desnecessárias. Uma posição que proporciona às mulheres serem passíveis e controláveis, que permite ao profissional que conduz o parto uma posição mais cômoda e confortável, mesmo que esteja em desacordo com a força da gravidade e com a sensação de protagonismo ao dar à luz ativamente (BALASKAS, 2014).

Nas últimas décadas, a crescente desilusão com a aplicação rotineira da alta tecnologia obstétrica fez com que pesquisadores internacionais começassem a explorar a fisiologia normal do parto. Evidências científicas nos últimos cinquenta anos, mostram as vantagens fisiológicas da posição vertical no trabalho de parto e parto, comprovando que certos princípios físicos aplicáveis ao parto, são negados ou mesmo anulados quando um parturiente adota a posição horizontal (BALASKAS, 2014).

Atualmente, o Ministério da Saúde preconiza a assistência humanizada ao parto, de modo que a mulher deve conduzir seu próprio processo de parto, respaldada por orientações fundamentadas em informações válidas e confiáveis acerca dos possíveis benefícios, relativos ao bem-estar materno e fetal, das diferentes posições maternas adotadas durante o trabalho de parto e de parto. Segundo as Diretrizes nacionais de assistência ao parto normal, deve-se desencorajar a mulher a ficar em posição supina, decúbito dorsal horizontal, ou posição semi-supina no segundo período do trabalho de parto. A mulher deve ser incentivada a adotar qualquer outra posição que ela achar mais confortável incluindo as posições de cócoras, lateral ou quatro apoios (BRASIL, 2017).

No entanto, ainda são escassos os dados sobre as experiências das mulheres brasileiras que realizaram partos nas diversas modalidades de posição, e sobre a relação dessas com a vivência do processo de parturição. Dessa forma, o estudo objetiva desvelar as diversas modalidades de posição materna vivenciadas durante 
o trabalho de parto e parto com o intuito de conhecer como esse resgate na posição para parir tem sido vivenciado pelas parturientes para avaliar se essa prática também tem sido considerada positiva, sob o ponto de vista da mulher.

\section{METODOLOGIA}

Trata-se de um estudo exploratório descritivo de abordagem qualitativa, realizado em uma maternidade pública do município de Teresina-PI, correspondente a uma instituição de referência obstétrica da esfera administrativa estadual.

Participaram do estudo treze mulheres no puerpério imediato de parto via vaginal e, que se enquadraram nos critérios da pesquisa: pacientes maiores de dezoito anos, multíparas com parto anterior via vaginal, com gestação de risco habitual e parto conduzido por enfermeiro obstetra; que no puerpério imediato encontrava-se em alojamento conjunto.

A produção dos dados aconteceu em três momentos: inicialmente houve uma breve apresentação sobre os objetivos da pesquisa para possível aceitação e assinatura do termo de consentimento livre e esclarecido; em seguida apresentouse à puérpera um cartaz para identificação visual das modalidades de posição para melhor assimilação das práticas posturais vivenciadas; posteriormente realizou-se uma entrevista semiestruturada no intuito de conhecer as experiências e percepções das mulheres sobre as modalidades de posição vivenciadas durante o trabalho de parto e parto, frente à assistência recebida, fazendo um comparativo entre parto anterior e atual.

0 roteiro de entrevista foi dividido em caracterização, história obstétrica e entrevista propriamente dita. As entrevistadas foram caracterizadas quanto as variáveis idade, ocupação/profissão, situação conjugal e naturalidade, e quão à história obstétrica identificou-se paridade, tipos de parto realizados, número de consultas pré-natal, profissional que realizou o pré-natal, participação em curso para gestantes e orientação em relação as variedades de posição materna durante o trabalho de parto e parto.

A coleta de dados ocorreu no período de maio a julho de 2015, nos turnos matutino e vespertino. Os encontros foram realizados no setor de alojamento 
conjunto, da referida maternidade. Para garantir a facilidade e impedir a perda de importantes informações coletadas, as entrevistas foram gravadas em formato Mp3 Player.

Para a análise dos resultados foi aplicada a técnica de conteúdo temática, que se estrutura em três etapas: pré-analise, exploração do material, e tratamento e interpretação dos resultados (MINAYO, 2014). Para resguardar e garantir o anonimato das participantes, as entrevistas foram codificadas como a abreviatura de entrevistadas (EN) seguida do número referente a ordem das entrevistas.

Os princípios éticos foram respeitados conforme a Resolução no 466/2012 e resoluções complementares do Conselho Nacional de Saúde, assim a pesquisa obteve aprovação do Comitê de Ética e Pesquisa da Universidade Federal do Piauí por meio da CAAE 44437615.9.0000.5214.

\section{RESULTADOS E DISCUSSÃO}

No que se refere a caracterização das puérperas entrevistadas, a idade variou entre 20 e 32 anos, em sua maioria eram profissionais do lar, em união estável e procedentes do estado do Piauí. Com relação a história obstétrica a maior parte eram tercigestas, com partos vaginais, apenas uma relatou cirurgia cesariana em partos anteriores; realizaram entre 5 e 12 consultas de pré-natal, estas intercaladas com enfermeiro e médico; apenas uma entrevistada participou de curso para gestante e somente esta foi orientada quanto modalidades de posição materna durante trabalho de parto e parto.

Diante da análise dos depoimentos apreendeu-se as seguintes categorias temáticas: Modalidades de posição materna vivenciadas durante o trabalho de parto e parto e Tecnologias não invasivas de cuidado.

\subsection{MODALIDADES DE POSIÇÃO MATERNA VIVENCIADAS DURANTE TRABALHO DE PARTO E PARTO}

Tendo em vista a abordagem das vivências de posições maternas durante o trabalho de parto e parto anterior e atual, decidiu-se separar essa categoria em duas subcategorias para melhor apresentação e discussão dos resultados. 


\subsubsection{MODALIDADES DE POSICÕES NO TRABALHO DE PARTO E PARTO}

\section{ANTERIOR}

Esta subcategoria envolve as modalidades de posição materna relatadas nos depoimentos de acordo com as experiências do processo de parturição antecedente. Nesse contexto, observou-se o predomínio da posição supina, o desconhecimento das mulheres quanto às posições alternativas, assim, elas acabaram aceitando a posição convencional, pré-determinada e imposta pelos profissionais: o decúbito dorsal.

Referente ao trabalho de parto anterior: nove puérperas mencionaram o decúbito dorsal, destas, oito negaram qualquer outro tipo de movimentação; quatro relataram deambulação, duas citaram o decúbito lateral, duas revelaram o banho de aspersão também como parte do processo durante o trabalho de parto. Como observado nos trechos a seguir:

O outro eu fiquei só deitada. A única posição que eu fiz foi só de ladinho, caminhei de jeito nenhum, só deitada. EN07

Deitada, só deitada mesmo, e aí a dor vinha e demora mais. Eu sofri bastante porque era só deitada, não fazia mais nada e é melhor caminhar e fazer esses outros movimentos. EN10

Tomei banho e caminhei, só. EN04

As mulheres, em sua maioria, encontram-se no cenário de parturição em inercia, imobilizadas, geralmente em decúbito dorsal, o que retarda e dificulta o trabalho de parto e parto, bem como as condições maternas e fetais. 0 confinamento da parturiente no leito, imposta pelo modelo assistencial implantado nos hospitais, constitui uma limitação importante da liberdade corporal, considerada essencial para o bom desenvolvimento do processo de parturição (ODENT, 2002). A EN10 narra o incomodo pelo decúbito dorsal relacionando a limitação postural e maior desconforto durante a contração, o que possivelmente sugere que a equipe não ofertou/incentivou outras possibilidades de movimento.

Apesar de ser mais conveniente para os profissionais envolvidos na assistência às parturientes que elas assumam repouso no leito, a maioria das parturientes preferem deambular, principalmente no início do trabalho de parto (HOFMEYR, 2005) como optou a entrevistada 04. 
Durante o primeiro período do trabalho de parto, a mulher não deve ser forçada a permanecer no leito. Deve-se incentivar a liberdade de movimentação, de forma espontânea, existindo uma tendência à alternância de posições como escolha da própria mulher (BRASIL, 2000).

Na ausência de evidências científicas que comprovem o contrário, a escolha da posição e deambulação durante o trabalho de parto deve ficar a critério da parturiente, encorajando-se as posições não supinas (LAWRENCE et al., 2010). Para a OMS (1996), se a posição escolhida for deitada no leito, a posição supina deve ser evitada, com base na evidência fisiológica da diminuição da contratilidade uterina e da perfusão placentária, dessa forma, recomenda-se a adoção do decúbito lateral esquerdo (WHO, 2003), como referido pela EN07 quando menciona a posição de "ladinho", não sabido se por orientação do profissional ou desejo da paciente.

A movimentação corporal contribui para que as parturientes se sintam mais empoderadas e livres. A mulher deve ser incentivada a atuar como sujeito do evento, pois ela tem o direito de participar das decisões sobre o nascimento, no entanto, muitas ainda têm dificuldades em assumir um papel participativo no trabalho de parto em função da cultura de subordinação a que estão submetidas (MELLO, NÓBREGA, LEMOS, 2011).

Em relação às posições materna no parto anterior, nove das entrevistadas destacaram o decúbito dorsal, caracterizando tal modalidade como atitude padrão, tradicional, como se desconhecesse ou mesmo não tivesse sido ofertado alternativas. As demais citaram a posição semi-sentada.

Aquela normal que fica com as pernas pra cima. EN01

Reta, deitada de papo pra cima. EN07

Aquela quase sentada. EN08

Deitada de perna pra cima, deitadona mesmo, dificultou bastante por esse motivo. EN10

Essa aqui (semi-sentada, apontando para quadro de imagens). EN13

Alguns autores ressaltam que a posição litotômica é adotada com frequência no contexto hospitalar devido o conforto do profissional, pois o privilegia durante a expulsão do bebê e também para realização de intervenções, muitas vezes desnecessárias, como por exemplo a episiotomia (OSAVA, 1990; MALDONADO, 1991; SANTOS, 2002). 
As mulheres demonstram não ter conhecimento sobre outras modalidades de posição, ou mesmo não se apropriaram de seu corpo, seu parto, suas escolhas, não empoderadas deixam de assumir seu protagonismo em detrimento do imposto, quisto pelo profissional obstetra. Isso fica explícito na fala da EN 08 quando relata:

Ele nem quer que você deite de lado, sempre é de papo pra cima. EN08

Prevalece nesse segmento o desejo do profissional e não o da mulher, esta por sua vez imóvel, passiva, coadjuvante, inerte ao processo; observa-se uma inversão de papéis e atores no cenário do parto.

\subsubsection{RELATOS DE UMA VIOLENCIA VELADA: RESOUICIOS DA} OBSTETRICIA TRADICIONAL

Outro aspecto relevante insurgiu das falas, fatos que repercutiram negativamente no ideário de parturição das entrevistadas foram revelados. Em meio ao movimento de humanização do parto e nascimento, o enfoque das boas práticas propostas pela OMS desde o ano de 1996, a Obstetrícia atual ainda enraizada ao modelo biomédico permite realizar condutas controversas, obsoletas e até mesmo abusivas - a manobra de Kristeller, o mal uso do fórceps e a episiotomia foram citados, como demonstram os depoimentos abaixo.

A mulher encima pressionando minha barriga, elas botaram força aqui (...) Ficou doído depois EN12

(...) eu não tive força pra botar ela, ela foi puxada com aquele aparelho (...) Aí ela machucou a cabeça, machucaram a cabeça dela aqui atrás e aqui na frente, ainda hoje ela tem a cicatriz EN10

(...) peguei sete pontos porque ele inda me cortou, mas ele mesmo corto não foi ela (referindo-se à recém-nascida quando passou pelo canal de parto - laceração) (...) eu só soube na hora que ele tava costurando. Falou não eu nem sabia, ele só cortou lá. EN01

(...) ele que cortou ENO2

(...) antes de ter eu fui cortada, teve um pequeno corte e peguei alguns pontos EN08

Segundo a OMS (1996) a pressão no fundo uterino durante o trabalho de parto e parto, manobra de Kristeller, se enquadra na categoria de práticas em relação as quais não existem evidências suficientes para apoiar uma recomendação 
clara e que devem ser utilizadas com cautela até que mais pesquisas esclareçam a questão. Ressalta-se no depoimento da EN12, a lembrança da manobra caracterizada pelo desconforto, dor.

Em relação ao fórceps, a decisão de um parto instrumental depende de vários fatores, e as indicações classicamente reconhecidas são período expulsivo prolongado, exaustão materna, emergências como prolapso de cordão ou descolamento prematuro da placenta diagnosticadas no período expulsivo, padrões de frequência cardíaca fetal não tranquilizadora e condições médicas, como eclampsia e cardiopatias. Não estão disponíveis ensaios clínicos randomizados validando essas indicações, de forma que a indicação do parto instrumental ainda depende fundamentalmente do obstetra, requerendo-se o consentimento informado da parturiente (O'MAHONY; HOFMEYR; MENON, 2010).

Em relação à episiotomia a recomendação da OMS (1996) não é de proibir, mas de restringir seu uso, admitindo-se que em alguns casos ela pode ser necessária. Entretanto a taxa de episiotomia não deve ultrapassar 10\%. É importante ressalvar que, como todo procedimento cirúrgico, a episiotomia só deveria ser realizada com o consentimento pós informação da parturiente (AMORIM; PORT; SOUZA, 2010); o que não aconteceu no caso da EN01. O American College of Obstetricians and Gynecology (ACOG) (2006) estabeleceu em seu Practical Bulletin que o uso de episiotomia deve ser restrito e que os médicos devem ser encorajados a usar seu raciocínio clínico para decidir quando o procedimento é necessário.

Infelizmente, no Brasil, a situação é ainda mais crítica. Estimativas confiáveis do número total de episiotomias não estão disponíveis, porque de tão banalizado o procedimento se tornou "invisível", não sendo sequer relatado em prontuários. Como descrevem Diniz e Chacham (2004), no país que é o "campeão" mundial de cesáreas, "quando não se corta por cima, se corta por baixo".

\subsubsection{MODALIDADES DE POSICÕES NO TRABALHO DE PARTO E PARTO ATUAL}

Nesta subcategoria averígua-se uma nova postura da mulher, dessa vez ativa no processo, disponível às alternativas de posição de acordo com suas preferências e a favor da verticalização do processo. A movimentação durante o trabalho de parto a partir do relato das puérperas se deu com as posições: decúbito lateral esquerdo, 
em pé, sentada, de joelhos, quatro apoios, balanço pélvico com auxílio da bola e também do cavalinho, cócoras sustentada e na banqueta, agachamento e deambulação.

(...) o da cama pra levantar a perna e o último que foi o que me ajudou mais foi o agachamento (...). Fiquei de cócora. Fiquei de lado, lado esquerdo. EN01

Fiz bastante exercício (...) de lado esquerdo (...) numa bola, num negócio que é tipo um cavalinho. Caminhei bastante, tomei banho (...), de quatro em cima da cama com a bola. Fiz agachamento (...), de cócoras. EN02

Os exercícios na bola, a massagem nas costa e fiquei de lado (...) primeiro eu fiquei de joelho, fiquei de quatro apoiada na bola, Fiquei um bom tempo de quatro depois eu virei de lado pra ter o neném (...) caminhei até chegar nos 7 centímetros (...) fiquei em pé, sentada e caminhei um pouquinho. EN07

Foi a cadeirinha, ficar tipo abraçada com a minha acompanhante em pé, (...) a caminhada que eu fiz bastante também eu tava disponível pra fazer todas, praticamente todas eu fiz (...), de cócoras, de quatro. EN10

Eu fiquei foi aqui mesmo o tempo todo de cócoras segurando no ferro (...) Eu deitei lá na cama de lado e pra mim ter ele mesmo a posição que eu achei adequada pra mim foi essa de ficar de cócora e botar força. EN12

Só fiquei deitada mesmo, caminhei pro banheiro mesmo e só. EN11

Os autores concluem que a deambulação e a posição vertical no primeiro estágio do trabalho de parto são recomendadas e não se associam com aumento de intervenções médicas ou efeitos negativos para mães e seus filhos. Destaca-se que as mulheres devem ser encorajadas a descobrir a posição mais confortável (LAWRENCE, et al., 2010).

Por outro lado, a deambulação pode aumentar a sensação da parturiente de controle de seu trabalho de parto, prover distração autorregulada e facilitar o suporte contínuo intraparto por um acompanhante, medidas que reduzem a necessidade de analgesia e a indicação de cesariana (HODNETT, et al., 2010). Também é sugerido que a deambulação aumenta o conforto materno durante o trabalho de parto (LAWRENCE et al., 2010).

A parturiente não deve ser obrigada a ficar no leito por longos períodos, mas sim deambular, sentar e deitar, condições que a parturiente pode aderir no seu trabalho de parto, de acordo com a sua preferência, salvo algumas exceções. A 
liberdade para deambular é crucial para a gestante tolerar e aliviar as dores do trabalho de parto (OLIVEIRA et al., 2014; SILVA et al., 2013).

Em relação às posições no parto atual, cinco participantes relataram a escolha pela posição semi-sentada, outras cinco optaram pelo decúbito lateral esquerdo e três de cócoras, uma sustentada e duas com auxílio da banqueta.

Deitada normal com as perna pra cima porque quando eu cheguei lá a minina já tava com a cabeça toda do lado de fora, porque o que fez a cabeça descer foi a posição de agachamento. É foi tipo assim, aliás foi assim mesmo (indicando no cartaz de ilustração para identificação visual das modalidades de posição materna a posição referida - semi sentada) EN01

Fiquei de cócora, botando força de cócora, aí quando tava nascendo ...a enfermeira veio e eu deitei na cama fiquei dessa posição... Semi sentada apontando quadro ilustrativo EN05

Sentei no banquinho que foi onde eu tive o bebê. Foi a do banquinho. EN08

Eu deitei lá na cama de lado e pra mim ter ele mesmo a posição que eu achei adequada pra mim foi essa de ficar de cócora e botar força. De cócoras encima da cama. EN12

As posições verticalizadas durante o parto estão associadas à redução da dor e maior grau de satisfação materna, como demonstrado em revisões sistemáticas (HODNETT, 2010).

A posição supina tem sido amplamente discutida no segundo período do trabalho de parto, a despeito da evidência fisiológica da redução da eficiência uterina e do fluxo sanguíneo placentário nessa posição. A posição litotômica é ainda recomendada em alguns tratados tradicionais de Obstetrícia, mas as posições alternativas incluem uma gama de posições que podem trazer benefícios para o parto: posição lateral (Sims), vertical (sentada, semi-sentada, de cócoras ou ajoelhada) e de quatro apoios (GUPTA; HOFMEYR, 2010) corroborando os relatos.

0 uso rotineiro da posição horizontal durante o período expulsivo foi classificado como uma das práticas claramente prejudiciais ou ineficazes e que deveriam ser eliminadas, havendo a recomendação praticamente consensual entre os autores de evitá-la. Com base nas recomendações da OMS (1996) para a assistência ao parto, o Ministério da Saúde sugere que as mulheres devam adotar a posição que melhor lhes agradar, desde que evitem longos períodos em decúbito 
dorsal e que os profissionais necessitam ser treinados no manejo do parto em outras posições além da supina (BRASIL, 2001).

As mulheres devem ser encorajadas a parir na posição que lhes for mais confortável, com o balanço das evidências a favor das posturas não-supinas (GUPTA; HOFMEYR, 2010), como proposto pela enfermagem obstétrica.

A posição verticalizada causa menos desconforto e dificuldade de puxos, menos dor durante o trabalho de parto, menos traumatismo vaginal ou perineal e infecções da incisão. Num estudo, observou-se uma menor duração do segundo estágio na posição verticalizada. Em relação ao resultado fetal, em alguns estudos houve menos escores de Apgar abaixo de 7 na posição verticalizada (OMS, 1996).

\subsection{TECNOLOGIAS NÃO INVASIVAS DE CUIDADO}

Ressalta-se as tecnologias não invasivas e não farmacológicas para o alívio da dor destacadas também como parte do processo de trabalho de parto, desse modo foram citados: massagem, banho de aspersão, exercícios respiratórios, uso da bola Suíça e cavalinho, presença do acompanhante, musicoterapia e deambulação.

As enfermeira (...) dando apoio, fazendo massagem nas minhas costa (...) EN07

Pegaram na minha mão, mandaram eu respirar e soltar pela boca quando viesse as contração e relaxar. EN12

Aquele exercício da bola, inda fiz aquele do cavalinho, aí eu caminhei um pouquinho EN02

Fiquei na bola e na cadeira, no balanço assim EN06

Fiz bastante exercício, ainda tomei banho ENO3

Fiquei no cavalinho e ela fazendo massagem EN02

(...) minha irmã mesmo quando veio ter aqui na maternidade antigamente o acompanhante não podia nem ficar na sala de parto hoje em dia assisti o parto né? Tanto faz ser o pai como alguém da família, minha irmã esteve presente na hora do parto, eu gostei, adorei, foi muito ótimo (...) EN08

(...) a minha cunhada que tava comigo me acompanhando me incentivava a fazer todas as posições (...) EN10

(...) tinha até uma musiquinha alegrando o ambiente, tirando a tensão. EN07 Caminhei bastante ENO3

Comecei a andar, caminhar, dançar ali, aí já evoluiu mais rápido EN06 
Gayeski e Brüggemann (2010) confirmam que a massagem é eficaz no alívio da ansiedade, do estresse e da dor. Segundo Gallo et al. (2011) os exercícios respiratórios podem não ser suficientes na redução da sensação dolorosa durante o primeiro estágio do trabalho de parto, porém são eficazes na redução da ansiedade e na melhora dos níveis de saturação materna de oxigênio, o que contribui para o alívio da dor. Os benefícios do banho são alívio da dor, diminuição da pressão arterial, aumento da dilatação do colo uterino, além de ser um método fácil e barato. A bola suíça e o cavalinho, são alternativas que auxiliam a mulher na mudança de posição durante a fase de trabalho de parto, proporcionam muitos benefícios entre eles a correção da postura, alongamento, relaxamento da musculatura, fortalecimento do assoalho pélvico (DAMACENO, 2015).

Sescato, Souza e Wall (2008) recomendam a bola como um recurso que deve ser utilizado com o objetivo de facilitar a adoção de postura vertical pela parturiente de forma confortável, através do exercício de balanço pélvico. Para muitos, a bola é um instrumento lúdico que distrai a parturiente, tornando o trabalho de parto mais tranquilo. Cabe ressaltar que a utilização desse método pela parturiente sem orientação e supervisão de um profissional de saúde pode provocar queda e não deve ser recomendada (GALLO, 2011).

A hidroterapia é uma medida que pode promover conforto e relaxamento também durante o trabalho de parto, corresponde um método de simples aplicabilidade, que pode ser oferecido com frequência na prática obstétrica, proporcionando melhor aconchego à mulher (LOWDERMILK; PERRY; BOBAK, 2002).

A análise dos dados na pesquisa de Mello, Nóbrega e Lemos (2011) evidenciou que as mulheres reconheceram a presença de um acompanhante como uma das principais tecnologias não invasivas utilizadas durante o trabalho de parto. 0 favorecimento da presença de acompanhante promove maior tranquilidade, segurança e força, diminuindo o medo e a ansiedade delas durante o trabalho de parto. 0 papel do acompanhante é definido como elemento fundamental para dar suporte emocional. Também tem contribuído para a redução de taxas de cesariana, duração do trabalho de parto, incentivo ao aleitamento materno, além de desenvolver na parturiente uma percepção positiva desse processo. 
Sabe-se a importância do acompanhante, no entanto tal presença faz-se ainda bastante limitada devido sua recusa por parte de alguns profissionais e instituições que veem o acompanhante como obstáculo e também as mulheres por não conhecerem seus direitos e não lutarem por ele. Percebe-se, todavia uma tímida mudança nesses últimos anos.

A musicoterapia tem a função de reduzir e/ou anular a dor pela ação do som. Tabarro et al. (2010) citaram a musicoterapia como tecnologia não invasiva de cuidado, em seus estudos foram relatados efeitos como alívio da dor durante as contrações, auxílio na diminuição da tensão e do medo, ambientalização da parturiente no hospital, estímulo à oração e à espiritualidade. Essas condições possibilitaram que a parturiente experimentasse um estado de relaxamento mais eficaz nos intervalos das contrações, levando a uma evolução mais amena e eutócica do trabalho de parto, elevando na mulher o limite de tolerância à dor e ao desconforto.

A deambulação é considerada não só um estimulante para o progresso do trabalho de parto, mas também alternativa não farmacológica para alívio da dor (SESCATO; SOUZA; WALL, 2008). A Enfermagem na saúde da mulher, na área obstétrica, se identifica com os principais preceitos de humanização da assistência obstétrica e objetiva amenizar a dor, com a utilização de recursos não farmacológicos, melhorar o conforto físico, viabilizar a aquisição de posturas verticais e a diversificação postural, além de contribuir para interação entre a equipe de saúde, o acompanhante e a parturiente.

\section{CONSIDERAÇOES FINAIS}

Constatou-se o predomínio da posição supina no trabalho de parto e parto anterior, a mulher restrita ao leito, somente em decúbito dorsal. A posição antifisiológica confortável ao profissional, mais acessível às práticas intervencionistas, apresentou-se em alguns relatos; foram citados o Kristeller, a episiotomia e o mal uso do fórceps, recordados de forma inesperada no estudo.

Em relação à vivência atual no trabalho de parto e parto evidenciou-se a mulher exercendo seu papel de protagonista assumindo sua autonomia e liberdade, ativa no processo. Percebeu-se nos relatos as mais variadas modalidades de posição 
durante trabalho de parto e parto, as entrevistadas mostraram-se favoráveis às posições verticais, destaque para as tecnologias não invasivas de cuidado, a participação do enfermeiro obstetra envolvido e disposto em oferecer terapias não farmacológicas para o alívio da dor e também atuante ao processo de verticalização, respeitando a fisiologia do parto normal.

\section{REFERÊMCIAS}

AMERICAN COLLEGE OF OBSTETRICIANS- GYNECOLOGY (ACOG). Practice Bulletin. Episiotomy. Clinical Management Guidelines for Obstetrician- Gynecologists. Number 71, April 2006. Obstet Gynecol. v.107, n. 4, p:957-62, 2006.

AMORIM, M.M.R.; PORT, A.M.F.; SOUZA, A.S.R. Assistência ao segundo e terceiro períodos do trabalho de parto baseada em evidências. Femina. v.38, n.11, p: 583-91, 2010.

BALASKAS J. Parto ativo: guia prático para o parto natural. 2. ed. - 2. Reimpr. São Paulo: Ground, 2014.

BARROS, S.M.O. Enfermagem obstétrica e ginecológica: guia para a prática assistencial. - 2. ed. - São Paulo: Roca, 2009.

BRASIL. Ministério da Saúde. Curumim G (ONG). Trabalhando com parteiras tradicionais. Brasília (DF): MS/ Grupo Curumim; 2000.

BRASIL. Ministério da Saúde. Parto, aborto e puerpério: assistência humanizada à mulher. 0 controle da dor no trabalho de parto. Brasília: Ministério da Saúde, 2001.

BRASIL. Ministério da Saúde. Parto e nascimento domiciliar assistidos por parteiras tradicionais: o programa trabalhando com parteiras tradicionais e experiências exemplares. Brasília: Editora do Ministério da Saúde, 2010.

BRASIL. Ministério da Saúde. Secretaria de Ciência, Tecnologia e Insumos Estratégicos. Departamento de Gestão e Incorporação de Tecnologias em Saúde. Diretrizes nacionais de assistência ao parto normal: versão resumida [recurso eletrônico] Brasília: Ministério da Saúde, 2017.

CARON, O.A.F.; SILVA, I.A. Parturiente e equipe obstétrica: a difícil arte da comunicação. Rev. Latino-American. Enferm. v.10, n.4, p:485-92, 2002.

DAMACENO DC. A importância do parto humanizado: atenção da equipe de Enfermagem. FACIDER Revista Científica. n. 07, 2015. 
DINIZ, S.G.; CHACHAM, A.S. "The cut above" and "the cut below": the abuse og cesareans and episiotomy in São Paulo, Brazil. Reprod Health Matters. v.12, n.23, p:100-10, 2004.

GALLO, R.B.S. et al. Recursos não-farmacológicos no trabalho de parto: protocolo assistencial. Femina, v.39, n. 1,p:41-48, 2011.

GAYESKI, M.E.; BRUGGEMANN, O.M. Métodos não farmacológicos para alívio da dor no trabalho de parto: uma revisão sistemática. Texto contexto - enferm.,v. 19 , n. $4,2010$.

GUPTA, J.K.; HOFMEYR, G.J. Position for women during second stage of labour. Cochrane Database Syst Rev. v.1, p: CD002006, 2004.

HOFMEYR, G.J. Evidence-based intrapartum care. Best Pract Res Clin Obstet Gynaecol. v.19, n.1, p: 103-15, 2005.

HODNETT, E.D. et al. Continuous support for women during childbirth. Cochrane Database Syst Rev. v.7, n.7, p: CD003766, 2017.

LAWRENCE, A et al. Maternal positions andmobility during first stage labour. Cochrane Database Syst Rev. v.15, n.2, CD003934, 2010.

LOWDERMILK, D.L.; PERRY, S.E.; BOBAK, I.M. O cuidado em enfermagem materna. 5. ed. Porto Alegre: Artmed editora, 2002.

MALDONADO, M.T. Psicologia da gravidez: Parto e puerpério. Petrópolis (RJ): Vozes; 1991.

MELLO, L.F.D.; NÓBREGA, L.F.; LEMOS, A. Estimulação elétrica transcutânea no alívio da dor do trabalho de parto: revisão sistemática e meta-análise. Rev. bras. fisioter. v.15,n. 3, p: 175-84, 2011.

MINAYO, M.C.S. 0 desafio do conhecimento: pesquisa qualitativa em saúde. 14. ed. - São Paulo: Hucitec, 2014.

NAGAHAMA, E.E.I.; SANTIAGO, S.M. A institucionalização médica do parto no Brasil. Ciência e saúde coletiva., v.10, n.3, p: 651-657, 2005.

ODENT, M. A cientificação do amor. 2. ed. Florianópolis: Saint Germain, 2002.

ORGANIZAÇÃO MUNDIAL DE SAÚDE (OMS). Maternidade segura. Assistência ao parto normal: um guia prático. Genebra, 1996.

OLIVEIRA, A.D.D. et al. Sentimentos e opiniões de mulheres que vivenciaram a experiência do parto humanizado no Hospital Santa Lucinda. Revista da Faculdade de Ciências Médicas de Sorocaba, v.16, n.1, p. 26-29, 2014. 
O’MAHONY, F.; HOFMEYR, G.J.; MENON, V. Choice of instruments for assisted vaginal delivery. Cochrane Database Syst Rev. v.10, n.11, CD005455, 2010.

OSAVA, R.H. Estudo das representações do parto entre enfermeiras de maternidade do Município Paulista [dissertação de mestrado]. Ribeirão Preto (SP): Escola de Enfermagem de Ribeirão Preto / USP; 1990.

SANTOS, V.S.C. Parto vertical: vivência do casal na dimensão cultural no processo de parir. Florianópolis (SC): Cidade Futura; 2002. p. 25-28.

SILVEIRA, I.P.; CARVALHO, F.A.M. Conhecimento das mulheres sobre posições para o parto normal. Rev. RENE. v. 4, n. 1, p. 36-39,2003.

SESCATO, A.C.; SOUZA, S.R.R.K.; WALL, M.L. Os cuidados não farmacológicos para alívio da dor no trabalho de parto: orientações da equipe de enfermagem. Cogitare Enferm. v.13, n.4, p: 585-90, 2008.

SILVA, R.C. et al. 0 discurso e as prática do parto humanizado de adolescentes. Revista Texto Contexto Enfermagem, v. 22, n. 3, p. 629-636, 2013.

TABARRO, C.S. et al. Efeito da música no trabalho de parto e no recém-nascido. Rev Esc Enferm USP. v.44, n. 2, p:445-52, 2010.

WORLD HEALTH ORGANIZATION (WHO). Managing Complications in Pregnancy and Childbirth. A guide for midwives and doctors. Geneva: Department of Reproductive Health and Research; 2003. 


\title{
MODAUIDADES DE POSICCAOO MATERNA DURANTEO TRABALHO DEPARTO EPARTO NORMAL
}

DDI: 10.51859/amplla.esp917.1121-9

Bruna Maria de Moura Soares ${ }^{1}$

Tatiana Maria Melo Guimarães ${ }^{2}$

Fernanda de Moura Soares ${ }^{3}$

Márcia Teles de Oliveira Gouveia ${ }^{3}$

Samila Gomes Ribeiro ${ }^{3}$

Priscilla Cavalcante Lima 4

\author{
${ }^{1}$ Mestranda em Saúde da Mulher. Mestrado Profissional em saúde da mulher - UFPI \\ 2Docente de enfermagem. Centro Universitário Santo Agostinho - UNIFSA \\ ${ }^{3}$ Mestre em Saúde do Adulto e da Criança. Centro Universitários Cristus \\ ${ }^{3}$ Docente. Universidade Federal do Piauí - UFPI \\ 3Docente. Universidade Federal do Piauí - UFPI \\ ${ }^{4}$ Doutoranda. Programa de Pós- Graduação em Enfermagem - UFPI
}

\section{RESUMO}

Nas últimas décadas, a crescente desilusão com a aplicação rotineira da alta tecnologia obstétrica fez com que pesquisadores internacionais começassem a explorar a fisiologia normal do parto. Deste modo, as evidências científicas nos últimos cinquenta anos, mostram as vantagens fisiológicas da posição vertical no trabalho de parto e parto, comprovando que certos princípios físicos aplicáveis ao parto, são negados, ou mesmo anulados, quando um parturiente adota a posição horizontal. 0 trabalho objetiva descrever a percepção das puérperas quanto aos benefícios e contribuições das modalidades de posição materna vivenciadas durante o trabalho de parto e parto e identificar a satisfação das puérperas em relação a assistência durante o processo de parturição. Trata-se de um estudo de abordagem qualitativa, realizado em uma maternidade pública de Teresina-PI. Foram entrevistadas treze puérperas, cujos relatos foram analisados segundo análise de conteúdo. Os resultados evidenciaram a real influência da verticalização no processo de trabalho de parto e parto. Em relação a satisfação da puérpera quanto ao profissional notou-se no parto anterior a presença do médico, as entrevistadas relataram de um modo geral como um bom atendimento; já no parto atual, com o enfermeiro obstetra, as pacientes revelaram maior satisfação pela maior vinculação, orientações e cuidados. Sugere-se novas pesquisas devido a carência de publicações sobre a temática e adoção de protocolos assistenciais baseados em evidências científicas.

Palavras-chave: Parto normal; Modalidades de posição; Enfermagem obstétrica. 
Acredita-se que o conhecimento das mulheres acerca do parto normal e da prática de se posicionarem para dar à luz venha de experiências tradicionais, relacionadas com a cultura e resultante dos conhecimentos passados de geração em geração (SILVEIRA; CARVALHO, 2003). Evidências etnológicas demonstraram que tribos primitivas adotavam diferentes posições para o parto, de acordo com seus instintos. Esses estudos destacam a fisiologia do parto, além de um número significativo de vantagens quanto à prática antiga, em que as mulheres pariam nas posições verticalizadas, elas assumiam várias posturas em diferentes momentos do trabalho de parto e parto (BALASKAS, 2014).

No entanto, com a institucionalização do parto no século XX a posição litotômica passou a ser considerada mais adequada para a realização dos procedimentos hospitalares e adotada como clássica para o nascimento, naquele momento a cultura hospitalar aderiu à posição horizontal como única para o parto (BALASKAS, 2014). Assim, as mulheres foram bruscamente deslocadas do aconchego do seu lar e da companhia dos seus familiares para um ambiente frio e impessoal, em que, na maioria das vezes, profissionais desconhecidos submetiam a posição do parto segundo suas conveniências, desapropriando as mulheres de exercerem sua maternidade de forma livre.

0 modelo tecnocrático, norteado pela assistência intervencionista, foi questionado no Brasil a partir da década de 1990 com a implantação da Política de Humanização do Parto e Nascimento. Sob as diretrizes dessa política e dos movimentos sociais, muitos enfermeiros, mesmo no âmbito hospitalar, começaram a estimular as mulheres quanto as posições verticalizadas no momento do parto. As posições verticalizadas, além de favorecerem em muitos aspectos o parto fisiológico, ainda representam o protagonismo feminino em contrapartida à passividade histórica imposta à parturiente, durante o processo de medicalização e institucionalização do parto (MOURA, 2005).

Nas últimas décadas, a crescente desilusão com a aplicação rotineira da alta tecnologia obstétrica fez com que pesquisadores internacionais começassem a explorar a fisiologia normal do parto. Deste modo, as evidências científicas nos últimos cinquenta anos, mostram as vantagens fisiológicas da posição vertical no 
trabalho de parto e parto, comprovando que certos princípios físicos aplicáveis ao parto, são negados, ou mesmo anulados, quando um parturiente adota a posição horizontal. Diversas vantagens são mencionadas a tomada de posturas verticais durante o processo de parturição, como: maior intensidade, regularidade e frequência das contrações uterinas; dilatação uterina mais eficiente; pressão maior exercida pela apresentação fetal; menor duração do primeiro e segundo períodos do trabalho de parto; maior disposição, menor estresse e menor sensação de dor; menor incidência de sofrimento fetal durante o parto e melhores condições do nascituro; a mulher assume seu real protagonismo (BALASKAS, 2014).

Diante do exposto, este estudo tem como objetivo descrever a percepção das puérperas quanto aos benefícios e contribuições das modalidades de posição materna vivenciadas durante o trabalho de parto e parto e identificar a satisfação das puérperas em relação a assistência durante o processo de parturição.

\section{REFERENCIAL TEÓRICO}

Durante o parto, é imprescindível que a contração uterina seja eficiente, que ocorra um encaixe adequado do feto e que haja possibilidade de boa mobilidade pélvica, a posição materna é um quarto fator que complementa esses anteriores. Associados aos fatores supracitados, acrescenta-se o efeito da força de gravidade. Dependendo da posição adotada, pode haver vantagem ou desvantagem no mecanismo do trabalho de parto, por alterar o efeito da gravidade e sua relação com as partes do corpo que são importantes para a progressão do trabalho de parto (MIQUELUTTI, 2006).

Desse modo, a permanência da mulher na posição horizontal, imposta pelo modelo assistencial implantado nos hospitais, constitui uma limitação importante da liberdade corporal, considerada essencial para o bom desenvolvimento do parto (ODENT, 2002).

Atualmente, o Ministério da Saúde preconiza a assistência humanizada ao parto, de modo que a mulher deve conduzir seu próprio processo de parto, respaldada por orientações fundamentadas em informações válidas e confiáveis acerca das possíveis vantagens relativas ao bem-estar materno e fetal e das diferentes posições maternas adotadas durante o trabalho de parto e parto. No 
entanto, ainda são escassos os dados sobre as experiências das mulheres brasileiras que realizaram partos nas diversas modalidades de posição, e sobre a relação dessas com a vivência do processo de parturição, por isso também se revela o interesse pelo estudo da temática, considerando a apreciação da mulher.

Somente o repercutir, o refletir de cada experiência vivida pela parturiente com o profissional e a instituição que a assisti permiti a ela comunicar seus sentimentos a quem a ela escuta. Este momento vivido rompe o ritmo habitual da sua existência, produz descontinuidade suficiente para lançar nova luz sobre o mundo. Assim, é necessário fazer com que essa mulher saia do silêncio, produza um sentimento e um significado através da própria comunicação (BARROS, 2008).

\section{METODOLOGIA}

Trata-se de um estudo exploratório descritivo de abordagem qualitativa, realizado em uma maternidade pública de referência obstétrica na esfera administrativa estadual localizada na capital Teresina.

Participaram do estudo treze mulheres no puerpério imediato de parto via vaginal e, que se enquadraram nos critérios da pesquisa: pacientes maiores de dezenove anos, multíparas com parto anterior via vaginal, com gestação de risco habitual e parto conduzido por enfermeiro obstetra; que no puerpério imediato encontravam-se em alojamento conjunto.

A produção dos dados aconteceu em três momentos: inicialmente houve uma breve apresentação sobre os objetivos da pesquisa para possível aceitação e assinatura do termo de consentimento livre e esclarecido; em seguida apresentouse à puérpera um cartaz para identificação visual das modalidades de posição para melhor assimilação das práticas posturais vivenciadas; posteriormente realizou-se uma entrevista semiestruturada no intuito de conhecer as experiências e percepções das mulheres sobre as modalidades de posição vivenciadas durante o trabalho de parto e parto, frente à assistência recebida, fazendo um comparativo entre parto anterior e atual. Após as entrevistas as mulheres foram orientadas sobre os cuidados gerais em relação ao puerpério e ao nascituro a partir de folder educativo produzido pelas pesquisadoras. 
0 roteiro de entrevista foi dividido em caracterização, história obstétrica e entrevista propriamente dita. As entrevistadas foram caracterizadas quanto as variáveis idade, ocupação/profissão, situação conjugal e naturalidade. Referente a história obstétrica identificou-se paridade, tipos de parto realizados, número de consultas pré-natal, profissional que realizou o pré-natal, participação em curso para gestantes e orientação em relação as variedades de posição materna durante o trabalho de parto e parto.

A coleta de dados ocorreu no período de maio a julho de 2015, nos turnos matutino e vespertino. Os encontros foram realizados no setor de alojamento conjunto, da referida maternidade. Para garantir a facilidade e impedir a perda de importantes informações coletadas, as entrevistas foram gravadas em formato $\mathrm{Mp3}$ Player.

Para a análise dos resultados foi aplicada a técnica de análise de conteúdo, que se estrutura em três etapas: pré-analise, exploração do material, e tratamento e interpretação dos resultados (MINAYO, 2008). Para resguardar e garantir o anonimato das participantes, as entrevistas foram codificadas como a abreviatura de entrevistadas (EN) seguida do número referente a ordem das entrevistas.

Os princípios éticos foram respeitados conforme a Resolução no 466/2012 e resoluções complementares do Conselho Nacional de Saúde, assim a pesquisa obteve aprovação do Comitê de Ética e Pesquisa da Universidade Federal do Piauí por meio da CAAE 44437615.9.0000.5214.

\section{RESULTADOS E DISCUSSÃO}

No que se refere a caracterização das puérperas entrevistadas, a idade variou entre 20 e 32 anos, em sua maioria eram profissionais do lar, em união estável e procedentes do estado do Piauí. Com relação a história obstétrica a maior parte eram tercigestas, com partos vaginais, apenas uma relatou cirurgia cesariana em partos anteriores; realizaram entre cinco e 12 consultas de pré-natal, estas intercaladas com enfermeiros e médicos; apenas uma entrevistada participou de curso para gestante e somente esta foi orientada quanto modalidades de posição materna durante trabalho de parto e parto. 
Diante da análise dos depoimentos apreendeu-se as seguintes categorias temáticas: Benefícios e contribuições das modalidades de posição materna para progressão do trabalho de parto e parto e Satisfação das puérperas em relação a assistência no processo de parturição, que a seguir serão apresentadas e discutidas a luz do referencial teórico.

\subsection{BENEFICIOS E CONTRIBUIÇOES DAS MODALIDADES DE POSIÇÃO MATERNA PARA PROGRESSÃO DO TRABALHO DE PARTO E PARTO}

Durante as entrevistas insurgiram nas falas as vantagens do processo de verticalização do trabalho de parto e parto. As mulheres revelaram, através das orientações assistenciais do enfermeiro obstetra e a partir da percepção quanto prática vivenciada, os benefícios e contribuições das modalidades de posição materna.

A EN01 refere alguns destes benefícios, citando auxílio na descida da apresentação e aumento das contrações; relaciona ainda a importância dos exercícios posturais para a evolução do parto normal, alegando o contrário à realização da cesariana. Já a EN12 atribui à posição vertical, de cócoras, maior confiança, melhor puxo e velocidade do período expulsivo. Assim desvelados:

Eu gostei demais, eles sempre falavam desses movimentos pra gente fazer mesmo sem dor, mesmo com pouca dilatação porque ajudava a descer, ajudava a ter dor, ajuda a ter contração, a gente não faz por preguiça, mas depois que eu fiz eu vi que era bom [...] É bom continuar, vocês tentando ajudar porque Ave Maria isso aí é ótimo, eu tava falando para outra menina "umbora mermã fica nessa bola, no cavalo" porque ela acabou tendo que ir pro cesáreo, porque ela não caminhava só deitada todo tempo, ela só ficava do lado esquerdo porque disseram que era bom... (EN01)

Fiquei de cócoras segurando o ferro botando força, foi questão de minutos ele saiu, aí ela botou ele em cima de mim [...] Porque além da posição que eu tava, elas me passaram confiança e assistência também, aí isso fez com que eu confiasse mais e botasse força [...] A posição ajudou porque eu achei mais rápido. (EN12)

A mulher quando deixa-se guiar pelo seu instinto mamífero, ela usa o córtex primitivo e procura movimentar-se seguindo o ritmo das contrações, movendo a pelve para frente e para trás, de um lado para o outro ou em movimentos circulares. Esses movimentos servem para facilitar o encaixe, a descida e a rotação do feto no canal de parto e ajudam a minimizar a dor, pois liberam naturalmente um coquetel 
de hormônios, dentre os quais a ocitocina e endorfina, o denominado "coquetel do amor" (ODANT, 2002).

De acordo com o "The Cochrane Pregnancy and Childbirth Group", uma fonte de informação reconhecida mundialmente, relacionada aos cuidados com base em evidências científicas, o uso de qualquer posição vertical ou deitada de lado, comparado com posições de supina ou litotomia está associada com os seguintes resultados: reduz a duração da segunda fase do trabalho de parto; pequena redução na necessidade de intervenção no parto; reduz os relatos de dores fortes; menor padrão de anomalia dos batimentos cardíacos fetal; um ligeiro aumento nas lacerações de $2^{\circ}$ grau (somente no grupo de posição vertical); um aumento na perda de sangue estimada(BIO, BITTAR, ZUGAIB, 2006).

Acrescenta-se ainda que, a posição de decúbito dorsal pode causar redução de pressão sanguínea da mulher em trabalho de parto e reduzir o fluxo sanguíneo para o bebê, devido ao peso que o útero exerce sobre as principais veias que aportam o fluxo de sangue, uma vez que a posição de litotomia, a mulher faz força contra a gravidade (ENKIN, et al, 2000).

Uma entrevistada menciona as orientações quanto as mudanças posturais, as diversas opções ofertadas, o direito pela livre escolha da posição de parir e enfatiza a contribuição destas para a progressão do trabalho de parto e parto. Em contraponto, outra entrevistada condena o decúbito dorsal, a limitação de movimento, a falta de informação e assistência omissa em gestação anterior. Confronta suas experiências e cita o auxílio das modalidades de posição em contrapartida à posição supina desfavorável ao desenvolvimento do parto fisiológico. Como evidenciam os depoimentos:

Ensinaram que eu podia sentar na bola, várias etapas assim, vários procedimentos, ficar agachada em cima da cama, várias posições, mas da qual eu escolheria a que eu pudesse no momento praticar, fazer a posição, aí graças a Deus ajudou muito [...] Mas graças a Deus ocorreu tudo bem, graças a essa opções de [...], que agora tem as opção de parto, você escolhe do jeito que quer ter a criança. E que ajuda mesmo e é verdade, ajuda muito, aí ficou tudo melhor. (EN08)

Outro parto não teve nem comparação desse, porque como eu era inexperiente, era a primeira gravidez eu só ficava mesmo deitada e aí é que a do vinha mais forte, $e$ eu não fazia nenhum outro tipo de movimento [...] foi demorado o parto [...] eu não tive 
esses outros movimentos e não me explicaram também o que tinha que ser feito [...] Eu sofri bastante porque era só deitada, não fazia mais nada e é melhor caminhar e fazer esses outros movimentos [...] Deitada de perna pra cima, deitadona mesmo, dificultou bastante. (EN10)

0 corpo em movimentação ativa constitui instrumento que oferece à parturiente um melhor manejo do parto normal, facilitando sua progressão. Esse recurso também proporciona o aumento da tolerância da dor e diminuição da duração da fase ativa do trabalho de parto (BIO, BITTAR, ZUGAIB, 2006).

Ao considerar a melhor evidência científica disponível, as posições verticais são vantajosas, reduzindo a duração do período expulsivo e a queixa de dor severa durante o mesmo, o número de partos operatórios, a necessidade de episiotomia e o número de alterações no batimento cardíaco fetal (GUPTA; HOFMEYR, 2004).

Todas as vantagens descritas colocam a mulher como protagonista do evento do parto, podendo influenciar positivamente sua percepção sobre a experiência que, resguardado o bem-estar materno e fetal, deve ser mais valorizada do que o suposto incômodo referido por alguns profissionais que resistem a assistir o parto na posição vertical (TEIXEIRA; PEREIRA, 2006).

Para haver mudança, é necessário romper com práticas que estão cristalizadas na atuação profissional, sendo imprescindível uma disposição para aceitar o novo e buscar soluções adequadas ao melhor cuidado. Nesse sentido, a prática baseada em evidências científicas, identificada como referencial apoiado na pesquisa clínica e na epidemiologia, representa uma tendência que vem ganhando espaço e adesão crescentes na área da saúde materna e perinatal. Em consonância às evidências científicas, a verticalização do trabalho de parto e parto é favorável ao desenvolvimento e progressão do processo parturitivo Cada vez mais, na prática cotidiana das enfermeiras obstétricas, a mulher vem adquirindo liberdade de expressão corporal. Tal fato evidencia o reconhecimento deste conjunto de vantagens divulgado sobre a posição vertical. Assim, uma vez oferecida a oportunidade, as mulheres escolhem a posição que desejam além do decúbito dorsal (MOURA et al., 2008). 


\subsection{SATISFAÇÃO DAS PUÉRPERAS EM RELAÇÃO A ASSISTÊNCIA NO PROCESSO DE PARTURIÇÃO}

Em razão do comparativo entre os partos anterior e atual, obtive-se duas distintas vivências em relação ao processo parturitivo, quanto a assistência profissional, decorreu-se na primeira experiência maior participação dos médicos e na segunda somente a participação assistencial de enfermeiras obstetras, por este ser um dos critérios de inclusão da pesquisa. Dessa forma analisou-se separadamente o grau de satisfação das parturientes nos dois momentos questionados.

No parto anterior doze das puérperas foram assistidas por médico apenas uma por enfermeira. Apesar de relatarem o pouco contato e a não formação de vínculo, todas as entrevistadas caracterizaram de forma positiva, através de respostas curtas e diretas, sua satisfação em relação ao profissional e sua assistência, mesmo não demonstrando grande contentamento.

Eu gostei porque ele não foi ignorante, passou tranquilidade para mim. (EN01)

Muito atencioso e paciente também (EN07), (EN11)

Achei bom o atendimento, só que eles não chegaram a conversar comigo assim não, foi rápido, não deu tempo ter aquele contato não. (EN12)

Enfermeira. Eu gostei do trabalho dela. Ela soube me atender bem. Falou comigo normal, conversou comigo, mandou eu não me desesperar, soube conversar Comigo. (EN13)

Já em relação ao parto atual conduzido por enfermeiro obstetra, os relatos foram também mencionados positivamente, no entanto de forma mais calorosa e até mesmo, por vezes, entusiástica como nota-se nas falas.

Foi bom, ela me ajudou bastante, ela muito educada, gostei. As enfermeiras conversavam, botavam pra caminhar, botou música, aí a gente vai relaxando mais, foi melhor este daqui (comparando o parto anterior com o atual). (EN06)

Gostei, foi bom [...] a menina direto comigo, conversando [...] As enfermeira dando apoio, fazendo massagem nas minhas costa, tinha até uma musiquinha alegrando o ambiente, tirando a tensão. A tensão que eu digo assim o clima tenso do momento. Foi boa, ele ficou direto aqui não saiu pra nada. Fui bem assistida. (EN07)

Foi bom, muito bom mesmo, eu fiquei na mão de pessoa maravilhosa que me ajudaram, me deram a maior força, eu num tenho nem o que dizer assim, foi muito 
bom. Pegaram na minha mão [...] num tenho nada que reclamar de jeito nenhum e nem o que falar das meninas [enfermeiras] que foram excelentes todas. Foi melhor que o primeiro porque eu não tive aquele contato, conversando uma pegava na minha mão, a outra na outra mão, foi totalmente diferente, a outra não foi assim, eu gostei mais desse. (EN12)

Ressalva-se a importância atribuída a permanência do profissional no ambiente da assistência. Ficar com a paciente durante o transcorrer do trabalho parturitivo é considerado um dos princípios básicos da assistência obstétrica. A palavra obstetrícia vem do latim obstare, que significa estar ao lado. Os benefícios dessa prática foram percebidos no presente estudo, visto que a mulheres expressaram sentimentos de contentamento, segurança e bem estar decorrentes desse apoio físico e emocional.

O acompanhamento contínuo das parturientes pelos enfermeiros obstetras representou uma experiência satisfatória. A presença dos profissionais significa uma rede de suporte importante para minimizar sentimentos de medo, dor, sofrimento, ansiedade pelas mulheres durante o trabalho de parto e parto (GUPTA; HOFMEYR, 2010).

Além da permanência contínua, a forma de estabelecer comunicação, o respeito, a paciência e o carinho demonstrados pelos profissionais foram considerados atributos de um bom atendimento. 0 relacionamento interpessoal que envolve vários aspectos, deve fazer parte da formação dos profissionais de saúde. 0 cuidado considerado satisfatório consistiu, entre outros aspectos, no estabelecimento de uma relação simpática e a educação demonstrada pelos profissionais no trato com as parturientes (PARADA; TONETE, 2008).

Assim, a prática de cuidado desenvolvida mediante a presença desses atributos, além dos esclarecimentos em relação aos procedimentos utilizados e a valorização da participação ativa no parto por meio do estabelecimento de comunicação terapêutica, gerou a sensação de confiança e promoveu a qualidade da assistência, segundo a perspectiva das parturientes (CARON; SILVA, 2002).

A disposição em aceitar o novo e buscar soluções adequadas para o melhor cuidado é imprescindível. 0 profissional que opta pela mudança em sua prática se torna agente de uma mudança mais ampla no modelo de atenção e no paradigma que lhe dá sustentação (SILVEIRA; RIESCO, 2008) 
Portanto, a enfermagem é a única profissão no campo da saúde que pode mover-se até a síntese de mente e corpo, comunidade e sociedade, tecnologia e humanismo. Nessa linha de pensamento, o enfermeiro deve demonstrar, em sua atitude profissional, o respeito pelo ser humano, proporcionando-lhe a liberdade de expressão, estabelecendo uma relação de empatia, sobretudo, mostrando interesse por sua situação (FOLTA, 1975) assim como foi explícito no cuidar e envolvimento do enfermeiro obstetra para com as parturientes.

\section{CONCLUSÃO}

Os resultados do estudo evidenciam a real influência da verticalização no processo de trabalho de parto e parto de acordo com a percepção das mulheres. As entrevistadas indicaram as contribuições das posições verticais para evolução do trabalho de parto e parto, mencionando vantagens na descida da apresentação, aumento das contrações, menor duração do período expulsivo, melhor força no puxo. Acredita-se que essas informações devam ser disponibilizadas às mulheres, de forma a capacitá-las para estas práticas, bem como a familiarizá-las com as mesmas, uma vez que essa consciencialização pode contribuir para a tomada de decisão e definição do seu plano de parto, no sentido de definir as escolhas a fazer para ter o parto que idealiza e deseja, como um resgate ao natural.

Em relação a satisfação da puérpera quanto ao profissional e a assistência por ele prestada durante o processo de parturição notou-se no parto anterior a presença do profissional médico, as entrevistadas relataram de um modo geral como um bom atendimento, no entanto objetivo, direto, sem estabelecimento de contato ou envolvimento. Todavia, no parto atual com a atuação do enfermeiro obstetra as mulheres se mostraram mais satisfeitas devido a maior aproximação, vínculo, destacaram o estar ao lado, o toque terapêutico, as orientações e cuidados, até mesmo o incentivo as tecnologias não invasivas para o alívio da dor.

Quanto as implicações para a prática da assistência obstétrica e melhor desenvolvimento do trabalho de parto e parto recomenda-se que as mulheres sejam orientadas sobretudo durante o pré-natal em relação as modalidades de posição materna que podem ser realizadas durante o processo de parturição, minimizando assim a gama de informações dispensadas à parturiente, muitas vezes não 
absorvidas devido à instabilidade emocional e cognitiva desse momento. Sugere-se ainda novas pesquisas devido a carência de publicações sobre a temática, além da adoção de protocolos assistenciais baseados em evidências científicas para melhor aceitação e aplicabilidade por parte dos profissionais.

\section{REFERÊMCIAS}

BALASKAS J. Parto ativo: guia prático para o parto natural. 2. ed. - 2. Reimpr. São Paulo: Ground, 2014.

BARROS, M.A. Enfermagem obstétrica e ginecológica: guia para a prática assistencial. São Paulo: Roca, 2008.

BIO, E.; BITTAR, R.E.; ZUGAIB, M. Influência da mobilidade materna na duração da fase ativa do trabalho de parto. Rev Bras Ginecol Obstet. v.28, n.11, p: 6719, 2006.

CARON, O.A.F.; SILVA, I.A. Parturiente e equipe obstétrica: a difícil arte da comunicação. Rev. Latino-American. Enferm. v.10, n.4, p:485-92, 2002.

ENKIN, M. et al. A guide to effective care in pregnancy and childbirth. New York: Oxford University Press. 2000.

FOLTA, R.J. Humanização dos serviços e o uso da tecnologia na assistência à saúde. São Paulo: Enf. Novas Dimens., 141-6, 1975.

GUPTA, J.K.; HOFMEYR, G.J. Position for women during second stage of labour. Cochrane Database Syst Rev. v.1, p: CD002006, 2004.

MINAYO, M.C.S. O desafio do conhecimento: pesquisa qualitativa em saúde. 14. ed. - São Paulo: Hucitec, 2014.

MIQUELUTTI, M.A. Avaliação da posição vertical durante o trabalho de parto em nulíparas [dissertação de mestrado] Campinas (SP): Faculdade de Ciências Médicas da Universidade Estadual de Campinas; 2006.

MOUTA, R.J.O. et al. Relação entre posição adotada pela mulher no parto, integridade perineal e vitalidade do recém-nascido. Rev. enferm. UERJ. v.16, n.4, p: 4726, 2008.

MOURA, F.M.J.S.P. Relatos de mulheres sobre a gestação e o parto normal: implicações para a assistência de enfermagem. 2005. 104f. Dissertação de mestrado (Mestrado em Enfermagem) - Universidade Federal do Piauí, Teresina, 2005.

ODENT, M. A cientificação do amor. 2. ed. Florianópolis: Saint Germain, 2002. 
PARADA, C.M.G.L.; TONETE, V.L.P. 0 cuidado em saúde no ciclo gravídico puerperal sob a perspectiva de usuárias de serviços públicos. Interface Comum Saúde Educ. v.12, n.24, p: 3546, 2008.

PROENF. Proenf: Saúde materna e neonatal. Programa de atualização em enfermagem. Ciclo 1. Módulo 1. Porto Alegre: Artmed, 2009.

SILVEIRA, I.P.; CARVALHO, F.A.M. Conhecimento das mulheres sobre posições para o parto normal. Rev. RENE. v. 4, n. 1, p. 36-39,2003.

TEIXEIRA, N.Z.F.; PEREIRA, W.R. Parto hospitalar: experiência de mulheres da periferia de Cuiabá-MT. Rev Bras Enferm. v.59, n.6, p:740-4, 2006. 


\section{CUIDADOS DA EQUIPEDE SAÚDE AO ALETTAMENTO MATERNO EM TEMPOS DE COUID-19: REVISÃO DE ESCOPO}

DDI: 10.51859/amplla.esp917.1121-10

Andressa Maria Laurindo Souza ${ }^{1}$

Amanda Lúcia Barreto Dantas ${ }^{2}$

Marcelo Victor Freitas Nascimento ${ }^{3}$

Silvana Santiago da Rocha ${ }^{4}$

${ }^{1}$ Enfermeira, residente em Enfermagem Obstétrica. Universidade Federal do Piauí - UFPI

2 Enfermeira, doutoranda em Enfermagem - UFPI, docente e coordenadora da Residência em Enfermagem Obstétrica - UFPI

${ }^{3}$ Enfermeiro, doutorando em Enfermagem - UFPI, docente da Residência em Enfermagem Obstétrica - UFPI

${ }^{4}$ Enfermeira, pós-doutorado em Enfermagem pela Universidade Federal do Ceará - UFC, docente de graduação e pós graduação em Enfermagem (mestrado e doutorado) pela Universidade Federal do Piauí - UFPI

\section{RESUMO}

Objetivou-se mapear a literatura cientifica sobre os cuidados da equipe de saúde ao aleitamento materno no contexto da pandemia de COVID-19. Trata-se de uma revisão de escopo com a questão norteadora: "Qual a produção cientifica sobre cuidados da equipe de saúde ao aleitamento materno em tempos de COVID-19?". A busca foi realizada no período de outubro de 2020 nas bases LILACS, CINAHL e MEDLINE. A amostra final foi de 06 artigos que foram analisados na íntegra. A partir dos resultados dos estudos, optou-se por discuti-los em duas categorias conceituais: "Risco de transmissão no aleitamento materno" e "Recomendações para evitar a transmissão e incentivar o aleitamento materno". Esta revisão apresenta um mapeamento da produção sobre a temática proposta, as principais recomendações são que devem ser feitos esforços para aconselhar e apoiar adequadamente as mães em amamentação, mesmo nos casos em que esta confirmou ou suspeitou de infecção por COVID-19.

Palavras-chave: Aleitamento materno. Infecções por corona vírus. Assistência à saúde. 
Para a Organização Mundial de Saúde (OMS) o aleitamento materno é fundamental para o estabelecimento do vínculo afetivo mãe-filho, favorece uma maior união e ligação emocional muito forte e precoce, é a estratégia isolada mais forte na prevenção da mortalidade infantil, promoção da saúde física e mental da criança e da mulher que amamenta, ele deve ser iniciado na primeira meia hora de vida, ser mantido de forma exclusiva durante os primeiros seis meses e complementado com alimentação diversificada até preferencialmente os dois anos de vida. O leite materno é o melhor alimento para o bebê pois contém em si propriedades nutricionais essenciais ao crescimento e desenvolvimento nos seus primeiros meses de vida, contém anticorpos fundamentais à prevenção de doenças frequentes na infância é completo, natural e sem custos associados. (GALVÃO, 2006; NETO, CARDOSO E OLIVEIRA, 2015; LEVI E BÉRTOLO, 2012; CORREIA, 2009; WHO, 2017).

No final do ano de 2019, foi descoberta uma doença causada por uma nova cepa do coronavírus (SARS-CoV-2), que se espalhou rapidamente para países do mundo todo, incluindo o Brasil. Em 30 de janeiro a OMS declarou Emergência de Saúde Pública Internacional, o que implica medidas de prevenção e coordenação a nível mundial, em fevereiro denominou a doença causada por este vírus de Coronavirus Disease 19 (COVID-19) e declarou como pandemia internacional no dia 11 de março de 2020. Suas manifestações mais comuns são febre, tosse e fadiga ou mialgia e dor de cabeça. Sua transmissão ocorre pela disseminação de gotículas respiratórias produzidas quando a pessoa infectada tosse, espirra ou fala, as quais podem ser depositadas diretamente em pessoas próximas ou em superfícies ou objetos contaminados não havendo até ao momento tratamento específico para esta infeção (BRASIL, 2020a; WHO, 2020a; MA et al, 2020; YANG E DUAN, 2020).

Foram identificados grupos de risco para melhor controle e atenção durante a pandemia, a exemplo de idosos, hipertensos, indivíduos com problemas respiratórios crônicos e foram incluídas as gestantes e puérperas. Segundo a Secretaria de Atenção Primária à Saúde (SAPS) as puérperas apresentam maior risco de gravidade se infectadas pelo vírus, os impactos nesse período podem ser diversos, além de alterações físicas, hormonais e emocionais inerentes a esta fase, 
soma-se ainda a mudança de hábitos em relação ao cuidado com o bebê e o aleitamento (PAZ et al, 2020; BRASIL, 2020b).

As informações sobre as apresentações clínicas da COVID-19 nos recémnascidos (RN) ainda são escassas, mas estudos apontam que os lactentes menores de um ano apresentam complicações mais graves do que as crianças mais velhas. Os RNs merecem atenção especial, visto que seu sistema imunológico ainda é imaturo, tornando-os mais suscetíveis à infecção pelo vírus. Não há evidências de transmissão vertical da SARS-CoV-2, seja pelo parto ou leite materno mas é sabido que uma mãe infectada pode transmitir o vírus através de gotículas respiratórias durante a amamentação e contato indireto com superfícies no ambiente imediato ou com objetos usados na pessoa infectada (CAO et al, 2020, DE LUCA, 2020; CDC,2020a; RASMUSSEN et al,2020, WHO, 2020c).

Segundo a OMS a amamentação protege contra a morbilidade e a morte no período pós-neonatal e durante toda a infância, seu efeito protetor é particularmente forte contra doenças infeciosas impedidas pela transferência direta de anticorpos e outros fatores anti-infeciosos, nesse sentido é recomendado a manutenção da amamentação em mães com COVID-19 desde que a mulher esteja em condições e desejo de amamentar e mediante a adoção de medidas para a redução da transmissão do vírus através de gotículas respiratórias durante o contato com a criança. Portanto as mães devem receber dos profissionais de saúde adequadamente treinados o apoio prático para iniciarem e estabelecerem a amamentação e gerirem as dificuldades comuns, bem como medidas de prevenção e controle da infeção (WHO, 2020d). Esta revisão tem por objetivo mapear a literatura cientifica sobre os cuidados da equipe de saúde ao aleitamento materno no contexto da pandemia de COVID-19.

\section{MÉTODOS}

Trata-se de uma revisão de escopo definida como uma forma de mapear os conceitos principais que dão fundamento a uma área de pesquisa por meio de um método rigoroso e transparente, o estado da arte em uma área temática, pretendendo fornecer uma visão descritiva dos estudos revisados, sem avalia-los criticamente ou sumarizar evidências de diferentes investigações, como ocorre em 
uma revisão sistemática. Dessa forma pode tanto auxiliar o revisor a examinar evidências emergentes, quando a produção científica existente é recente e ou incipiente, quanto examinar como as pesquisas estão sendo conduzidas em áreas já consolidadas. Diante da emergência do conteúdo abordado e do baixo número de evidências científicas encontradas sobre o tema, a escolha por essa metodologia ganha forças ao conseguir contemplar todo tipo de literatura científica possível, indo além de questões relacionadas apenas à eficácia de uma intervenção ou experiência com tratamentos ou cuidados (ARKEY E O'MALLEY, 2005; TRICCO et al, 2016; CORDEIRO E SOARES, 2019).

A construção da estratégia de busca foi composta pelas seguintes etapas: formulação do problema e elaboração da pergunta norteadora: "Qual a produção científica sobre cuidados da equipe de saúde ao aleitamento materno em tempos de COVID-19?". Os estudos incluídos nesta revisão de escopo foram elencados a partir da estratégia mnemônica PCC (População, Conceito e Contexto), conforme recomenda o protocolo do Instituto Joanna Briggs (JBI) para as revisões desse tipo. Para esta revisão, denominaram-se, como população, profissionais de saúde, o conceito de interesse foi o cuidado ao aleitamento materno e o contexto analisado foi COVID-19. Em seguida, foram selecionados os descritores controlados (MeSH) e não controlados (Entry Terms), por meio de consulta ao Medical Subject Headings (MeSH) (JBI, 2015).

A busca foi realizada no período de outubro de 2020 nas seguintes bases de dados: LILACS (Literatura Latino-americana e do Caribe em Ciências da Saúde), CINAHL (Cumulative Index of Nursing and Allied Health Literature ) e na MEDLINE via PubMed (NationalLibrary of Medicine), mediante o cruzamento dos seguintes (MeSH terms): "Delivery of Health care", "Health Personnel”, “COVID-19” e "Breastfeeding" e seus Entry terms (descritores não controlados), para busca na CINAHL foram utilizados os títulos CINAHL correspondentes.

Dentre os critérios de inclusão, foram selecionados estudos disponíveis com as mais variadas metodologias (estudos primários de pesquisa, revisões da literatura, editoriais e diretrizes), nos idiomas inglês, português e espanhol, publicados até setembro de 2020, que tratassem especificamente dos cuidados ao aleitamento materno no contexto da pandemia do COVID-19. Foram excluídos artigos que não se adequaram ao objetivo do estudo ou não possuíam informações 
pertinentes para a contribuição. A seleção por meio da leitura de títulos e resumos, seguido pelo acesso de textos selecionados na íntegra foi realizada por dois revisores independentes, os motivos para exclusão dos artigos lidos na integra foram registrados e relatados na presente revisão, após o consenso entre os pesquisadores. Todo o processo foi detalhado e ilustrado por meio de fluxograma especifico para a metodologia escolhida.

A qualidade metodológica dos estudos primários não foi avaliada, dado que esse aspecto não é considerado nas revisões de escopo. Porém, na extração dos dados, foi utilizado o formulário recomendado pelo JBI com o intuito de facilitar a síntese de informações e a qualidade das recomendações. Para o mapeamento das informações, a coleta de dados ocorreu por meio de um instrumento adaptado do formulário. Tal ferramenta apresenta como campos de extração: dados de publicação (ano, autores e país de publicação); objetivos de estudo; características metodológicas e principais resultados. Os resultados extraídos foram apresentados em quadro e discutidos de forma narrativa com base em classificações de categorias conceituais (ARKSEY E O'MALLEY, 2005; TRICCO et al, 2016).

\section{RESULTADOS}

$\mathrm{Na}$ busca inicial nas bases de dados foram obtidos 29 artigos potencialmente elegíveis, dentre estes nenhuma publicação estava disponível na base de dados LILACS, foram encontradas 28 publicações na base MEDLINE (via Pubmed) e 01 artigo na base CINAHL. Não foram encontradas duplicatas de estudos durante a pesquisa nas bases. Destes 29 artigos, após leitura de títulos e resumos foram excluídos 15 estudos por não se adequarem a temática proposta, dentre estes após leitura dos textos na íntegra foram selecionados 06 estudos que atendiam aos objetivos dessa revisão. Assim a amostra final foi de 06 artigos que foram lidos na íntegra e analisado por dois pesquisadores e autores desse estudo. Esse processo de elegibilidade é demonstrado na Figura 1 a seguir. 


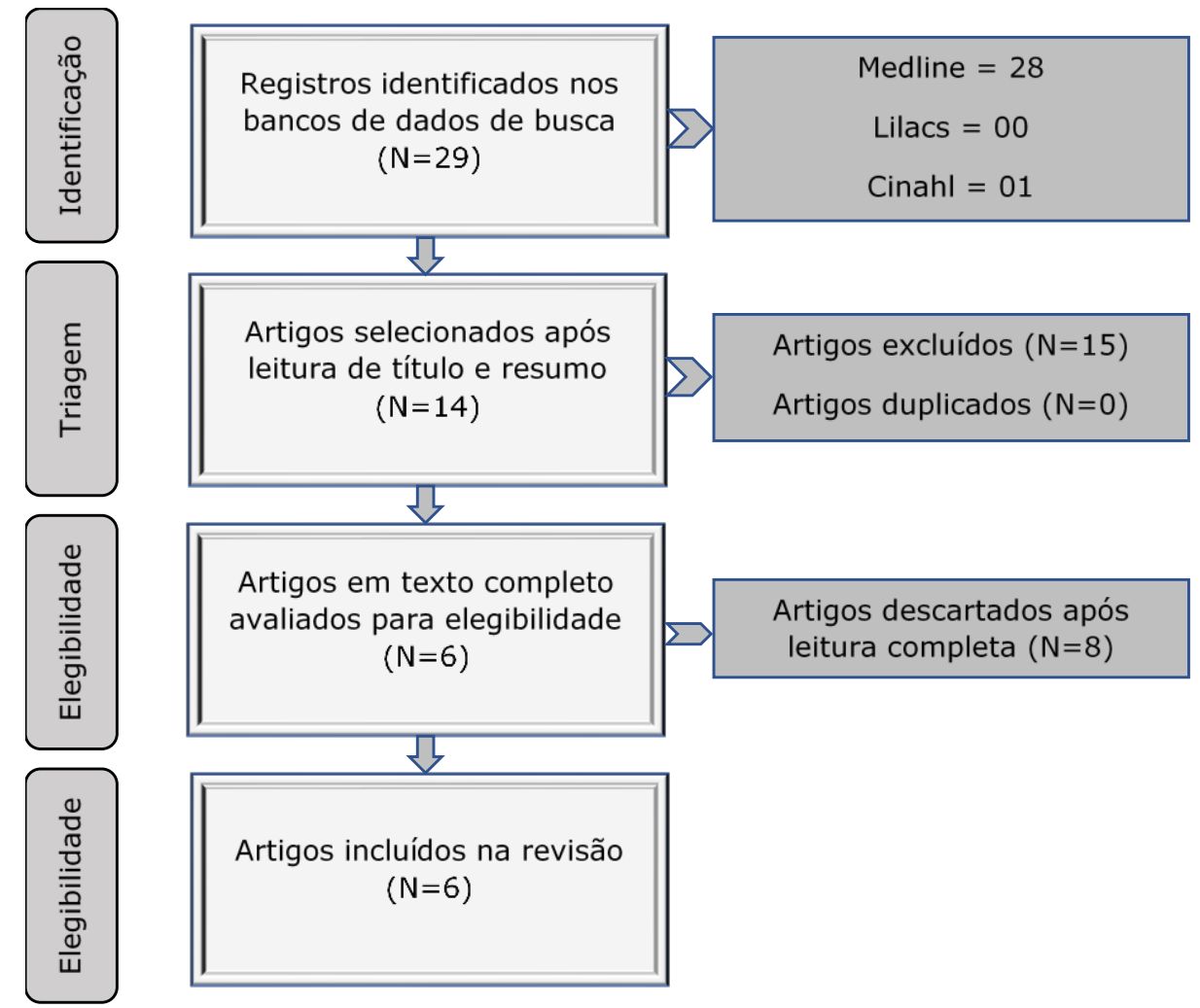

Figura 1: Fluxograma do processo de seleção dos artigos. Teresina-PI, 2020. Fonte: autoria própria

A maioria dos estudos foi desenvolvido por autores provenientes da Itália (03), os demais foram desenvolvidos na Bélgica (01), Brasil (01) e Estados Unidos (01). Todos os estudos foram publicados em 2020, na língua inglesa em diversos tipos de periódicos. Dentre eles são encontrados principalmente artigos de recomendações e orientações aos profissionais de saúde acerca dos cuidados ao aleitamento materno em meio a pandemia, estes estudos foram desenvolvidos através de revisão da literatura disponível de importantes instituições pesquisadoras, totalizando 04 publicações, além destas revisões também se encontram um estudo transversal, observacional, realizado através de questionários online com as lactantes, e um outro artigo de um estudo de coorte observacional prospectivo com neonatos nascidos de mães positivas para COVID19.

Algumas características específicas dos artigos selecionados (autor, citação nas referências, objetivos do estudo, delineamento metodológico e principais resultados) foram apresentadas no quadro a seguir (Quadro 1). A partir dos resultados advindo dos estudos analisados, optou-se por apresenta-los e discuti-los em duas categorias conceituais, são estas: "Risco de transmissão no aleitamento 


\section{materno" e "Recomendações para evitar a transmissão e incentivar o aleitamento}

materno".

Quando 1: registros incluídos na revisão de escopo segundo autores/citação, objetivos, método e principais contribuições. Teresina-PI, 2020.

\begin{tabular}{|c|c|c|c|}
\hline Autores & Objetivo & Método & Principais contribuições \\
\hline $\begin{array}{c}\text { Celeumans et } \\
\text { al. }\end{array}$ & $\begin{array}{l}\text { Avaliar impacto } \\
\text { percebido pelas } \\
\text { mulheres na pandemia } \\
\text { nas práticas de } \\
\text { amamentação, suporte } \\
\text { social e aconselhamento } \\
\text { médico e durante } \\
\text { gravidez e lactação. }\end{array}$ & $\begin{array}{l}\text { Estudo } \\
\text { transversal } \\
\text { observacional } \\
\text { retrospectivo }\end{array}$ & $\begin{array}{l}\text { O suporte social e aconselhamento } \\
\text { médico das mulheres foram afetados } \\
\text { negativamente principalmente entre } \\
\text { mulheres sem experiência na } \\
\text { amamentação e no período pós- } \\
\text { parto inicial. }\end{array}$ \\
\hline Davanzo et al. & $\begin{array}{l}\text { Fornecer orientações } \\
\text { gerencias as } \\
\text { maternidades sobre } \\
\text { manejo do aleitamento } \\
\text { materno em mães } \\
\text { suspeitas ou confirmadas } \\
\text { com COVID-19. }\end{array}$ & $\begin{array}{l}\text { Documento de } \\
\text { orientação da } \\
\text { Sociedade } \\
\text { Italiana de } \\
\text { Neonatologia, } \\
\text { construído por } \\
\text { meio de revisão } \\
\text { de literatura das } \\
\text { instruções de } \\
\text { importantes } \\
\text { órgãos de saúde } \\
\text { sobre o tema. } \\
\end{array}$ & $\begin{array}{c}\text { A primeira escolha é a manutenção } \\
\text { do alojamento conjunto e } \\
\text { aleitamento materno ao seio, a } \\
\text { depender do estado de saúde } \\
\text { materno e do RN. } \\
\text { Devem ser tomadas medidas de } \\
\text { higiene antes da amamentação. } \\
\text { Se necessário pode ser realizada a } \\
\text { extração do leite materno fresco para } \\
\text { ser dado ao RN. } \\
\text { Não se recomenda uso de substitutos } \\
\text { do leite materno como fórmulas. }\end{array}$ \\
\hline Giuliani et al. & $\begin{array}{l}\text { Apresentar sugestões do } \\
\text { Woman Study Group of } \\
\text { AMD sobre o manejo do } \\
\text { aleitamento materno } \\
\text { durante pandemia de } \\
\text { COVID-19. }\end{array}$ & $\begin{array}{l}\text { Construído por } \\
\text { meio de revisão } \\
\text { da literatura } \\
\text { médica } \\
\text { disponível. }\end{array}$ & $\begin{array}{l}\text { Em mães com teste positivo para } \\
\text { Covid-19 o alojamento conjunto é } \\
\text { aplicável com atenção às precauções } \\
\text { de doenças respiratórias. } \\
\text { Se necessário mãe e RN podem ser } \\
\text { separados temporariamente e este } \\
\text { alimentado com leite materno } \\
\text { ordenhado. }\end{array}$ \\
\hline Calil et al. & $\begin{array}{l}\text { Fornecer orientações } \\
\text { sobre amamentação para } \\
\text { mães com suspeita ou } \\
\text { confirmação de Covid-19 }\end{array}$ & $\begin{array}{l}\text { Revisão da } \\
\text { literatura médica } \\
\text { recente }\end{array}$ & $\begin{array}{l}\text { Deve-se manter e incentivar o } \\
\text { aleitamento materno mesmo em } \\
\text { mães positivas para COVID-19, } \\
\text { usando de precauções para evitar a } \\
\text { transmissão. } \\
\text { As mães devem ter condições } \\
\text { clínicas, desejarem e sentirem } \\
\text { segurança para amamentar. } \\
\text { A extração de leite materno ou o uso } \\
\text { de leite materno doado deve ser } \\
\text { orientado por profissional } \\
\text { qualificado. }\end{array}$ \\
\hline Salvatore et al. & $\begin{array}{l}\text { Acompanhar neonatos } \\
\text { nascidos de mães } \\
\text { positivas para SARS-CoV- } \\
2 \text { no momento do parto, } \\
\text { para elucidar melhores } \\
\text { práticas em relação ao } \\
\text { controle de infecção e } \\
\text { identificação fatores de }\end{array}$ & $\begin{array}{l}\text { Estudo de coorte } \\
\text { observacional } \\
\text { prospectivo }\end{array}$ & $\begin{array}{l}\text { Os dados sugeriram que a } \\
\text { transmissão perinatal da doença é } \\
\text { improvável de ocorrer se houver } \\
\text { higiene correta e precauções } \\
\text { necessárias forem tomadas, permitir } \\
\text { que os neonatos fiquem com suas } \\
\text { mães e amamentação direta são } \\
\text { procedimentos seguros quando }\end{array}$ \\
\hline
\end{tabular}




\begin{tabular}{|c|c|c|c|}
\hline Autores & Objetivo & Método & Principais contribuições \\
\hline & $\begin{array}{c}\text { risco potenciais } \\
\text { associados à transmissão. }\end{array}$ & & $\begin{array}{l}\text { combinados com educação parental } \\
\text { eficaz de estratégias de proteção } \\
\text { infantil. }\end{array}$ \\
\hline Willians et al. & $\begin{array}{l}\text { Orientar pediatras sobre } \\
\text { amamentação e medidas } \\
\text { de segurança } \\
\text { relacionadas durante a } \\
\text { pandemia, } \\
\text { particularmente nos } \\
\text { casos em que a mãe tem } \\
\text { ou pode ter COVID-19 }\end{array}$ & $\begin{array}{l}\text { Revisão da } \\
\text { literatura das } \\
\text { recomendações } \\
\text { de importantes } \\
\text { órgão de saúde } \\
\text { europeus. }\end{array}$ & $\begin{array}{l}\text { Apoia fortemente a continuação da } \\
\text { prática do aleitamento materno. } \\
\text { Devem ser feitos esforços para } \\
\text { aconselhar e apoiar adequadamente } \\
\text { as mães no processo de } \\
\text { amamentação, mesmo nos casos em } \\
\text { que estas estão em suspeita ou } \\
\text { confirmação de COVID-19. }\end{array}$ \\
\hline
\end{tabular}

Fonte: autoria própria

\section{DISCUSSÃO}

A seguir serão apresentados de forma narrativa os principais conceitos discutidos pelos autores incluídos nesta revisão. Para melhor organização dos conteúdos foi realizada a divisão em duas categorias conceituais referentes aos conhecimentos sobre o risco de transmissão da infecção durante o aleitamento materno e sobre as principais recomendações propostas pelos autores para se realizar o incentivo ao aleitamento materno exclusivo associado as medidas de prevenção da transmissão da doença.

\subsection{RISCO DE TRANSMISSÃO NO ALEITAMENTO MATERNO}

Com relação ao risco de transmissão vertical, uma revisão de estudos que objetivaram a investigação de uma possível transmissão através do leite materno teve como resultado em apenas um estudo de um único caso clínico em que foi detectada a presença do vírus em amostras do leite humano, em contrapartida os demais estudos dessa revisão em nenhum outro caso foi encontrada presença do vírus em amostras de leite, porém foram encontrados em alguns casos a presença de anticorpos específicos para SARS-CoV-2. Portanto os autores incluídos nesta revisão bem como a OMS concordam que o risco de transmissão de Covid-19 da mãe para recém-nascido através do leite materno é ainda improvável. Por outro lado, há a possibilidade da transmissão horizontal através das vias respiratórias, é sabido que uma mãe infectada pode transmitir o vírus por meio de gotículas respiratórias durante amamentação e contato íntimo com o recém-nascido (CEULEMANS et al, 
2020; DAVANZO et al, 2020; GIULIANI et al, 2020; SALVATORE et al, 2020; WILLIANS et al, 2020; MELO et al, 2020; WHO, 2020b).

Em meio a esse risco de contágio, um estudo de coorte observacional prospectivo avaliou neonatos nascidos em uma maternidade dos Estados Unidos, eles foram testados para SARS-CoV-2 através de esfregaços nasofaríngeos coletados em 24h, 5-7 dias e 14 dias de vida, seguindo-se de avaliação clínica com 1mês de idade, bem como as práticas de controle da infecção no hospital e em domicílio. No estudo nenhum neonato apresentou resultados positivos para COVID-19 em quaisquer dos testes realizados e todos mantiveram o aleitamento materno ao seio como recomendado pela equipe de saúde, esse resultado pôde demostrar que quando adotada as medidas corretas de prevenção da transmissão, a contaminação do recém-nascido é também pouco provável (SALVATORE et al, 2020).

Alguns autores enfatizam que embora exista a possibilidade de risco de transmissão do vírus da mãe para seu filho, o aleitamento materno não deve ser contraindicado visto que os benefícios desta prática superam os riscos de uma possível infecção, contribuem ainda afirmando que dentre os benefícios do aleitamento materno temos que a passagem de anticorpos pelo leite materno pode modular a expressão clínica da infecção no lactente, ou seja, embora este neonato esteja sob o risco potencial de contaminação através da amamentação, a função imunoprotetora do leite materno poderia minimizar os efeitos da infecção por SARS-Cov-2 em seu organismo (DAVANZO et al, 2020; WILLIANS et al, 2020; MELO et al, 2020; TRAN et al, 2020; WHO, 2020b) .

\subsection{RECOMENDACÕES PARA EVITAR A TRANSMISSÃO E INCENTIVAR O ALEITAMENTO MATERNO}

Embora alguns autores considerem a separação do recém-nascido de sua mãe infectada pelo Covid-19, os estudos presentes nesta revisão em consenso com as atuais evidências discordam desta prática e alguns ainda a consideram prejudicial visto que a separação da mãe de seu RN prejudica o relacionamento da díade como também é uma medida tardia para um contágio que já pode ter ocorrido em uma fase pré-sintomática da infecção, afirmam ainda que a separação precoce aumenta a probabilidade de infecção do RN por outros patógenos de doenças mais graves, além de aumentar o contato com profissionais potencialmente infectados (TRAN et al, 2020; DAVANZO et al, 2020; WANG et al, 2020; AAP, 2020; CDC, 2020b). 
A separação só se justifica em situações de más condições de saúde da mãe ou do RN e essa decisão deve ser tomada em acordo com a família e estar baseada em incentivo ao aleitamento materno exclusivo e orientações por parte dos profissionais sobre os riscos e benefícios da prática e ser ofertada à mãe as melhores possibilidades de alimentação para seu filho caso esta não se sinta segura ou não esteja em condições clínicas para tal feito. A recomendação de primeira escolha é pelo alojamento conjunto mesmo quando a mãe apresenta suspeita ou confirmação para COVID-19. A OMS e outros estudos reforçam e indicam ainda a aplicação do contato pele a pele em sala de parto e enfermaria como medida de incentivo ao aleitamento materno exclusivo, utilizando-se das medidas de higiene adequadas. Já outros autores sugerem que se mantenha a distância mínima de dois metros da cama da mãe para o berço do RN quando este não estiver mamando (DAVANZO et al, 2020; GIULIANI et al, 2020; CALIL et al, 2020; SALVATORE et al, 2020; WILLIANS et al, 2020; VIVANTINI et al, 2020; WHO, 2020b).

O quarto/enfermaria deve ser isolada, não permitindo visitas de parentes ou amigos, poucos estudos relatam sobre a presença de acompanhante, porém enfatizam da necessidade de uma pessoa saudável e bem orientada pela equipe de saúde para auxiliar a mãe se esta precisar. Atenção para medidas de higiene como limpeza das mãos antes de tocar no RN, das superfícies que a mãe contaminada tocar e onde o neonato tiver contato, a OMS ainda traz que não é necessária a higienização das mamas a cada mamada, exceto nos casos que os seios ou colo materno tiver sido exposto a secreções respiratórias. É recomendado o uso de máscara cirúrgica pela mãe durante amamentação e contato íntimo com o recém-nascido, evitando-se falar ou tossir nesses momentos. Não é indicado o uso de máscara pelo recém-nascido em nenhum momento da internação hospitalar ou em domicílio (CELEUMANS et al, 2020; DAVANZO et al, 2020; GIULIANI et al, 2020; CALIL et al, 2020; SALVATORE et al, 2020; WILLIANS et al, 2020; TRAN et al, 2020; WHO, 2020b).

Se não for possível o estabelecimento da amamentação ao seio, a mãe deve ser encorajada a realizar a extração ou ordenha do leite para dar ao filho, este pode ser ordenhado de forma manual ou através de bomba de extração própria a depender da necessidade da mãe ou das condições do serviço. Devem ser tomadas medidas de higiene como lavagem das mãos antes das coletas e uso de máscara durante todo o procedimento assim como a higienização adequada dos 
equipamentos para extração do leite. A ordenha ainda é apontado como uma prática importante para se manter a produção adequada do leite materno enquanto durar a separação de mãe e bebê e, se necessário, deve ser orientada a relactação como método para retornar a amamentação ao seio quando as condições clínicas de mãe e bebe forem favoráveis para tal prática (DAVANZO et al, 2020; GIULIANI et al, 2020; CALIL et al, 2020; WILLIANS et al, 2020; TRAN et al, 2020; WHO, 2020b).

0 procedimento de extração do leite deve ser orientado por profissional capacitado, deve ser realizado em sala reservada, o leite pode ser armazenado em geladeira por até 12 horas e não há necessidade de pasteurização. A criança pode ser alimentada com o leite ordenhado pela equipe de saúde ou mesmo por cuidador/familiar saudável e que seja bem orientado e treinado sobre os cuidados com o procedimento. Caso as condições clínicas da mãe não a permitam a extração de leite materno, a recomendação é que a alimentação deste neonato seja feita com leite materno doado pasteurizado por meio dos bancos de leite humano. Embora essa opção possa ser limitada devido à redução nas doações de leite materno durante a pandemia se esta for uma opção viável deve ser utilizada em preferência ao uso de fórmula infantil (GIULIANI et al, 2020; CALIL et al, 2020).

Um estudo transversal, observacional incluído nesta revisão que teve como objetivo avaliar o impacto da pandemia percebido pelas mães em suas práticas de amamentação, aconselhamento médico e suporte social durante gravidez e lactação, obteve como um dos resultados que embora o isolamento social não tenha surtido efeitos consideráveis na continuidade do aleitamento materno exclusivo, as mulheres referiram que foram afetadas negativamente com relação a aconselhamento por profissionais de saúde, suporte familiar e social, questões que foram geradoras de maior ansiedade, preocupações com a amamentação e cuidados com o bebê, além de acúmulo de funções (cuidados com a casa, filhos, trabalho remoto) que foram sentidas principalmente nas mulheres sem experiência pregressa de amamentação no período de pós parto inicial (CELEUMANS et al, 2020).

Visto isto devemos reforçar a importância de quaisquer das decisões tomadas com relação ao manejo do aleitamento materno devem ser orientadas e bem discutidas com a família juntamente com os profissionais de saúde, que devem incentivar, orientar e manejar, baseada em evidências científicas, as melhores 
alternativas para a manutenção do aleitamento materno que garanta saúde, qualidade de vida e garantia de direitos para a díade mãe e filho.

\section{CONCLUSÃO}

Esta revisão de escopo possibilitou apresentar um mapeamento da produção de conhecimento acerca das recomendações para a assistência ao aleitamento materno em meio a pandemia de covid-19. O leite materno é considerado o alimento ideal para o bebê, porque é seguro, limpo e fornece toda a energia e nutrientes que atendam às suas necessidades nos primeiros meses de vida, contém anticorpos que ajudam a proteger as crianças contra muitas doenças da primeira infância, e a amamentação confere muitos benefícios de saúde de curto e longo prazo para a mãe e filho. Visto isso, as principais recomendações é que devem ser feitos esforços para aconselhar e apoiar adequadamente as mães em amamentação, mesmo nos casos em que esta confirmou ou suspeitou de infecção por COVID-19.

Durante a pesquisa percebeu-se que a quantidade de estudo primários encontrados para sua realização foi escassa visto que é um tema ainda novo, isto de certa forma limitou o estudo em relação a uma melhor análise, argumentação e síntese de evidências cientificas. Tendo em vista que alguns dos estudos analisados nesta revisão são provenientes de importantes órgãos internacionais de assistência materna e neonatal podemos compreender que as recomendações prestadas possuem um grau de confiabilidade elevado, entretanto, por ser a pandemia uma situação ainda recente (emergente) devemos ter em mente que novos estudos devem ser realizados para maior compreensão e maior grau de evidência das recomendações. Sugere-se então a realização de novos estudos para investigação e orientação das instituições e profissionais de saúde com relação aos conceitos abordados nesse estudo.

\section{REFERÊNCIAS}

AAP (American Academy of Pediatrics). FAQs: Gerenciamento de bebês nascido de mães com COVID-19. Academia Americana de Pediatria, 2020. https://services.aap.org/en/pages/2019-novel-coronaviruscovid- 19infecções / orientação-clínica / faqs-gerenciamento-de-bebêsnascido para covid-19-mães / (acessado em 06 de out de 2020). 
ARKSEY, H.; O'MALLEY L. Scoping studies: towards a methodological framework. Int. J. Soc. Res. Methodol., v. 8, fev. 2007. Disponível em: <https://doi.org/10.1080/1364557032000119616>. Acesso em: 28 jul. 2020.

BRASIL, Ministério da Saúde [homepage na internet]. Painel de casos de doença pelo coronavírus 2019 (COVID-19) no Brasil pelo Ministério da Saúde [acesso em 27 de jul. de 2020]. Disponível em: https://covid.saude.gov.br (A)

BRASIL. Ministério da Saúde. Secretaria de Vigilância em Saúde [homepage na internet]. Boletim Epidemiológico 11. Doença pelo Coronavírus 2019 (COE - COVID-19) [acesso em 27 de jul. de 2020]. Disponível em: https://portalarquivos.saude.gov.br/images/pdf/2020/April/18/2020-0417---BE11---Boletim-do-COE-21h.pdf (B)

CALIL, V. M. L. T.; KREBS, V. L. J.; CARVALHO, W. B. Guidance on breastfeeding during the Covid-19 pandemic. Rev. Assoc. Med. Bras, v.66, abr. 2020. Disponível em: http://dx.doi.org/10.1590/1806-9282.66.4.541. Acesso em: 05 out. 2020.

CAO, Q; CHEN, Y.C; CHEN, C.L; CHIU, C.H. SARS-CoV-2 infection in children: Transmission dynamics and clinical characteristics. J Formos Med Assoc [Internet]. 2020 mar.[acesso em 28 Jul. 2020];119(3):670-673. Disponível em: https://doi.org/10.1016/j.jfma.2020.02.009

CDC (Centers for Disease Control and Prevention) [homepage na internet]. Coronavirus Disease 2019 (COVID-19). Interim considerations for infection prevention and control of coronavirus disease 2019 (COVID19) in inpatient obstetric healthcare settings [acesso em 26 de Jul. 2020]. Disponível em: https://www.cdc.gov/coronavirus/2019ncov/hcp/inpatient-obstetric healthcare-guidance.html (A)

CDC (Centers for Disease Control and Prevention). Avaliação e considerações de gestão para recém-nascidos em risco para COVID-19. Centros de Controle e Prevenção de Doenças, 2020. https://www.cdc.gov/coronavirus/2019ncov/hcp/caring-fornewborns. html (acessado em 06 de out de 2020) (B)

CEULEMANS M. et al. SARS-CoV-2 Infections and Impact of the COVID-19 Pandemic in Pregnancy and Breastfeeding: Results from an Observational Study in Primary Care in Belgium. International Journal of Environmental Research and Public Health, v. 17, set. 2020. Disponível em: <http://dx.doi.org/10.3390/ijerph17186766>. Acesso em: 05 out. 2020.

CORDEIRO, L.; SOARES, C. B. Revisão de escopo: potencialidades para a síntese de metodologias utilizadas em pesquisa primária qualitativa. Boletim do Instituto de Saúde - BIS, v. 20, dez. 2019. Disponível em: <https://pesquisa.bvsalud.org/portal/resource/pt/biblio-1021863>. Acesso em: 05 out. 2020.

CORREIA, A. C. S. Aleitamento materno como um fator preventivo da obesidade. Porto. Monografia [Graduação em Ciências da Nutrição] - Universidade do 
Porto (FCNAUP); 2009. Disponível em: https://repositorioaberto.up.pt/bitstream/10216/54499/3/132244_0998TCD98.pdf

DAVANZO R. et al. Breastfeeding and coronavirus disease-2019: Ad interim indications of the Italian Society of Neonatology endorsed by the Union of European Neonatal \& Perinatal Societies. Maternal \& child nutrition, v. 16, abr. 2020. Disponível em: <https://doi.org/10.1111/mcn.13010>. Acesso em: 05 out. 2020.

DE LUCA D. Managing neonates with respiratory failure due to SARS-CoV-2. Lancet Child Adolesc Health, v. 4, abr. 2020. Disponível em: <https://doi.org/10.1016/S2352-4642(20)30073-0>. Acesso em: 30 de jul. 2020.

GALVÃO, D. M. P. G. Amamentação bem sucedida: alguns factores determinantes. Porto. 2002.

GIULIANI, C. et al. Breastfeeding during the COVID-19 pandemic: Suggestions on behalf of woman study group of AMD. Diabetes Research and Clinical Pratice, v. 165, jul. 2020. Disponível em: <https://doi.org/10.1016/j.diabres.2020.108239>. Acesso em: 05 out. 2020.

JBI (THE JOANNA BRIGGS INSTITUTE). Joanna Briggs Institute Reviewers' Manual: 2015 edition/ Supplement. Adelaide: The Joanna Briggs Institute, 2015.

LEVY, L.; BÉRTOLO, H. Manual de aleitamento materno. Lisboa: UNICEF, 2012.

MA, K. et al. Management and Clinical Thinking of Coronavirus Disease 2019. Zhonghua Gan Zang Bing Za Zhi. 2020. Mar 3;28(0):E002. PubMed PMID: 32125126. Disponível em: https://pubmed.ncbi.nlm.nih.gov/32125126/ DOI: $10.3760 /$ cma.j.issn.1007-3418.2020.0002

MELO, L. P. C. et al. Aleitamento materno em tempos de covid-19: uma revisão integrativa. Research, Society and Development, Vargem Grande Paulista, v. 9, n. 9, ago. 2020. Disponível em: <https://rsdjournal.org/index.php/rsd/article/view/7074>. Acesso em: 10 out. 2020.

NETO, A. C.; CARDOSO, A. M.; OLIVEIRA, M. S. Fatores que levam ao desmame precoce com puérperas da unidade básica de saúde Palmeiras em Santa Inês Maranhão. In: Safety, Health and Environment World Congress, 15., 2015, Porto. Anais... Porto: COPEC, 2002. p. 288-292.

PAZ, M. M. S; ALMEIDA, M, ASSIS T, MENDES C. Barreiras impostas na relação entre puérperas e recém-nascidos no cenário da pandemia do COVID19. Manuscript ID: RBSMI-2020-0231. 2020. [acessado em 30 de Jul. de 2020]. Disponível em: https://doi.org/10.1590/SciELOPreprints.965

RASMUSSEN, S. A. et al. Coronavirus Disease 2019 (COVID-19) and Pregnancy: what Obstetricians Need to Know. Am J Obstet Gynecol, v. 222, mai. 2020. 
Disponível em: <https://www.ajog.org/article/S0002-9378(20)301976/fulltext>. Acesso em: 16 nov. 2020.

SALVATORE, C. M. et al. Neonatal management and outcomes during the COVID-19 pandemic: an observation cohort study. The Lancet Child \& Adolescent Health v. 4, jul. 2020. Disponível em: <https://doi.org/10.1016/S23524642(20)30235-2>. Acesso em 05 out. 2020.

TRAN, H. T. et al. Appropriate care for neonates born to mothers with COVID-19 disease. Acta Pediatrica, Solnavägen, v. 109, set. 2020. Disponpivel em: <https://doi.org/10.1111/apa.15413>. Acesso em: 05 out. 2020.

TRICCO, A. C. et al. Knowledge synthesis methods for generating or refining theory: a scoping review reveals that little guidance is available. J. Clin. Epidemiol, v. 73, fev. 2016. Disponível em: <https://www.jclinepi.com/article/S08954356(16)00100-1/fulltext>. Acesso em: 05 out. 2020.

VIVANTI, A. J. et al. Post-natal follow-up for women and neonates during the COVID19 pandemic: French National Authority for Health recommendations. J Gynecol Obstet Hum Reprod, França, v. 49, set. 2020. Disponível em: <https://doi.org/10.1016/j.jogoh.2020.101805>. Acesso em: 05 out. 2020.

WANG, L. et al. Chinese expert consensus on the perinatal and neonatal management for the prevention and control of the 2019 novel coronavirus infection (First edition). Annals of Translational Medicine, Sha Tin, v. 8, fev. 2020. Disponível em: <https://www.ncbi.nlm.nih.gov/pmc/articles/PMC7036629/>. Acesso em: 04 out. 2020.

WHO (World Health Organization). 10 facts on breastfeeding. 2017. Disponível em http://www.who.int/features/factfiles/breastfeeding/en/[acesso em $27 \mathrm{de}$ jul. de 2020]

WHO (World Health Organization). Coronavirus disease (COVID-19) outbreak situation [Internet]. Geneva: WHO; 2020. Acesso em 25 de julho de 2020. Disponível em: https://www.who.int/emergencies/diseases/novelcoronavirus-2019 (A)

WHO (World Health Organization). Frequently Asked Questions: Breastfeeding and COVID-19 For health care workers. Journal of Human Lactation [Internet]; 2020 Abr. [acesso em 05 Out. 2020];36(3):392-396. Disponível em: http://www.who.int/publications-detail/clinical-management-ofsevere-acute-respiratory-infection-when-novel-coronavirus-(ncov)infection-is-suspected (B)

WHO (World Health Organization). Modes of transmission of the COVID-19 virus-Scientific brief. 2020. Disponível em: https://www.who.int/Newsroom/commentaries/detail/modes-of-transmission-of-viruscausing-covid19-implications-for-ipc-precaution-recommendations.. (C) 
WHO (World Health Organization). Q\&A on COVID-19, pregnancy, childbirth and breastfeeding. 2020. Disponível em https://www.who.int/news-room/q-adetail/q-a-on-covid-19-pregnancy-childbirth-and breastfeeding (D)

WILLIAMS J. et al. The Importance of Continuing Breastfeeding during Coronavirus Disease-2019: In Support of the World Health Organization Statement on Breastfeeding during the Pandemic. The Journal of pediatrics, 223, ago. 2020. Disponível em: <https://doi.org/10.1016/j.jpeds.2020.05.009>. Acesso em: 05 out. 2020.

YANG, H.Y; DUAN, G.C. Analysis on the epidemic factors for COVID-19. Zhonghua yu Fang yi xue za zhi [Chinese Journal of Preventive Medicine]. 2020 Jun;54(6):608-613. DOI: 10.3760/cma.j.cn112150-20200227-00196 


\section{ASSISTÊNCIA AO RECÉM-NASCIDO DEMÄE SUSPEITA OU CONFIRMADA PARA COUID-19: REUISÃO DE ESCOPO}

DDI: 10.51859/amplla.esp917.1121-11

Açucena Barbosa Nunes ${ }^{1}$ Márcia Teles de Oliveira Gouveia ${ }^{1}$

1 Universidade Federal do Piauí (UFPI). Teresina. Brasil.

\section{RESUMO}

Introdução: A rápida progressão para uma pandemia global do COVID-19 teve profundas consequências médicas, sociais e econômicas. Por ser um novo patógeno, pessoas de todas as idades não têm imunidade a ele e geralmente são suscetíveis a infecções, contaminando desde recém-nascidos até idosos. Os neonatos são vulneráveis a essa infecção e é imprescindível o conhecimento sobre o manejo e assistência prestada a este grupo. Objetivo: Mapear a produção de conhecimento sobre as recomendações para a assistência ao recém-nascido de mãe suspeita ou confirmada para COVID-19. Métodos: Trata-se de uma revisão de escopo, na qual o período de busca foi de abril a setembro de 2020 nas bases de dados National Library of Medicine (MEDLINE)- acesso via PubMed; Cumulative Index to Nursing and Allied Health Literature (CINAHL); Scopus; Web of Science e Latino-Americana de Informação Bibliografia (LILACS). A amostra final foi composta por 19 artigos, os quais foram submetidos à análise descritiva do conteúdo e apresentados em quadros analíticos. Conclusões: Os resultados demonstram que os neonatos representam um grupo suscetível e vulnerável para complicações referentes ao COVID-19, tendo em vista sua imaturidade. Portanto, esta revisão de escopo, possibilitou apresentar um mapeamento da produção de conhecimento sobre as recomendações para a assistência ao recém-nascido, incluindo cuidados em sala de parto, alojamento conjunto, unidades neonatais, alta hospitalar e no domicílio, abordando os principais aspectos como amamentação, reanimação neonatal, contato pele a pele, clampeamento do cordão umbilical e cuidados ventilatórios.

Palavras-chave: Recém-Nascido; Infecções por Coronavirus; Assistência Integral à Saúde; Assistência ao Paciente; Cuidados de saúde. (DeCS) 
Introducción: La rápida progresión del COVID-19 a una pandemia mundial ha tenido profundas consecuencias médicas, sociales y económicas. Debido a que es un patógeno nuevo, las personas de todas las edades no tienen inmunidad $\mathrm{y}$ generalmente son susceptibles a las infecciones, que contaminan desde los recién nacidos hasta los ancianos. Los recién nacidos son vulnerables a esta infección y el conocimiento sobre el manejo y la asistencia brindados a este grupo es esencial. Objetivo: Mapear la producción de conocimiento sobre las recomendaciones de asistencia al recién nacido de una madre sospechosa o confirmada de COVID-19. Métodos: Esta es una revisión de alcance, en la que el período de búsqueda fue de abril a septiembre de 2020 en las bases de datos de la Biblioteca Nacional de Medicina (MEDLINE) - acceso a través de PubMed; Índice acumulativo de literatura sobre enfermería y salud afín (CINAHL); Scopus; Web of Science y Bibliografía Informativa Latinoamericana (LILACS). La muestra final estuvo conformada por 19 artículos, los cuales fueron sometidos a análisis descriptivo de contenido y presentados en tablas analíticas. Conclusiones: Los resultados demuestran que los neonatos representan un grupo susceptible y vulnerable a las complicaciones relacionadas con COVID-19, dada su inmadurez. Por tanto, esta revisión de alcance permitió presentar un mapeo de la producción de conocimiento sobre las recomendaciones de atención al recién nacido, incluyendo el cuidado en la sala de partos, acomodación conjunta, unidades neonatales, alta hospitalaria y domiciliaria, abordando los principales aspectos tales como como lactancia materna, reanimación neonatal, contacto piel a piel, pinzamiento del cordón umbilical y cuidados ventilatorios.

Palabras clave: Recién nacido; Infecciones por coronavirus; Atención Integral de Salud; Asistencia al paciente; Cuidados de la salud. (DeCS)

\section{ABSTRACT}

Introduction: The rapid progression to a global pandemic from COVID-19 has had profound medical, social and economic consequences. Because it is a new pathogen, people of all ages have no immunity to it and are generally susceptible to infections, contaminating newborns to the elderly. Neonates are vulnerable to this infection and knowledge about the management and assistance provided to this group is essential. Objective: To map the production of knowledge about the recommendations for assistance to the newborn of a suspected or confirmed mother for COVID-19. Methods: This is a scope review, in which the search period was from April to September 2020 in the National Library of Medicine (MEDLINE) databases - access via PubMed; Cumulative Index to Nursing and Allied Health Literature (CINAHL); Scopus; Web of Science and Latin American Information Bibliography (LILACS). The final sample consisted of 19 articles, which were submitted to descriptive analysis of the content and presented in analytical tables. Conclusions: The results demonstrate that neonates represent a susceptible and vulnerable group for complications related to COVID-19, in view of its immaturity. Therefore, this scope review made it possible to present a mapping of the production of 
knowledge about the recommendations for assistance to the newborn, including care in the delivery room, joint accommodation, neonatal units, hospital discharge and at home, covering the main aspects such as breastfeeding, neonatal resuscitation, skin-to-skin contact, clamping of the umbilical cord and ventilatory care.

Keywords: Newborn; Coronavirus infections; Comprehensive Health Care; Patient Assistance; Health care. (MeSH)

\section{INTRODUĈ̣̃O}

A doença de coronavírus (COVID-19) tem como agente causador o SARS-CoV2 e sugere-se que sua origem zoonótica seja proveniente da cidade de Wuhan, província de Hubei, na China, em dezembro de 2019, após um amplo número de pessoas infectadas expostas ao mercado de animais úmidos. Em 30 de Janeiro de 2020, a Organização Mundial da Saúde (OMS) declarou oficialmente a epidemia COVID-19 como uma emergência de saúde pública de interesse internacional e em 11 de março de 2020, considerou seu potencial de surto de pandemia após a rápida disseminação mundial, sendo atualmente um grande problema de saúde pública global. (1)

Por ser uma doença infecciosa respiratória aguda emergente, é transmitida principalmente pelo trato respiratório, por gotículas, secreções respiratórias e contato direto, além de evidências de transmissão pelas fezes. As manifestações clínicas comuns incluem febre, tosse, fadiga, mialgia, produção de escarro, coriza, dispnéia, dor de garganta, cefaléia e sintomas gastrointestinais, como diarréia e vômitos. $(2,3)$

A rápida progressão para uma pandemia global do COVID-19 teve profundas consequências médicas, sociais e econômicas. Por ser um novo patógeno, pessoas de todas as idades não têm imunidade a ele e geralmente são suscetíveis a infecções, contaminando desde recém-nascidos até idosos. (4)

Nesse sentido, as gestantes e recém-nascidos representam uma população vulnerável e pertencem aos grupos de risco para complicações da COVID-19. No entanto, o impacto preciso desse novo vírus no feto e no recém-nascido permanece incerto. Considera-se que, especialmente os neonatos prematuros, correm um risco maior de adquirir e apresentarem complicações do COVID-19 pós-natal secundário por ocasião de um sistema imunológico ainda imaturo. ${ }^{(5)}$ 
Por conseguinte, sabe-se que a transmissão materno-fetal da doença é controversa, e as evidências demonstraram que, até o momento, a infecção neonatal por COVID-19 é incomum, porém, quando ocorre é geralmente adquirida no pósnatal, sendo associada a resultados respiratórios favoráveis. A razão pela qual os neonatos exibem um espectro mais brando da doença permanece incerta. No entanto, existe o risco de doença grave ou crítica em pacientes jovens (6).

Apesar da preocupação dos órgãos nacionais e internacionais, os estudos científicos sobre infecção pelo vírus SARVS-Cov-2 e a doença COVID-19 são ainda incipientes, especialmente em relação ao manejo de recém-nascidos e gestantes contaminados ou suspeitos. Nessa perspectiva, diante desse cenário, o estudo tem como objetivo mapear a produção de conhecimento sobre as recomendações para a assistência ao recém-nascido de mãe suspeita ou confirmada para COVID-19.

\section{METODOS}

Trata-se de uma revisão de escopo caracterizada como um tipo de estudo utilizado para sintetizar evidências de pesquisas e mapear na literatura existente de um determinado campo em termos de natureza, características e volume, pois podem ser conduzidas para mapear um corpo de literatura com relevância para tempo, localização, fonte (por exemplo, literatura revisada por pares ou literatura cinza) e origem. Considerando a temática emergente e de recente surgimento no cenário atual, a escolha desta metodologia foi pertinente, visto que contempla tipos de literatura diversos. ${ }^{(7,8)}$

Considerou-se as cinco etapas propostas por Arksey e O'Malley para desenvolver a estrutura metodológica deste estudo: identificação da questão de pesquisa; identificação de estudos relevantes; seleção de estudos; extração dos dados; agrupamento, resumo e relato dos resultados. (7)

O protocolo do Instituto Joanna Briggs (JBI) (2015) destaca que uma revisão de escopo será mais ampla, com inclusão correspondentemente menos restritiva e recomenda que a pergunta seja elaborada com base no mnemônico PCC (População, Conceito e Contexto) (9). Foram definidos: P - recém-nascidos; C - COVID-19 e C assistência. Com base nessas definições elaborou-se a pergunta norteadora: "Qual a 
produção de conhecimento sobre as recomendações para a assistência ao recémnascido de mãe suspeita ou confirmada para COVID-19?".

O período de busca foi de abril a setembro de 2020 e as bases selecionadas, considerando o tópico em estudo foram a National Library of Medicine (MEDLINE)acesso via PubMed; Cumulative Index to Nursing and Allied Health Literature (CINAHL); Scopus; Web of Science e Latino-Americana de Informação Bibliografia (LILACS).

O processo de busca ocorreu em três etapas: 1) Realizou-se uma pesquisa inicial utilizando descritores controlados adequados para cada base de dados (Medical Subject Headings - MeSH, CINAHL Headings e Descritores em Ciências da Saúde - DeCS); 2) com o intuito de ampliar a busca, uma segunda pesquisa foi realizada, usando descritores não controlados (palavras-chave) executados em todos os bancos de dados incluídos, com a utilização dos operadores booleanos "AND" e "OR" na busca dos artigos; 3 ) a terceira etapa consistiu na identificação e seleção na lista de referência de todos os relatórios e artigos identificados.

Verificou-se a relevância dos estudos incluídos por dois revisores independentes, que tiveram acesso aos mesmos resultados de busca. Os casos de desacordo quanto à inclusão foram resolvidos por meio de consenso entre os pares ou pela avaliação de um terceiro revisor. Ressalta-se que a verificação da qualidade metodológica dos estudos primários não foi realizada. Utilizou-se o software online Endnote Web com a finalidade de armazenar e organizar as referências obtidas na busca, bem como verificar a duplicidade dos estudos. Os descritores controlados e não controlados foram sintetizados conforme a estratégia PCC (Quadro 1).

Quadro 1 - Estratificação da pergunta de pesquisa seguindo a estratégia PCC. Teresina, Piauí, Brasil, 2020.

\begin{tabular}{|c|c|c|c|c|}
\hline DESCRIÇÃO & COMPONENTES & TIPO & DC & DNC \\
\hline \multirow{2}{*}{$\begin{array}{c}\text { Participantes } \\
\text { (P) }\end{array}$} & Recém-nascidos & DeCS & Recém-Nascido & Neonato \\
\cline { 3 - 5 } & COVID-19 & Títulos Cinahl & Infant, Newborn & - \\
\cline { 3 - 5 } & & Infant, Newborn & - \\
\hline $\begin{array}{c}\text { Conceito } \\
\text { (C) }\end{array}$ & DeCS & $\begin{array}{c}\text { Infecções por } \\
\text { Coronavirus }\end{array}$ & $\begin{array}{c}\text { COVID-19 } \\
\text { Doença pelo } \\
\text { Novo } \\
\text { Coronavírus } \\
\text { (2019-nCoV) } \\
\text { SARS-CoV-2 }\end{array}$ \\
\hline
\end{tabular}




\begin{tabular}{|c|c|c|c|c|}
\hline DESCRIÇÃO & COMPONENTES & TIPO & DC & DNC \\
\hline & & $\mathrm{MeSH}$ & $\begin{array}{l}\text { Coronavirus } \\
\text { Infections }\end{array}$ & - \\
\hline & & Títulos Cinahl & $\begin{array}{c}\text { COVID-19 } \\
\text { Coronavirus } \\
\text { Infections }\end{array}$ & - \\
\hline \multirow{3}{*}{$\begin{array}{l}\text { Contexto } \\
\text { (C) }\end{array}$} & \multirow{3}{*}{ Assistência } & DeCS & $\begin{array}{c}\text { Assistência } \\
\text { Integral à Saúde } \\
\text { Assistência ao } \\
\text { Paciente }\end{array}$ & $\begin{array}{l}\text { Cuidados de } \\
\text { saúde }\end{array}$ \\
\hline & & $\mathrm{MeSH}$ & $\begin{array}{c}\text { Comprehensive } \\
\text { Health Care } \\
\text { Patient Care } \\
\end{array}$ & - \\
\hline & & Títulos Cinahl & Newborn Care & - \\
\hline
\end{tabular}

Fonte: elaborado pelos autores.

Os descritores selecionados para a busca foram cruzados e suas combinações foram usadas para construir as estratégias de busca (Quadro 2).

Quadro 2 - Estratégias de busca referentes às bases de dados pesquisadas. Teresina, Piauí,

\begin{tabular}{|c|c|}
\hline Base de dados & Estratégia de busca \\
\hline MEDLINE-PubMed & $\begin{array}{l}\text { (((Infant, Newborn[MeSH Terms]) AND (coronavirus infections[MeSH } \\
\text { Terms])) AND(Patient Care[MeSH Terms]) }\end{array}$ \\
\hline Scopus & $\begin{array}{l}\text { TITLE-ABS-KEY (infant, AND newborn) AND (coronavirus AND infections) } \\
\text { AND } \\
\text { (comprehensive AND health AND care) OR (patient AND care) }\end{array}$ \\
\hline WoS & $\begin{array}{l}\text { TS }=(\text { Infant }, \text { Newborn } * \text { AND Coronavirus Infections }) \\
\text { Indexes=SCI-EXPANDED, SSCI, A\&HCI, CPCI-S, CPCI-SSH, ESCI Timespan=All } \\
\text { years }\end{array}$ \\
\hline CINAHL & $\begin{array}{l}\text { infant, newborn AND coronavirus infections OR covid-19 AND newborn } \\
\text { care }\end{array}$ \\
\hline LILACS & $\begin{array}{l}\text { Recém-nascido [Descritor de assunto] and Infecções por Coronavirus } \\
\text { [Descritor de assunto] }\end{array}$ \\
\hline
\end{tabular}

Fonte: elaborado pelos autores.

Como critério de inclusão, optou-se por estudos disponíveis com as mais variadas metodologias (estudos primários de pesquisa, revisões da literatura, protocolos, editoriais e diretrizes), nos idiomas inglês, espanhol ou português, sem limite temporal, que abordem os cuidados ao recém-nascido de mãe suspeita ou confirmada para COVID-19. Foram excluídos os estudos que não responderam à questão de pesquisa, bem como as publicações duplicatas. 
Para facilitar a síntese e avaliação da qualidade dos estudos, utilizou-se um formulário para extração dos dados, adaptado com base nas recomendações do JBI, no qual constam algumas informações relevantes como: dados de publicação (ano, autores e país de origem); objetivos de estudo; características metodológicas (população, métodos, tipo de intervenção) e principais resultados. (9)

Os resultados deste estudo foram submetidos à análise descritiva do conteúdo, e apresentados em quadros analíticos que sintetizaram as informações chave, interpretando e comparando as produções, alinhando com o objetivo e escopo da revisão. Utilizou-se o checklist PRISMA como base para adequar as partes constituintes desta revisão, visando a qualidade do estudo. (10)

No que concerne à seleção e inclusão dos artigos, obedeceu-se à extensão PRISMA específica para revisões de escopo (PRISMA-ScR), que segue as orientações publicadas da Rede EQUATOR (Enhancing the Quaity and Transparency Of Health Research). (11)

A amostra inicial foi composta por 523 artigos, 50 registros foram removidos por duplicidade, resultando em 473 artigos selecionados para leitura de título e resumo. Dois revisores, de forma independente, selecionaram os estudos que julgaram serem adequados para leitura de texto completo. Após essa leitura, foram excluídos 377 registros com base nos critérios de inclusão e exclusão, restando 96 artigos, que foram lidos na integra e excluídos 77 por não apresentarem recomendações significativas para esta revisão. Por conseguinte, 19 atenderam aos critérios de inclusão e fizeram parte da amostra final (Figura 1). 


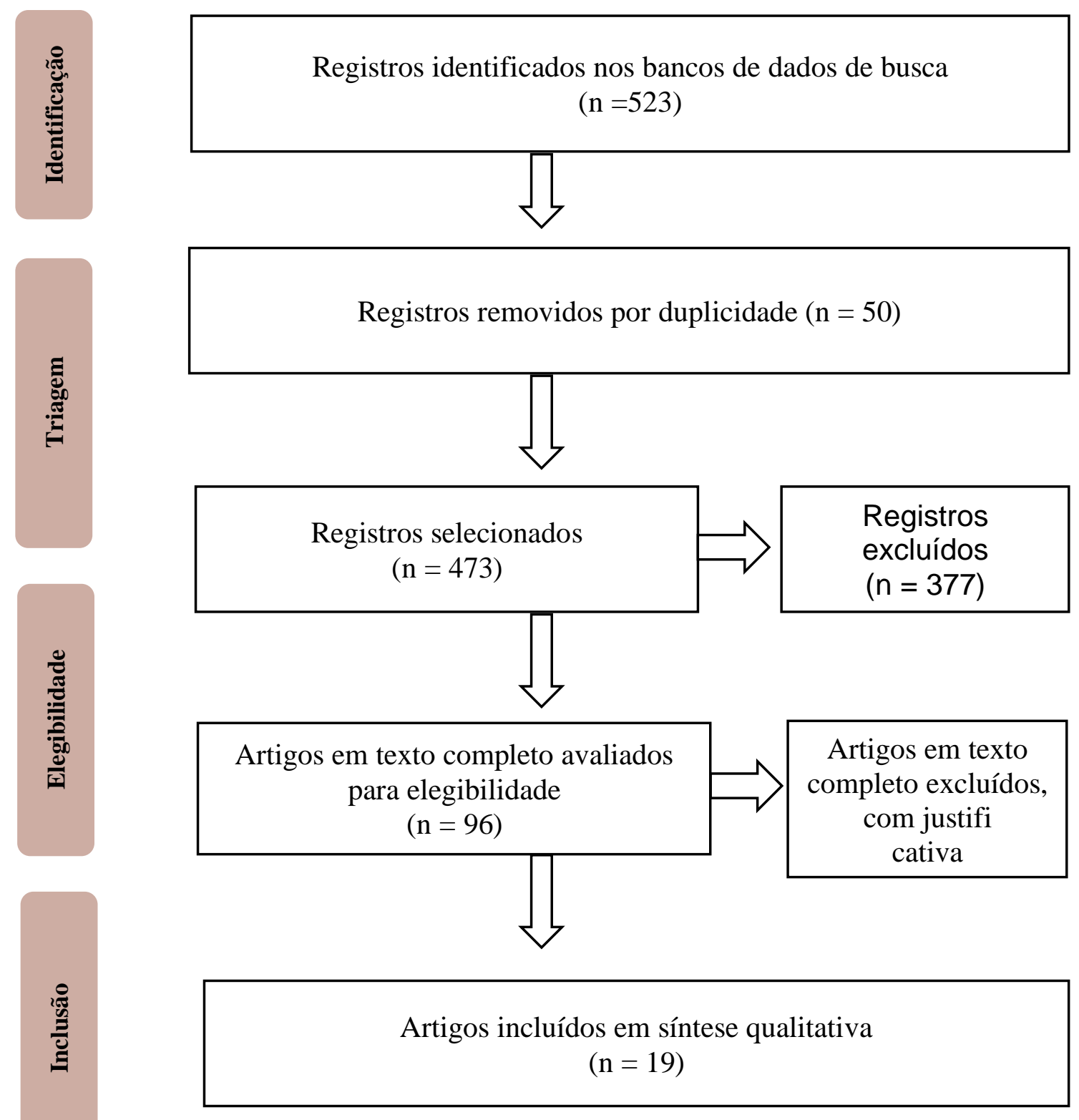

Figura 1 - Diagrama de fluxo do processo de seleção dos artigos da revisão, PRISMA-ScR.

Teresina, PI, Brasil, 2020.

\section{DESENVOLVIMENTO}

Os 19 estudos selecionados após análise e que compõem a amostra final são apresentados a seguir (Quadro 3): 
Quadro 3 - Registros incluídos pela revisão de escopo, segundo título, periódico e país de origem. Teresina, PI, Brasil, 2020.

\begin{tabular}{|c|c|c|c|}
\hline Citação & Título do artigo & Título do periódico & $\begin{array}{l}\text { País de } \\
\text { origem }\end{array}$ \\
\hline (12) & $\begin{array}{l}\text { Management of newborns exposed to } \\
\text { mothers with confirmed or suspected } \\
\text { COVID-19 }\end{array}$ & Journal of Perinatology & EUA \\
\hline (13) & $\begin{array}{l}\text { Guidance on breastfeeding during the } \\
\text { Covid-19 pandemic }\end{array}$ & REV ASSOC MED BRAS & Brasil \\
\hline (5) & $\begin{array}{l}\text { Neonatal Resuscitation and } \\
\text { Postresuscitation Care of Infants Born } \\
\text { to Mothers with Suspected or } \\
\text { Confirmed SARS-CoV-2 Infection }\end{array}$ & Am J Perinatol & EUA \\
\hline (14) & $\begin{array}{l}\text { Perinatal-Neonatal Management of } \\
\text { COVID-19 Infection - Guidelines of the } \\
\text { Federation of Obstetric and } \\
\text { Gynaecological Societies of India } \\
\text { (FOGSI), National Neonatology Forum } \\
\text { of India (NNF), and Indian Academy of } \\
\text { Pediatrics (IAP) }\end{array}$ & Indian Pediatr & Índia \\
\hline (15) & $\begin{array}{l}\text { Skin-to-Skin Contact at Birth in the } \\
\text { COVID-19 Era: In Need of Help! }\end{array}$ & $\begin{array}{l}\text { American Journal of } \\
\text { Perinatology }\end{array}$ & EUA \\
\hline (16) & $\begin{array}{l}\text { Breastfeeding and coronavirus disease- } \\
\text { 2019: Ad interim indications of the } \\
\text { Italian Society of Neonatology endorsed } \\
\text { by the Union of European Neonatal \& } \\
\text { Perinatal Societies }\end{array}$ & Maternal \& Child Nutrition & Itália \\
\hline (17) & $\begin{array}{l}\text { Novel Coronavirus disease (COVID-19) } \\
\text { in newborns and infants: what we know } \\
\text { so far }\end{array}$ & Italian Journal of Pediatrics & Itália \\
\hline (18) & $\begin{array}{c}\text { Management of neonates after } \\
\text { postpartum discharge and all children } \\
\text { in the ambulatory setting during the } \\
\text { coronavirus disease } 2019 \text { (COVID-19) } \\
\text { pandemic }\end{array}$ & Curr Opin Pediatr & EUA \\
\hline (19) & $\begin{array}{l}\text { Care recommendations for parturient } \\
\text { and postpartum women and newborns } \\
\text { during the COVID-19 pandemic: a } \\
\text { scoping review }\end{array}$ & $\begin{array}{l}\text { Rev. Latino-Am. } \\
\text { Enfermagem }\end{array}$ & Brasil \\
\hline (20) & SARS-CoV-2 Infection and the Newborn & Frontiers in Pediatrics & Itália \\
\hline
\end{tabular}




\begin{tabular}{|c|c|c|c|}
\hline Citação & Título do artigo & Título do periódico & $\begin{array}{l}\text { País de } \\
\text { origem }\end{array}$ \\
\hline (21) & $\begin{array}{l}\text { Management of the mother-infant dyad } \\
\text { with suspected or confirmed SARS-CoV- } \\
2 \text { infection in a highly epidemic context }\end{array}$ & J Neonatal Perinatal Med & Itália \\
\hline$(22)$ & $\begin{array}{l}\text { Care of newborns born to mothers with } \\
\text { COVID-19 infection; a review of existing } \\
\text { evidence }\end{array}$ & $\begin{array}{l}\text { Journal of Maternal-Fetal \& } \\
\text { Neonatal Medicine }\end{array}$ & EUA \\
\hline (23) & $\begin{array}{l}\text { Care of the COVID-19 exposed complex } \\
\text { newborn infant }\end{array}$ & Seminars in Perinatology & EUA \\
\hline (24) & $\begin{array}{c}\text { COVID-19 and Neonatal Respiratory } \\
\text { Care: Current Evidence and Practical } \\
\text { Approach }\end{array}$ & $\begin{array}{l}\text { American Journal of } \\
\text { Perinatology }\end{array}$ & EUA \\
\hline (25) & $\begin{array}{l}\text { Expert recommendations for the CARE } \\
\text { of newborns of mothers with COVID-19 }\end{array}$ & CLINICS & Brasil \\
\hline (26) & $\begin{array}{c}\text { Management of covid-19: a practical } \\
\text { guideline for maternal and newborn } \\
\text { health care providers in Sub-Saharan } \\
\text { Africa }\end{array}$ & $\begin{array}{l}\text { The Journal of Maternal- } \\
\text { Fetal \& Neonatal Medicine }\end{array}$ & Nigéria \\
\hline (27) & $\begin{array}{l}\text { Nota técnica no 10/2020- } \\
\text { COCAM/CGCIVI/DAPES/SAPS/MS: } \\
\text { Atenção à saúde do recém-nascido no } \\
\text { contexto da infecção do novo } \\
\text { Coronavírus (SARS-COV-2). }\end{array}$ & Ministério da Saúde & Brasil \\
\hline (28) & $\begin{array}{c}\text { Nota Técnica no } 004 / 2020- \\
\text { DAPS/SPS/SES: Orientações sobre o } \\
\text { Atendimento da Gestante, Puérpera e } \\
\text { Recém Nascido no enfrentamento à } \\
\text { pandemia de COVID-19. }\end{array}$ & Ministério da Saúde & Brasil \\
\hline (29) & $\begin{array}{l}\text { Nota de Recomendação №: } 2 / 2020 \text { - } \\
\text { SAIS- 03083: Recomendações dos } \\
\text { Tutores Estaduais para a estratégia de } \\
\text { Atenção Humanizada ao Recém-Nascido } \\
\text { - Método Canguru, frente aos desafios } \\
\text { enfrentados diante da pandemia } \\
\text { decorrente de COVID-19. }\end{array}$ & Ministério da Saúde & Brasil \\
\hline
\end{tabular}

Ao analisar os estudos selecionados, observa-se que a maioria é proveniente dos Estados Unidos da América (EUA) ( $n=7)$, seguido por Brasil $(n=6)$, Itália $(n=4)$, Nigéria $(n=1)$ e Índia $(n=1)$. Considerando a atualidade do tema abordado, quanto ao ano de publicação, todos foram em 2020, nos idiomas inglês e português, publicados em periódicos diversos, como detalhado no quadro acima. 
Referente aos desenhos de pesquisas dos registros incluídos, tratam-se de notas técnicas $(n=2)$, artigos de recomendações $(n=5)$, artigos de revisão $(n=9)$, editoriais $(n=1)$ e artigos de opinião $(n=2)$.

A partir da análise dos resultados dos estudos selecionados, optou-se por apresentar e discuti-los em categorias conceituais gerais: $1^{\mathfrak{a}}$ ) recomendações assistenciais ao RN em sala de parto, sendo subdividida em contato pele a pele; clampeamento do cordão umbilical e reanimação em sala de parto; 2 ${ }^{\underline{a}}$ ) recomendações assistenciais ao $\mathrm{RN}$ internado em unidades neonatais e $3^{\underline{a}}$ ) recomendações assistenciais ao RN em alojamento conjunto e cuidados pós-alta, composta por subcategorias, incluindo: aleitamento materno; alta hospitalar e cuidados ao RN em domicílio (Quadro 4).

Quadro 4 - Recomendações assistenciais ao RN em sala de parto, unidades neonatais, alta hospitalar e domicílio. Teresina, PI, Brasil, 2020.

\section{Recomendações assistenciais ao RN em sala de parto}

\section{Contato pele a pele}

- Mães ou bebês com suspeita ou COVID-19 confirmado, podem permanecer junto com contato pele a pele, especialmente imediatamente após o nascimento durante o início da amamentação (30).

- Nenhum dado, até o momento, apresenta um risco aumentado de contágio de SARS-CoV-2 do recém-nascido após contato pele a pele com uma mãe COVID-19 positiva. Portanto, aconselha-se que deve continuar a ser praticado, conforme recomendação da OMS para todas as mulheres, incluindo aquelas positivas para COVID-19, desde que sejam seguidas cuidadosamente as medidas de prevenção de infecções. (16)

- A tomada de decisão compartilhada com os pais antes do parto em relação aos riscos potenciais e benefícios dos cuidados pele a pele e mãe canguru é recomendado. (5)

- Recomenda-se que as parturientes sintomáticas ou que tenham contato domiciliar com pessoa com síndrome gripal ou infecção respiratória comprovada por SARS-CoV-2, deve ser suspenso o contato pele a pele e o recém-nascido pode ser secado com o cordão intacto, não sendo necessário banho. (27)

\section{Clampeamento do cordão umbilical}

- A Sociedade Internacional de Ultrassom em Obstetrícia e Ginecologia (ISUOG), segundo as evidências existentes, recomenda que o cordão umbilical deve ser pinçado rapidamente para reduzir o risco de transmissão vertical. No entanto, o Royal College of Obstetricians e Ginecologistas (RCOG) recomendam que o clampeamento tardio do cordão umbilical pode ser feito rotineiramente porque durante o parto é improvável o risco de transmissão com mais de um minuto de perfusão através da placenta.

- Os benefícios superam o risco improvável de adquirir COVID-19 por meio do clampeamento tardio, devendo ser realizado por pelo menos 60 segundos se o bebê é vigoroso. (5)

\section{Reanimação em sala de parto}

- Se possível, a ressuscitação do neonato pode ser feita em uma sala adjacente fisicamente separada, reservada para este objetivo. Se não for viável, o aquecedor de ressuscitação deve ser fisicamente separado da mãe na sala de parto por uma distância de pelo menos 2 metros;

- Um número mínimo de pessoal deve comparecer (uma pessoa em casos de baixo risco e dois em casos de alto risco onde a ressuscitação extensa pode ser antecipada); 
- $\quad 0$ cordão umbilical deve ser clampeado prontamente e contato pele a pele evitado;

- Se a ventilação com pressão positiva for necessária, bolsa e máscara auto infláveis ou um reanimador de peça em T com tubos descartáveis podem ser usados. Peças descartáveis devem ser descartadas (mesmo que não sejam usadas) e equipamentos reutilizáveis devem ser desinfetados após cada uso;

- As indicações para intubação não devem mudar por causa de status de COVID-19 materno;

- Realizar aspiração somente se necessário para evitar aerossolização;

- Bebês prematuros que requerem ventilação mecânica devem ser isolados de preferência em uma sala de pressão negativa.

\section{Recomendações assistenciais ao RN internado em unidades neonatais}

- Deve-se respeitar as distâncias entre os leitos e incubadoras.

- As discussões à beira do leito e atividades coletivas na unidade neonatal devem ser suspensas.

- Informações sobre o RN deverão ser fornecidas aos pais por meio telefônico ou virtual.

- Recomenda-se que as instituições avaliem a suspensão da entrada nas UTIN, UCINCo, UCINCa de qualquer outra pessoa além do pai ou da mãe, ainda que assintomáticas e que não sejam contatos domiciliares com o intuito de evitar aglomerações nas unidades.

- Todos os visitantes devem ser triados antes da entrada no hospital e na UTIN para sintomas consistentes com COVID-19 incluindo febre subjetiva ou medida, tosse, dispneia, dor de garganta, congestão nasal, coriza, mialgia, fadiga, diarreia ou perda do paladar ou do olfato.

- Todos os bebês nascidos de mães COVID-19-positivas devem ter uma amostra de esfregaço nasofaríngeo para SARS-CoV-2 obtido em 24 horas de vida. Se o resultado do teste de 24 horas for negativo, deve ser repetido e realizado de acordo com os sintomas e recursos locais de teste, por exemplo, no $5^{\circ}$ e $14^{\circ}$ dias de vida.

- Se a unidade neonatal está muito ocupada, crianças com resultados semelhantes podem estar na mesma enfermaria, a 2 metros de distância entre eles.

- Os RNs devem ser transportados dentro do hospital e entre os hospitais em uma incubadora e ambulância fechada e deve ser equipada com um ventilador, medicamentos, desinfetantes de superfície e para as mãos. Antes e após o transporte, a incubadora e a ambulância devem ser desinfectados.

\section{Cuidados ventilatórios ao $\mathrm{RN}$ internado}

- Durante o uso de CPAP ou VNI, as estratégias de precaução incluem: isolamento em local bem ventilado, sala de pressão negativa com troca de ar ideal, prevenção de vazamento em torno da interface e adição de filtros virais/bacterianos na porta de expiração do reservatório de água do CPAP.

- 0 uso de alto fluxo ou cânula nasal não é recomendado, pois pode ser associado a uma dispersão significativa de partículas virais.

- Devido ao risco potencial de transmissão, a intubação endotraqueal deve ser realizada por profissionais qualificados e experientes, usando EPI completo.

\section{Recomendações assistenciais ao RN em alojamento conjunto e cuidados pós-alta}

\section{Aleitamento materno}

- Até o momento, não há evidências que comprovem a transmissão do SARS-CoV-2 por meio do leite materno.

- 0 aleitamento materno deve ser encorajado, pois os benefícios superam o possível risco de contaminação pelo vírus.

- Não há consenso nas evidências disponíveis quanto a conduta de iniciar e dar continuidade no aleitamento por mães com COVID-19. Essa decisão deve ser tomada de comum acordo entre a puérpera e os profissionais de saúde envolvidos no cuidado.

- A amamentação deve continuar com a mãe lavando cuidadosamente as mãos usando uma máscara durante o procedimento para minimizar a exposição viral adicional do RN.

- Se o alojamento conjunto não for possível por causa da doença no neonato ou na mãe, o RN deve ser alimentado com leite materno ordenhado da mãe por uma enfermeira ou 


\begin{tabular}{|l|}
\hline $\begin{array}{l}\text { um membro da família treinado que não esteve em contato com a mãe ou outro caso } \\
\text { suspeito/comprovado, desde que o recém-nascido possa tolerar a alimentação enteral. }\end{array}$ \\
\hline Alta hospitalar \\
\hline - \\
Bebês infectados podem receber alta do hospital se: \\
1) Não há febre por 3 dias consecutivos \\
2) Os sintomas respiratórios remitem \\
3) Os achados radiológicos pulmonares graves resolvem \\
4) Os esfregaços nasofaríngeos colhidos com 24 horas de intervalo são negativos. \\
- No momento da alta, a mãe deve ser orientada para os sinais de alerta de adoecimento \\
do recém-nascido, incluindo febre; má alimentação; vômito ou inchaço; letargia; \\
sonolência; dificuldade respiratória; gemidos; piora da intensidade da icterícia; diurese \\
reduzida e cianose e a procurar assistência de acordo com o fluxo estabelecido pelos \\
protocolos assistenciais validados pelo Ministério da Saúde. \\
Orientação sobre o uso de luvas e a higiene das mãos deve ser fornecida aos membros \\
da família e cuidadores, considerando que indivíduos não infectados com mais de 60 \\
anos de idade e com comorbidades não devem cuidar do recém-nascido. (25) \\
\hline Cuidados ao RN em domicílio \\
- Se a mãe positiva estiver na mesma casa, ela deve manter uma distância de pelo menos \\
1,8 m pelo maior tempo possível. Quando for necessário estar perto do recém-nascido, \\
ela deve usar máscara e realizar frequentemente a higiene das mãos; \\
Manter o quarto com temperatura e umidade adequadas; \\
- Manter o quarto bem arejado, de preferência com janelas; \\
- Minimizar as visitas e contatos físicos; \\
Deve ser dada atenção especial à primeira semana de vida do RN, visto que esta é a fase \\
de maior risco para os óbitos infantis. As condições de saúde da criança, o apoio ao \\
aleitamento materno e a triagem neonatal são ações importantes e indispensáveis neste \\
período.
\end{tabular}

A partir dos resultados, foi possível verificar que as publicações sobre a infecção neonatal por COVID-19 ainda são incipientes, com poucos estudos originais desenvolvidos até então, visto que ainda é uma doença surgida recentemente no cenário atual e principalmente se tratando dos cuidados aos RNs confirmados ou suspeitos.

No que se refere ao conceito, considera-se suspeito de infecção por SARSCoV-2 os recém-nascidos de mães com histórico de infecção pelo vírus entre 14 dias antes do parto até 28 dias após o parto ou os neonatos diretamente expostos àqueles infectados (incluindo familiares, cuidadores, equipe de saúde e visitantes), independentemente de apresentarem sintomas. (31,32,33,34)

As informações sobre a transmissão de SARS-CoV-2 de grávidas infectadas para o feto ainda são incertas. Considera-se que a viremia é vista em apenas $1 \%$ dos casos de COVID-19, sugerindo que a transmissão materno-fetal pode ser bastante rara. (33) No entanto, se a viremia estiver presente, a doença é mais grave, pois o receptor da Enzima Conversora de Angiotensina (ECA2) é amplamente expresso na placenta, com um domínio de ligação ao receptor semelhante a estrutura do SARS- 
CoV-2. Porém, até agora, os achados de Reação de cadeia de Polimerase (PCR) de fetos suspeitos foram negativos, bem como do líquido amniótico e achados de placenta. (35)

Por conseguinte, os dados existentes até o momento, embora não muito sólidos do ponto de vista científico, sugerem que a principal via de transmissão de Covid-19 para neonatos é por gotículas infectadas de cuidadores, incluindo os profissionais da saúde, ou, secundariamente, através do contato com material biológico inato. (15)

Nesse sentido, recomenda-se que sejam tomadas precauções para prevenir gotículas e contaminações durante o cuidado de recém-nascidos e suas mães, por meio do uso de Equipamento de Proteção Individual (EPI), incluindo aventais, luvas, máscaras cirúrgicas e proteção para os olhos (óculos ou protetor facial), para assim, evitar a contaminação tanto do paciente, quanto do profissional cuidador. (15)

O impacto das infecções pelo novo coronavírus tem aumentado rapidamente à medida que cresce exponencialmente o quantitativo de infectados, e suas repercussões em gestantes e recém-nascidos ainda são incertas. Um amplo estudo pediátrico de base populacional, evidenciou 2.143 casos, e mais de $90 \%$ deles variou de assintomático a moderado. No entanto, a proporção de casos graves e críticos foi de 10,6\% com menos de 1 ano de idade, em comparação com 7,3, 4,2, 4,1 e 3,0\% entre os 1-5, 6-10, 11-15 e subconjuntos> 15 anos, sugerindo que bebês podem estar em maior risco de insuficiência respiratória grave do que inicialmente pensado. (31)

Quanto às manifestações clínicas, não há achado específico para os recémnascidos. A temperatura corporal pode ser alta, normal ou baixa e podem apresentar sintomas respiratórios, como tosse, taquipnéia, apnéia, dilatação nasal e taquicardia, bem como letargia, vômitos, diarréia e distensão abdominal. (36,37) Em casos graves e em casos de deficiência imunológica, doença cardíaca congênita, displasia broncopulmonar, anomalias do trato respiratório, desnutrição ou anemia, os resultados devem ser interpretados com mais cautela. (20)

Considerando a assistência ao recém-nascido (RN), no que se refere às recomendações em sala de parto, deve ocorrer em uma sala com pressão negativa e toda a equipe deve usar EPI. Caso a sala com pressão negativa não estiver disponível, um local separado deve ser usado e a quantidade de profissionais presentes deve 
ser mantida no mínimo. 0 cuidado inicial do recém-nascido não deve ser atrasado devido ao COVID-19, e deve ser feito de acordo com os procedimentos padrão. (38)

Com relação ao contato pele a pele, a OMS recomenda que mães ou bebês com suspeita ou COVID-19 confirmado, podem permanecer em contato pele a pele, especialmente imediatamente após o nascimento, se possível durante o início da amamentação ${ }^{(5,31)}$. No entanto, alguns estudos não recomendam esse contato direto entre mães e recém-nascidos, considerando o atual cenário de pandemia, já que eles acreditam que a transmissão de SARS-Cov-2 através do contato pele a pele não pode ser descartado. (39)

O clampeamento oportuno do cordão umbilical para o bebê vigoroso permite uma redistribuição de sangue da placenta de volta para o bebê e mantém a précarga, o que não aumenta o risco de transmissão vertical da COVID-19 e seus benefícios incluem aumento de hemoglobina, ferro e neurodesenvolvimento melhorado. (5)

Nesse sentido, a Faculdade de Obstetrícia e Ginecologia Americana (ACOG) não recomenda mudança na prática de clampeamento tardio do cordão em casos de COVID-19 confirmados ou suspeitos, até que haja evidência suficiente (40). Em contrapartida, alguns especialistas defendem a abstenção de clampeamento tardio do cordão umbilical, apesar da escassez de evidências científicas. (22,41,42)

Nos casos em que seja necessário realizar reanimação neonatal, é importante ressaltar que durante os procedimentos as equipes multidisciplinares devem estar equipadas com EPI como uma precaução contra a transmissão por ar, gotículas e por contato, devido ao aumento da probabilidade de aerossóis com vírus maternos e a necessidade potencial de intubação traqueal, aspiração das vias aéreas e ventilação com pressão positiva, que também podem gerar aerossóis para o recém-nascido. (25)

Um dos princípios para realizar a ressuscitação cardiopulmonar durante uma pandemia é minimizar a exposição do profissional de saúde, para isso, se faz necessário montar uma equipe pequena - com dois a quatro profissionais - levando em consideração a complexidade de cada caso, podendo aumentar o quantitativo de profissionais presentes. Ressalta-se que a necessidade varia em intensidade dependendo da condição do recém-nascido e fatores de risco. (23)

A avaliação da necessidade de internação em unidade neonatal é feita com base na idade gestacional, condição do recém-nascido, necessidade para 
antibióticos, fluidos intravenosos, suporte respiratório e política hospitalar individual. Salienta-se que uma equipe treinada para o atendimento aos recémnascidos de mãe suspeita ou confirmada para COVID-19 pode minimizar a transmissão e propagação do SARS-CoV-2 entre os profissionais de saúde. (5)

É ressaltado que para a proteção dos profissionais de saúde é necessário implementar de forma consistente as práticas de cuidado que incluem isolamento adequado, uso de EPI de maneira correta e vias aéreas seguras / cuidados respiratórios. Além disso, é imperativo manter as melhores práticas de alimentação e vínculo para melhorar todos os resultados neonatais. (23)

No que tange à amamentação, a maior preocupação atual é a contaminação do recém-nascido por gotículas eliminadas pela mãe contaminada, todavia deve ser encorajada, caso seja possível e adiada para o momento em que os cuidados de higiene e as medidas de prevenção da contaminação do neonato, como limpeza da parturiente (banho no leito), troca de máscara, touca, camisola e lençóis, tiverem sido adotados. (28,43)

Por fim, devido à proporção mundial da COVID-19, os estudos selecionados para compor esta revisão foram de países diversos. A proporção maior de estudos foram: artigos de revisão, recomendações, notas técnicas e artigos de opinião, o que denotaria baixa evidência científica.

Presume-se que esta revisão de escopo contribui para o avanço científico, ao passo que realizou o mapeamento da produção de conhecimento disponível sobre as principais recomendações para a assistência ao recém-nascido de mãe suspeita ou confirmada para COVID-19. Além disso, as recomendações apresentadas neste estudo podem servir como reflexões para as práticas clínicas atuais, bem como estímulo à produção de novos estudos sobre este tema e metodologia, considerando o alto fluxo de conhecimento científico acerca do novo coronavírus e a necessidade de conhecimento dos possíveis impactos futuros aos recém-nascidos expostos ao vírus.

Entende-se como limitações desta revisão de escopo o intenso fluxo de informações sobre a temática, o que dificulta a disponibilidade de recomendações estáveis. Além da escassez de ensaios clínicos controlados ou observacionais e a presença majoritária de estudos de revisão e recomendações, o que aumenta os riscos de viés das informações. Outra limitação dos achados, foi a escolha por 
selecionar estudos em apenas três idiomas, visto que alguns artigos que poderiam ter sido incorporados foram originados na China e utilizaram o idioma nativo.

\section{CONCLUSÕES}

Esta revisão de escopo, possibilitou apresentar um mapeamento da produção de conhecimento sobre as recomendações para a assistência ao recém-nascido de mãe suspeita ou confirmada para COVID-19, incluindo cuidados em sala de parto, alojamento conjunto, unidades neonatais, alta hospitalar e no domicílio, abordando os principais aspectos como amamentação, reanimação neonatal, contato pele a pele, clampeamento do cordão umbilical e cuidados ventilatórios.

Os resultados demonstram que os neonatos representam um grupo suscetível e vulnerável para complicações referentes ao COVID-19, tendo em vista a imaturidade do seu sistema imunológico. Deste modo, considerou-se relevante a produção de conhecimento sobre as recomendações assistenciais aos recémnascidos de mãe suspeita ou confirmada para coronavírus.

Ainda que as evidências científicas não sejam suficientes para a definição de recomendações precisas e protocoladas para o enfrentamento do coronavírus, o que pode ser justificado pelo seu recente surgimento, foi possível mapear as diversas práticas que podem ser recomendadas na assistência neonatal por meio do conhecimento prévio e dos resultados dos artigos disponíveis, especificamente no que se refere aos cuidados em sala de parto, reanimação neonatal, medidas de precaução, contato pele a pele, clampeamento do cordão umbilical, assistência em unidades neonatais, cuidados respiratórios, recomendações na alta hospitalar e em domicílio.

Propõe-se que estudos adicionais com maior rigor metodológico devem ser desenvolvidos com o intuito de superar as controvérsias sobre o contato pele a pele, o clampeamento tardio do cordão umbilical e o banho imediato do RN. Por se tratar de um conteúdo novo, algumas recomendações apresentadas podem ser modificadas de acordo com o surgimento de novos conhecimentos e com as diretrizes de cada país. 
1. Rothan HA, Byrareddy SN. The epidemiology and pathogenesis of coronavirus disease (COVID-19) outbreak. Journal of autoimmunity. [Internet]. 2020 [acceso: 25/05/2020]; 109:102433. DOI: https://doi.org/10.1016/j.jaut.2020.102433.

2. Guan WJ, Ni ZY, Hu Y, Liang WH, Ou CQ, He JX. Clinical Characteristics of Coronavirus Disease 2019 in China. N Engl J Med. [Internet]. 2020 [acceso: 22/05/2020]; 382 (18): 1708-1720. DOI: https://doi.org/10.1056/nejmoa2002032.

3. Li Q, Guan X, Wu P, Wang X, Zhou L, Tong Y et al. Early Transmission Dynamics in Wuhan, China, of Novel Coronavirus-Infected Pneumonia. N Engl J Med. [Internet]. 2020 [acceso: 23/05/2020]; 382(13):1199-1207. DOI: https://doi.org/10.1056/nejmoa2001316.

4. Deng CX. The global battle against SARS-CoV-2 and COVID-19. Int J Biol Sci. [Internet]. 2020; 16(10):1676-1677. DOI:10.7150/ijbs.45587. Available from: https://www.ijbs.com/v16p1676.htm.

5. Chandrasekharan P, Vento M, Trevisanuto D, Partridge E, Underwood MA, Wiedeman $\mathrm{J}$ et al. Neonatal Resuscitation and Postresuscitation Care of Infants Born to Mothers with Suspected or Confirmed SARS-CoV-2 Infection. Am J Perinatol. 2020; 37 (8): 813-824. DOI: https://doi.org/10.1055/s-0040-1709688.

6. Shalish W, Lakshminrusimha S, Manzoni P, Keszler M, Sant'Anna GM. COVID19 and Neonatal Respiratory Care: Current Evidence and Practical Approach. Am J Perinatol. [Internet]. 2020; 37 (8): 780-791. DOI: https://dx.doi.org/10.1055\%2Fs-0040-1710522.

7. Arksey H, O'Malley L. Scoping studies: towards a methodological framework. International journal of social research methodology. [Internet]. 2005; 8(1): 19-32. DOI: https://doi.org/10.1080/1364557032000119616.

8. Anderson S, Allen P, Peckham S, Goodwin N. Asking the right questions: scoping studies in the commissioning of research on the organisation and delivery of health services. Health research policy and systems. [Internet]. 2008; 6 (1): 1-12. DOI: https://doi.org/10.1186/1478-4505-6-7.

9. Joanna Briggs Institute. The Joanna Briggs Institute. Joanna Briggs Institute Reviewers' Manual: 2015 edition. The Joanna Briggs Institute. [Internet]. 2015.

10. Tricco AC, Lillie E, Zarin W, O'Brien KK, Colquhoun H, Levac D et al. PRISMA extension for scoping reviews (PRISMA-ScR): checklist and explanation. Annals of internal medicine. [Internet]. 2018; 169 (7): 467-473. DOI: https://doi.org/10.7326/M18-0850. 
11. Moher D, Liberati A, Tetzlaff J, Altman DG. PRISMA GROUP. Preferred reporting items for systematic reviews and meta-analyses: the PRISMA statement. PLoS Med. [Internet]. 2009; 6(7):e1000097. DOI: https://doi.org/10.1371/journal.pmed.1000097.

12. Amatya S, Corr TE, Gandhi CK, Glass KM, Kresch MJ, Mujsce DJ et al. Management of newborns exposed to mothers with confirmed or suspected COVID-19. Journal of Perinatology. [Internet]. 2020; 40 (7): 987996. DOI: https://doi.org/10.1038/s41372-020-0695-0.

13. Calil VMLT, Krebs VLJ, Carvalho WB. Guidance on breastfeeding during the Covid-19 pandemic. Revista da Associação Médica Brasileira. 2020; 66 (4): 541-546. DOI: http://dx.doi.org/10.1590/1806-9282.66.4.541.

14. Chawla D, Chirla D, Dalwai S, Deorari AK, Ganatra A, Gandhi A et al. Perinatalneonatal management of COVID-19 infection- guidelines of the Federation of Obstetric and Gynaecological Societies of India (FOGSI), National Neonatology Forum of India (NNF), and Indian Academy of Pediatrics (IAP). Indian pediatrics. [Internet]. 2020.57 (6): 536-548. DOI: https://doi.org/10.1007/s13312-020-1852-4.

15. Davanzo R, Merewood A, Manzoni P. Skin-to-Skin Contact at Birth in the COVID-19 Era: In Need of Help!. American Journal of Perinatology. [Internet]. 2020; 37 (S02): S1-S4. DOI: 10.1055/s-0040-1714255. Disponível em: :https://www.thieme-

connect.com/products/ejournals/abstract/10.1055/s-0040-1714255\#info.

16. Davanzo R, Moro G, Sandri F, Agosti M, Moretti C, Mosca F. Breastfeeding and coronavirus disease-2019: Ad interim indications of the Italian Society of Neonatology endorsed by the Union of European Neonatal \& Perinatal Societies. Maternal \& Child Nutrition. [Internet]. 2020. 16 (3): e13010. DOI: https://doi.org/10.1111/mcn.13010.

17. De Rose DU, Piersigilli F, Ronchetti MP. Novel Coronavirus disease (COVID19) in newborns and infants: what we know so far. Ital J Pediatr. [Internet]. 2020; 46 (56):1-8. DOI: https://doi.org/10.1186/s13052-020-0820-x.

18. Harriel KL, Nolt D, Moore S, Kressly S, Bernstein HH. Management of neonates after postpartum discharge and all children in the ambulatory setting during the coronavirus disease 2019 (COVID-19) pandemic. Current opinion in pediatrics. [Internet]. 2020. 32, (4): 610. DOI: https://dx.doi.org/10.1097\%2FMOP.0000000000000931.

19. Mascarenhas VHA, Caroci-Becker A, Venâncio KCMP, Baraldi NG, Durkin AC, Riesco MLG. Care recommendations for parturient and postpartum women and newborns during the COVID-19 pandemic: a scoping review. Revista latino-americana de enfermagem. [Internet]. 2020; 28. DOI: http://dx.doi.org/10.1590/1518-8345.4596.3359. 
20. Ovali, F. SARS-CoV-2 Infection and the newborn. Frontiers in Pediatrics, [Internet]. $2020 ; \quad 8: 294 . \quad$ DOI: https://dx.doi.org/10.3389\%2Ffped.2020.00294.

21. Pietrasanta C, Pugni L, Ronchi A, Schena F, Davanzo R, Gargantini G et al. Management of the mother-infant dyad with suspected or confirmed SARSCoV-2 infection in a highly epidemic context. Journal of Neonatal-Perinatal Medicine. [Internet]. 2020; 13 (3): 307-311. DOI: 10.3233/NPM-200478. Disponível em:

22. https://content.iospress.com/articles/journal-of-neonatal-perinatalmedicine/npm200478.

23. Shahbazi Sighaldeh S, Ebrahimi Kalan M. Care of newborns born to mothers with COVID-19 infection; a review of existing evidence. The Journal of Maternal-Fetal \& Neonatal Medicine. [Internet]. 2020; p. 1-13. DOI: https://doi.org/10.1080/14767058.2020.1777969.

24. Krishnamurthy G, Sahni R, Leone T, Kim F, Brooks MC, Morales SV et al. Care of the COVID-19 exposed complex newborn infant. In: Seminars in perinatology. 2020; $44(7): \quad 151282 . \quad$ DOI: https://dx.doi.org/10.1016\%2Fj.semperi.2020.151282.

25. Shalish W, Lakshminrusimha S, Manzoni P, Keszler M, Sant'Anna GM. COVID19 and neonatal respiratory care: current evidence and practical approach. American journal of perinatology. [Internet]. 2020; 37 (8): 780. DOI: https://dx.doi.org/10.1055\%2Fs-0040-1710522.

26. Carvalho WBD, Gibelli MABC, Krebs VLJ, Calil VMLT, Johnston C. Expert recommendations for the care of newborns of mothers with COVID19. Clinics, [Internet]. 2020; $75 . \quad$ DOI: https://doi.org/10.6061/clinics/2020/e1932.

27. Ezenwa BN, Fajolu IB, Akinajo OR, Makwe CC, Oluwole AA, Akase IE et al. Management of covid-19: a practical guideline for maternal and newborn health care providers in Sub-Saharan Africa. The Journal of Maternal-Fetal \& Neonatal Medicine. [Internet]. 2020; 1-7. DOI: https://doi.org/10.1080/14767058.2020.1763948.

28. Ministério da Saúde (BR). Secretaria de Atenção Primária à Saúde. Nota Técnica no 10/2020-COCAM/CGCIVI/ DAPES/SAPS/MS. Atenção à saúde do recém-nascido no contexto da infecção pelo novo coronavírus (SARS-CoV-2). 2020. Disponível

em: https://saude.rs.gov.br/upload/arquivos/202006/03180219-notatecnica10-2020-cocamcgcividapessapsms-003.pdf.

29. Ministério da Saúde (BR). Secretaria de Estado da Saúde. Nota Técnica $\mathrm{n}$ o 004/2020- DAPS/SPS/SES. Orientações sobre o Atendimento da Gestante, Puérpera e Recém Nascido no enfrentamento à pandemia de COVID-19. 2020. Disponível em: https://www.cosemssc.org.br/nota-tecnica-no-0042020-daps-sps-ses-sc/. 
30. Ministério da Saúde (BR). Secretaria de Estado da Saúde. Nota de Recomendação №: 2/2020 - SAIS- 03083. Recomendações dos Tutores Estaduais para a estratégia de Atenção Humanizada ao Recém-Nascido Método Canguru, frente aos desafios enfrentados diante da pandemia decorrente de COVID-19. 2020. Disponível em: https://docs.bvsalud.org/biblioref/2020/07/1104106/nota-de-recom-no22020-sais-recom-tutores-estaduais-atencao-hu_SNTTXFE.pdf.

31. World Health Organization. Clinical management of severe acute respiratory infection when COVID-19 disease is suspected. [Internet]. 2020. [acceso 2020 Jun 5]. Disponível em: https://apps.who.int/iris/bitstream/handle/10665/331446/WHO-2019nCoV-clinical-2020.4-chi.pdf.

32. Dong Y, Mo X, Hu Y, Qi X, Jiang F, Jiang Z et al. Epidemiology of COVID-19 Among Children in China. Pediatrics. [Internet]. 2020;145(6):e20200702. DOI: https://doi.org/10.1542/peds.2020-0702.

33. Li F, Feng ZC, Shi Y. Proposal for prevention and control of the 2019 novel coronavirus disease in newborn infants. Arch Dis Child Fetal Neonatal Ed. 2020;0 (0):F1. DOI: http://dx.doi.org/10.1136/archdischild-2020-318996.

34. Wang L, Shi Y, Xiao T, Fu J, Feng X, Mu D et al. Chinese expert consensus on the perinatal and neonatal management for the prevention and control of the 2019 novel coronavirus infection (First edition). Ann Transl Med. 2020;8(3):47. DOI: https://dx.doi.org/10.21037\%2Fatm.2020.02.20.

35. Xia W, Shao J, Guo Y, Peng X, Li Z, Hu D. Clinical and CT features in pediatric patients with COVID-19infection: Different points from adults. Pediatric Pulmonology. 2020;1-6. DOI: https://doi.org/10.1002/ppul.24718.

36. Chen H, Guo J, Wang C, Luo F, Yu X, Zhang W, et al. Clinical characteristics and intrauterine vertical transmission potential of COVID-19 infection in nine pregnant women: a retrospective review of medical records. The Lancet. 2020; 20: 30360-3. DOI: https://doi.org/10.1016/S0140-6736(20)30360-3.

37. Shek CC, Ng PC, Fung GPG, Cheng FWT, Chan PKS, Peiris MJS, et al. Infants born to mothers with severe acute respiratory syndrome. Pediatrics. 2003; 112 (4): e254. DOI: https://doi.org/10.1542/peds.112.4.e254.

38. Cai JH, Wang XS, Ge YL, Xia AM, Chang HL, Tian H, et al. First case of 2019 novel coronavirus infection in children in Shanghai. Chin J Pediatr. 2020; 58:E002. DOI: https://doi.org/10.3760/cma.j.issn.0578-1310.2020.02.002.

39. Zhu H, Wang L, Fang C, Peng S, Zhang L, Chang G, et al. Clinical analysis of 10 neonates born to mothers with 2019-nCoV pneumonia. Transl Pediatr. 2020; 9 (1): 51-60. DOI: https://doi.org/10.21037/tp.2020.02.06.

40. Ashokka B, Loh MH, Tan CH. Care of the pregnant woman with COVID-19 in labor and delivery: anesthesia, emergency cesarean delivery, differential diagnosis in the acutely ill parturient, care of the newborns, and protection 
of the health care personnel. Am J Obstet Gynecol. 2020; 9: e2:1-9. D0I: https://doi.org/10.1016/j.ajog.2020.04.005.

41. American College of Obstetricians and Gynecologists. COVID-19 FAQs for Obstetrician-Gynecologists, Obstetrics. 2020. Available online at: https://www.acog.org/clinical-information/physician-faqs/covid-19-faqsfor-ob-gyns-obstetrics.

42. Poon LC, Yang H, Lee JCS, Copel JA, Leung TY, Zhang Y, et al. ISUOG interim guidance on 2019 novel coronavirus infection during pregnancy and puerperium: information for healthcare professionals. Ultrasound Obstet Gynecol. 2020. DOI: https://doi.org/10.1002/uog.22013.

43. Chen D, Yang H, Cao Y, Cheng W, Duan T, Fan C, et al. Expert consensus for managing pregnant women and neonates born to mothers with suspected or confirmed novel coronavirus (COVID19) infection. Int J Gynaecol Obstet. 2020. 149 (2): 130-136. DOI: https://doi.org/10.1002/ijgo.13146.

44. Mariani Neto C. Nota complementar sobre COVID-19 e aleitamento materno. FEBRASGO, 18 Março 2020. Disponível em: https://www.febrasgo.org.br/pt/noticias/ item / 949-notulacomplementar-sobre-covid-19-e-aleitamento-materno.

\section{CONFLITO DE INTERESSE}

Os autores declaram não haver conflitos de interesse

\section{CONTRIBUIÇÕES DOS AUTORES}

Açucena Barbosa Nunes: Participou do delineamento do estudo, contextualização, busca nas bases, análise dos artigos identificados, apresentação e discussão dos resultados, redação do manuscrito, revisão crítica do artigo, edição e aprovação da versão final.

Márcia Teles de Oliveira Gouveia: Participou da análise crítica e aprovação da versão final do artigo. 


\title{
CAPITULO XII
}

\section{PRÁTICAS OBSTÉTRICAS HUMANIZADORAS REALIZADAS PELA EQUIPEDEENFERMAGEM}

DDI: 10.51859/amplla.esp917.1121-12

Ivana Mayra da Silva Lira ${ }^{1}$

Simone Santos e Silva Melo ${ }^{2}$

Márcia Teles de Oliveira Gouveia ${ }^{3}$

Maria Carolina da Silva Costa 4

\begin{abstract}
${ }^{1}$ Mestre em Enfermagem pela Universidade Federal do Piauí -UFPI, Enfermeira Obstetra - UFPI, Teresina, PI, Brasil

${ }^{2}$ Mestre em Enfermagem pela Universidade Federal do Piauí - UFPI, Teresina, PI, Brasil

3 Doutora em Ciências pela Escola de Enfermagem de Ribeirão Preto da Universidade de São Paulo. Professora Adjunta do Departamento de Enfermagem da Universidade Federal do Piauí. Teresina, Piauí, Brasil.

${ }^{4}$ Enfermeira pela Universidade Federal do Piauí - UFPI. Especializanda em Enfermagem Neonatal e Pediátrica UFPI, Teresina, PI, Brasil
\end{abstract}

Objetivo: Analisar na literatura nacional e internacional quais são as práticas obstétricas utilizadas pela equipe de enfermagem na perspectiva do cuidado humanizado. Método: Trata-se de uma revisão integrativa da literatura, em que foram selecionados artigos do ano de 2010 a 2017 nas bases Scientific Eletronic Library Online - Scielo, Scientific Eletronic Library Online - CINALH e Banco de Dados em Enfermagem - BDENF. Foram encontrados 516, dos quais apenas 12 foram analisados depois de aplicados critérios de inclusão e exclusão. Resultados: após analise dos artigos selecionados, os resultados foram organizados em duas categorias: práticas que estimulam o vínculo enfermagem-parturiente e cuidados obstétricos humanizadores proporcionados pela equipe de enfermagem. Conclusão: 0 vínculo profissional - parturiente é essencial para a construção do cuidado que respeite os valores, crenças e demandas da parturiente. A equipe de enfermagem ao viabilizar o exercício do direito do parto humanizado, favorece o sentimento de segurança que é significativo para o sucesso do parto.

Palavras-chave: Parto humanizado. Humanização da Assistência. Enfermeiro Obstetra. 
O parto, até o século XX, era um acontecimento de natureza íntima e privativa, sendo compartilhado apenas entre mulheres, considerado fenômeno natural, cercado de significados culturais, e o nascimento celebrado como evento marcante da vida. Todavia, no decorrer dos anos, houve mudanças que tornaram essa cultura um acontecimento médico-hospitalar (ROCHA; MELO; MEDEIROS, 2017).

Por outro lado, o parto humanizado é entendido como prática de cuidado ao parto e ao nascimento, garantindo uma qualidade de assistência segura que valoriza a escolha do ato de dar à luz de forma natural privativa e familiar. 0 conceito de atenção humanizada ao parto é amplo e envolve um conjunto de conhecimentos, práticas e atitudes que visam à promoção do parto e do nascimento saudável e à prevenção da morbimortalidade materna e perinatal. Faz- se necessário uma relação de confiança, que foque nas necessidades e anseios da parturiente, além de permitir uma concepção segura (PEREIRA et al., 2016).

Diante disso, o Brasil implantou políticas públicas aplicadas ao contexto da assistência obstétrica e neonatal visando à promoção do parto e do nascimento saudáveis e à prevenção da morbimortalidade materna e perinatal, de modo a garantir que profissionais médicos e enfermeiras parteiras realizem procedimentos comprovadamente benéficos para a mulher e neonato, evitando intervenções desnecessárias e preservando a privacidade e a autonomia desses sujeitos, reforçando assim as boas práticas de assistência ao parto (ROCHA; MELO; MEDEIROS, 2017).

Os profissionais de saúde são coadjuvantes desta experiência, pois têm a oportunidade de colocar seu conhecimento a serviço do bem-estar da mulher e do bebê, reconhecendo os momentos críticos em que suas intervenções são necessárias para assegurar a saúde de ambos. Podem minimizar a dor, ficar ao lado, dar conforto, esclarecer, orientar, enfim, ajudar a parir e a nascer (PEREIRA et al., 2016).

0 acolhimento da parturiente pela equipe de enfermagem pode contribuir para um atendimento humanizado, porém essa contribuição só existirá se o acolhimento for entendido como um processo onde todos os que compõem uma equipe multiprofissional estejam qualificados e capacitados para tal ato (SILVA et al., 2016). 
Assim esse contexto é um meio de contribuir para a melhoria do atendimento prestado as mulheres pela equipe de enfermagem no âmbito da obstetrícia, observando as práticas de atenção ao parto e nascimento recomendados pela Organização Mundial Saúde. Nesse intuito, o objetivo desse estudo é analisar na literatura nacional e internacional, quais são as práticas obstétricas utilizadas pela equipe de enfermagem na perspectiva do cuidado humanizado.

\section{MATERIAIS E MÉTODOS}

Trata-se de uma revisão integrativa, método que tem como finalidade sintetizar as pesquisas publicadas, para obter novas conclusões a partir de um tema de interesse. Na operacionalização dessa revisão, utilizaram-se as seguintes etapas: definiçãa da pergunta norteadora; definição dos critérios de inclusão das produções científicas; busca dos estudos nas bases de dados; análise dos resumos dos estudos; seleção dos estudos, de acordo com os critérios de inclusão; avaliação criteriosa e fichamento dos estudos selecionados; e análise dos dados (MENDES; SILVEIRA; GALVÃO, 2008).

A pergunta norteadora foi: que práticas obstétricas são utilizadas pela equipe de enfermagem na perspectiva da humanização do cuidado? Utilizou-se a estratégia PICO para busca dos artigos a qual viabiliza o processo de encontrar respostas apropriadas às duvidas advindas da prática (NOBRE; BERNARDO, JATENE, 2003).

Desse modo, empregaram-se critérios de inclusão: artigos que disponibilizassem o texto completo, artigos com a versão online de maneira gratuita, publicados nos idioma português, inglês ou espanhol. 0 espaço temporal delimitado foram os anos de 2010 a 2017 a fim de retratar a produção científica da atualidade. Foram excluídas teses, dissertações, monografias e artigos de revisão integrativa ou que, após leitura do resumo, não convergiam com o objeto do estudo proposto, além das publicações que se repetiram nas bases de dados.

A busca dos artigos foi realizada nas bases Scientific Eletronic Library Online - Scielo, Scientific Eletronic Library Online - CINALH e Banco de Dados em Enfermagem - BDENF, realizadas no mês de setembro e outubro de 2017. Foram utilizados descritores padronizados e disponíveis nos Descritores em Ciências da Saúde (DeCS): Parto humanizado; humanização da assistência; e enfermeiro 
obstetra; e no Medical Subject Headings - (MeSH): Obstetric nursing; Vaginal birth; humanization of care. Empregou-se a busca com o uso do conector and, que permitiu acessar os artigos que possuíam intersecção entre os diferentes descritores.

Inicialmente foram encontrados 576 artigos, sendo excluídos 370 por não estarem disponíveis na íntegra e ou não atender os critérios de inclusão. Outros 20 artigos foram excluídos por encontrarem se em duplicidade, mantendo o somente uma vez. Logo após foram retirados 168 por não ter relação com a temática estudada. Restaram 18 artigos para leitura minuciosa, dos quais apenas 12 artigos possibilitaram responder a pergunta norteadora. A amostra final para elaboração desta revisão foi de 12 artigos.

\section{RESULTADOS E DISCUSSÃO}

O levantamento dos resultados e a realização das discussões deram-se após a leitura minuciosa de todos os artigos compilados, descritos a seguir:

Tabela 1 - Síntese dos estudos incluídos (n=12). Teresina, PI, Brasil, 2021.

\begin{tabular}{|c|c|c|c|}
\hline Título & $\begin{array}{c}\text { Autor } \\
\text { principal/ } \\
\text { revista/ ano }\end{array}$ & $\begin{array}{l}\text { Tipo de } \\
\text { estudo }\end{array}$ & Principais resultados \\
\hline $\begin{array}{l}\text { Care Practices In } \\
\text { Normal Birth: } \\
\text { Residence Type } \\
\text { Formation }\end{array}$ & $\begin{array}{c}\text { Santos et al./ J } \\
\text { Nurs UFPE/ } \\
2017\end{array}$ & $\begin{array}{c}\text { Quantitativo } \\
\text { Descritivo }\end{array}$ & $\begin{array}{c}\text { A maioria das parturientes } \\
\text { contou com acompanhante; } \\
\text { foi incentivada a realizar } \\
\text { técnicas de respiração } \\
\text { deambular e tomar banho } \\
\text { morno. A taxa de } \\
\text { episiotomia foi de } 5,1 \% \text {. }\end{array}$ \\
\hline $\begin{array}{l}\text { As práticas } \\
\text { humanizadas } \\
\text { desenvolvidas } \\
\text { por enfermeiras } \\
\text { obstétricas na } \\
\text { assistência ao } \\
\text { parto hospitalar }\end{array}$ & $\begin{array}{l}\text { Porfírio et al./ } \\
\text { Rev. Eletr. } \\
\text { Enf./ } 2010\end{array}$ & Qualitativo & $\begin{array}{l}\text { As práticas incorporadas no } \\
\text { contexto da humanização } \\
\text { foram referentes ao banho } \\
\text { de aspersão, a orientação } \\
\text { para uma respiração } \\
\text { tranquila, a valorização da } \\
\text { liberdade de movimentos. }\end{array}$ \\
\hline $\begin{array}{l}\text { Normal Birth } \\
\text { Assisted By } \\
\text { Nurse: } \\
\text { Experience And } \\
\text { Satisfaction Of } \\
\text { Puerperals } \\
\end{array}$ & $\begin{array}{c}\text { Freire et al./ J } \\
\text { Nurs UFPE/ } \\
2017\end{array}$ & $\begin{array}{l}\text { Descritivo } \\
\text { Transversal }\end{array}$ & $\begin{array}{c}48,6 \% \text { das mulheres } \\
\text { referiram ter usado } \\
\text { bastantes métodos de } \\
\text { relaxamento e respiração } \\
\text { no trabalho de parto e } \\
\text { parto. }\end{array}$ \\
\hline
\end{tabular}




\begin{tabular}{|c|c|c|c|}
\hline Título & $\begin{array}{c}\text { Autor } \\
\text { principal/ } \\
\text { revista/ ano }\end{array}$ & $\begin{array}{l}\text { Tipo de } \\
\text { estudo }\end{array}$ & Principais resultados \\
\hline $\begin{array}{c}\text { The Care Of } \\
\text { Nurses Of An } \\
\text { Obstetric } \\
\text { Residence } \\
\text { Program Under } \\
\text { The Scope Of } \\
\text { Humanization }\end{array}$ & $\begin{array}{l}\text { Giantaglia et } \\
\text { al./ J Nurs } \\
\text { UFPE/2017 }\end{array}$ & $\begin{array}{c}\text { Descritivo } \\
\text { Qualitativo }\end{array}$ & $\begin{array}{c}\text { Verificou-se a } \\
\text { importância do profissional } \\
\text { oferecer respeito e } \\
\text { segurança por meio da } \\
\text { assistência qualificada. }\end{array}$ \\
\hline $\begin{array}{c}\text { Nursing Care } \\
\text { Experienced By } \\
\text { Women During } \\
\text { The Child-Birth } \\
\text { In The } \\
\text { Humanization } \\
\text { Perspective }\end{array}$ & $\begin{array}{l}\text { Silva et al./ J } \\
\text { Nurs UFPE/ } \\
\quad 2017\end{array}$ & $\begin{array}{l}\text { Exploratório } \\
\text { Descritivo } \\
\text { Qualitativo }\end{array}$ & $\begin{array}{c}\text { As vivências das } \\
\text { puérperas sobre a atuação } \\
\text { humanizada da } \\
\text { enfermagem são ambíguas, } \\
\text { destacam-se a comunicação } \\
\text { e o emprego de técnicas } \\
\text { não farmacológicas para } \\
\text { alívio da dor. }\end{array}$ \\
\hline $\begin{array}{l}\text { Características } \\
\text { Assistenciais Dos } \\
\text { Partos Normais } \\
\text { Atendidos Pelas } \\
\text { Enfermeiras } \\
\text { Obstétricas }\end{array}$ & $\begin{array}{c}\text { Pereira; } \\
\text { Dantas/ J Nurs } \\
\text { UFPE/ } 2012\end{array}$ & $\begin{array}{l}\text { Retrospectiva } \\
\text { Análise } \\
\text { documental }\end{array}$ & $\begin{array}{l}\text { No parto, a maioria das } \\
\text { mulheres pariu na posição } \\
\text { horizontal e ocorreu } \\
\text { laceração de períneo, com } \\
\text { predominância da } \\
\text { laceração de primeiro grau. } \\
\text { A episiotomia foi pouco } \\
\text { realizada }(15,5 \%) .\end{array}$ \\
\hline $\begin{array}{c}\text { Cuidados } \\
\text { humanizados: a } \\
\text { inserção de } \\
\text { enfermeiras } \\
\text { obstétricas em } \\
\text { um hospital de } \\
\text { ensino }\end{array}$ & $\begin{array}{c}\text { Medeiros et } \\
\text { al./ Rev Bras } \\
\text { Enferm/ } 2016\end{array}$ & Transversal & $\begin{array}{l}\text { Os resultados sugerem que } \\
\text { a inserção das enfermeiras } \\
\text { obstétricas contribuiu para } \\
\text { a qualificação da assistência } \\
\text { ao parto e ao nascimento, } \\
\text { uma vez que ocorreu a } \\
\text { redução de intervenções, } \\
\text { tais como a episiotomia e as } \\
\text { cesarianas. }\end{array}$ \\
\hline $\begin{array}{l}\text { Contribuição de } \\
\text { enfermeiras } \\
\text { obstétricas para } \\
\text { consolidação do } \\
\text { parto } \\
\text { humanizado em } \\
\text { maternidades no } \\
\text { Rio de Janeiro- } \\
\text { Brasil } \\
\end{array}$ & $\begin{array}{c}\text { Vargens; Silva; } \\
\text { Progianti/ Esc. } \\
\text { Anna Nery/ } \\
2017\end{array}$ & Transversal & $\begin{array}{l}\text { Nos partos, predominou a } \\
\text { adoção de posições } \\
\text { verticalizadas. O estímulo à } \\
\text { deambulação ocorreu em } \\
\text { 37,29\% dos partos. A } \\
\text { episiotomia ocorreu em } \\
\text { apenas 4,0\% dos partos. }\end{array}$ \\
\hline $\begin{array}{l}\text { Enfermagem } \\
\text { obstétrica: } \\
\text { contribuições às } \\
\text { metas dos }\end{array}$ & $\begin{array}{c}\text { Reis et al./ } \\
\text { Rev. Gaúcha } \\
\text { Enferm/ } 2015\end{array}$ & $\begin{array}{l}\text { Quantitativo } \\
\text { Retrospectivo }\end{array}$ & $\begin{array}{l}\text { Destaca-se que } 55,6 \% \text { das } \\
\text { mulheres não foram } \\
\text { submetidas a nenhuma } \\
\text { intervenção obstétrica }\end{array}$ \\
\hline
\end{tabular}




\begin{tabular}{|c|c|c|c|}
\hline Título & $\begin{array}{c}\text { Autor } \\
\text { principal/ } \\
\text { revista/ ano }\end{array}$ & $\begin{array}{l}\text { Tipo de } \\
\text { estudo }\end{array}$ & Principais resultados \\
\hline \multicolumn{4}{|l|}{$\begin{array}{c}\text { Objetivos de } \\
\text { Desenvolvimento } \\
\text { do Milênio }\end{array}$} \\
\hline $\begin{array}{c}\text { Practices in } \\
\text { childbirth care in } \\
\text { maternity with } \\
\text { inclusion of } \\
\text { obstetric nurses } \\
\text { in Belo } \\
\text { Horizonte, Minas } \\
\text { Gerais }\end{array}$ & $\begin{array}{l}\text { Sousa et al./ } \\
\text { Esc. Anna } \\
\text { Nery/2016 }\end{array}$ & Transversal & $\begin{array}{c}\text { Práticas úteis: dieta oral } \\
(54,6 \%), \text { livre } \\
\text { movimentação }(96 \%), \\
\text { métodos não } \\
\text { farmacológicos para dor } \\
(74,2 \%), \text { acompanhante } \\
(95,4 \%), \text { partograma } \\
(77,4 \%) ; \text { posição deitada } \\
(66,8 \%), \text { Kristeller }(9,3 \%) ; \\
\text { práticas usadas } \\
\text { inapropriadamente: } \\
\text { amniotomia }(67,1 \%), \\
\text { ocitocina }(41,7 \%), \\
\text { analgesia }(14 \%), \\
\text { episiotomia }(8,4 \%) .\end{array}$ \\
\hline $\begin{array}{c}\text { The Speech And } \\
\text { Practice Of } \\
\text { Humanizing } \\
\text { Childbirth In } \\
\text { Adolescents }\end{array}$ & $\begin{array}{c}\text { Silva et al./ } \\
\text { Texto } \\
\text { contexto/2013 }\end{array}$ & $\begin{array}{l}\text { Qualitativo } \\
\text { Descritivo }\end{array}$ & $\begin{array}{l}\text { Como práticas prejudiciais } \\
\text { salientaram-se a posição de } \\
\text { litotomia e o uso da } \\
\text { ocitocina. Destacaram-se } \\
\text { como práticas inadequadas } \\
\text { a restrição alimentar e a } \\
\text { utilização da amniotomia. }\end{array}$ \\
\hline $\begin{array}{c}\text { Humanização do } \\
\text { parto: } \\
\text { significados e } \\
\text { percepções de } \\
\text { enfermeiras }\end{array}$ & $\begin{array}{l}\text { Possati et al./ } \\
\text { Esc. Anna } \\
\text { Nery/2017 }\end{array}$ & Qualitativa & $\begin{array}{l}\text { A humanização do parto foi } \\
\text { compreendida como um } \\
\text { conjunto de práticas e } \\
\text { atitudes pautadas no } \\
\text { diálogo, empatia e } \\
\text { acolhimento; o } \\
\text { fornecimento de } \\
\text { orientações; a valorização } \\
\text { da singularidade da } \\
\text { parturiente. }\end{array}$ \\
\hline
\end{tabular}

Fonte: Autoria própria.

A discussão baseou-se na síntese do conhecimento evidenciado nos artigos analisados sobre a temática, a fim de contribuir para uma compreensão mais ampla das práticas obstétricas realizadas pela equipe de enfermagem na perspectiva do cuidado humanizado. A análise dos artigos possibilitou a construção de duas categorias que serão discutidas a seguir, a saber: práticas que estimulam o vínculo 
enfermagem-parturiente e cuidados obstétricos humanizados proporcionados pela equipe de enfermagem.

\subsection{PRÁTICAS QUE ESTIMULAM O VÍNCULO ENFERMAGEM-PARTURIENTE}

Em uma abordagem humanizada, é imprescindível que as demandas da mulher sejam valorizadas e respeitadas. É de suma importância que, durante a assistência à parturiente, haja uma escuta ativa e uma relação atenciosa, valorizando as questões subjetivas inerentes ao ser mulher, no intuito de que suas ações atendam às demandas e necessidades específicas de cada parturiente (PORFÍRIO; PROGIANTI; SOUZA, 2010).

Neste sentido, estar constantemente presente, dar atenção, conversar e até os pequenos gestos, como o contato físico, são elementos fundamentais no acolhimento e estabelecem uma relação de troca que favorece uma relação de confiança. $\mathrm{O}$ diálogo entre a equipe de enfermagem e a parturiente é imprescindível tendo em vista que ao acompanhar as mulheres durante o processo de parto, estes profissionais devem saber ouvi-las e valorizar suas necessidades, reconhecendo a importância de estabelecer uma comunicação neste momento por influenciar na vivência da mulher no parto e promover o vínculo entre equipe e a parturiente (SILVA et al., 2016).

A enfermeira obstétrica tem sido a profissional que, por entender e pensar sobre o parto numa perspectiva desmedicalizada e adotar as técnicas de alívio da dor com dialogo, compartilha, busca uma relação de parceria, respeita e fortalece a mulher durante o trabalho de parto e parto instrumentalizando-a no enfrentamento da dor fisiológica no parto além de prestar uma assistência de qualidade (VARGENS; SILVA; PROGIANTI, 2017).

Esclarecer a rotina e os procedimentos que serão realizados também auxilia no processo de parturição seja vivenciado de maneira tranquila e confiante pela mulher. Assim, ao conceituar a humanização do parto, pode-se entendê-la como um movimento pautado na individualidade e singularidade feminina, valorizando o protagonismo da mulher e permitindo uma maior congruência do cuidado com o sistema cultural de crenças e valores (POSSATI et al., 2017). 


\subsection{CUIDADOS OBSTÉTRICOS HUMANIZADOS PROPORCIONADOS PELA EQUIPE DE ENFERMAGEM}

A humanização, dentro do contexto hospitalar, inicia-se pela admissão e acolhimento da mulher, na identificação desta, procurando aplicar a empatia e passar todo conforto e segurança para que, assim, seja conquistada a confiança desta mulher (GIANTAGLIA et al., 2017).

0 parto realizado de forma humanizada visa à superação do medo e do isolamento que as mulheres sofrem no modelo assistencial obstétrico hegemônico, medicalizado e intervencionista. Para tal, o cuidado humano, integral e individualizado, cujas expectativas, necessidades e direitos das parturientes sejam considerados (PEREIRA, 2012).

Nessa perspectiva, enfatiza-se a importância da atuação da enfermeira obstetra no cenário de assistência ao parto e nascimento de risco habitual. Além de um cuidado menos intervencionistas, inerente a sua formação, a enfermeira obstetra mostra-se mais instigada a promover o uso de práticas baseadas em evidências e sensibilizada para o resgate do protagonismo da mulher no processo de parturição (REIS et al., 2015).

Dentre as práticas úteis e que devem ser estimuladas, a OMS inclui os métodos não invasivos e não farmacológicos de alívio da dor, como massagem e técnicas de relaxamento, durante o trabalho de parto. Deixar a parturiente escolher a posição preferida para cada momento, os exercícios que ela quer realizar, o que quer fazer neste momento único. Deixa- lá ser “dona do seu próprio corpo”, dando a ela toda a autonomia. Isso é essencial para que o respeito seja criado e, assim, haver o vínculo do profissional-paciente e com a família também (SANTOS et al., 2017; FREIRE et al., 2017).

Neste sentido, é importante salientar o termo paciência, o qual é discutido no cenário do trabalho de parto, e sua análise não deve se restringir ao seu significado de senso comum que a associa à personalidade de determinadas pessoas. No parto, a paciência está atrelada à qualidade da espera, principalmente em deixar o processo acontecer naturalmente, para que ocorra no tempo certo, ou seja, em esperar o tempo fisiológico do nascimento que deve ser determinado pela ação conjunta do feto e parturiente (SILVA et al., 2016). 
Há uma grande importância na presença do acompanhante no período de pré-parto, parto e puerpério, no entanto, em algumas instituições de saúde, o direito a ter um acompanhante durante o trabalho de parto e parto ainda é negado, geralmente em locais onde a atenção ao parto e nascimento segue predominantemente o modelo médico tecnocrático, tendo como consequência à negação de vários direitos das mulheres, dentre eles o direito a ter um acompanhante de sua escolha no momento do parto (SILVA et al., 2013).

0 contato pele a pele durante a primeira meia hora de vida do recém-nascido é outra ação humanizada que pode reduzir os índices de morbimortalidade materna e neonatal promovendo benefícios adicionais a curto e longo prazo, pois facilita o estabelecimento da amamentação, possibilita maior estabilidade térmica do RN, ajuda na expulsão placentária e incentiva o vínculo entre mãe e filho. Um estudo evidenciou que o recém-nascido se acalma ao sentir o calor materno e ao reconhecer a mãe. Esse contato traz alívio, segurança e emoção para a mãe, contribuindo para a formação de vínculo e atenua o sofrimento do parto (MEDEIROS et al., 2016).

Um estudo demonstrou que a realidade brasileira ainda clama pela incorporação de práticas obstétricas na assistência ao trabalho de parto, tais como: oferta de dieta oral $(25,2 \%)$, liberdade de posição e movimento $(44,3 \%)$, o uso de métodos não invasivos e não farmacológicos de alívio da dor $(26,7 \%)$, a presença contínua do acompanhante de livre escolha das mulheres $(18,8 \%)$ e monitoramento do progresso do parto por meio do uso do partograma (41,4\%) (SOUSA et al., 2016).

Dentre os procedimentos não farmacológicos para o alívio da dor utilizados, os mais recorrentes foram o banho de aspersão morno (58,2\%), o uso da bola suíça $(54,6 \%)$ e a deambulação $(47,1 \%)$. Trata-se de práticas de baixo custo que podem ser facilmente ofertadas pelos serviços de saúde, sendo que apresentam grande impacto na qualidade da assistência, principalmente por substituírem, na medida do possível, o uso de medicações anestésicas e analgésicas (MEDEIROS et al., 2016).

O uso da água por meio do banho morno de aspersão, das técnicas de respiração e da massagem promovem a redução da dor e o conforto da parturiente. No entanto, há uma divergência relacionada com a deficiência na estrutura física nas unidades brasileiras para a acomodação de banheiras ou piscinas de parto. Já a utilização da bola suíça promove a realização de alongamentos e exercícios ativos de circundução, anteversão e retroversão pélvica, o que favorece a participação mais 
ativa e o relaxamento global da mulher, deixando, assim, o processo de parturição mais tranquilo e servindo de suporte para outras técnicas como, por exemplo, a massagem e o banho de chuveiro (VARGENS; SILVA; PROGIANTI, 2017; GIANTAGLIA et al., 2017).

\section{CONSIDERAÇÕES FINAIS}

Diante do objetivo de discutir as práticas obstétricas humanizadas realizadas pela equipe de enfermagem foram evidenciados vários cuidados. As orientações acerca das posições maternas durante o trabalho de parto e parto são indispensáveis para o fortalecimento da autonomia da parturiente. Possibilitando a liberdade de movimentos à parturiente favorecemos a progressão fetal. 0 estabelecimento do vínculo com a parturiente é essencial para a construção do cuidado que respeite os valores, crenças e demandas da parturiente. Contribui para que o saber profissional não entre em choque com o saber da mulher, o que resulta em uma relação que favorece o relacionamento interpessoal.

A presença do acompanhante mostrou-se um componente importante para a manutenção de uma atmosfera familiar, natural e segura para o desenvolvimento do parto e nascimento. Desta forma, a equipe de enfermagem ao viabilizar o exercício deste direito da parturiente, favorece o sentimento de segurança que é significativo para o sucesso do parto.

\section{REFERÊNCIAS}

FREIRE H.S.S., et al. Normal Birth Assisted By Nurse: Experience And Satisfaction Of Puerperals. J Nurs UFPE on line, v.11, n.6, p.2357-67, 2017.

GIANTAGLIA F.N., et al. The Care Of Nurses Of An Obstetric Residence Program Under The Scope Of Humanization. J Nurs UFPE on line, v.11, n.5, p.1882-91, 2017.

MEDEIROS R.M.K., et al. Humanized Care: insertion of obstetric nurses in a teaching hospital. Rev. Bras. Enferm, v.69, n.6, p.1091-1098, 2016.

MENDES K.D. S; SILVEIRA R.C.C. P; GALVÃO C.M. Revisão integrativa: método de pesquisa para a incorporação de evidências na saúde e na enfermagem. Texto contexto enferm, v.17, n.4, p.758-764, 2008. 
NOBRE M.R. C; BERNARDO W.M; JATENE F.B. A prática clínica baseada em evidências. Parte I: questões clínicas bem construídas. Rev. Assoc. Med. Bras, v.49, n.4, p.445-449, 2003.

PEREIRA A.L; DANTAS F. Assistance Characteristics Of Normal Deliveries Attended By Obstetrical Nurses. Rev enferm UFPE on line, v.6, n.1, p.76-82, 2012.

PEREIRA S.S., et al. Parto natural: a atuação do enfermeiro diante da assistência humanizada. Tempus actas de saúde colet, v.10, n.3, p.199-213, 2016.

PORFÍRIO A.B; PROGIANTI J.M; SOUZA D.O.M. As práticas humanizadas desenvolvidas por enfermeiras obstétricas na assistência ao parto hospitalar. Rev. Eletr. Enf., v.12, n.2, p.331-6, 2010.

POSSATI A.B., et al. Humanização do parto: significados e percepções de enfermeiras. Esc. Anna Nery, v.21, n.4, p.1-6, 2017.

REIS T.R., et al. Enfermagem obstétrica: contribuições às metas dos Objetivos de Desenvolvimento do Milênio. Rev. Gaúcha Enferm, v.36, n.esp, p.94-101, 2015.

ROCHA F.R; MELO M.C; MEDEIROS G.A. Análise da Assistência ao Binômio Mãe-Bebê Em Centro De Parto Normal. Cogitare Enferm, v.22, n.2, p.1- 8, 2017.

SANTOS A.H.L., et al. Care Practices In Normal Birth: Residence Type Formation. J Nurs UFPE on line, v.11, n.1, p. 1-9, 2017.

SOUSA A.M.M., et al. Práticas na assistência ao parto em maternidades com inserção de enfermeiras obstétricas, em Belo Horizonte, Minas Gerais. Esc. Anna Nery, v.20, n.2, p.324-331, 2016.

SILVA R.C., et al. The speech and practice of humanizing childbirth in adolescents. Texto contexto - enferm, v.22, n.3, p.629-636, 2013.

SILVA U., et al. Nursing Care Experienced By Women During The Child-Birth In The Humanization Perspective. J Nurs UFPE on line, v.10, n.4, p. 1273-9, 2016.

VARGENS O.M. C; SILVA A.C. V; PROGIANTI J.M. Contribuição de enfermeiras obstétricas para consolidação do parto humanizado em maternidades no Rio de Janeiro-Brasil. Esc. Anna Nery, v.21, n.1, p.1-8, 2017. 


\section{CAPITULO XIII}

\section{SIFFLIS EM GESTANTES: ESTUDO EPIDEMIOLÓGICO SOBRE AS NOTIFICACÖES DO NORDESTEBRASILEIROE DO ESTADO DO PIAUÍ}

미: 10.51859/amplla.esp917.1121-13

Bárbara Emanuelly do Nascimento Silva ${ }^{1}$

Débora Vieira Lima Carvalho Guimarães ${ }^{1}$

Suelen Cristina Ramos da Rocha ${ }^{1}$

Lívia Maria Nunes de Almeida ${ }^{2}$

Izabel Cristina da Silva Carvalho ${ }^{3}$

Jardeliny Corrêa da Penha ${ }^{2}$

\footnotetext{
${ }^{1}$ Enfermeira. Egressa da Universidade Federal do Piauí, Campus Amílcar Ferreira Sobral - UFPI/CAFS

${ }^{2}$ Professora do Curso de Graduação Bacharelado em Enfermagem. Universidade Federal do Piauí, Campus Amílcar Ferreira Sobral - UFPI/CAFS

${ }^{3}$ Enfermeira. Secretária Municipal de Saúde de Floriano-Piauí - SMS
}

\section{RESUMO}

A sífilis é uma doença infecciosa transmitida por via sexual ou vertical. Quando acontece na gestação, pode gerar complicações ao binômio mãe-feto. Assim, objetivou-se descrever o cenário epidemiológico da sífilis em gestantes no Nordeste brasileiro e no estado do Piauí, no período de 2010 a 2020. É um estudo epidemiológico descritivo, retrospectivo, quantitativo, realizado a partir de dados secundários sobre casos de sífilis gestantes registrados no Painel de Indicadores Epidemiológicos sobre Sífilis. Foram coletados dados em abril de 2021 acerca do perfil sociodemográfico, idade gestacional, características clínicas e número de casos. Os dados foram tabulados e analisados descritivamente no Microsoft Excel, versão 2010. Sobre o perfil sociodemográfico, prevaleceram gestantes com ensino fundamental (in) completo, no Nordeste, 31.613 (43,2\%), e, no Piauí, 1.651 (46,5\%); de 20 a 29 anos de idade, no Nordeste, 37.839 (51,8\%), e no Piauí, 1.808 (50,9\%); e pardas, no Nordeste, $49.548(67,8 \%)$, e, no Piauí, 2.567 (72,2\%). Quanto à idade gestacional, predominou o $3^{\circ}$ trimestre, no Nordeste, 28.253 (38,7\%) e, no Piauí 1.469 (41,3\%). Acerca da classificação clínica, no Nordeste, 23.016 (31,5\%) casos eram de sífilis primária e, no Piauí, 1.169 (32,9\%), latente. A penicilina predominou como tratamento instituído, no Nordeste, 37.913 (86,9\%), e, no Piauí, 2.098 (91,3\%). Ademais, observou-se uma curva crescente de casos do início do período investigado até 2018, no Nordeste, e, no Piauí, até 2019. Esses achados desvelam que é necessário o desenvolvimento de ações de prevenção, rastreamento e tratamento precoce de sífilis em gestantes para evitar complicações ao binômio mãe-feto.

Palavras-chave: Sífilis. Gravidez. Epidemiologia Descritiva. 
Em todo mundo são diagnosticadas por dia cerca de um milhão de pessoas com infecções sexualmente transmissíveis (IST), entre as mais prevalentes estão: tricomoníase, clamídia, gonorreia e sífilis (BRASIL, 2018). Esta última é uma infecção de evolução crônica, provocada pela bactéria espiroqueta Treponema pallidum, do tipo gram negativa, a qual foi identificada em 1905, por Schaudinn e Hoffmann (SALES, 2021; TEIXEIRA; AZEVEDO, 2017)

A sífilis é de fácil disseminação, pode atingir diversos órgãos e sistemas, como pele, coração, fígado e sistema nervoso central, e ser transmitida por diversos meios, como contato direto com lesões de pacientes infectados, acidentes com substância contaminada e, principalmente, durante o ato sexual, sendo, nestes casos, classificada como sífilis adquirida, ou ainda por via transplacentária, da mãe para o concepto durante a gestação, dando origem à sífilis congênita (BRASIL, 2015; REINEHR et al., 2017; RODRIGUES, 2016).

Essa doença se torna extremamente preocupante ao acometer gestantes pela possibilidade de transmissão vertical, quando, disseminada pela corrente sanguínea da mãe, pode atravessar a barreira placentária e contaminar o feto, em qualquer período da gravidez (REIS et al., 2020), o que acarretará diferentes consequências, como parto prematuro, baixo peso ao nascer, manifestações congênitas de início precoce ou tardio, anemia, sofrimento respiratório, lesões cutaneomucosas, hidropsia fetal, abortamento ou natimortalidade, além de infertilidade e maior risco de a mulher contrair o Vírus da Imunodeficiência Humana(HIV) (BRASIL,2019;BORBA, 2020; DELBEN;PENHA, 2020;SILVA, 2017).

A fim de rastrear precocemente a sífilis em gestantes e facilitar tratamento o mais rápido possível e ainda impedir a transmissão vertical, o Ministério da Saúde (MS) recomenda que durante o pré-natal seja realizado pelo menos dois testes de Venereal Disease Research Laboratory (VDRL), um nos primeiros três meses e outro no início do último trimestre de gestação (BRASIL, 2010).

Ademais, considerando a possibilidade de uma reinfecção da mãe ou a não aderência ao tratamento, é recomendada a realização de um teste rápido antes do parto, no sentido de que, caso o bebê tenha um diagnóstico positivo, os cuidados necessários sejam iniciados precocemente (BRASIL, 2010). 0 teste rápido também 
deverá ser realizado em casos nos quais as mulheres residem em locais de recurso escasso, visto que otimizam o rastreamento e implantação do tratamento (PEREIRA, 2020).

Apesar de a sífilis ser uma doença de fácil diagnóstico, com tratamento eficiente e de baixo custo, disponível no Sistema Único de Saúde brasileiro, ela ainda ocupa um patamar de alta prevalência na população, sendo considerada um problema saúde pública, principalmente quando não ocorre o diagnóstico e tratamento em tempo oportuno (GUIMARÃES, 2018; SILVA; MORATO, 2019). A Organização Mundial de Saúde (OMS) estima que ocorram cerca de 12 milhões de casos de sífilis por ano em todo mundo, dos quais dois milhões são em gestantes (BRASIL, 2018; AMORAS et al., 2015).

Considerando esses dados epidemiológicos e as consequências da sífilis ao binômio mãe-feto, nota-se que é uma a magnitude dessa doença. Logo, o objetivo do presente estudo foi descrever o cenário epidemiológico da sífilis em gestantes no Nordeste brasileiro e no estado do Piauí, no período de 2010 a 2020.

\section{METODOLOGIA}

Trata-se de estudo epidemiológico descritivo, retrospectivo, de abordagem quantitativa, realizado a partir de dados secundários sobre notificações de sífilis em gestantes ocorridas na região Nordeste e no estado do Piauí, no período de 2010 a 2020, e contidas no Painel de Indicadores Epidemiológicos sobre Sífilis (http://indicadoressifilis.aids.gov.br/).

Os dados foram coletados em abril de 2010 no referido painel, utilizando-se "dados regionais e nacionais", em abrangência de dados, e "Nordeste", na subcategoria. Já para a coleta dos dados sobre o estado investigado, usou-se "dados estaduais", em abrangência de dados, e "Piauí", na subcategoria.

As informações coletadas foram sobre as seguintes variáveis: escolaridade, faixa etária, cor/raça, idade gestacional, classificação clínica, esquema de tratamento e o número de casos por ano.

Após a coleta, os dados foram tabulados e analisados descritivamente no “Microsoft Excel 10.0". Os resultados são apresentados por meio de frequências 
absolutas e relativas, demonstradas em texto, tabela e gráfico, e discutidas conforme literatura pertinente.

Pelo fato de se tratar de um estudo que analisa dados secundários, disponibilizados de forma pública e com acesso livre pela internet, não existiu a necessidade de submissão ao Comitê de Ética e pesquisa.

\section{RESULTADOS}

No presente estudo, foi avaliada a ocorrência de sífilis na gestação, entre os anos 2010 e 2020. Observou-se ao todo 73.056 casos notificados, no Nordeste, e 3.553, no Piauí. Sobre o perfil sociodemográfico das gestantes acometidas por esta doença, prevaleceram aquelas com ensino fundamental (in) completo, no Nordeste, 31.613 (43,2\%), e, no Piauí, 1.651 (46,5\%); de 20 a 29 anos de idade, no Nordeste, 37.839 (51,8\%), e no Piauí, 1.808 (50,9\%); e pardas, no Nordeste, 49.548 (67,8\%), e, no Piauí, 2.567 (72,2\%).

Quanto à idade gestacional, o terceiro trimestre predominou entre os casos registrados tanto no Nordeste, 28.253 (38,7\%), como no estado do Piauí, 1.469 $(41,3 \%)$.

Além das variáveis sociodemográficas e da idade gestacional, foram analisadas também as características clínicas (classificação clínica e esquema de tratamento), as quais são apresentadas na tabela 1.

Tabela 1. Caracterização clínica dos casos de sífilis identificados em gestantes, no período de 2010 a 2020, no Nordeste e no Piauí. 2021.

\begin{tabular}{lcccc} 
& \multicolumn{3}{c}{ CASOS DE SÍFILIS EM GESTANTES } \\
\cline { 2 - 5 } \multicolumn{1}{c}{ VARIÁVEIS } & \multicolumn{2}{c}{$\begin{array}{c}\text { Nordeste } \\
\text { (n=73.056) }\end{array}$} & \multicolumn{2}{c}{$\begin{array}{c}\text { Piaúi } \\
\text { (n=3.553) }\end{array}$} \\
\cline { 2 - 5 } & $\mathbf{N}$ & $\mathbf{\%}$ & & \% \\
\hline Classificação clínica & & & & \\
Sífilis primária & 23.016 & 31,5 & 962 & 27,1 \\
Sífilis secundária & 4.790 & 6,6 & 222 & 6,2 \\
Sífilis terciária & 8.614 & 11,8 & 535 & 15,1 \\
Sífilis latente & 15.420 & 21,1 & 1169 & 32,9 \\
Ignorada & 21.216 & 29,0 & 665 & 18,7 \\
Esquema de tratamento & & & & \\
Penicilina & 37.913 & 86,9 & 2.098 & 91,3 \\
Outro esquema & 1.166 & 2,7 & 27 & 1,2 \\
Não realizado & 2.467 & 5,7 & 146 & 6,4 \\
Ignorado & 2.070 & 4,7 & 27 & 1,2 \\
\hline
\end{tabular}

Fonte: Painel de Indicadores Epidemiológicos sobre Sífilis. 
De acordo com a tabela 1, a classificação clínica da sífilis predominante, no Nordeste, foi a primária, com 23.016 (31,5\%) registros, e, no Piauí, a latente, 1.169 $(32,9 \%)$. Em relação ao tratamento instituído, a penicilina foi o prevalente em ambas as localidades investigadas: Nordeste, com $37.913(86,9 \%)$ registros e o Piauí, com $2.098(91,3 \%)$.

A seguir, apresenta-se, por meio das frequências absolutas (porcentagens), a notificação dos casos de sífilis no Nordeste e no Piauí (figura 1), de 2010 a 2020.

Figura 1. Percentual da ocorrência de casos de sífilis em gestantes, no período de 2010 a 2020, ocorridos na região Nordeste e no estado do Piauí. 2021.

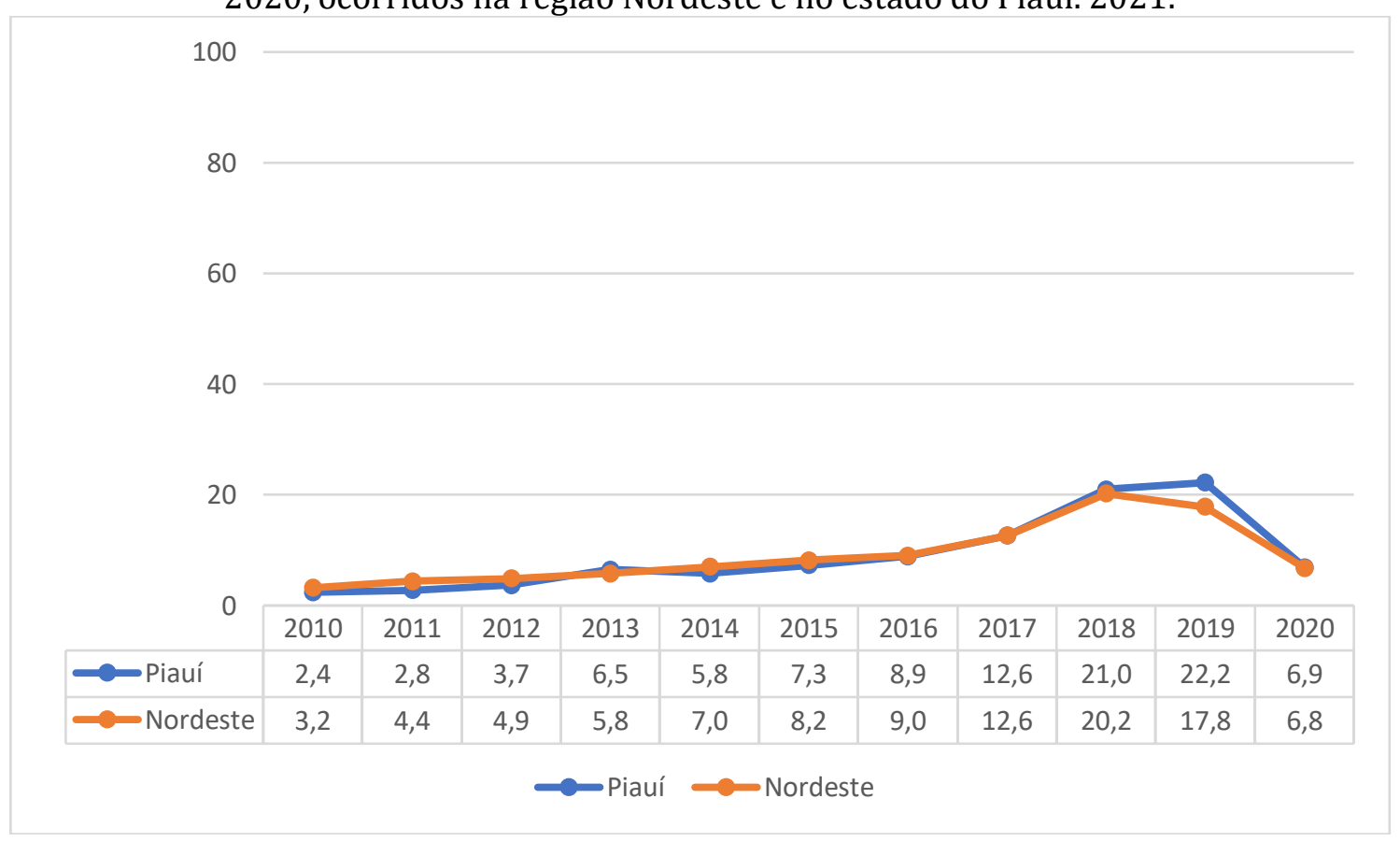

Fonte: próprias pesquisadoras.

No que se refere à ocorrência de sífilis em gestantes, observa-se que o ano de 2018 teve o maior percentual de ocorrência de casos de sífilis em gestantes na região Nordeste, 20,2\%, o que equivale a 14.780 notificações. Já no estado do Piauí, o ano de 2019 se destacou, com 788 (22,2\%) registros.

Além da avaliação acima, identifica-se, no gráfico, uma curva crescente dos casos de sífilis em gestantes notificados do início do período investigado até o ano de 2018, no Nordeste, e até o ano de 2019, no Piauí.

Ademais, nota-se que em apenas três anos o Piauí apresentou um percentual de ocorrência da doença maiores que o da região brasileira analisada, foram eles: 2013, 6,5\%; 2019, 22,2\%; e 2020, 6,9\%; comparados, respectivamente, com 5,8\%, 
17,8\% e 6,8\%. 0 ano de 2017 obteve percentual semelhantes nas duas localidades investigadas.

\section{DISCUSSÃO}

O presente estudo permitiu o levantamento dos casos de sífilis em gestantes, ocorridos nos anos de 2010 a 2020, no Nordeste e no estado Piauí. Quanto ao perfil sociodemográfico, observou-se mulheres com ensino fundamental completo e incompleto, adultas jovens, com 20 a 29 anos de idade, e pardas.

De maneira a corroborar com parte desses achados, estudo realizado em um Hospital Universitário, por Cabral et al. (2017), em Santa Cruz, Rio Grande do Norte, no qual foram utilizadas as fichas de notificação e prontuários das gestantes com sífilis, identificou que, dentre os 41 casos registrados no período de 2013 a 2015, 22 $(53,7 \%)$ mulheres tinham ensino fundamental incompleto e completo. Do mesmo modo, pesquisa desenvolvida por Trevisan et al. (2018), no município de Francisco Beltrão, Paraná, que também investigou as fichas de notificação de gestantes com sífilis, constatou que $24(61,5 \%)$ gestantes também tinham cursado até o ensino fundamental.

A baixa escolaridade é um fator importante para a maior ocorrência de agravos à saúde materna e infantil, como exemplo: para o desfecho de sífilis congênita, pois a gestante não possui instrução para reconhecimento da sua situação clínica e, assim, os estágios da infecção ganha progressão tendo como resultante a sífilis congênita (NONATO et al., 2015; XIMENES et al., 2008). Monteiro et al. (2015) destacam ainda que a ocorrência de sífilis é maior em primigestas com baixa escolaridade.

No que se refere à faixa etária, houve predomínio de mulheres adultas jovens nos dois locais desta pesquisa. Semelhantemente, estudo retrospectivo realizado a partir de dados da Secretária Municipal de Vespasiano e Belo Horizonte, Minas Gerais, do período de janeiro de 2013 a dezembro de 2018, revelou que, dos 327 casos identificados em Vespasiano, 183 (55,9\%) eram de mulheres entre 20 e 29 anos de idade, e dos 1.511 (52,1\%) casos de Belo Horizonte, gestantes com sífilis também possuíam a mesma faixa etária (TOGNERI; PÁDUA; LAGE, 2019). 
No Brasil, no estado e cidade de São Paulo, estudo epidemiológico de caráter transversal, observacional, que avaliou dados secundários de sífilis gestacional notificados pelo Sistema de Informação de Agravos de Notificação (SINAN), entre os anos de 2007 e 2016, mostrou que a faixa etária mais encontrada foi de 20 a 29 anos na cidade de São Paulo foi de, 1.512 (50,40\%) (BOTTURA et al., 2019). De 2014 a 2018, resultado similar foi encontrado por Costa et al. (2021), em São Paulo.

Esses achados podem ser justificados pelo fato de as mulheres estarem no ápice da vida reprodutiva. Além disso, por estarem grávidas, podem ter optado pelo não uso do preservativo. Fernandes et al. (2000), em pesquisa realizada em São Paulo, revelaram que $27,0 \%$ das mulheres não utilizaram preservativos por estarem grávidas.

O preservativo garante uma dupla proteção, prevenindo a ocorrência de IST. Além disso, destaca-se que o fato de a mulher estar grávida faz com que ocorra um rebaixamento do padrão de imunidade, alteração no $\mathrm{pH}$ da vagina e fragilidade da mucosa vaginal, acarretando mais vulnerabilidade às IST, entre elas a sífilis (FERNANDES, 2000).

Barbosa et al. (2019) afirmam que grande parte das mulheres possuem conhecimento da importância do uso de preservativo, mas que, mesmo assim, não o utiliza para prevenção de infecções, pois diversos fatores podem impedir o acordo para a utilização de preservativo, como a inserção da sociedade patriarcal, na qual somente o homem pode decidir a utilização ou não desse método, além da falsa percepção de segurança devido o afeto entre casais e a não percepção da exposição da própria suscetibilidade incitando ao não uso de preservativo.

No que concerne à cor/raça, o achado deste estudo assemelha-se aos resultados dos estudos desenvolvidos em Três Corações, Minas Gerais (NOGUCHI et al., 2018), em um município da região do Cariri, Ceará (MIRANDA et al., 2020), e Montes Claros, Minas Gerais (LAFETÁ et al., 2016). Todos corroboram, portanto, com o último censo realizado pelo Instituto Brasileiro de Geografia e Estatística (IBGE, 2010), 43,1\% da população brasileira declarou ser parda.

Sobre a idade gestacional, o terceiro trimestre foi comum na Região Nordeste e no estado do Piauí. Do mesmo modo, em Caxias, Maranhão, estudo realizado a partir de dados fornecidos pela Vigilância Epidemiológica da Secretária Municipal de Saúde, com informações proeminentes do SINAN, identificou a predominância de 
gestantes com sífilis diagnosticadas no 3ํㅡㄹ trimestre, 69 (46,3\%) (CONCEIÇÃO et al., 2020). Já Cavalcante et al. (2017), em pesquisa que descreveu o perfil epidemiológico dos casos notificados de sífilis em gestantes e sífilis congênita, de 2007 a 2014, em Palmas, Tocantins, revelaram que 63 (36,8\%) das gestantes foram identificadas com sífilis no segundo trimestre.

Esses achados podem estar associados a uma possível falha na assistência pré-natal, colaborando para um diagnóstico tardio (LIMA, 2019). Por outro lado, elas podem ter sido rastreadas no início da gestação e não existiu resultado positivo e se infectaram ao longo da gravidez, devido ao não uso do preservativo durante as relações sexuais.

Destaca-se aqui que o risco de transmissão vertical da sífilis é proporcional ao avanço da gestação (MAEDA, 2018), pois a permeabilidade da barreira placentária aumenta com a idade gestacional (FEDERAÇÃO BRASILEIRA DAS ASSOCIAÇÕES DE GINECOLOGIA E OBSTETRÍCIA - FEBRASGO, 2018; MAEDA, 2018). Portanto, é fundamental seguir a recomendação do MS brasileiro sobre o rastreamento e detecção precoces dessa doença.

Além das variáveis sociodemográficas e da idade gestacional, foram analisadas as características clínicas dos casos de sífilis em gestantes notificados. Quanto à classificação clínica da sífilis em gestantes, na região Nordeste, predominou a primária e, no Piauí, a fase latente. Corroborando com este último achado, em Joinville, Santa Catarina, estudo realizado por Ayala et al. (2021), com objetivo de analisar os casos notificados/confirmados de sífilis gestacional, identificou que, das 1.039 gestantes com a doença e notificadas entre 2010 e 2019, 416 (40,0\%) estavam em fase latente da infecção. Já Mesquita et al. (2012), em análise do perfil epidemiológico dos casos de sífilis em gestantes no município de Sobral, Ceará, de 2006 a 2010, evidenciaram que a maioria, 79 (71,0\%), de um total 156 casos, foi diagnosticada com sífilis primária.

A identificação da classificação clínica da sífilis é importante, pois isso determinará a duração do tratamento na gestante infectada. Essa doença pode ser classificada em primária, secundária, latente e terciária (KALININ, 2015; GUANABARA et al., 2014).

A fase primária é considerada a de maior infecção devido à grande quantidade de treponemas. Nela ocorre a formação do cancro duro no local de 
inoculação, geralmente na região externa da genitália. Essa lesão geralmente é única, de coloração rósea, posteriormente, avermelhada, de bordas endurecidas, indolor, e de fundo liso. Possui resolução espontânea num período de três a seis semanas (LEITE, 2016; PIRES, 2014).

A secundária se caracteriza por uma explosão de sintomas, pois a bactéria se espalha pelo sistema linfático e sanguíneo, fazendo com que surjam vários sinais e sintomas, como de lesões em forma de máculas e pápulas de coloração roséola na pele, placas esbranquiçadas na mucosa e simétricas, sendo característico o acometimento da palma das mãos e planta dos pés, mialgia, mal-estar, artralgias, febre baixa e cefaleia. Surge de 4 a 10 semanas após o aparecimento do cancro duro e normalmente tem resolução espontânea de três a 12 semanas. Caso não ocorra tratamento adequado nessa fase, a sífilis entra num momento de latência (AVELLEIRA et al., 2006; BRASIL, 2010).

É importante destacar, quanto à sífilis na gestação, que o risco de transmissão vertical será maior nessas fases acima descritas, pois a carga de treponema circulante é maior nessa situação (FREBASGO, 2018).

No período de latência, os pacientes são assintomáticos, mas os testes sorológicos continuam apresentando resultado positivo. Essa fase pode ter duração de um a 30 anos, sendo considerada latente recente quando tem menos de um ano e tardia, maior que um ano. As pessoas acreditam estar curadas, o que facilita maior transmissão (SARACENI, 2005).

Já a fase terciária da sífilis é considerada a mais crítica, acometendo cerca de $30,0 \%$ dos casos em que não foram implementados os cuidados adequados ou o não tratamento. A infecção nesta fase acomete a pele; o sistema vascular e nervoso, provocando a neurossífilis, que tem como manifestações frequentes a psicose, paresia, meningite e acidente vascular cerebral; as articulações, gerando a artropatia de Charcot; a formação de gomas, granulomas não infectantes e indolores, nodulares e endurecidos. Os testes sorológicos nesta fase geralmente têm resultado positivo, já os não treponêmicos normalmente são negativos (BRASIL, 2015; BRASIL, 2017; LEÃO, 2006; LEITE, 2016).

No que se refere ao tratamento estabelecido às gestantes com sífilis, foi observado o uso unânime da penicilina nos locais investigados. De modo semelhante, estudo, que buscou conhecer as gestantes com sífilis no estado de São 
Paulo, entre os anos de 2014 e 2018, constatou que 41.951 (93,4\%) foram tratadas com penicilina G benzantina (COSTA et al., 2021). Silva et al. (2019), na cidade Cascavel, Paraná, a partir da análise do perfil epidemiológico de gestantes com sífilis, entre 2007 e 2016, verificaram que 226 (97,0\%) receberam a penicilina como tratamento. E Conceição et al. (2020) identificaram, em Caxias, Maranhão, 105 $(70,5 \%)$ gestantes com sífilis tratadas com penicilina.

A penicilina $G$ benzantina é um medicamento altamente eficaz, de baixo custo, de resistência microbiana rara e o único fármaco capaz de prevenir a transmissão vertical, de mãe para filho, apresentando 98,2\% de eficácia, além de ter 99,7\% de eficácia no tratamento de gestantes. Em casos de gestante alérgica a penicilina, deve ser estabelecida a processo de dessensibilização, com esquemas orais ou intravenosos, e posteriormente tratadas com penicilina (ARAUJO, 2020; HENZ, 2018).

Nos últimos anos o abastecimento de penicilina $\mathrm{G}$ benzantina no Brasil e em diversos países está em risco. Em território brasileiro, determinado fato ocorre porque, para produzir penicilina, o Brasil necessita da importação de insumo farmacêutico ativo (IFA), que por muitas vezes está em falta, pois existe um pequeno número de fabricantes, ou sem qualidade, o que coloca este país na dependência do mercado internacional. E muitas empresas abandonaram o mercado global de penicilina em busca de remédios mais rentáveis. Tudo isso leva a uma situação de fragilidade, visto que a penicilina é o único medicamento utilizado para o tratamento efetivo em gestante, no sentindo de prevenir a sífilis congênita (ARAUJO, 2020)

Isso justifica, portanto, o crescente número de casos observados no gráfico 1 , desde o início do período investigado até 2018 ou 2019. Em pesquisa descritiva de dados secundários realizada por Santos et al. (2020), que evidenciou o perfil epidemiológico de gestantes com sífilis, de 2010 a 2019, foi identificado o aumento do número de casos notificados a partir de 2014, atingindo o maior número de registro em 2018. E Marques et al. (2018) observaram o aumento de 300,0\% dos casos de sífilis gestacional entre 2010 e 2016. No entanto vale ressaltar que nos últimos dois anos das três regiões há uma tendência de queda no número de casos.

O aumento do número de casos de sífilis gestacional notificados pode se relacionar também, além da escassez de penicilina, à implantação da Rede Cegonha, que ocorreu a partir de 2011. A Rede Cegonha foi criada com o objetivo de fomentar 
uma nova forma de assistência na atenção à saúde da mulher e da criança, e uma das ações implementadas é a realização de testes rápidos para sífilis, por exemplo, no âmbito da atenção básica, a fim de ampliar e facilitar o acesso da população à detecção e diagnóstico precoce (BRASIL, 2012).

Em face disso, o profissional de saúde dever possuir uma estrutura de atendimento pautada em condutas acolhedoras, informativas, educativas e preventivas, permitindo escuta qualificada e garantindo o bem-estar do binômio mãe-filho. Neste ínterim, o enfermeiro exerce papel fundamental na assistência prénatal, pois é capacitado para identificar alterações durante a gestação e fatores de risco a que essa gestante possa estar exposta. Assim, o olhar amplo desse profissional é extremamente importante na atenção básica e principalmente no prénatal de qualidade, eficiente e eficaz.

Ademais, ressalta-se a queda observada na curva do percentual de ocorrência da sífilis em gestantes, no gráfico, em especial para o ano 2020. Determinado achado pode estar associado à pandemia do novo coronavírus. Tal problema de saúde pública fez com que os serviços de saúde sofressem um processo de sobrecarga o que prejudicou a assistência já prestada nesses locais aos diferentes grupos, sendo um deles o de gestantes, embora as organizações e instituições recomendassem a continuidade do acompanhamento pré-natal (RAIMUNDO, 2021). Isto se torna preocupante, pois pode não ter permitido a investigação de doenças preveníveis na gestação, bem como tratamento adequado e em tempo oportuno.

\section{CONSIDERAÇÕES FINAIS}

O presente estudo atingiu o objetivo proposto, porém apresentou uma limitação: a existência no painel, utilizado como fonte dos dados, informações ignoradas, que possivelmente decorre do não preenchimento ou da ausência de melhor investigação sobre itens da Ficha de Investigação de Sífilis em Gestante. Frente a isso, sugere-se que os gestores invistam em capacitação e educação permanente dos profissionais de saúde sobre a temática em questão, a fim de que esses possam tanto atuar na prevenção desse agravo como também na detecção precoce e prestação de assistência de qualidade frente aos casos diagnosticados. 
Além disso, é importante que, em posse dos resultados desta pesquisa, os quais permitiram conhecer o cenário epidemiológico do Nordeste e do Piauí quanto à ocorrência de sífilis em gestantes, que gestores, profissionais de saúde e pesquisadores proponham estratégias quem alcancem melhor esse público e favoreçam a prevenção dessa doença e a promoção da saúde do binômio mãe-feto.

\section{REFERÊMCIAS}

AMORAS, B.C.; CAMPOS, A.R.; BESERRA, E.P. Reflexões sobre vulnerabilidade dos adolescentes a infecções sexualmente transmissíveis. PRACS: Rev. Elet. de Humanidades do Curso de Ciências Sociais da UNIFAP, v. 8, n. 1, p. 163$171,2015$.

AVELLEIRA, J. C. R.; BOTTINO, G. Sífilis: Diagnóstico, tratamento e controle. An Bras Dermatol., v. 81, n. 54, p. 111-126, 2006.

ARAUJO, R.S.; SOUZA, A.S.S.; BRAGA, J.U. A quem afetou o desabastecimento de penicilina para sífilis no Rio de Janeiro, 2013-2017. Rev Saúde Pública., v. 54, n. $109,2020$.

AYALA, A.L.M.; JASKO, B.G.D.; BILISKI, M.J.B. Análise da sífilis em gestantes nos anos de 2010 a 2019 em Joinville-SC. Espac. Saúde., v. 22, e762, 2021.

BARBOSA, K.F.; BATISTA, A.P.; NACIFE, M.B.P.S.L.; VIANNA, V.N.; OLIVEIRA, W.W.; MACHADO, E.L.; MARINHA, C.C.; COELHO, G.L.L.M. Fatores associados ao não uso de preservativo e prevalecia de HIV, hepatites virais B e C e sífilis: estudo transversal em comunidades rurais de Ouro Preto, Minas Gerais, entre 2014 e 2016. Epidemiol. Serv. Saude, v. 28, n. 2, e2018408, 2019.

BOTTURA, B.R.; MATUDA, L.; RODRIGUES, P.S.S.; AMARAL, C.M.C.A.; BABOSA, L.G. Perfil epidemiológico da sífilis gestacional e congênita no Brasil-período de2007a 2016. Arq Med Hosp Fac Cienc. Med Santa Casa São Paulo, v. 64, n. 2, p. 69-75, 2019.

BORBA, B.A.M.; CASTRO, A.G.; NUNES, A.F.; SILVEIRA, C.F.; BARROS, A.M. As consequências do manejo inadequado da sífilis gestacional: uma revisão de literatura. Revista de Patologia do Tocantins., v. 7, n. 2, p. 31-33, 2020.

BRASIL. Ministério da Saúde. Secretaria de Vigilância em Saúde. Departamento de doenças de condições crônicas e Infecções Sexualmente Transmissíveis. Sífilis 2019. Boletim Epidemiológico, número especial, 2019.

BRASIL. Ministério da Saúde. Secretária de Vigilância em Saúde. Departamento de doenças de condições crônicas e Infecções Sexualmente Transmissíveis. Sífilis 2017. Boletim Epidemiológico, v. 48, n. 36, 2017. 
BRASIL. Ministério da Saúde. Secretária de Vigilância em Saúde. Protocolo Clínico e Diretrizes Terapêuticas para Atenção Integral às Pessoas com Infecções sexualmente transmissíveis. Brasília: Ministério da Saúde, 2015.

BRASIL. Ministério da saúde. Secretaria de Vigilância em Saúde. Nota Técnica Conjuntura n³91/2012/SAS/SVS/MS. Brasília: Ministério da Saúde, 2012.

CABRAL, B.T.V.; DANTAS, J.C.; SILVA, J.A.; OLIVEIRA, D.A. Sífilis em gestante e sífilis congênita: um estudo retrospectivo. Revista Ciência Plural, v. 3, n. 3, p. 3244, 2017.

CAVALCANTE, P.A.M.; PEREIRA, R.B.L.; CASTRO, J.G.D. Sífilis gestacional e congênita em Palmas, Tocatins 2007-2014. Epidemiol. Serv. Saude, v. 2, n. 26, p. 255264, 2017.

CONCEIÇÃO, H.N.; CÂMARA, J.T.; PEREIRA, B.M. Análise epidemiológica e espacial dos casos de sífilis gestacional e congênita. Saúde Debate, v. 13, n. 123, p. 1145-1158, 2020.

COSTA, D.F.; AANHOLT, D.P.J.; CIOSAK, S.I. A realidade da sífilis em gestantes: análise epidemiológica entre 2014 a 2018. REVISA, v. 10, n. 1, p. 195-294, 2021.

DELBEN, T.V.T; VIANA, T.R. Sífilis características e nova abordagem. Saúde e Conhecimento. v. 1, p. 8-11, 2018.

FEDERAÇÃO BRASILEIRA DAS ASSOCIAÇÕES DE GINECOLOGIA E OBSTETRÍCIA FEBRASCO. Sífilis na gravidez. Rio de Janeiro: FEBRASCO, 2018. Disponível em: $\quad<$ https://www.febrasgo.org.br/pt/noticias/item/700-sifilis-nagravidez $>$. Acesso $\quad$ em 12 agos. 2021.

FERNANDES, A.M.S.; ANTONIO, D.G.; BAHAMONDES, L.G.; CUPERTINO, C.V. Conhecimentos, atitudes e práticas de mulheres brasileiras atendidas pela rede básica de saúde com relação às doenças de transmissão sexual. Cad. Saúde Pública, v. 16, n. 1, p. 103-112, 2000.

GOVERNO DO ESTADO DE SÃO PAULO. Secretaria de Saúde. Projeto Linha de cuidado à gestante, parturiente e puérpera no SUS/SP. Pré-natal e puerpério: manual técnico. São Paulo: São Paulo, 2010.

HENZ, C. Sífilis na gestação e desfechos adversos. Dissertação (Mestrado) Universidade Federal do Rio Grande do Sul, Faculdade de Medicina, Programa de Pós-Graduação em Ciências da Saúde: Ginecologia e Obstetrícia. Porto Alegre, 85 p., 2018.

INSTITUTO BRASILEIRO DE GEOGRAFIA E ESTATÍSTICAS - IBGE. Desigualdades Sociais por Cor ou Raça no Brasil. Estudos e Pesquisas, Informação Demográfica e Socioeconômica, n. 41, 2019. 
LAFÉTA, K.R.G.L.; JÚNIOR, H.M.; SILVEIRA, M.F.; PARANAÍBA, L.R.M. Sífilis materna e congênita, subnotificação e difícil controle. Rev. Bras. Epedimiol., v. 19, n. 1, p. 63-74, 2016.

LEÃO, J. C.; GUEIROS L. A.; PORTER, S. R. Oral Manifestations of syphilis. Clinics., v. 61, n. 2, p. 161-166, 2006.

LEITE I, OLIVEIRA J.M; LEÃO, M.C.M.; LOPES, S.F.; FRANÇA, A.M.B. Assistência da enfermagem na sífilis na gravidez: uma revisão integrativa. Caderno Graduação Ciências Biológicas e da Saúde, v. 3, n. 3, p. 76-165, 2016.

LIMA, R.S. 0 panorama epidemiológico da sífilis em gestantes no município de Cajazeiras-PB. Monografia (Graduação) - Universidade Federal de Campina Grande, Centro de Formação de Professores, Curso de Graduação de Medicina. Paraíba, 46 p., 2019.

MAEDA, A.T.N.; ERMITA, L.B.; ALVES, W.C.; RODRIGUES, A.M. Perfil clínico e epidemiológico das gestantes com sífilis e sífilis congênita no município de Cocal, Rondônia, Brasil, 2007 a 2016. Rev. Eletrônica FACIMEDIT, v. 7, n. 1, p. 1-10, 2018.

MARQUES, J.V.S.; ALVES, B.M.; MARQUES, M.V.S.; ARCANJO, F.P.N.; PARENTE, C.C.; VASCONSELOS, R.L. Perfil epidemiológico da sífilis gestacional: clínica e evolução de 2012 a 2017. Rev. Sanare, v. 17, n. 2, p. 13-12, 2018.

MESQUITA, K.O.; LIMA, G.K.; FLOR, S.M.C.; FREITAS, C.A.S.L.; LINHARES, M.S.C. Perfil epidemiológico dos casos de sífilis em gestante no município de Sobral, Ceará, de 2006 a 2010. Rev. Sanare, v. 11, n. 1, p. 13-17, 2012.

MIRANDA, B.L.; MARÇAL, F.A.; COELHO, H.P.; SALES, J.K.D.; MELO, C.S.; FEITOSA, A.C. Perfil epidemiológico de gestantes portadoras de sífilis em um município da região do Cariri. Rev. Epidemiol. Controle Infecç., v. 10, n. 2, p. 146-150, 2020.

MONTEIRO, M.O.P.; COSTA, M.C.O.; VIEIRA, G.O.; SILVA, C.A.L. Fatores associados a ocorrência de sífilis em adolescentes do sexo masculino, feminino e gestantes de um centro de referência municipal/CRM-DST/HIV/AIDS de Feira de Santana, Bahia. Rev. Adolesc. Saude., v. 12, n. 13, p. 21-32, 2015.

NONATO, S.M.; MELO, A.P.S.; GUIMARÃES, M.D.C. Sífilis na gestação e fatores associados à sífilis congênita em Belo Horizonte-MG, 2010-2013. Rev. Epidemiol. Serv. Saúde, v. 24, n. 4, p. 681-694, 2015.

NOGUCHI, T.F.B.; DOMINGUES, E.A.R.; CARVALHO, M.R.F.; ALCANTRA, E. Prevalência de sífilis em gestantes em uma cidade do sul de Minas Gerais: Análise Documental. Rev. da Universidade Vale do Rio Verde, v. 16, n. 3, p. 1-14, 2018. 
PENHA, J.S.; RABELO, P.P.S.; LOPES, G.S.G.; SOUSA, S.M.F.; SÁ, R.C.; PALMEIRA, C.R.; ROLIM, I.L.T.P. Reações adversas e anafiláticas após o uso da penicilina benzatina em gestantes com sífilis: Revisão integrativa. Rev. UNINGÁ, v. 57, n. 2, p. 83-94, 2020.

PINTO, D. Pesquisa revela que a pandemia afasta grávidas do pré-natal. Brasília: Radioagência Nacional, 2020. Disponível em: <https://agenciabrasil.ebc.com.br/radioagencianacional/saude/audio/2020-08/pesquisa-revela-que-pandemia-afastagravidas-do-pre-natal>. Acesso em 12 agos. 2021.

PEREIRA, B.B.; SANTOS, C.P.; GOMES, G.C. Realização de testes rápidos em gestantes por enfermeiros na atenção básica. Rev. Enferm. UFSM- REUFSM, v. 10, n. 84, p.1-13, 2020.

PIRES, A.C.S.; OLIVEIRA, D. D.; ROCHA, G.M. N. M.; SANTOS, A. dos. Ocorrência de sífilis congênita e os principais fatores relacionados aos índices de transmissão da doença no Brasil da atualidade. Rev. Uningá, v. 19, n. 1, p. 5864, 2014.

RAIMUNDO, V.L. Saúde Reprodutiva na pandemia Covid-19: os desafios e respostas na atenção básica ao pré-natal em Franco da Rocha. Monografia (Especialização) - Instituto de Saúde, Secretária de Estado da Saúde de São Paulo. São Paulo, 59 p., 2021.

REIS, L.P.L.; REIS, A.C.R.; VINHAL, J.G.F.B.; ANDRADE, L.F.; ROSA, M.K.S.; SANTOS, M.C.O. Sífilis na gestação e sua influência nas complicações maternos fetais. Braz. J. Hea. Rev., v. 3, n.6, p. 19748-19758, 2020.

RODRIGUES, A.R.M.; SILVA, M.A.M.; CAVALCANTE, A.E.S. MOREIRA, A.C.A; NETTO, J.J.M.; GOYANNA, N.F. Atuação de Enfermeiros no acompanhamento da sífilis na atenção primária. Rev. Enf. UFPE online, v. 10, n. 4, p. 49-55, 2016.

REINEHR, C.P.H.; KALIL, C.L.P.V.; REINEHR, V.P.H. Sífilis secundária: a grande imitadora não pode ser esquecida. Rev. de Ass. Med. Bras., v. 63, n. 6, p. 481483, 2017.

SANTOS, D.M.; RODRIGUES, D.N.; CAHET, Y.N.S.; LOBO, A.L.S.F.; FRANÇA, A.C.F.; SANTOS, B.B. Análise epidemiológica dos casos de sífilis em gestantes no estado de Alagoas. Rev. Port. Saúde e Soc., v. 5, n. 3, p. 1518-1526, 2020.

SALES, J.R.P. Sífilis Gestacional e Congênita: análise epidemiológica dos fatores relacionados às notificações no estado do Rio Grande do Norte. Dissertação (Mestrado Acadêmico) - Universidade Federal do Rio Grande do Norte, Centro de Ciências da Saúde, Programa de Pós-Graduação em Enfermagem. Natal, 129 p., 2021.

SARACENI, V. Avaliação da Efetividade das Campanhas para Eliminação da Sífilis Congênita, 
Município do Rio de Janeiro, 1999 e 2000. Tese (Doutorado) - Fundação Oswaldo Cruz, Escola Nacional de Saúde Pública, Departamento de Epidemiologia e Métodos Quantitativos em Saúde. Rio de Janeiro, 116p., 2005.

SILVA, M.E.; MORATO, C.B.A.A avaliação da prevalência de pacientes com sífilis atendidos em uma instituição de ensino superior em recife. Ciências Biológicas e de Saúde Unit., v. 4, n. 2, p. 85-100, 2019.

SILVA, G.F.; MEIRA, C.; BORGES, A.I.G.; OGURA, A.F. Perfil epidemiológico de gestantes com sífilis na cidade de Cascavél-PR no período de 2007 a 2016. Rev. Thêma et Scientia. v. 9, n. 2, p. 1-14, 2019.

SILVA, D.A.R.; ALVES, I.G.F.G.; BARROS, M.T.; DORNELES, F.V. Prevalência de sífilis em mulheres. Enferm. Foco., v. 3, n. 8, p. 61-64, 2017.

TOGNERI, B.P.; PÁDUA, C.L.; LAGE, I.A. Estudo do perfil epidemiológico dos casos notificados de gestantes com sífilis nos municípios de Vespasiano e Belo Horizonte no período de 2013 a 2018. Monografia (Graduação) Faculdade da Saúde e Ecologia Humana, Curso de Graduação em Medicina. Vespasiano, 2019.

TREVISAN, M.G.; BECHI, S.; TEIXEIRA, G.T.; MARCHI, A.D.A.; COSTA, L.D. Prevalência da sífilis gestacional e congênita no município de Francisco Beltrão. Rev. Espaço para a Saúde, v. 2, n. 19, p. 84-96, 2018.

GUIMARÃES, T.A.; RODRIGUES, L.C.; FONSECA, L.M.B.; GONÇALVES, M.M.C.; SILVA, M.P. Sífilis em gestantes e sífilis congênita no maranhão. Arq. Ciênc. Saúde., v. 2, n. 25, p. 24-30, 2018.

TEIXEIRA, R.L; AZEVEDO, S.D. Prevalência de casos de notificados de sífilis congênita e em gestantes no estado de Sergipe. Monografia (Graduação) - Universidade Federal de Sergipe, Centro de Ciências Biológicas e da Saúde, Curso de Graduação em Farmácia. São Cristóvão, 30 p., 2017.

XIMENES, I.P.E.; MOURA, E.R.F.; FREITAS, G.L.; OLIVEIRA, N.C. Incidência e controle da sífilis congênita no Ceará. Rev. Rene Fortaleza, v. 9, n. 3, p. 74-80, 2008. 


\section{CAPITULO XIV}

\section{EUOLUCÃO DAS POLITICAS PÚBUICAS PARA HUMANIZAÇÃO DO PARTO ENASCIMENTO NO BRASIL}

DDI: 10.51859/amplla.esp917.1121-14

Gaubeline Teixeira Feitosa ${ }^{1}$ Államy Danilo Moura e Silva ${ }^{2}$ Lucas Manoel Oliveira Costa ${ }^{3}$ Inez Sampaio Nery ${ }^{4}$

${ }^{1}$ Enfermeira. Mestre em Enfermagem pelo Programa de Pós-Graduação em Enfermagem da Universidade Federal do Piauí- UFPI

${ }^{2}$ Enfermeiro. Doutorando e Mestre em Enfermagem pelo Programa de Pós-Graduação em Enfermagem da Universidade Federal do Piauí - UFPI

${ }^{3}$ Graduando do curso de enfermagem. Instituto de Ensino Superior Múltiplo-IESM

${ }^{4}$ Enfermeira. Pós-doutorado pela Universidade Federal do Ceará-UFC, Doutora e Mestre em Enfermagem pela Universidade Federal do Rio de Janeiro- UFRJ

Objetivo: proporcionar uma reflexão a respeito da realidade obstétrica no Brasil, como também de suas políticas públicas e da humanização do parto. Método: Tratase de um estudo reflexivo, construído com base na leitura crítica sobre a realidade obstétrica brasileira, sua evolução no campo das políticas públicas e do processo de humanização referente a esta temática. Revisão Bibliográfica: Historicamente, 0 parto enquanto processo fisiológico, vem sendo alvo de diversas intervenções dos avanços científicos, que, continuamente mascararam seu real significado e distorceram esta realidade. Assim, o parto humanizado veio como um processo de reestruturação desta assistência e proporcionar a reflexão de que o parto necessita de cuidados, e não de controle. Considerações Finais: Desta forma, este artigo viabiliza a reflexão das boas práticas assistenciais, além de colaborar para a formação profissional, proporcionando subsídios teóricos-reflexivos para compor a adequação de boas práticas de saúde, fomentando o fortalecimento das ações não invasivas, para que assim sejam propagadas as atitudes que visem a promoção do parto e nascimento saudáveis.

Palavras-chave: Enfermagem Obstétrica. Parto Humanizado. Serviços de Saúde. 
Sabe-se que a percepção acerca do trabalho de parto engloba diferentes visões, na qual aborda tanto sobre as suas manifestações fisiológicas como, psicológicas e culturais. Desta forma, compreende-se que tais valores, possuem um caráter significativo e enriquecedor para aqueles que os vivenciam, como também para seus familiares (MAFFEI et al., 2020).

Historicamente, o nascimento era compreendido como um processo natural, e a arte de partejar considerada uma atividade exclusivamente feminina, realizada por parteiras, que, embora não dominassem o conhecimento científico, eram reconhecidas pelas suas experiências e adquiriam saberes sobre o parto por meio da tradição oral, ou seja, o conhecimento era transmitido oralmente de uma geração para outra (SANTOS et al., 2011; SANTOS et al., 2012).

Esta assistência perdurou até meados do século XIX, onde o atendimento, antes prioritário das parteiras, passou a ser inserido gradativamente ao ambiente hospitalar devido a incorporação da obstetrícia na prática médica. Desta forma, as parteiras se distanciaram do cenário do nascimento, e ocorreu um incentivo à hospitalização do parto nos países industrializados, inclusive no Brasil, tornando a pessoa gestante e sua vida reprodutiva em um objeto de estudo nas faculdades de medicina (SILVA et al., 2021; VELHO; SANTOS; COLLAÇO, 2014).

Ainda no século XIX, ocorreu à construção de maternidades, e profissionais que atuavam na obstetrícia começaram a realizar campanhas nas quais se difundia a ideia de que as maternidades seriam lugares mais seguros para as mulheres darem à luz. Desse modo, a institucionalização do parto se consolidou em meados do século XX, configurando-se como um ato médico e patológico (SANFELICE et al., 2014).

Nesse sentido, tendo em base os estudos de Silva et al., (2021) e de Pinheiro e Bittar (2012), a pessoa gestante é considerada uma máquina complexa, fragmentada e incapaz de compreender suas necessidades e de tomar decisões sobre sua saúde. Sendo assim, o parto um processo defeituoso, que necessita de um profissional para corrigir as imperfeições e a utilizar tecnologias.

Sabe-se que essas intervenções são bem aplicáveis e melhoram a qualidade da assistência obstétrica em partos de alto risco, entretanto essa assistência medicalizada, muitas vezes, preza pelo comodismo dos profissionais de saúde, dessa 
forma a cesariana tornou-se mais segura, a qual passou a ser executada de maneira excessiva e não somente quando possuía a indicação correta para um nascimento cirúrgico (VELHO et al., 2012; VELHO; SANTOS; COLLAÇO, 2014).

Nas últimas décadas o Brasil apresentou aumentos significativos nas taxas de cesarianas. Estimativas de 1970 indicam que a taxa desta via de parto era de cerca de $15 \%$, subindo para 38\% em 2001 e para 48,8\% em 2008, representando 35\% dos partos do Sistema Único de Saúde (SUS) e 80\% dos partos do setor privado. No ano de 2009, a taxa de cesariana foi 50,1\%, superando, pela primeira vez, o número de partos vaginais. Esse número continua aumentando, tendo a cesárea representado 55,7\% dos partos no ano de 2012 (MASCARELLO; HORTA; SILVEIRA, 2017).

A adoção do modelo biomédico difundiu amplamente a realização desse procedimento como forma de nascer, respaldando esta ideia na diminuição da "dor de parir". Apesar das recomendações da Organização Mundial da Saúde (OMS), do Ministério da Saúde (MS), de associações, federações e conselhos federais e regionais de medicina e de enfermagem relacionadas à obstetrícia, de programas e políticas públicas de saúde, bem como de redes e organizações da sociedade civil, o Brasil segue sendo um dos países do mundo que mais utiliza a técnica cirúrgica para o nascimento (ROSSETTO et al., 2020).

Desse modo, a institucionalização do parto no Brasil ocorreu na década de 1940, e o uso inapropriado de procedimentos invasivos contribuiu para que o país apresentasse umas das maiores taxas de cesariana e índices de mortalidade materna e neonatal elevados. Ao analisar os resultados perinatais nacionais, apresentam-se dados preocupantes, por serem os piores quando comparados com valores encontrados em países com o mesmo índice de desenvolvimento socioeconômicos ou com índice inferior ao do Brasil. Outro agravante é o fato de mulheres que vivenciaram o parto normal relatarem ter sofrido algum tipo de violência obstétrica por parte da equipe de saúde (SANTOS et al., 2012; SANFELICE; SHIMO, 2015).

Destarte, partindo do pressuposto de Cardoso et al. (2020), a humanização do parto envolve a participação de toda equipe multidisciplinar munida de conhecimento técnico-científico, ética profissional, responsabilidade e respeito à mulher assistida ofertando um processo de parto e nascimento saudável e digno, ademais, a capacitação da equipe de saúde é de extrema importância para garantia da adesão da humanização durante assistência prestada, além de estabelecer a 
relação profissional-paciente e facilitar o processo de educação, promoção, prevenção, recuperação e autonomia em saúde.

\section{REVISÃO BIBLLIOGRÁFICA}

\subsection{INDICADORES OBSTÉTRICOS E POLÍTICAS RELACIONADAS HUMANIZAÇÃO DA ASSISTÊNCIA AO PARTO E NASCIMENTO NO BRASIL}

Trata-se de um estudo reflexivo, construído com base na leitura crítica sobre a realidade obstétrica brasileira, sua evolução no campo das políticas públicas e do processo de humanização referente a esta temática. A construção desse tipo de estudo relaciona-se com os pressupostos da abordagem qualitativa, com o intuito de interpretar e a analisar os elementos teóricos alcançados através de bibliografias, leituras, interpretação e discussão (LOPES; SILVA; NÓBREGA-THERRIEN, 2015).

O processo parturitivo constitui um acontecimento fisiológico em que, na maioria dos casos, não há necessidade de intervenções. Nesse sentido, deve ser acompanhado de maneira não invasiva, sendo fundamental que os profissionais de saúde promovam uma relação de cuidado com a parturiente, além de compartilhar as decisões com a pessoa e seus familiares, em que deve ocorre o respeito aos seus direitos e o incentivo à sua posição protagonista do parto (SOUZA et al., 2015).

A Organização Mundial da Saúde (OMS) reitera que 70 a 80\% das gestações que acontecem em todo o mundo são consideradas de risco habitual. Além disso, muitas das de alto risco têm um curso normal da gravidez e do parto. Por isso sempre deve existir uma razão válida para interferir no processo natural do nascimento (PIMENTA et al., 2014).

Neste propósito, a OMS preconiza uma taxa de cesariana entre 10 e $15 \%$ do total de partos ocorridos, pois, com base na revisão sistemática e no estudo ecológico realizado em 2014 por ela, sobre a associação das taxas de cesáreas e os desfechos materno, perinatais e infantis, observou-se que as cesarianas realizadas com a indicação correta pautadas em uma prática baseada em evidências científicas estão associadas com a redução da mortalidade materna e neonatal. Contudo, apesar dessa recomendação, o Brasil é conhecido como um dos países com maiores índices de nascimentos cirúrgicos no mundo (OMS, 2015; MELO; DAVIM; SILVA, 2015). 
Tal afirmativa é ratificada quando se consideram as taxas de cesariana, que, desde a década de 1990, têm evidenciado um aumento consecutivo no país. Em 1994, apresentou-se um percentual de 32\%, em 2000, de 38\%, de 43\% em 2005 e, pela primeira vez, no ano de 2010, ultrapassou-se a proporção de partos normais com um valor de 52\%, chegando a 54\% em 2011. Os dados mais recentes, de 2014, mostram que esse valor se manteve em 52\%, sendo que $88 \% 21$ das cesarianas foram realizadas no setor privado, isto é, valores discrepantes dos que a OMS preconiza (PARIS et al., 2014; MAFETONI; SHIMO, 2015).

Diante deste contexto, ao considerar o quantitativo de cesariana em 2014 por regiões do país, a única onde os nascimentos cirúrgicos não ultrapassaram os partos normais foi a região Norte, que apresentou uma taxa de $47 \%$ de cesáreas, sendo, porém, uma quantidade ainda elevada. Nas demais localidades, as cesarianas excederam os partos vaginais. A região Centro-Oeste teve a maior taxa, seguida da Sul, da Sudeste e, logo após, da região Nordeste, que, do total de partos ocorridos no mesmo ano, 51\% foram por via cirúrgica, sendo que o Piauí apresentou uma taxa de 53\% (BRASIL, 2016b).

Uma das justificativas do aumento dessas taxas é a possibilidade de escolha sobre o tipo de parto, porém, segundo Melo, Davim e Silva (2015), é preferível o parto vaginal, e quando se submetem a uma cesariana é por indicação médica. Tal afirmação também é confirmada no estudo realizado por Weidle et al. (2014), no qual ratifica que a falta de atenção humanizada e de apoio dos profissionais acaba por induzir a preferência pelo nascimento cirúrgico, assim como a falta de confiança em acreditar na sua capacidade de parir.

A cesariana, a princípio, era uma intervenção cirúrgica utilizada somente em mulheres mortas com o intuito de salvar a vida do bebê. Foi um procedimento desenvolvido para reduzir o risco de complicações maternas e neonatais. Assim, sua indicação correta traz vantagens, porém sua realização de maneira generalizada, sem critérios bem delimitados, pode acarretar em riscos para o binômio mãe e filho, por se caracterizar como qualquer outra cirurgia e por possuir a capacidade de gerar complicações anestésicas e acidentes operatórios (PATAH; MALIK, 2011; WEIDLE et al., 2014).

Dessa forma, por mais que a cesariana seja considerada uma cirurgia segura e importante para a saúde materna e infantil, quando realizada de maneira 
indiscriminada e não fundamentada em evidências científicas, acaba por viabilizar riscos desnecessários (ROSSETTO et al., 2020).

Além disso, a transformação do parto normal ao longo dos anos, no qual passou a ser assistido de forma desumana, vivenciado com sofrimento e medo, fez com que a cesariana fosse uma possibilidade de refúgio desse parto visto com degradante, submetendo os pacientes a muitos procedimentos invasivos, sem seu consentimento, além de permanecerem isoladas, são impostas a condições sem fundamentação científica como jejum, lavagem intestinal e restrição ao leito. Outra explicação é a cultura de que a qualidade da assistência esteja relacionada à utilização de tecnologias duras (BRASIL, 2014).

Sabe-se, mediante resultados de pesquisas, que existe associação entre o uso indiscriminado de cesarianas com a morbimortalidade materna e neonatal. Isso porque pode acarretar o risco de infecção puerperal, hemorragias, tromboembolismo, aumento dos dias de internação hospitalar, como também eleva o risco de placenta prévia, placenta acreta, rotura uterina e histerectomia intraparto em gestações posteriores. Para o recém-nascido, observa-se a incidência de prematuridade, baixo peso ao nascer, distúrbios respiratórios e possível associação com o sobrepeso na infância e adolescência, além do início do aleitamento materno ser tardio (OLIVEIRA, 2013; PARIS et al., 2014).

Entretanto existem mulheres que não são informadas sobre todas essas complicações que um nascimento cirúrgico pode provocar e acabam por decidir pela realização dele. Assim, cabe aos profissionais de saúde proporcionar informações às gestantes desde o pré-natal, alertando-as sobre os riscos da via cirúrgica, comunicando sobre as vantagens do parto normal e comparando-o com a cesariana, para que seja garantida uma escolha orientada.

Todas essas observações realizadas até o momento levam a reflexões sobre os elevados índices de mortalidade materna e neonatal no Brasil, que revela uma situação crítica na assistência obstétrica, além da violência obstétrica realizadas contra diversas mulheres durante o período gravídico-puerperal.

Nesse sentido, Zanard et al. (2017) definem em sua pesquisa o conceito relacionado à violência contra mulheres nas instituições de saúde e discutem em maior detalhe sobre quatro tipos de violência: negligência (omissão do atendimento), violência psicológica (tratamento hostil, ameaças, gritos e 
humilhação intencional), violência física (negar o alívio da dor quando há indicação técnica) e violência sexual (assédio sexual e estupro).

Partindo do pressuposto citado anteriormente, Zanard et al. (2017) definem a violência obstétrica como uma violência psicológica, caracterizada por ironias, ameaça e coerção, assim como a violência física, por meio da manipulação e exposição desnecessária do, dificultando e tornando desagradável o momento do parto. Incluem condutas como mentir para a paciente quanto a sua condição de saúde para induzir cesariana eletiva ou de não informar a paciente sobre a sua situação de saúde e procedimentos necessários.

Além disso, também está associado à violência obstétrica o uso excessivo de medicamentos e intervenções no parto, assim como a realização de práticas consideradas desagradáveis e muitas vezes dolorosas, não baseadas em evidências científicas. Alguns exemplos são a raspagem dos pelos pubianos, episiotomias de rotina, realização de enema, indução do trabalho de parto e a proibição do direito ao acompanhante escolhido pela mulher durante o trabalho de parto (ZANARD et al., 2017).

Contudo, apesar de valores tão alarmantes, por meio de programas e de políticas para melhorar a atenção obstétrica, o Brasil apresentou uma queda na mortalidade materna, passando de 120 óbitos por 100.000 nascidos vivos em 1999 para 69 óbitos com a mesma proporção de nascidos vivos em 2013. Mesmo com uma queda tão significativa, o país não atingiu o quinto objetivo do milênio, que seria o de alcançar, em 2015, uma razão de mortalidade materna igual ou inferior a 35 óbitos por 100.000 nascidos vivos (RESENDE; RODRIGUES; FONSECA, 2015).

Nesse sentido, o Brasil, declarou uma luta pela humanização do parto e nascimento, com o objetivo de transformar esses elevados índices e propiciar o renascimento do parto normal como algo fisiológico, ao incentivar os profissionais a tomarem condutas humanizadas e ao devolver à mulher o protagonismo da parturição.

A primeira tentativa ocorreu em 1970, após a extinção do Departamento Nacional da Criança (DNCr), com a criação da Coordenação de Proteção MaternoInfantil (CPMI), conforme o Decreto no 66.623, de 22 de maio de 1970. Esta coordenação tinha por objetivo reduzir os indicadores de morbidade e mortalidade entre crianças e mães. Após isso, final desta década, a CPMI passou a chamar-se de 
Divisão Nacional de Saúde Materno-Infantil responsabilizando-se pela assistência materna, da criança e do adolescente, ainda na tentativa de reduzir os índices de morbidade e mortalidade (JUSTINO et al., 2019).

Diante deste contexto, a partir da década de 80, deu-se o princípio de um grande movimento organizado para priorizar os avanços tecnológicos apropriados ao parto e uma melhor assistência à parturiente. Propagando estes avanços e estendendo-se a um maior número de mulheres, com inutilização de meios danosos à saúde da mulher, como o fórceps que era muito utilizado na época. No Brasil, essa militância teve o nome de humanização do parto. Outras Organizações Não Governamentais e simpatizantes da causa reivindicam a humanização como defesa dos diretos humanos, relacionando ao direito social, direito reprodutivo e sexual (DAMACENO, 2015).

Com o intuito de promover a saúde da mulher, em 1984 houve a criação do Programa de Assistência Integral à Saúde da Mulher (PAISM) que visava romper com exagerado intervencionismo sobre o corpo feminino e possuía como objetivos o aumento da cobertura ao atendimento pré-natal e a melhoria da assistência ao parto, apresentando, pela primeira vez, o planejamento familiar nas ações de atenção à saúde da mulher, na tentativa de evitar o aborto provocado mediante a prevenção da gravidez indesejada (DAMACENO, 2015; BRASIL, 2011a).

A proposta de humanização do processo parturitivo, no entanto, ainda se apresentava enfraquecida em relação aos demais planos de aperfeiçoamento à saúde feminina, pois o Brasil se encontrava em um momento político-social no qual os grupos feministas realizavam movimentos para a criação de políticas públicas que contemplasse todo o ciclo de vida da mulher, e não somente o lado reprodutivo. Apesar disso, já se pensava, mesmo que de maneira sutil, na redução do excesso de intervenções aplicadas à mulher no momento do parto.

Nessa perspectiva, o tema de humanização do parto e do nascimento ganhou importância em 1985, na cidade de Fortaleza-CE, onde ocorreu a Conferência sobre Tecnologias Apropriadas para o Parto, na qual participaram representantes da OMS e da Organização Pan-Americana da Saúde (OPAS). Nesse evento, houve a orientação de rever as práticas rotineiras realizadas durante o processo parturitivo, de estimular a autonomia e o protagonismo da mulher, além do estabelecimento da taxa ideal de cesariana (BRASIL, 2011b; SILVA; NASCIMENTO; COELHO, 2015). 
Desse modo, para minimizar as práticas intervencionistas inadequadas durante o trabalho de parto, foi criado pela OMS em 1996 o manual intitulado Maternidade Segura - assistência ao parto normal: um guia prático, ele propôs a classificação das práticas relacionadas ao parto normal em quatro categorias levando em consideração sua utilidade, efetividade e ausência de periculosidade. Essas categorias foram: a) práticas demonstradamente úteis e que devem ser estimuladas; b) práticas claramente prejudiciais ou ineficazes e que devem ser eliminadas; c) práticas sobre as quais não existem evidências suficientes para apoiar uma recomendação clara, e, por isso, devem ser usadas com cautela; d) práticas frequentemente utilizadas de modo inadequado (PARADA, 2019).

Em relação a essas quatro categorias, têm-se, sem pormenorizar, condutas descritas a seguir. Na categoria A, o guia traz: monitorar o bem-estar físico e emocional da mulher durante o trabalho de parto e parto; ingestão hídrica durante o período parturitivo; respeitar o direito à privacidade da mulher no ambiente do parto, como também o acompanhante de sua escolha; liberdade de deambulação e posição; estimular, durante o trabalho de parto e parto, as posições não supinas; utilizar métodos não invasivos e não farmacológicos para o alívio da dor, tais como massagem e técnica de relaxamento; realizar monitoramento fetal com ausculta intermitente; dentre outras ações (WHO, 1996).

Nesse sentido, partindo para a categoria B, a World Health Organization (WHO) (1996) estabelece como práticas que devem ser eliminadas, e que são enfatizadas aqui: o uso frequente de enema; a rotina de raspagem dos pelos pubianos; a adoção da posição supina durante o processo parturitivo e de massagens ou distensão do períneo durante o parto. Em seguida, na categoria $\mathrm{C}$, destaca-se: o uso rotineiro de amniotomia precoce durante o início do trabalho de parto; pressão no fundo uterino; e manejo do polo cefálico no momento do parto. Por fim, na categoria D, observa-se: a restrição de comida e líquidos durante o trabalho de parto; exames vaginais repetitivos; uso rotineiro de episiotomia; cesariana; transferência da mulher de uma sala para outra no início do segundo estágio do trabalho de parto e parto, dentre outras condutas utilizadas de forma inadequada.

Em seguida, para assegurar a inserção e a autonomia da enfermeira obstetra no cenário do nascimento, por ser uma profissional que OMS julga essencial para 
proporcionar a humanização obstétrica, o Ministério da Saúde expediu a Portaria no 2.815, de 29 de maio de 1998, que acrescentou na tabela do Sistema de Informações Hospitalares, do Sistema Único de Saúde (SUS), o parto normal sem distocia realizado pela enfermeira obstetra, como também a Portaria no 163, de 22 de setembro de 1998, na qual permitiu a emissão do laudo de internação pela enfermeira obstetra (BRASIL, 1998a; BRASIL, 1998b).

Dessa maneira, ao acreditar que a humanização da assistência obstétrica é o elemento primordial para um acompanhamento adequado da gestação, do parto e do puerpério, o Ministério da Saúde criou o Programa de Humanização do Pré-Natal e Nascimento (PHPN), por meio da Portaria no 569, de 1 de junho de 2000, o qual correspondeu a outra estratégia brasileira para reduzir a mortalidade materna e neonatal, além de proporcionar atendimento digno e de qualidade à mulher e ao recém-nascido (BRASIL, 2000; PIMENTA; RESSEL; STUMM, 2013).

Cabe ressaltar que a OMS, desde de 1996, estimula a presença do acompanhante durante o trabalho de parto e parto. E, para garantir essa orientação, o Ministério da Saúde elaborou a Portaria no 2.418, de 2 de dezembro de 2005, que regulamenta a Lei no 11.108, de 07 de abril de 2005, conhecida como a "Lei do acompanhante", a qual assegura às mulheres, durante todo o período de trabalho de parto, parto e pós-parto imediato, o direito a um acompanhante de sua escolha e autoriza ao estabelecimento de saúde a cobrança das despesas com o acompanhante de acordo com a tabela do Sistema Único de Saúde (SUS) (BRASIL, 2005).

Posteriormente, é lançada a Resolução da Diretoria Colegiada (RDC) no 36, de 3 de junho de 2008, que se aplica a todo serviço de saúde no país que exerçam atividades de atenção obstétrica e neonatal, seja ele público, privado, civil ou militar. Esta Resolução determina que as unidades de saúde, onde se presta assistência obstétrica, sejam providas de infraestrutura física e de recursos humanos para a proporcionar um cuidado humanizado, com ambientes confortáveis e privados, equipamentos para o alívio não farmacológico da dor, profissionais treinados, assegurando também o direito da mulher a um acompanhante (BRASIL, 2008).

Desta forma, atualmente, a Rede Cegonha é uma das principais estratégias instituída pelo Ministério da Saúde, criada por meio da Portaria no 1.459, de 24 de junho de 2011, para garantir às mulheres - durante a gestação, o parto e o puerpério - a saúde, a qualidade de vida e o bem-estar, como também propiciar à criança o 
direito ao nascimento seguro e o acompanhamento de seu desenvolvimento até os dois primeiros anos de vida (BRASIL, 2011c).

Nesse sentido, tal Rede possui como objetivos promover a implementação de um novo modelo de assistência ao parto e ao nascimento, reduzir as mortalidades materna e infantil, especialmente no componente perinatal, e estruturar a rede de atenção à saúde da mulher e da criança para garantir acesso, acolhimento e resolutividade. Essa estratégia do Ministério da Saúde é composta de quatro componentes: 1) Pré-Natal; 2) Parto e Nascimento; 3) Puerpério e Atenção Integral à Saúde da Criança; 4) Sistema Logístico (Transporte Sanitário e Regulação) (BRASIL, 2013a).

No componente "Parto e Nascimento", ocorre o incentivo para a incorporação das boas práticas de assistência ao parto e ao nascimento, baseadas em evidências científicas. Institui-se também a realização de acolhimento com classificação de riscos nos serviços de atenção obstétrica e neonatal e a implantação de Centros de Parto Normal (CPNs), de Casas da Gestante, Bebê e Puérpera, dentre outros elementos (BRASIL, 2013a).

Nesse sentido, como se pode observar, o Brasil, desde a década de 1980, tem realizado esforços no sentido de transformar o paradigma da assistência obstétrica e neonatal, entretanto o modelo que ainda se destaca no país é o biomédico, principalmente em hospitais de ensino, que deveriam ser os primeiros a desenvolver uma assistência humanizada e entender que o parto necessita de cuidados, e não de controle (BRASIL, 2014).

Dessa forma, conhecer o cenário da assistência obstétrica, no que se refere às práticas baseadas em evidências científicas, principalmente em maternidadesescolas, instituições formadoras de novos profissionais, pode contribuir para a construção de um modelo de ensino humanizado em conformidade com as diretrizes da Rede Cegonha, como recomenda o Ministério da Saúde (SILVA et al., 2021).

De acordo com o Ministério da Saúde, a humanização obstétrica e neonatal tem como finalidades proporcionar uma experiência positiva da parturição, em que as unidades de saúde devem oferecer uma recepção com respeito e dignidade, tendo em vista que os profissionais precisam ofertar uma escutatória, favorecendo a 
relação entre pais e o filhos após o nascimento e possibilitar um conjunto de atitudes que visem a promoção do parto e nascimento saudáveis (VERSIANI et al., 2015).

Nesse contexto, a humanização do parto torna-se de grande importância para garantir uma boa prática assistencial com respeito aos princípios da integralidade e oferecer acolhimento de forma global e permitindo que o momento do parto seja uma experiência positiva e sem intervenções desnecessárias que podem trazer um trauma por resto da vida (CARDOSO et al., 2020).

Assim, Damaceno (2015) afirma que humanizar o ato de parir é criar condições próprias para respeitar todas as dimensões da mulher como ser humano, sejam elas espirituais, psicológicas e biológicas. Todas as circunstâncias que envolvem cada parturiente em particular precisam ser respeitadas e as intervenções de saúde relacionadas à interação entre os sujeitos também, cuidadores e pacientes.

Nessa narrativa, o processo de humanização do parto traz um grande benefício para o desenvolvimento desse momento, ajudando a parturiente ser mais participativa nas condutas que estão sendo feitas, portanto, auxiliará os profissionais de saúde realizarem os procedimentos durante o parto de forma mais tranquila (CARDOSO et al., 2020).

Nesse sentido, diante da realidade do Brasil e da evolução das políticas públicas a favor da humanização do parto e do nascimento apresentadas, percebese como a situação do país é de alerta e os esforços nacionais para sensibilizar os profissionais da saúde a adotarem práticas humanizadas na atenção obstétrica e neonatal. Para isso, cabe aos profissionais e às instituições de saúde se adaptarem, aceitarem e apoiarem esse movimento, com o intuito de alcançar esse objetivo e, consequentemente, modificar os indicadores obstétricos.

\section{CONSIDERACÕES FINAIS}

Desta forma, é necessário refletir os processos culturais e sociais associados ao parto, bem como a validação das políticas públicas vigentes e como elas refletem na assistência prestada diariamente durante o pré-natal, parto e puerpério. Acrescenta-se também que esta reflexão possa viabilizar boas práticas assistenciais, bem como colaborar para a formação profissional, proporcionando subsídios 
teóricos-reflexivos para compor a adequação de boas práticas de saúde que visem favorecer o protagonismo à pessoa parturiente, minimizar as práticas intervencionistas inadequadas e contribuir para o decaimento dos elevados índices de mortalidade materna e neonatal no Brasil.

Apesar de possuir diversas políticas públicas relacionadas ao parto e nascimento, no Brasil, ainda é perceptível que esse processo se encaminha vagarosamente. Assim, para corroborar com a difusão das boas práticas relacionadas à assistência obstétrica, validando as políticas vigentes, os paradigmas referentes ao parto devem ser repensados e o processo de reflexão das atuais abordagens sejam questionados, para que haja reestruturação desta prática assistencial, fortalecimento das ações não invasivas, para que sejam propagadas as atitudes que visem a promoção do parto e nascimento saudáveis.

\section{REFERÊMCIAS}

BARBOSA, E. C. V.; VIANA, L. O. Um Olhar Sobre a Formação do Enfermeiro/Docente no Brasil. Rev. Enferm. UERJ, v. 3, p.339-344, 2008.

BRASIL. Ministério da Saúde. Humanização do parto e do nascimento. Cadernos Humaniza SUS; v. 4. Universidade Estadual do Ceará. - Brasília: Ministério da Saúde, 2014.

BRASIL. Secretaria de Atenção à Saúde. Gravidez, parto e nascimento com saúde, qualidade de vida e bem-estar. Brasília: Ministério da Saúde, 2013.

BRASIL. Nascidos Vivos. Nascimento por tipo de parto segundo Região/Unidade da Federação. Brasília, DF: Datasus, 2016. Disponível em: <http://tabnet.datasus.gov.br/cgi/tabcgi.exe?sinasc/cnv/nvuf.def>.

BRASIL. Secretaria de Atenção à Saúde. Área Técnica de Saúde da Criança e Aleitamento Materno. Gestões e gestores de políticas públicas de atenção à saúde da criança: 70 anos de história. Brasília: Ministério da Saúde, 2011a.

BRASIL. Secretária de Atenção à Saúde. Parto e nascimento domiciliar assistidos por parteiras tradicionais: o Programa Trabalhando com Parteiras Tradicionais e experiências exemplares. Brasília: Ministério da Saúde, 2011b.

BRASIL. Ministério da Saúde. Portaria no 2.815/GM, de 29 de maio de 1998. Institui o procedimento de parto normal realizado por enfermeiro obstetra no Sistema Único de Saúde. Brasília, 1998a. 
BRASIL. Portaria no 163/GM, de 22 de setembro de 1998. Regulamenta a realização do procedimento 35.080.01.9 - Parto Normal sem Distócia realizado por enfermeiro obstetra. Brasília, 1998b.

BRASIL. Portaria no 569/GM, de 01 de junho de 2000. Institui o Programa de Humanização no Pré-natal e Nascimento, no âmbito do Sistema Único de Saúde. Brasília, 2000.

BRASIL. Portaria no 2. 418/GM, de 02 de dezembro de 2005. Regulamenta, em conformidade com o art. 10 da Lei no 11.108, de 7 de abril de 2005, a presença de acompanhante para mulheres em trabalho de parto, parto e pósparto imediato nos hospitais públicos e conveniados com o Sistema Único de Saúde - SUS. Brasília, 2005.

BRASIL. Resolução - RDC No 36, de 3 de junho de 2008. Dispõe sobre Regulamento Técnico para Funcionamento dos Serviços de Atenção Obstétrica e Neonatal. Brasília, 2008.

BRASIL. Portaria no 1.459/GM, de 24 de junho de 2011. Institui no âmbito do Sistema Único de Saúde a Rede Cegonha. Brasília, 2011c. Disponível em http://bvsms.saude.gov.br/bvs/saudelegis/gm/2011/prt1459_24_06_2011 .html.

CARDOSO, D. C. et al. A importância do parto humanizado: uma revisão bibliográfica. Revista Eletrônica Acervo Saúde, Bahia, v. 41, ed. 2442, p. 01-12, 2020. Disponível

em: https://acervomais.com.br/index.php/saude/article/view/2442\#: :text=R esultados\%3A\%200\%20Paro\%20Humanizado\%20atender,no\%20per\%C3 \%ADodo\%20gestacional\%20e\%20pu\%C3\%A9rperio.

DAMACENO, D. C. A importância do parto humanizado: atenção da equipe de Enfermagem. FACIDER Revista Científica , Mato Grosso, ed. 07, p. 01-13, 2015. Disponível em: http://docplayer.com.br/30834519-A-importanciado-parto-humanizado-atencao-da-equipe-de-enfermagem.html.

JUSTINO, D. C. P. et al. Avaliação histórica das políticas públicas de saúde infantil no brasil: Revisão Integrativa. Revista Ciência Plural, Rio Grande do Norte, v. 5, ed. 1, p. 71-88, 2019.

LOPES, R. E.; SILVA, A. C., NÓBREGA-THERRIEN, S. M. Formação reflexiva no ensino da enfermagem: discussão à luz de Schön. Cadernos de Pesquisa. v.22, n.1, p.47-58, 2015.

MAFETONI, R. R.; SHIMO, A. K. K. Efeitos da acupressão na evolução do parto e taxa de cesárea: ensaio clínico randomizado. Rev Saúde Pública. v.49, n.9, p.1-9, 2015.

MAFFEI, M.C.V. et al. Uso de métodos não farmacológicos durante o trabalho de parto. Rev enferm UFPE on line, Paraná, v. 15, ed. 245001, p. 01-10, 2020. 
Disponível

em:

https://periodicos.ufpe.br/revistas/revistaenfermagem/article/view/2450 $01 / 38104$.

MASCARELLO, K. C.; HORTA, B. L; SILVEIRA, M. F. Complicações maternas e cesárea sem indicação: revisão sistemática e meta-análise. Rev Saude Publica. v. 51, ed. 105, p. 01-12, 2017.

MELO, J. K. F.; DAVIM, R. M. B.; SILVA, R. R. A. Vantagens e desvantagens do parto normal e cesariano: opinião de puérperas. J. res. fundam. care. online. v.7, n.4, p. 3197-3205, 2015.

OLIVEIRA, A. R. Fatores associados e indicações para a prática de cesariana: um estudo caso-controle. Rev Port Med Geral Fam.v.29, p.151-159, 2013.

ORGANIZAÇÃO MUNDIAL DE SAÚDE (OMS). Departamento de Saúde Reprodutiva e Pesquisa. Declaração da OMS sobre Taxas de Cesáreas. Genebra, 2015.

PARADA, C. M. G. L. Women's health during pregnancy, childbirth and puerperium: 25 years of recommendations from international organizations. Rev Bras Enferm, São Paulo, v. 72, ed. 3, p. 01-02, 2019.

PATAH, L. E. M.; MALIK, A. M. Modelos de assistência ao parto e taxa de cesárea em diferentes países. Rev. Saúde Pública, v. 45, n. 1, p. 185-194, 2011.

PIMENTA, L. F. et al. A cultura interferindo no desejo sobre o tipo de parto. J. res. $\begin{array}{llll}\text { fundam.care. } & \text { online. } & \text { v.6, } & \end{array}$

PIMENTA, L. F.; RESSEL, L. B.; STUMM, K. E. A construção cultural do processo de parto. J. res. fundam. care. online. v.5, n.4, p.591-598, 2013.

RESENDE, L. V.; RODRIGUES, R. N.; FONSECA, M. C. Mortes maternas em Belo Horizonte, Brasil: percepções sobre qualidade da assistência e vitalidade. Rev Panam Salud Publica. v.37, n.4/5, p.218-224, 2015.

ROSSETTO, M. et al. Fatores associados à cesariana eletiva em mulheres atendidas em um hospital referência do oeste catarinense. Rev. Enferm. UFSM REUFSM. v. 10, ed. 54, p. 01-17, 2020. Disponível em: https://docs.bvsalud.org/biblioref/2020/10/1123218/39398-232804-1pb.pdf.

SANFELICE, C. F. O. et al. Do parto institucionalizado ao parto domiciliar. Rev Rene. v.15, n.2, p.362-370, 2014.

SANFELICE, C. F. O.; SHIMO, A. K. K. Parto domiciliar: compreendendo os motivos dessa escolha. Texto Contexto Enferm. v.24, n.3, p.875-882, 2015. 
SANTOS, L. M. et al. Atenção no processo parturitivo sob o olhar da puérpera.

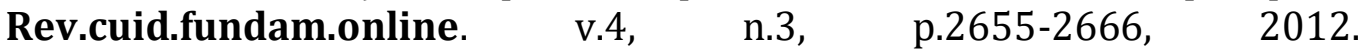

SANTOS, L.M. et al. Relacionamento entre profissionais de saúde e parturientes: um estudo com desenhos. R. Enferm. UFSM. v.1, n.2, p.225-237, 2011.

SILVA, A. L.S.; NASCIMENTO, E. R.; COELHO, E. A. C. Práticas de enfermeiras para promoção da dignificação, participação e autonomia de mulheres no parto normal. Esc Anna Nery. v.19, n.3, p.424 - 431, 2015.

SILVA, L. F. et al. Adesão às boas práticas obstétricas: construção da assistência qualificada em maternidades-escolas. Rev. baiana enferm, Alagoas, v. 35, ed. 37891, p. 01-09, 2021.Disponível em: http://www.revenf.bvs.br/pdf/rbaen/v35/1984-0446-rbaen-35e37891.pdf.

SOUZA, M. G. et al. A preocupação das mulheres primíparas em relação ao trabalho de parto e parto. J. res. fundam. care. online. v. 7, n.1, p.1987-2000, 2015.

VELHO, M. B. et al. Vivência do parto normal ou cesáreo: revisão integrativa sobre a percepção de mulheres. Texto Contexto Enferm. v.21, n.2, p.458-466, 2012.

VELHO, M. B.; SANTOS, E. K. A.; COLlACO, V. S. Parto normal e cesárea: representações sociais de mulheres que os vivenciaram. Rev Bras Enferm. v. $67, \quad$ n. $2, \quad$ p.282-289, 2014.

VERSIANI, C. C. et al. Significado de parto humanizado para gestantes. J. res. fundam. care. online. v.7, n.1. p. 1927-1935, 2015.

WEIDLE, W. G. et al. Escolha da via de parto pela mulher: autonomia ou indução? Cad.Saúde Colet. v.22, n.1, p.46-53, 2014.

ZANARD, G. L. P. et al. Violência obstétrica no brasil: Uma Revisão Narrativa. Psicologia \& Sociedade, Porto Alegre, v. 29, ed. 155043, p. 01-11, 2017. Disponível em: https://www.scielo.br/j/psoc/a/J7CMV7LK79LJTnX9gFyWHNN/?format= pdf\&lang=pt. 


\section{CAPITULO XV}

\section{ASSISTENNCIA DE ENFERMAGEM ÀS MULHERES NO PROCESSO DEABORTAMENTO: REUISÃO INTEGRATIUA}

DDI: 10.51859/amplla.esp917.1121-15

Walicy Cosse Silva ${ }^{1}$

Raquel Vilanova Araújo ${ }^{2}$

${ }^{1}$ Residente em Enfermagem Obstétrica pelo Programa de Residência em Área Profissional da Saúde Enfermagem Obstétrica da Universidade Federal do Piauí (UFPI)

${ }^{2}$ Orientadora do trabalho. Mestre em Ciências e Saúde pela Universidade Federal do Piauí (UFPI)

\section{RESUMO}

Objetivo: buscar evidências científicas sobre a assistência de enfermagem prestada às mulheres em situação de abortamento. Métodos: trata-se de uma revisão integrativa da literatura, com uso da estratégia PICo. A busca dos estudos foi realizada na Base de Dados de Enfermagem (BDENF), Literatura Latino-americana e do Caribe em Ciências da Saúde (LILACS), Medical Literature Analysis and Retrieval System Online (MedLine), base de dados CINAHL e Web Of Science, com os termos Cuidados de Enfermagem, Mulheres, Aborto, e suas variantes. Resultados: Os estudos destacaram a importância da integralidade e humanização no cuidado de enfermagem, e problemas como o cuidado mecânico, discriminação, mau atendimento, necessidades das pacientes não atendidas e falta de capacitação/preparo dos profissionais de enfermagem. Conclusão: As evidências mostram que a assistência de enfermagem prestada às mulheres em situação de abortamento se dá muitas vezes de maneira discriminatória, influenciada por valores e costumes éticos e religiosos dos profissionais, com cuidados tecnicistas que focam apenas aspectos físicos, com falta de integralidade e olhar holístico. Evidenciam também a necessidade de preparo e capacitação dos profissionais para o cuidado a essas mulheres.

Palavras-chave: Cuidados de Enfermagem. Mulheres. Aborto. 
O aborto tem como definição a interrupção, espontânea, induzida ou provocada da gravidez, com consequente expulsão do produto gestacional, em tempo inferior há 22 semanas de gestação, ou quando o concepto apresenta peso inferior a 500 gramas e comprimento menor que 25 centímetros. No mundo todo, são estimadas cerca de 85 milhões de gestações não desejadas, das quais 22 milhões resultam em abortamentos inseguros, e destes, 98\% são realizados em países em desenvolvimento (AYRES et al., 2018; PITILIN et al., 2016).

Em território brasileiro, as estimativas mostram que o aborto é a causa de 10 a 15\% dos óbitos maternos, ocupando o quarto lugar entre as causas de mortalidade materna. Por ano, o aborto é responsável por aproximadamente 238 mil internações no pais, resultando em custos financeiros que se aproximam dos 29,7 milhões de reais no Sistema Único de Saúde (SUS), não contabilizando nestes números despesas como as internações em decorrência das complicações pós-abortivas, que aumentam esses gastos, levando em consideração que, na maioria dos casos, as internações duram mais de 24 horas (BRITO; SANTOS; SILVA, 2015).

O aborto, com destaque para o abortamento provocado, é considerado um problema público de saúde, e com consequências graves para a mulher, como hemorragia, septicemia, peritonite, traumatismo dos órgãos reprodutivos e abdominais, além dos custos financeiros já mencionados. Além dessas complicações de ordem fisiológica, o abortamento traz importantes repercussões de natureza psicológica. Dentre eles, tem destaque o sentimento de culpa e o luto que permeia a mente da mulher e que estão ligadas às concepções culturais, morais e religiosas deste fenômeno, e que podem, se não tratadas adequadamente, conduzir a mulher a quadros de depressão (AYRES et al., 2018; BRITO; SANTOS; SILVA, 2015).

Nesse contexto, o aborto é um fenômeno impactante para a mulher, sobretudo quando ela não espera por este acontecimento. 0 sofrimento advindo engloba sentimentos de medo, angústia e solidão. Grande parte destas mulheres não conseguem reconhecer os sinais e sintomas do abortamento, o que causa medo pela possibilidade de perda do filho. Ao procurarem a unidade de saúde, o prognóstico muitas vezes é responsável por sentimento de culpa, depressão e revolta. As condições clínicas apresentadas na chegada ao serviço de saúde são desfavoráveis e 
incluem sangramento vaginal excessivo, fortes dores abdominais, febre, e outros sinais que são característicos do abortamento e que colocam em risco suas vidas (SILVA et al., 2020; LIMA et al., 2017).

As pacientes que se encontram nessa situação ao adentrar o estabelecimento de saúde, necessita de assistência integral e holística por parte da equipe de saúde, onde o enfermeiro é peça fundamental deste cuidado. Esta necessidade contrasta com a realidade evidenciada em muitos casos, onde a atuação do enfermeiro se dá de forma tecnicista, sem construção de vínculo afetivo com a paciente, e onde os profissionais não conseguem desfazer-se de práticas discriminatórias advindas de valores éticos, morais, culturais e religiosos, resultando em uma assistência precária e desrespeitosa (PITILIN et al., 2016).

A atenção oferecida às mulheres em situação de abortamento deve ter como pilar uma postura ética e profissional, pautada no cuidado, cuidado humanizado, sem descriminação e marginalização, desde a entrada dela no serviço de saúde, até o momento de sua saída. Para tanto, torna-se fundamental que os profissionais da equipe de enfermagem tenham conhecimentos sobre o aborto e as repercussões que este fenômeno gera na mulher, para estabelecimento de condutas éticas e respeitosas, com acolhimento e construção de vínculo com a paciente, tendo como objetivo a prestação de assistência integral que busque a recuperação da saúde desta mulher (LIMA et al., 2017; RODRIGUES et al., 2017).

Em face da necessidade de conhecer as evidências sobre a assistência de enfermagem prestada às mulheres em situação de abortamento para identificação de possíveis lacunas nas práticas de cuidado, este estudo objetivou buscar evidências científicas sobre a assistência de enfermagem prestada às mulheres em situação de abortamento.

\section{METODOLOGIA}

Trata-se de um estudo de revisão integrativa da literatura. Este tipo de estudo favorece a síntese de conhecimento através de um processo sistemático de análise de evidências publicadas e caracteriza-se pela presença de etapas bem delimitadas e complementares, as quais são: 1) elaboração da pergunta da revisão;

2) busca e seleção dos estudos; 3 ) extração de dados dos estudos; 4) avaliação crítica 
dos estudos incluídos na revisão; 5) síntese dos resultados da revisão e 6) apresentação da revisão (MENDES; SILVEIRA; GALVÃO, 2019).

A fim de responder à pergunta de pesquisa: "Quais as evidências científicas disponíveis acerca da assistência de enfermagem prestada às mulheres em situação de abortamento"? Utilizou-se o acrômio PICo, onde P corresponde à população, I corresponde o fenômeno de interesse, e Co ao contexto (KARINO; FELLI, 2012).

A seleção dos descritores (controlados e não-controlados) se deu a partir dos vocabulários controlados em ciências da saúde DeCS (Descritores em Ciências da Saúde) e MeSH (Medical Subject Headings), para busca nas bases de dados da BDENF (Base de Dados de Enfermagem) e LILACS (Literatura Latino-americana e do Caribe em Ciências da Saúde) via Portal da BVS (Biblioteca Virtual em Saúde), MEDLINE (Medical Literature Analysis and Retrieval System Online) via PUBMED. Foram utilizados os Títulos Cinahl para busca base de dados Cinahl, e palavras-chave para pesquisa na plataforma da Web Of Science.

O Quadro 1 apresenta a estratégia de busca formulada com base em processo composto de cinco etapas (extração, conversão, combinação, construção e uso), com a equação de busca aplicada para busca de dados na MEDLINE (ARAÚJO, 2020).

Quadro 1 - Apresentação da estratégia PICo para busca dos estudos. Teresina, PI, 2020.

\begin{tabular}{|c|c|c|c|}
\hline \multirow[t]{2}{*}{$\begin{array}{l}\text { Objetivo/ } \\
\text { Problema }\end{array}$} & \multicolumn{3}{|c|}{$\begin{array}{l}\text { Quais as evidências científicas disponíveis acerca da assistência de enfermagem prestada às } \\
\text { mulheres em situação de abortamento? }\end{array}$} \\
\hline & $\mathbf{P}$ & I & Co \\
\hline Extração & Mulheres & $\begin{array}{l}\text { Assistência de } \\
\text { enfermagem }\end{array}$ & Abortamento \\
\hline Conversão & Women & Nursing Care & Abortion \\
\hline Combinação & $\begin{array}{l}\text { Women; Pregnant } \\
\text { Women; Women's } \\
\text { Health; Female; } \\
\text { Pregnancy; Woman; } \\
\text { Pregnant Woman; } \\
\text { Woman's Health; } \\
\text { Gestation }\end{array}$ & $\begin{array}{l}\text { Nursing Care; } \\
\text { Nursing Services; } \\
\text { Care, Nursing; } \\
\text { Management, } \\
\text { Nursing Care; } \\
\text { Services, Nursing }\end{array}$ & $\begin{array}{l}\text { Abortion; Abortion, Spontaneous; } \\
\text { Abortion, Criminal; Abortion, Eugenic; } \\
\text { Abortion, Habitual; Abortion, Incomplete; } \\
\text { Abortion, Induced; Abortion, Legal; } \\
\text { Abortion, Missed; Abortion, Therapeutic; } \\
\text { Induced Abortion; Abortions, Induced; } \\
\text { Abortions, Legal; Abortion on Demand; } \\
\text { Abortions, Eugenic; Abortions, Criminal; } \\
\text { Abortion, Illegal }\end{array}$ \\
\hline Construção & $\begin{array}{l}\text { (women OR "pregnant } \\
\text { women" OR "women's } \\
\text { health" OR female OR } \\
\text { pregnancy OR woman } \\
\text { OR "pregnant woman" } \\
\text { OR "woman's health" } \\
\text { OR gestation) }\end{array}$ & $\begin{array}{l}\text { ("nursing care" OR } \\
\text { "nursing services" } \\
\text { OR "care, nursing" } \\
\text { OR "management, } \\
\text { nursing care" OR } \\
\text { "services, nursing") }\end{array}$ & $\begin{array}{l}\text { (abortion OR "abortion, spontaneous" OR } \\
\text { "abortion, criminal" OR "abortion, } \\
\text { eugenic" OR "abortion, habitual" OR } \\
\text { "abortion, incomplete" OR "abortion, } \\
\text { induced" OR "abortion, legal" OR } \\
\text { "abortion, missed" OR "abortion, } \\
\text { therapeutic" OR "induced abortion" OR } \\
\text { "abortions, induced" OR "abortions, legal" } \\
\text { OR "abortion on demand" OR "abortions, }\end{array}$ \\
\hline
\end{tabular}




\begin{tabular}{|c|c|}
\hline & $\begin{array}{l}\text { eugenic" OR "abortions, criminal" OR } \\
\text { "abortion, ilegal") }\end{array}$ \\
\hline Uso & 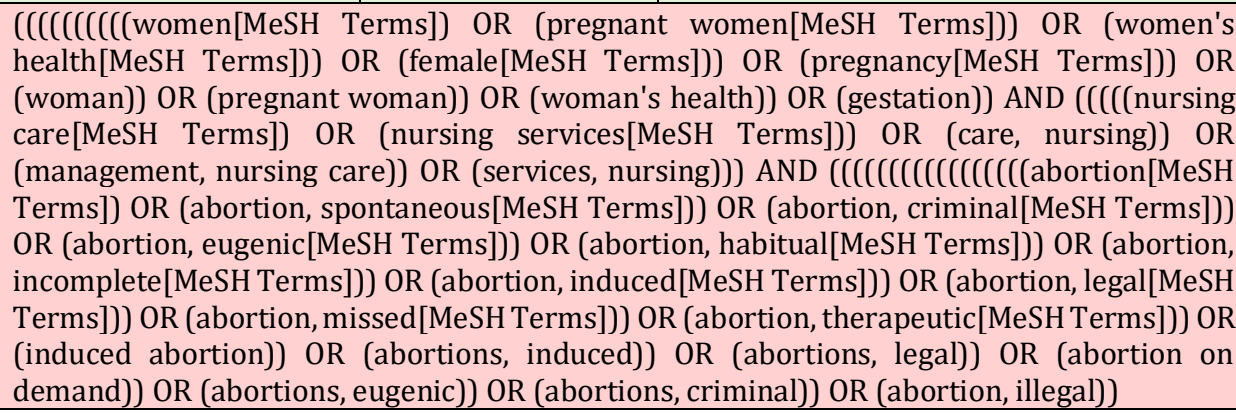 \\
\hline
\end{tabular}
Fonte: Autoria própria.

Já o Quadro 2 mostra as estratégias de busca adaptadas para pesquisa nas bases de dados Web of Science, Cinahl, LILACS e BDENF. A busca nas bases de dados LILACS e BDENF se deu com uso dos descritores (DECS) em versão portuguesa.

Quadro 2 - Apresentação das estratégias de busca de acordo com a base de dados pesquisada. Teresina, PI, 2020.

\begin{tabular}{|c|c|}
\hline 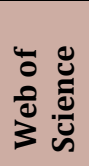 & $\begin{array}{l}\text { TS }=(\text { Women OR Pregnant Women OR Women's Health OR Female OR Pregnancy) AND } \\
\text { TS }=(\text { Nursing Care OR Nursing Services }) \text { AND TS }=(\text { Abortion OR Abortion, Spontaneous OR Abortion, } \\
\text { Criminal OR Abortion, Eugenic OR Abortion, Habitual OR Abortion, Incomplete OR Abortion, } \\
\text { Induced OR Abortion, Legal OR Abortion, Missed OR Abortion, Therapeutic) }\end{array}$ \\
\hline & $\begin{array}{l}\text { ( (MH "Women") OR "Pregnant Women" OR (MH "Expectant Mothers") OR (MH "Women's Health") OR } \\
(M H \text { "Female") OR (MH "Pregnancy") ) AND ( (MH "Nursing Care") OR (MH "Nursing Service") ) AND ( } \\
\text { (MH "Abortion, Spontaneous") OR (MH "Abortion, Criminal") OR (MH "Abortion, Habitual") OR (MH } \\
\text { "Abortion, Incomplete") OR (MH "Abortion, Induced") OR "Abortion" OR "Abortion, Eugenic" OR } \\
\text { "Abortion, Legal" OR "Abortion, Missed" OR "Abortion, Therapeutic") }\end{array}$ \\
\hline & $\begin{array}{l}\text { tw:((tw:(tw:((tw:(mulheres)) OR (tw:(saúde da mulher)) OR (tw:(feminino)) OR (tw:(gravidez)) OR } \\
\text { (tw:(gestantes)) OR (tw:(mulher)) OR (tw:(saúde feminina)) OR (tw:(grávidas)) OR (tw:(mulher } \\
\text { grávida)) OR (tw:(gestação))))) AND (tw:(tw:((tw:(cuidados de enfermagem)) OR (tw:(serviços de } \\
\text { enfermagem)) OR (tw:(assistência de enfermagem)) OR (tw:(atendimento de enfermagem)) OR } \\
\text { (tw:(cuidado de enfermagem))))) AND (tw:(tw:((tw:(aborto)) OR (tw:(aborto espontâneo)) OR } \\
\text { (tw:(aborto criminoso)) OR (tw:(aborto eugênico)) OR (tw:(aborto habitual)) OR (tw:(aborto } \\
\text { incompleto)) OR (tw:(aborto induzido)) OR (tw:(aborto legal)) OR (tw:(aborto retido)) OR } \\
\text { (tw:(aborto terapêutico)) OR (tw:(abortamento)) OR (tw:(aborto tubário)) OR (tw:(abortos } \\
\text { espontâneos)) OR (tw:(interrupção involuntária da gravidez)) OR (tw:(perda precoce da gravidez)) } \\
\text { OR (tw:(perdas precoces das gestações)) OR (tw:(aborto ilegal)) OR (tw:(abortos criminosos)) OR } \\
\text { (tw:(aborto seletivo)) OR (tw:(abortos eugênicos)) OR (tw:(abortamento habitual)) OR (tw:(aborto } \\
\text { recidivante)) OR (tw:(perda recidivante do feto)) OR (tw:(perda recorrente do embrião)) OR } \\
\text { (tw:(abortos incompletos)) OR (tw:(aborto provocado)) OR (tw:(aborto sob demanda)))))) }\end{array}$ \\
\hline
\end{tabular}
Fonte: Autoria própria.

Foram incluídos na pesquisa os estudos primários e que discorriam sobre a assistência de enfermagem prestada às mulheres em processo de abortamento, publicados em inglês, espanhol ou português, a partir de 2003, ano em que foi publicado o primeiro manual global sobre cuidados relacionados ao abortamento intitulado "Abortamento seguro: orientação técnica e de políticas para sistemas de saúde" da Organização Mundial da Saúde (WHO, 2003), e outubro de 2020 excluídos 
estudos duplicados, estudos de revisão da literatura, editoriais, teses, dissertações, monografias e manuais.

A busca nas bases de dados ocorreu entre o mês de setembro e outubro de 2020. A princípio foram resgatados 1.240 estudos. Dos 39 estudos préselecionados, 12 eram pesquisas secundárias e outros 10 não abordavam a assistência de enfermagem no abortamento, os quais foram descartados. A amostra final foi constituída por 14 estudos primários, conforme descrito no fluxograma abaixo (Figura 1), de acordo com as recomendações do grupo PRISMA (MOHER et al., 2009).

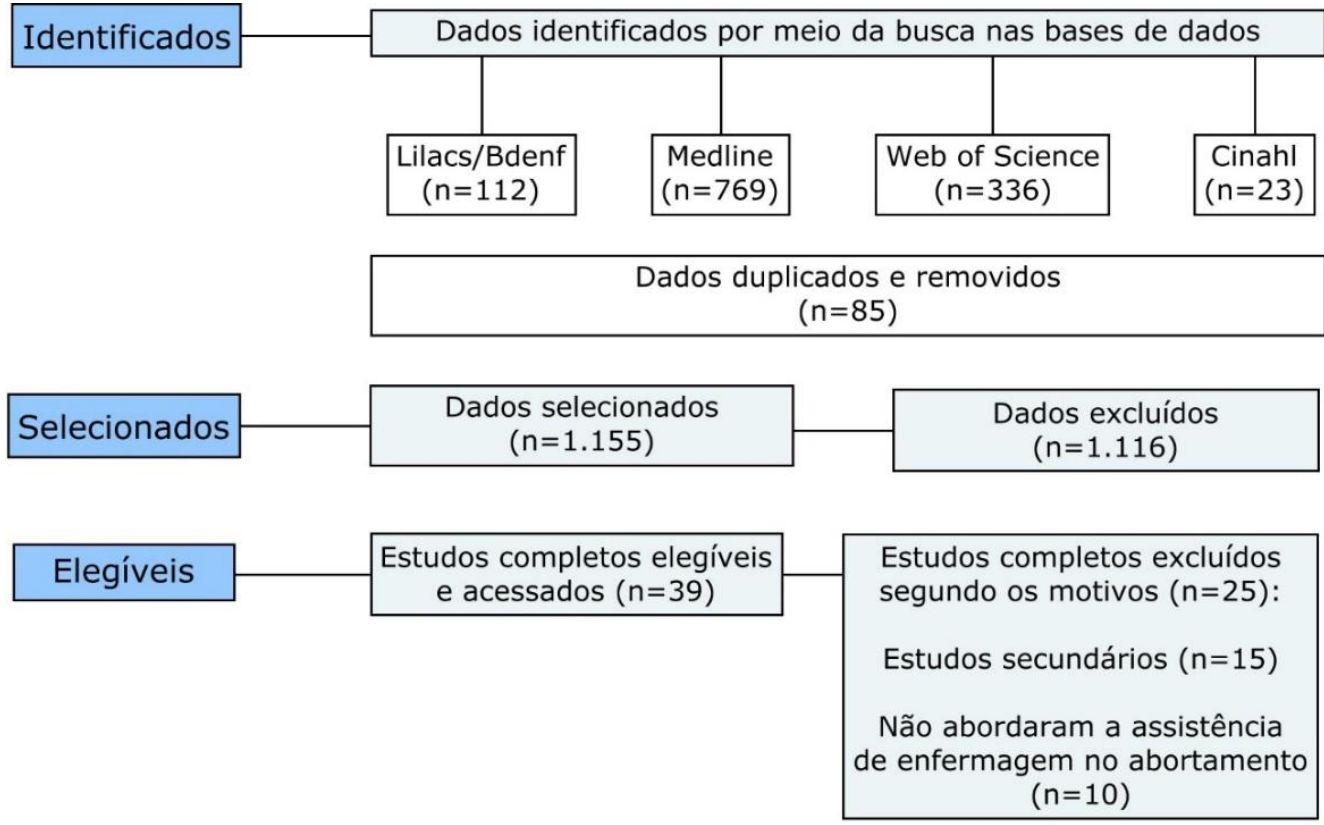

\begin{tabular}{|c|c|}
\hline Incluídos & $\begin{array}{l}\text { Estudos incluídos para síntese } \\
\qquad(n=14)\end{array}$ \\
\hline
\end{tabular}

Figura 1 - Fluxograma para seleção dos estudos encontrados, Teresina, PI, Brasil, 2020.

Fonte: Autoria própria.

O gerenciamento das referências para remoção de duplicatas se deu por meio do software online EndNote Web. A seguir foi realizado a leitura minuciosa dos estudos que compuseram a amostra final e a extração das seguintes informações: ano de publicação, país de realização do estudo, autores, periódico, tipo de estudo, objetivos, resultados e limitação dos estudos, com auxílio de um instrumento já validado para realização de estudo de revisão integrativa (URSI; GALVÃO, 2006). A busca nas bases de dados foi realizada por dois pesquisadores independentes a fim 
de reduzir a probabilidade de viés de seleção, bem como análise e interpretação dos resultados. A amostra final dos estudos selecionados se deu sob o consenso dos dois pesquisadores.

Todos os estudos selecionados foram classificados quanto ao nível de evidência, que diz respeito ao método de identificação da força de evidência apresentada nos diferentes estudos científicos. Para tal, utilizou-se a classificação: Nível 1 - evidências vindas de revisão sistemática ou metanálise de ensaios clínicos randomizados controlados ou de diretrizes clínicas baseadas em revisões sistemáticas de ensaios clínicos randomizados controlados; Nível 2 - evidências oriundas de pelo menos um ensaio clínico randomizado controlado bem delineado; Nível 3 - evidências de ensaios clínicos bem delineados não randomizados; Nível 4 - evidências de estudos de coorte e de caso-controle bem delineados; Nível 5 evidências provenientes de revisão sistemática de estudos descritivos e qualitativos; Nível 6 - evidências de um único estudo descritivo ou qualitativo; e Nível 7 - evidências vindas de opinião de autoridades e/ou relatório de comitês de especialistas (MELNYK; FINEOUT-OVERHOLT, 2005).

\section{RESULTADOS}

A Tabela 1 apresenta o perfil das publicações de acordo com os aspectos ano, país, periódico de publicação e modalidade. Verifica-se maior predominância de estudos publicados entre os anos de 2007 (14,29\%), 2012 (14,29\%), 2014 (14,29\%) e 2017 (14,29\%). 0 país com maior concentração de publicações foi o Brasil, com 11 estudos (78,6\%). Quanto ao periódico, houve ampla heterogeneidade, com maior percentual para a revista Esc Anna Nery (14,29\%). Quanto ao método, todos os estudos eram observacionais descritivos, dos quais 12 eram qualitativos $(85,71 \%)$.

Tabela 1 - Perfil dos estudos conforme o ano, país de publicação e periódico. Teresina, PI, 2020.

\begin{tabular}{lll} 
& VARIÁVEIS & \multicolumn{2}{c}{ QUANTIDAD } & PERCENTUAL \\
\hline ANO & & \\
2007 & 2 & 14,29 \\
2008 & 1 & 7,14 \\
2011 & 1 & 7,14 \\
2012 & 2 & 14,29 \\
2013 & 1 & 7,14 \\
2014 & 14,29 \\
\hline
\end{tabular}




\begin{tabular}{lll}
\hline \multicolumn{1}{c}{ VARIÁVEIS } & QUANTIDAD & PERCENTUAL \\
\hline 2015 & 1 & 7,14 \\
2017 & 2 & 14,29 \\
2019 & 1 & 7,14 \\
2020 & 1 & 7,14 \\
PAÍS & & \\
Brasil & 11 & 78,57 \\
Suécia & 1 & 7,14 \\
Turquia & 1 & 7,14 \\
Itália & 1 & 7,14 \\
PERIÓDICo & 1 & \\
Cienc Cuid Saude & & 7,14 \\
Rev Latino-am Enfermagem & 1 & 7,14 \\
Acta Paul Enferm & 1 & 7,14 \\
Online braz. J. nurs. & 1 & 7,14 \\
Rev Esc Enferm USP & 1 & 7,14 \\
Rev Rene & 1 & 7,14 \\
Esc Anna Nery & 1 & 14,29 \\
Contraception & 2 & 7,14 \\
Rev Enferm UFSM & 1 & 7,14 \\
Rev enferm UFPE on line. & 1 & 7,14 \\
The european journal of contraception \& reproductive health & 1 & 7,14 \\
care & 1 & 7,14 \\
Perspect Psychiatr Care. & 1 & 7,14 \\
Revista Ciência Plural & 1 & \\
MoDALIDADE & & 85,71 \\
Estudo descritivo qualitativo & 14,29 \\
Estudo descritivo quantitativo & 1 & \\
\hline & & \\
\hline
\end{tabular}

Fonte: Autoria própria.

O Quadro 3 apresenta os estudos conforme o título, nível de evidência, objetivos e principais resultados. Os estudos objetivaram conhecer os cuidados/assistência de enfermagem prestada às mulheres em situação de abortamento. Todos os artigos selecionados foram classificados com nível VI de evidência por tratarem-se de pesquisas observacionais descritivas simples, de acordo com a classificação proposta no método. Entre os resultados principais das publicações, a assistência de enfermagem integral e humanizada foi destaque em cinco estudos. Quatro estudos destacaram o cuidado mecânico. Descriminação, mau atendimento e necessidades não atendidas foram identificados em outras quatro publicações. Dois artigos apontaram para a falta de capacitação/preparo dos profissionais de enfermagem. Em duas pesquisas os resultados apontaram para a 
satisfação das mulheres com o atendimento por parte dos profissionais de

enfermagem.

Quadro 3 - Apresentação dos estudos de acordo com o título, nível de evidência, objetivos e resultados encontrados. Teresina, PI, 2020.

\begin{tabular}{|c|c|c|c|c|}
\hline № & Título & $\begin{array}{c}\text { Nível de } \\
\text { Evidência }\end{array}$ & Objetivos & Resultados \\
\hline 1 & $\begin{array}{l}\text { Percepção das } \\
\text { mulheres em situação } \\
\text { de Abortamento } \\
\text { frente ao cuidado de } \\
\text { Enfermagem. }\end{array}$ & VI & $\begin{array}{l}\text { Identificar o cuidado da } \\
\text { enfermagem a partir dos } \\
\text { relatos das mulheres em } \\
\text { situação de abortamento. }\end{array}$ & $\begin{array}{l}\text { Os relatos evidenciaram o } \\
\text { acolhimento satisfatório desde a } \\
\text { chegada até o atendimento final, } \\
\text { com resolutividade, } \\
\text { correlacionando com os } \\
\text { sentimentos vivenciados e que } \\
\text { foram expressos em relatos das } \\
\text { pacientes (SILVA et al., 2020). }\end{array}$ \\
\hline 2 & $\begin{array}{l}\text { Abortamento: } \\
\text { protocolo } \\
\text { assistência } \\
\text { enfermagem. }\end{array}$ & VI & $\begin{array}{l}\text { Relatar sobre a aplicação do } \\
\text { Protocolo de Enfermagem } \\
\text { na Assistência às Mulheres } \\
\text { em processo de } \\
\text { abortamento. }\end{array}$ & $\begin{array}{l}\text { A utilização de um protocolo de } \\
\text { assistência representa maior } \\
\text { segurança e interação } \\
\text { multiprofissional, bem como uma } \\
\text { atenção mais humanizada e } \\
\text { integral para as mulheres em } \\
\text { processo de abortamento ou pós- } \\
\text { aborto (RODRIGUES et al., 2017). }\end{array}$ \\
\hline 3 & $\begin{array}{l}\text { Atenção à mulher em } \\
\text { processo de } \\
\text { abortamento } \\
\text { induzido: a percepção } \\
\text { de profissionais de } \\
\text { enfermagem. }\end{array}$ & VI & $\begin{array}{l}\text { Conhecer a percepção de } \\
\text { profissionais } \\
\text { enfermagem em relação à } \\
\text { atenção à mulher em } \\
\text { processo de abortamento } \\
\text { induzido. }\end{array}$ & $\begin{array}{l}\text { As profissionais entrevistadas } \\
\text { não se sentiam capacitadas para } \\
\text { o atendimento e percebiam que } \\
\text { exerciam o cuidado de forma } \\
\text { mecânica (SILVA et al., 2015). }\end{array}$ \\
\hline 4 & $\begin{array}{l}\text { Integralidade do } \\
\text { cuidado em } \\
\text { enfermagem para a } \\
\text { mulher que vivenciou } \\
\text { o aborto inseguro. }\end{array}$ & VI & $\begin{array}{l}\text { Discutir o cuidado de } \\
\text { enfermagem para a mulher } \\
\text { que realizou o aborto } \\
\text { inseguro na perspectiva da } \\
\text { integralidade do cuidado e } \\
\text { da promoção da saúde } \\
\text { reprodutiva. }\end{array}$ & $\begin{array}{l}\text { A atenção recebida foi relatada } \\
\text { como péssima ou ruim, } \\
\text { ressaltando a discriminação e o } \\
\text { mau atendimento pelos } \\
\text { profissionais de saúde quando } \\
\text { percebem que o aborto foi } \\
\text { provocado, inferindo pré- } \\
\text { julgamentos (CARVALHO; PAES, } \\
2014 \text { ). }\end{array}$ \\
\hline 5 & $\begin{array}{l}\text { Cuidado integral e } \\
\text { aconselhamento } \\
\text { reprodutivo à mulher } \\
\text { que abortou: } \\
\text { percepções ra } \\
\text { enfermagem. }\end{array}$ & VI & 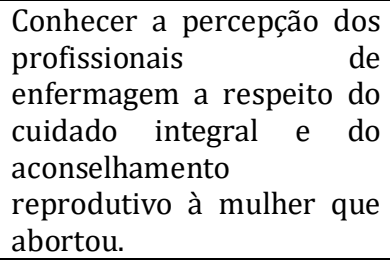 & $\begin{array}{l}\text { Os sujeitos revelaram perceber o } \\
\text { cuidado integral como a } \\
\text { satisfação das necessidades } \\
\text { biológicas e o aconselhamento } \\
\text { reprodutivo centrado nas no } \\
\text { orientações à contracepção } \\
\text { (STREFLING et al., 2013). }\end{array}$ \\
\hline 6 & $\begin{array}{l}\text { Representações de } \\
\text { enfermeiras sobre o } \\
\text { cuidado com mulheres } \\
\text { em situação de aborto } \\
\text { inseguro. }\end{array}$ & VI & $\begin{array}{l}\text { Relatar as representações } \\
\text { de enfermeiras da Atenção } \\
\text { Básica à Saúde do } \\
\text { município de Chapecó (SC) } \\
\text { sobre o cuidado com } \\
\text { mulheres em situação de } \\
\text { abortamento/aborto } \\
\text { inseguro. }\end{array}$ & $\begin{array}{l}\text { Os discursos expressam o } \\
\text { desencadeamento de vários } \\
\text { conflitos na prática do cuidado, e } \\
\text { indicam que a atenção prestada } \\
\text { vem permeado de conflitos entre } \\
\text { posicionar-se contra o aborto, } \\
\text { apoiar as mulheres ou manter-se } \\
\text { na imparcialidade (MORTARI; } \\
\text { MARTINI; VARGAS, 2012). }\end{array}$ \\
\hline 7 & $\begin{array}{lr}\text { Práticas } & \text { de } \\
\text { enfermagem } & \text { na } \\
\text { atenção às mulheres } \\
\text { em situação de } \\
\text { abortamento. }\end{array}$ & VI & $\begin{array}{l}\text { Investigar aspectos } \\
\text { norteiam as práticas de } \\
\text { enfermagem voltadas às } \\
\text { mulheres em situação de } \\
\text { abortamento. }\end{array}$ & $\begin{array}{l}\text { Os resultadosevidenciaram que o } \\
\text { olhar da enfermagem para a } \\
\text { mulher na situação de } \\
\text { abortamento ainda é } \\
\text { discriminatório e técnico } \\
\text { (SOARES et al., 2012). }\end{array}$ \\
\hline 8 & $\begin{array}{l}\text { Vivência e cuidado no } \\
\text { abortamento }\end{array}$ & VI & $\begin{array}{l}\text { Compreender a vivência } \\
\text { das mulheres em } \\
\text { situação }\end{array}$ & $\begin{array}{l}\text { As mulheres manifestam desejo } \\
\text { de receber apoio, atenção e }\end{array}$ \\
\hline
\end{tabular}




\begin{tabular}{|c|c|c|c|c|}
\hline № & Título & $\begin{array}{c}\text { Nível de } \\
\text { Evidência }\end{array}$ & Objetivos & Resultados \\
\hline & $\begin{array}{l}\text { espontâneo: um } \\
\text { estudo qualitativo. }\end{array}$ & & $\begin{array}{l}\text { de abortamento } \\
\text { espontâneo, no contexto da } \\
\text { assistência de serviços de } \\
\text { saúde públicos e privados, e } \\
\text { a vivência de enfermeiros } \\
\text { frente ao cuidado realizado. }\end{array}$ & $\begin{array}{l}\text { informações e avaliam o cuidado } \\
\text { recebido como satisfatório. Os } \\
\text { enfermeiros } \\
\text { inicialmente, obter informações } \\
\text { sobre o abortamento, condições } \\
\text { de saúde e necessidades de } \\
\text { cuidado e, a partir daí, fornecem } \\
\text { orientações e apoiam as } \\
\text { mulheres para que possam } \\
\text { superar este momento } \\
\text { (DOMINGOS; MERIGHI, 2011). }\end{array}$ \\
\hline 9 & $\begin{array}{l}\text { Assistência à mulher } \\
\text { em processo de } \\
\text { abortamento } \\
\text { provocado: discurso } \\
\text { de profissionais de } \\
\text { enfermagem. }\end{array}$ & VI & $\begin{array}{l}\text { Analisar o discurso de } \\
\text { profissionais } \\
\text { enfermagem em relação à } \\
\text { assistência prestada às } \\
\text { mulheres em processo de } \\
\text { abortamento provocado. }\end{array}$ & $\begin{array}{l}\text { As profissionais da equipe de } \\
\text { enfermagem percebem o } \\
\text { abortamento como crime, } \\
\text { pecado, e a assistência, como } \\
\text { discriminatória. À mulher é } \\
\text { negado o direito à fala, de onde o } \\
\text { silêncio observado ao longo do } \\
\text { processo do aborto (GESTEIRA; } \\
\text { DINIZ; OLIVEIRA, 2008). }\end{array}$ \\
\hline 10 & 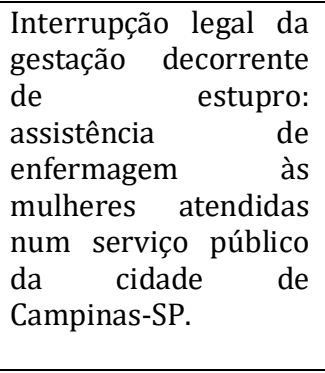 & VI & $\begin{array}{l}\text { Descrever a assistência de } \\
\text { enfermagem às mulheres } \\
\text { que optaram pela } \\
\text { interrupção legal } \\
\text { gravidez da } \\
\text { estupro. }\end{array}$ & $\begin{array}{l}\text { A utilização do processo de } \\
\text { enfermagem proporciona à } \\
\text { cliente cuidado individual, } \\
\text { integral e humanizado; concorre } \\
\text { para a adesão ao tratamento e a } \\
\text { recuperação física, psicológica e } \\
\text { social, proporcionando } \\
\text { assistência com qualidade e } \\
\text { segurança (HIGA; REIS; LOPES, } \\
\text { 2007). }\end{array}$ \\
\hline 11 & $\begin{array}{lrr}0 & \text { cuidado } & \text { de } \\
\text { enfermagem na } & \text { visão } \\
\text { de } & \text { mulheres } & \text { em } \\
\text { situação } & \text { de } \\
\text { abortamento. } & \end{array}$ & VI & $\begin{array}{l}\text { Compreender } \quad \text { como } \\
\text { mulheres em situação de } \\
\text { abortamento vivenciam o } \\
\text { cuidado de enfermagem } \\
\text { que recebem. }\end{array}$ & $\begin{array}{l}\text { Os resultados apontaram a } \\
\text { necessidade de criar um } \\
\text { ambiente que propicie a escuta, } \\
\text { ajudando essas mulheres a } \\
\text { elaborar seus sentimentos, } \\
\text { permitindo aos profissionais } \\
\text { conduta mais próxima da } \\
\text { realidade delas (MARIUTTI; } \\
\text { ALMEIDA; PANOBIANCO, 2007). }\end{array}$ \\
\hline 12 & $\begin{array}{l}\text { Assessment } \quad \text { of } \\
\text { depression, anxiety, } \\
\text { and social support in } \\
\text { the context of } \\
\text { therapeutic abortion. }\end{array}$ & VI & $\begin{array}{l}\begin{array}{l}\text { Determinar os níveis de } \\
\text { ansiedade, } \\
\text { suporte social e cuidadossãde }\end{array} \\
\text { enfermagem necessários } \\
\text { para mulheres submetidas } \\
\text { ao aborto terapêutico. }\end{array}$ & $\begin{array}{l}\text { Como resultado, as necessidades } \\
\text { de enfermagem das mulheres que } \\
\text { se submeteram ao aborto } \\
\text { terapêutico não são atendidas, e } \\
\text { as mulheres precisam do apoio } \\
\text { das enfermeiras nos estágios } \\
\text { iniciais de tomada de decisão } \\
\text { (TOPAL; TERZIOGLU, 2019). }\end{array}$ \\
\hline 13 & $\begin{array}{l}\text { The experience } \\
\text { Italian nurses and } \\
\text { midwives in the } \\
\text { termination } \\
\text { pregnancy. }\end{array}$ & VI & $\begin{array}{l}\text { Fornecer informações } \\
\text { sobre as experiências de } \\
\text { enfermeiras e parteiras que } \\
\text { trabalham no serviço de } \\
\text { aborto italiano. }\end{array}$ & $\begin{array}{l}\text { Entre os temas principais } \\
\text { analisados se encontraram: o } \\
\text { enfrentamento do cuidar da } \\
\text { mulher em interrupção da } \\
\text { gravidez; melhorar a formação } \\
\text { profissional; abordar o trabalho } \\
\text { de forma mecanicista como } \\
\text { forma de superar as dificuldades } \\
\text { (MAURI; SQUILLACE, 2014). }\end{array}$ \\
\hline 14 & $\begin{array}{lr}\text { Caring for } & \text { women } \\
\text { undergoing } & \text { second- } \\
\text { trimester } & \text { medical } \\
\text { termination } & \text { of } \\
\text { pregnancy. } & \\
\text { Contraception. } & \end{array}$ & VI & $\begin{array}{l}\text { Explorar as experiências e } \\
\text { percepções de enfermeiras } \\
\text { / parteiras que cuidam de } \\
\text { mulheres submetidas à } \\
\text { interrupção médica da } \\
\text { gravidez no segundo } \\
\text { trimestre. }\end{array}$ & $\begin{array}{l}\text { Os resultados deste estudo } \\
\text { apoiam a necessidade de } \\
\text { treinamento, orientação e apoio } \\
\text { de colegas experientes para } \\
\text { ajudar as enfermeiras/parteiras } \\
\text { a se sentirem seguras em seu } \\
\text { papel profissional em situações }\end{array}$ \\
\hline
\end{tabular}




\begin{tabular}{|c|c|c|l|l|}
\hline No & Título & Nível de & \multicolumn{1}{|c|}{ Objetivos } & \multicolumn{2}{|c|}{ Resultados } \\
\hline & & & & difíceis e confiantes em sua \\
& & & situação de vida pessoal \\
& & & (ANDERSSON; \\
& & & DANIELSSON; CHRISTENSSON, \\
& & & \\
\hline
\end{tabular}

Fonte: Autoria própria.

\section{DISCUSSÃO}

0 abortamento é um acontecimento complexo e que repercute intensamente na vida da mulher que vivencia essa perda, com manifestação de sentimentos como medo, arrependimento, culpa, além de forte estigma e censura por parte de familiares, profissionais de saúde e sociedade (PITILIN et al., 2016).

Neste estudo, a assistência de enfermagem prestada de forma integral, humanizada, pautada no apoio à mulher em processo de abortamento foi vista como essencial. Estudo publicado em 2020 destaca que a assistência realizada pelos profissionais de enfermagem é fundamental no acompanhamento de mulheres que estão em processo de abortamento. Ressaltam a necessidade de que este atendimento esteja pautado na dignidade humana, independentemente da causa do aborto. Essa assistência deve contar com acolhimento com escuta qualificada, preparo do ambiente terapêutico e oferta de apoio, buscando atender as necessidades da paciente (ANDRADE et al., 2020).

Poucas pesquisas nesta revisão apontaram satisfação com a assistência prestada pela enfermagem às mulheres em processo de abortamento. Essa pequena quantidade de evidências positivas sobre essa prestação de cuidados corrobora com achados publicados sobre a insatisfação de mulheres com a assistência recebida. Um estudo realizado mostrou que as mulheres que vivenciaram esse processo descreveram a assistência recebida pela equipe de enfermagem como fragmentada, normativas e com ausência de construção de vínculo. Tornou-se dessa maneira, na visão das mulheres, como insuficiente, e necessitando de melhoria, tendo em vista que se trata de um momento complexo, doloroso e desafiador, com necessidade de cuidados que compreendam a paciente em sua integralidade (STREFLING et al., 2015).

O cuidado mecânico, pautado apenas em aspectos físicos, a descriminação e o atendimento insuficiência para atender às necessidades das mulheres em situação 
de abortamento foram amplamente destacados nas pesquisas desta revisão. Esses achados assemelham-se aos observados em pesquisa que mostrou que o cuidado de enfermagem à pacientes que enfrentaram o processo de abortamento foi visto como tecnicista, voltado somente para as necessidades físicas, e com assistência muitas vezes discriminatória, não estando pautada na atenção holística que é necessária (PITILIN et al., 2016).

Outro estudo reforça essa problemática na assistência de enfermagem, sobretudo durante o pós-abortamento, sendo intensificadas nos casos de pacientes em que o aborto foi provocado. Os autores citam práticas como julgamento, ameaças de denúncia à polícia, bem como negligência no controle da dor, e internação ao lado de puérperas. São casos em que se observam violência institucional para com essas mulheres e que violam seus direitos ao cuidado humanista e digno (NASCIMENTO et al., 2019).

Desta forma, o profissional de enfermagem deve prestar sua assistência visando o aconselhamento das pacientes, e reduzir essa discriminação enfrentada pela mulher por meio de práticas humanistas acolhedoras dentro de sua assistência. Essa forma de cuidar, livre de aspectos morais e religiosos que influenciem em suas condutas profissionais, tornarão a assistência satisfatória para essas mulheres, e livres de julgamentos, culpa e descriminação. É importante ressaltar a necessidade de avaliar a paciente para além de suas necessidades físicas, incluindo no cuidado também o componente emocional dessas mulheres, o que torna a assistência humanizada e holística, evitando a prática de cuidados mecânicos meramente reproduzidos no dia a dia (LIMA et al., 2017).

A respeito dessa assistência centrada na pessoa humana, é essencial que o profissional de enfermagem estenda seus cuidados para o pós-abortamento, com orientações que contribuam para dar maior segurança e conforto a mulher, uma vez que muitas tendem a desenvolver problemas depressivos após esse processo, despertados a parir de sentimentos de culta e arrependimento. Assim, sintomas de depressão, ansiedade e luto perinatal podem se estender por longo período após a perda, devendo ser também campo de atuação do enfermeiro ao lidar com mulheres que estão vivenciando ou já vivenciaram o aborto (NASCIMENTO et al., 2019; DeMONTIGNY et al., 2020). 
Nesta pesquisa foi evidenciado ainda o despreparo e falta de capacitação profissional para a prestação de cuidados às mulheres em situação de abortamento. Tal evidência é fortalecida em estudo que apontou para a necessidade de capacitação do enfermeiro para a prestação de assistência humanizada às mulheres no processo de abortamento e pós-aborto, trabalhando questões como o cuidar holístico e a realização desses cuidados isentos de opiniões pessoais. Essa necessidade de preparo profissional é observada desde a formação acadêmica, por meio da transformação do processo de formação dos futuros enfermeiros, por meio da construção de uma base acadêmica de qualidade, que englobem assuntos diversos e atuais da prática clínica, de alta complexidade, como o abortamento. Tal modificação, aliada à preocupação dos profissionais e gestores em saúde pela busca de qualificação, contribuem para uma assistência prestada de maneira integral e que abranja a todos os aspectos da paciente (ANDRADE et al., 2020; BORGES; CLEMENTE; NETTO, 2020).

Os achados desta pesquisa evidenciaram a importância da assistência de enfermagem à mulher em processo de abortamento, visto tratar-se de um momento complexo e permeado de sentimentos como dor, culpa e arrependimento por parte da mulher, e que necessita de uma assistência inclusiva e que atenda às suas necessidades. Não obstante, observa-se que a assistência prestada pelos profissionais de enfermagem é tida ainda como insatisfatória para muitas mulheres que vivenciam esse processo.

As limitações da presente pesquisa referem-se sobretudo ao grau das evidências encontradas (nível VI), com ausência de estudos de maior impacto como ensaios clínicos. Ademais, embora os estudos explorem questões relacionadas à assistência de enfermagem prestada às mulheres em situação de abortamento, percebe-se grande subjetividade nas evidências encontradas, bem como ausência de estudos com intervenções que explorem a padronização do cuidado a essas pacientes, como rotinas, manuais e sistematização da assistência de enfermagem.

\section{CONSIDERAÇÕES FINAIS}

As evidências apontaram para uma assistência que se dá de maneira discriminatória, influenciada por valores e costumes éticos e religiosos dos 
profissionais, com cuidados realizados de forma mecânica, onde são amparados apenas aspectos físicos, em uma linha de cuidado que se desenha para fora das necessidades de integralidade e humanização que são necessárias na assistência a essas mulheres em situação de abortamento. Ressalta-se então, a necessidade de que os profissionais de enfermagem prestem assistência integral, holística, englobando os aspectos físicos, sociais e psicológicos da paciente, com construção de vínculo e apoio à mesma. É necessário ainda que estes profissionais sejam preparados para essa prestação de cuidados, desde a graduação, e enquanto profissionais, com busca contínua de qualificação.

Neste estudo, destacamos ainda a necessidade de realização de mais pesquisas sobre o tema, com maior rigor metodológico e nível de evidência, que explorem os cuidados de enfermagem de forma objetiva e não apenas dentro da subjetividade do tema, de modo a contribuir para a formulação de instrumentos assistenciais que possam ser adotados na prática clínica.

\section{REFERÊMCIAS}

ANDERSSON, I. M.; GEMZELL-DANIELSSON, K.; CHRISTENSSON, K. Caring for women undergoing second-trimester medical termination of pregnancy. Contraception, v. 89, n. 5, p. 460-5, 2014. Disponível em: https://doi.org/10.1016/j.contraception.2014.01.012. Acesso em: 09 nov. 2020.

ANDRADE, J. S. et al. A percepção da equipe de enfermagem sobre o cuidado à mulher em situação de abortamento: revisão integrativa. Revista Eletrônica Acervo Saúde, v. 12, n. 10, p. e557, 2020. Disponível em: https://doi.org/10.25248/reas.e557.2020. Acesso em: 09 nov. 2020.

ARAÚJO, W. C. O. Recuperação da informação em saúde: construção, modelos e estratégias. Convergências em Ciência da Informação, v. 3, n. 2, p. 100-34, 2020. Disponível em: https://doi.org/10.33467/conci.v3i2.13447. Acesso em: 27 jul. 2020.

AYRES, R. et al. A contextualização do aborto sob a ótica do enfermeiro. Nursing, v. 28, n. 244, p. 2334-7, 2018. Disponível em: http://www.revistanursing.com.br/revistas/244Setembro2018/A_contextualizacao_aborto.pdf. Acesso em: 25 jul. 2020.

BORGES, L. C. V.; CLEMENTE, N. R.; NETTO, L. (In)congruência na assistência às mulheres em situação de abortamento: o que dizem os acadêmicos sobre seus processos formativos. Rev Min Enferm, v. 24, n. e1297, 2020. 
Disponível em: DOI: 10.5935/1415-2762.20200026. Acesso em: 10 nov. 2020.

BRITO, R. S.; SANTOS, D.; SILVA, A. B. D. Perfil de mulheres em situação de abortamento internadas em uma maternidade escola. Rev enferm UFPE on line, v. $9, \quad$ n. 1 , p. 15-22, 2015. Disponível em: https://periodicos.ufpe.br/revistas/revistaenfermagem/article/viewFile/1 0301/10965. Acesso em: 25 jul. 2020.

CARVALHO, S. M.; PAES, G. O. Integralidade do cuidado em enfermagem para a mulher que vivenciou o aborto inseguro. Esc Anna Nery, v. 18, n. 1, p. 130-4, 2014. DOI: 10.5935/1414-8145.20140019. Acesso em: 05 nov. 2020.

DEMONTIGNY, F. et al. Protective and risk factors for women's mental health after a spontaneous abortion. Rev. Latino-Am. Enfermagem, v. 28, n. e3350, 2020. Disponível em: http://dx.doi.org/10.1590/1518-8345.3382.3350. Acesso em: 10 nov. 2020.

DOMINGOS, S. R. F.; MERIGHI, M. A. B.; JESUS, M. C. P. Vivência e cuidado no abortamento espontâneo: um estudo qualitativo. Online braz. J. nurs. (Online), v. 10, n. 2, p. 1-10, 2011. Disponível em: http://www.objnursing.uff.br/index.php/nursing/article/download/3236/ pdf_2. Acesso em: 29 jul. 2020.

GESTEIRA, S. M. A.; DINIZ, N. M. F.; OLIVEIRA, E. M. Assistência à mulher em processo de abortamento provocado: discurso de profissionais de enfermagem. Acta Paul Enferm, v. 21, n. 3, p. 449-53, 2008. Disponível em: https://doi.org/10.1590/S0103-21002008000300011. Acesso em: 29 jul. 2020.

HIGA, R.; REIS, M. J.; LOPES, M. H. B. M. Interrupção legal da gestação decorrente de estupro: assistência de enfermagem às mulheres atendidas num serviço público da cidade de Campinas-SP. Ciência, Cuidado e Saúde, v. 6, n. 3, p. 372-376, 2007. Disponível em: https://doi.org/10.4025/cienccuidsaude.v6i3.1747. Acesso em: 07 nov. 2020.

KARINO, M. E.; FELLI, V. Enfermagem baseada em evidências: avanços e inovações em revisões sistemáticas. Ciência, Cuidado e Saúde, v. 11, n. 5, p. 11-5, 2012. Disponível em: http://periodicos.uem.br/ojs/index.php/CiencCuidSaude/article/downloa d/17048/pdf. Acesso em: 27 jul. 2020.

LIMA, L. M. et al. Cuidado humanizado às mulheres em situação de abortamento: uma análise reflexiva. Rev. enferm. UFPE on line, v. 11, n. 12, p. 5074-8, 2017. Disponível em: https://doi.org/10.5205/1981-8963v11i12a25126p5074-5078-2017. Acesso em: 25 jul. 2020. 
MARIUTTI, M. G.; ALMEIDA, A. M.; PANOBIANCO, M. S. O cuidado de enfermagem na visão de mulheres em situação de abortamento. Rev Latino-am Enfermagem, v. 15, n. 1, p. 1-8, 2007. Disponível em: https://www.scielo.br/pdf/rlae/v15n1/pt_v15n1a04.pdf. Acesso em: 07 nov. 2020.

MAURI, P. A.; SQUILLACE, F. The experience of Italian nurses and midwives in the termination of pregnancy: a qualitative study. Eur J Contracept Reprod Health Care, v. 22, n. 3, p. 227-32, 2017. Disponível em: http://dx.doi.org/10.1080/13625187.2017.1318846. Acesso em: 07 nov. 2020.

MELNYK, B. M.; FINEOUT-OVERHOLT, E. Making the case for evidence-based practice. In: Melnyk BM, Fineout-Overholt E. Evidence-based practice in nursing \& healthcare. A guide to best practice. Philadelphia: Lippincot Williams \& Wilkins, 2005.

MENDES, K. D. S.; SILVEIRA, R. C. C. P.; GALVÃO, C. M. Uso de gerenciador de referências bibliográficas na seleção dos estudos primários em revisão integrativa. Texto Contexto Enferm, v. 28, n. e20170204, 2019. Disponível em: https://dx.doi.org/10.1590/1980-265X-TCE-2017-0204. Acesso em: 27 jul. 2020.

MOHER, D. et al. The PRISMA Group 2009: Preferred reporting items for systematic reviews and meta-analyses: the PRISMA Statement. PLoS Med, v. 6, n. 6, p. e1000097, 2009. DOI: 10.1371/journal.pmed.1000097. Acesso em: 29 jul. 2020.

MORTARI, C. L. H.; MARTINI, J. G.; VARGAS, M. A. Representações de enfermeiras sobre o cuidado com mulheres em situação de aborto inseguro. Rev Esc Enferm USP, v. 46, n. 4, p. 914-21, 2012. Disponível em: https://doi.org/10.1590/S0080-62342012000400019. Acesso em: 05 nov. 2020.

NASCIMENTO, L. et al. Percepção de mulheres em situação de aborto em relação ao atendimento dos profissionais de enfermagem. R. Enferm. UFJF, v. 5, n. 2, p. 1-13, $2019 . \quad$ Disponível em: https://periodicos.ufjf.br/index.php/enfermagem/article/view/27179/21 535. Acesso em: 10 nov. 2020.

PITILIN, É. B. et al. Assistência de enfermagem em situações de aborto induzido/provocado: uma revisão integrativa da literatura. Enfermería Global, v. 15, n. 3, p. 439-79, 2016. Disponível em: https://doi.org/10.6018/eglobal.15.3.229511. Acesso em: 25 jul. 2020.

RODRIGUES, W. F. G. et al. Abortamento: protocolo de assistência de enfermagem: relato de experiência. Rev. enferm. UFPE on line, v. 11, n. 8, p. 3171-5, 2017. Disponível em: 10.5205/reuol.11064-98681-4-ED.1108201724. Acesso em: 25 jul. 2020. 
SILVA, E. F. et al. Atenção à mulher em processo de abortamento induzido: a percepção de profissionais de enfermagem. Rev Enferm UFSM, v. 5, n. 3, p. 454-64, 2015. DOI: http://dx.doi.org/10.5902/2179769214801. Acesso em: 29 jul. 2020.

SILVA, L. et al. Percepção das mulheres em situação de Abortamento frente ao cuidado de Enfermagem. Revista Ciência Plural, v. 6, n. 1, p. 44-55, 2020. Disponível

em: https://periodicos.ufrn.br/rcp/article/download/18627/12528. Acesso em: 25 jul. 2020.

SOARES, M. C. S. et al. Práticas de enfermagem na atenção às mulheres em situação de abortamento. Rev Rene, v. 13, n. 1, p. 140-6, 2012. Disponível em: http://www.periodicos.ufc.br/rene/article/view/3783/2990. Acesso em: 29 jul. 2020.

STREFLING, I. D. S. S. et al. Cuidado de enfermagem à mulher em situação de aborto: revisão integrativa. Revista de Enfermagem da UFSM, v. 5, n. 1, p. 169-77, 2015. Disponível em: https://doi.org/10.5902/2179769212533. Acesso em: 09 nov. 2020.

STREFLING, I. S. S. et al. Cuidado integral e aconselhamento reprodutivo à mulher que abortou: percepções da enfermagem. Esc Anna Nery, v. 17, n. 4, p. 698704, 2013. DOI: 10.5935/1414-8145.20130014. Acesso em: 05 nov. 2020.

TOPAL, C. A.; TERZIOGLU, F. Assessment of depression, anxiety, and social support in the context of therapeutic abortion. Perspect Psychiatr Care, v. 55, n. 4 p. 618-23, 2019. Disponível em: https://doi.org/10.1111/ppc.12380. Acesso em: 07 nov. 2020.

URSI, E. S.; GALVÃO, C. M. Prevenção de lesões de pele no perioperatório: revisão integrativa da literatura. Rev Latino-Am Enferm, v. 14, n. 1, p. 124-31, 2006. DOI: https://doi.org/10.1590/S0104-11692006000100017. Acesso em: 29 jul. 2020.

WORLD HEALTH ORGANIZATION. WHO. Safe abortion: technical and policy guidance for health systems. Geneva: World Health Organization, 2003. 132 p. 


\section{IMPLANTAÇÃO DA CONSULTA DEENFERMAGEM NO SEGUIMENTO DO PREMATURO DE RISCO}

DDI: 10.51859/amplla.esp917.1121-16

Aline Macêdo da Silva ${ }^{1}$

Márcia Teles de Oliveira Gouveia ${ }^{2}$

Amanda Lúcia Barreto Dantas ${ }^{3}$

Anna Katharinne Carreiro Santiago 4

Maria Carolina da Silva Costa 5

${ }^{1}$ Enfermeira Obstetra - UFPI, Teresina, PI, Brasil

2 Doutora em Enfermagem Fundamental-USP. Professora do Programa de Pós-Graduação em Enfermagem UFPI, Teresina, PI, Brasil

${ }^{3}$ Mestre em Enfermagem - UFPI. Docente de Enfermagem da UFPI, Teresina, PI, Brasil

4 Mestre em Enfermagem - UFPI. Teresina, PI, Brasil

${ }^{5}$ Enfermeira - UFPI. Especializanda em Enfermagem Neonatal e Pediátrica UFPI, Teresina, PI, Brasil

Objetivo: Implantar a consulta de enfermagem na terceira etapa do método canguru, em uma Estratégia Saúde da Família, de Teresina-PI. Métodos: uma pesquisa intervencionista desenvolvida em uma Maternidade de referência e na Unidade de Atenção Básica vinculada ao Programa de Residência em Enfermagem Obstétrica de Teresina- PI. A amostra foi de 60 profissionais da saúde na primeira etapa e 04 enfermeiros na segunda etapa, durante os meses de agosto a dezembro. Resultados: Do total dos profissionais da maternidade, 57 (88,33\%) eram do sexo feminino e $3(11,67 \%)$ enfermeiros. Dos enfermeiros da UBS, 2(50\%) tinham experiência profissional maior que cinco anos, 4(100\%) possuíam pós graduação e $4(100 \%)$ não se sentiam seguros durante a consulta do prematuro de risco. Quanto a avaliação do instrumento da SAE implantado na UBS, 4(100\%) dos enfermeiros avaliaram que era importante, de fácil entendimento e aplicação. Conclusão: observou-se o interesse dos profissionais nas atividades educativas, assim como a implantação do instrumento na consulta de enfermagem do prematuro.

Palavras-chave: Enfermagem neonatal. Criança prematura. Método mãe canguru. 
0 recém-nascido (RN) antes das $37^{a}$ semana de gestação é considerado prematuro. Quanto ao grau de prematuridade, pode ser classificado em: prematuro extremo (nasce antes da $28^{\underline{a}}$ semana de idade gestacional), muito prematuro (nasce antes da $32^{\underline{a}}$ semana) e prematuro tardio (que nasce com $34^{\underline{a}}$ a $36^{\underline{a}}$ semanas). 0 RN também pode ser classificado quanto ao seu peso, como de baixo peso (peso entre $1.000 \mathrm{~g}$ e $1.499 \mathrm{~g}$ ) e extremo baixo peso (menor que $1.000 \mathrm{~g}$ ) (GONTIJO et al., 2018).

A prematuridade tem uma incidência mundial de um a cada dez nascimentos. No ano de 2010, o Brasil esteve entre os dez países com o maior índice de partos prematuros, que coincidiu com as elevadas taxas de nascimentos de prematuros na Alemanha (9,2\%). Em 2013, as regiões brasileiras com os maiores percentuais de prematuridade formam: a região Sul (12\%) e Sudeste $(12,5 \%)$, comparadas ao Centro-oeste $(11,5 \%)$, Nordeste $(10,9 \%)$ e região Norte $(10,8 \%)$. 0 nascimento de um recém-nascido prematuro é imprevisível e por diversas circunstâncias, independe de classe social ou localidade (SALES, 2018).

A principal causa de mortalidade neonatal no mundo é a prematuridade. 0 uso de tecnologias e recursos humanos no âmbito neonatal possibilita o aumento da sobrevivência de recém-nascidos prematuros. Um dos métodos que ganha destaque é método canguru (MC), que promove o contato direto do neonato com a mãe. Esse modelo insere a família no tratamento do $\mathrm{RN}$, sempre respeitando os limites paternos e os cuidados ao prematuro. A denominação do método canguru é devido à posição vertical sobre o tórax, permitindo o contato pele a pele, que atuam como uma fonte direta de calor, formação de vínculo e aleitamento materno (MARQUES et al., 2016).

O método canguru ocorre em etapas, sendo a primeira etapa iniciada no prénatal. A gestante classificada com uma gestação de alto risco recebe as instruções até a internação do RN na Unidade de Terapia Intensiva Neonatal (UTIN) ou na Unidade de Cuidados Intermediários Neonatais Convencionais (UCINCo). A segunda etapa se caracteriza pela permanência contínua do neonato com sua mãe, que acontece na Unidade de Cuidados Intermediários Neonatal Canguru (UCINCa). $\mathrm{Na}$ segunda etapa é realizada a posição canguru pelo maior tempo possível. A terceira compreende a alta hospitalar após o RN atingir $1.600 \mathrm{~g}$, em que será realizado o 
acompanhamento da criança com três consultas na primeira semana de alta, duas na segunda semana e uma a partir da terceira semana, até ser atingido o peso ideal (AIRES et al., 2017).

A terceira etapa é caracterizada pelo acompanhamento do prematuro por uma equipe multiprofissional. Os principais objetivos desta etapa são: acompanhamento seguro, favorecer a amamentação, intervir nas possíveis intercorrências e em casos mais graves realizar a regulação do $\mathrm{RN}$ à maternidade. 0 recém-nascido permanece vinculado à maternidade de origem e pode retornar caso aja necessidade. 0 acompanhamento ambulatorial ocorre concomitante às consultas da puericultura na Atenção Básica (LEITE et al., 2016).

O papel do enfermeiro no acompanhamento do recém-nascido prematuro vai além da supervisão, coordenação e encaminhamento. Ele atuará diretamente na avaliação, identificação de agravos, resoluções de problemas que os competem, orientações dos pais, tornando-os mais seguros no processo de cuidar de seus filhos (DINIZ et al., 2015).

A consulta de enfermagem deve ser norteada pela Sistematização da Assistência de Enfermagem (SAE), um método científico com aplicação e etapas específicas. A consulta detecta precocemente os desvios de saúde, viabiliza o trabalho do enfermeiro no atendimento, além de facilitar a identificação de problemas e decisões a serem tomadas (OLIVEIRA et al., 2012). Nesse sentido, objetivou-se implantar na consulta de enfermagem a terceira etapa do método canguru na Estratégia Saúde da Família.

\section{MATERIAIS E MÉTODOS}

Trata-se de estudo intervencional, que buscou implementar na Unidade Básica de Saúde a terceira etapa do método canguru à consulta de enfermagem, tendo como contra referência a maternidade de referência do estado do Piauí, vinculadas ao Programa de residência em enfermagem obstétrica, assim como a sensibilização dos profissionais da unidade. A intervenção iniciou-se no Instituto de Perinatologia da Maternidade de referência, onde são realizadas consultas de prénatal e acompanhamento ambulatorial do prematuro de alto risco. As consultas são 
realizadas por equipes multiprofissionais, tendo continuidade na Unidade Básica de Saúde da capital, que realiza também esse acompanhamento de forma paralela.

Os participantes do estudo foram enfermeiros, técnicos de enfermagem, auxiliares de enfermagem do ambulatório e residentes de enfermagem. Como critérios de inclusão foram os profissionais de enfermagem que trabalham na assistência direta ao recém-nascido e que demonstraram interesse em participar da consulta. Como critério de exclusão foram considerados os profissionais que não participaram do curso de capacitação e os afastados do serviço por férias, licença maternidade e/ou licença saúde.

A intervenção foi realizada em três etapas consecutivas e dependentes: a primeira etapa consistiu em uma aula ministrada durante um curso de atualização realizado para os profissionais de enfermagem da referida maternidade, envolvidos na assistência direta ao recém-nascido. Este ocorreu como uma iniciativa dos discentes do programa de residência em enfermagem obstétrica, em parceria com o Núcleo de Educação Permanente e Práticas de Saúde da Instituição (NEPPS). A cada aula foram abordadas temáticas voltadas para a humanização dos cuidados com ao recém-nascido prematuro.

As aulas foram divididas em três momentos: no primeiro momento a palestrante convidada abordou a temática do Método Canguru, em seguida ocorreu uma dinâmica. Posteriormente o foco foi direcionado para a terceira etapa do método canguru, em que se discutiu sobre a Sistematização da Assistência de Enfermagem a ser aplicado durante a consulta de enfermagem ao recém-nascido prematuro na terceira etapa do Método Canguru, com os principais diagnósticos e intervenções de enfermagem voltada para essa especificidade, com um breve histórico do bebê e exame físico. As metodologias aplicadas foram diversas, com o intuito de melhorias na assistência ao recém-nascido prematuro, mas também podendo ser aplicado os cuidados a todos os recém-nascidos.

O curso teve carga horária de 20 horas, com o desenvolvimento de atividades durante quatro dias do mês de agosto de 2018, no turno da manhã, com organização e divulgação pelo NEPPS em todos os setores de assistência ao recém-nascido da instituição. Ao final do curso foi aplicado um pós-teste com o intuito de avaliar o aprendizado e as sugestões sobre o curso ministrado. 
Na segunda etapa houve o treinamento e aplicação do instrumento para a consulta de enfermagem no seguimento do prematuro de risco. A proposta inicial seria desenvolvida somente no Instituto de Perinatologia da Maternidade, no entanto, por dificuldades organizacionais, também foram incluídos enfermeiros e residentes da Unidade Básica de Saúde que realiza o acompanhamento desses recém-nascidos. Durante esta etapa foram realizadas rodas de conversa com os enfermeiros e residentes para a implantação da terceira etapa na consulta de enfermagem na Atenção Básica. Foi apresentado o impresso a ser utilizado, assim como realizado o treinamento para o seu uso.

A última etapa ocorreu à aplicação do instrumento da consulta aos recémnascidos prematuros, pelos profissionais da Unidade Básica de Saúde. Após um mês de implantação do instrumento realizou se uma avaliação para possíveis ajustes no instrumento, se necessário, e se estava sendo utilizado de forma correta, a fim de realizar quaisquer esclarecimentos.

Os dados obtidos no estudo foram digitados e armazenados em um banco de dados eletrônico criado no programa Excel 2010 e posteriormente analisados quantitativamente e qualitativamente. Por conseguinte, os resultados obtidos foram apresentados em tabelas e gráficos. A pesquisa foi submetida ao Comitê de Ética e pesquisa da instituição do estudo, com parecer favorável.

\section{RESULTADOS E DISCUSSÃO}

A primeira etapa da intervenção foi desenvolvida durante a semana de práticas educativas na maternidade, com a participação de 60 profissionais de diversos setores assistenciais (UCINCA, UTIN 1 e 2, ala A, B, C, D, e E, instituto de Perinatologia, centro de parto normal, centro obstétrico superior e centro cirúrgico). Na tabela 1 estão descritas as informações sobre o perfil dos profissionais participantes do curso de atualização.

A amostra do estudo foi constituída por $88,33 \%$ profissionais do sexo feminino. Quanto à profissão dos participantes, 26,67\% eram enfermeiros e 46,66\% técnicos de enfermagem. Observou-se que o público esteve presente entre 2 a 3 dias da programação desenvolvida, estratificados por eixos temáticos, como observados na Tabela 1. 
Tabela 1 - Caracterização do público durante o curso de Atualização da Assistência de Enfermagem ao recém-nascido, (n=60), Teresina-PI, 2018.

\begin{tabular}{|c|c|c|c|}
\hline Variáveis & & $\mathbf{N}$ & $\%$ \\
\hline \multirow{2}{*}{ Sexo } & Feminino & 57 & $88,33 \%$ \\
\hline & Masculino & 03 & $11,67 \%$ \\
\hline Categoria Profissional & $\begin{array}{c}\text { Enfermeiro } \\
\text { Técnico de Enfermagem } \\
\text { Outros profissionais }\end{array}$ & $\begin{array}{l}28 \\
16 \\
16\end{array}$ & $\begin{array}{l}46,66 \% \\
26,67 \% \\
26,67 \%\end{array}$ \\
\hline $\begin{array}{c}\text { Participação durante o } \\
\text { curso }\end{array}$ & $\begin{array}{l}1 \text { a } 2 \text { dias } \\
2 \text { a } 3 \text { dias } \\
4 \text { dias }\end{array}$ & $\begin{array}{l}20 \\
26 \\
14 \\
\end{array}$ & $\begin{array}{l}33,33 \% \\
43,33 \% \\
23,34 \% \\
\end{array}$ \\
\hline $\begin{array}{c}\text { Participação do curso por } \\
\text { eixos temáticos }\end{array}$ & $\begin{array}{c}\text { Humanização da Assistência ao RN } \\
\text { Assistência de Enfermagem ao } \\
\text { Prematuro de risco } \\
\text { Cuidados com a pele do recém-nascido } \\
\text { Cuidados com o RN em tratamento } \\
\text { fototerápico }\end{array}$ & $\begin{array}{l}52 \\
44 \\
\\
39 \\
46\end{array}$ & $\begin{array}{l}86,67 \% \\
73,33 \% \\
65,00 \% \\
76,67 \%\end{array}$ \\
\hline Total & & 60 & 100,0 \\
\hline
\end{tabular}

Fonte: Autoria própria.

Ao final do curso, foi aplicado um questionário para avaliação da intervenção educativa, representada na tabela 2, que abordam oito indicadores: divulgação, programação, organização, tema abordado, metodologia de ensino utilizada pelos ministrantes, qualidade do material, capacidade dos palestrantes em transmitir o conteúdo, alcance dos objetivos propostos.

Tabela 2 - Avaliação do curso: Intervenções na assistência ao recém-nascido, Teresina-PI, 2018.

\begin{tabular}{|l|c|c|c|c|}
\hline \multicolumn{1}{|c|}{ Variáveis } & $\begin{array}{c}\text { Fraco } \\
\mathbf{N ( \% )}\end{array}$ & $\begin{array}{c}\text { Médio } \\
\mathbf{N ( \% )}\end{array}$ & $\begin{array}{c}\text { Bom } \\
\mathbf{N ( \% )}\end{array}$ & $\begin{array}{c}\text { Excelente } \\
\mathbf{N}(\%)\end{array}$ \\
\hline Divulgação & $2(5,8 \%)$ & $9(26,4 \%)$ & $17(50 \%)$ & $4(11,7 \%)$ \\
\hline Programação & $0(0 \%)$ & $0(0 \%)$ & $17(50 \%)$ & $15(44,1 \%)$ \\
\hline Organização & $1(2,9 \%)$ & $4(11,7 \%)$ & $8(23,5 \%)$ & $19(55,8 \%)$ \\
\hline Temas Abordados & $0(0 \%)$ & $0(0 \%)$ & $8(23,5 \%)$ & $24(70,5 \%)$ \\
\hline $\begin{array}{l}\text { Metodologia de ensino utilizada } \\
\text { pelos ministrantes }\end{array}$ & $0(0 \%)$ & $2(5,8 \%)$ & $12(35,2 \%)$ & $18(52,9 \%)$ \\
\hline Qualidade do Material & $0(0 \%)$ & $2(5,8 \%)$ & $\begin{array}{c}15 \\
(44,1 \%)\end{array}$ & $15(44,1 \%)$ \\
\hline $\begin{array}{l}\text { Capacidade do palestrante de } \\
\text { transmitir o conteúdo }\end{array}$ & $0(0 \%)$ & $1(2,9 \%)$ & $14(41,1 \%)$ & $15(44,1 \%)$ \\
\hline Alcance dos objetivos propostos & $0(0 \%)$ & $3(8,8 \%)$ & $\begin{array}{c}14 \\
(41,1 \%)\end{array}$ & $15(44,1 \%)$ \\
\hline
\end{tabular}

Fonte: Autoria própria. 
Em relação à avaliação da intervenção educativa segundo os participantes presentes, os indicadores: organização $(55,8 \%)$, temas abordados $(70,5 \%)$ e metodologia de ensino utilizada pelos ministrantes $(52,9 \%)$ obtiveram as melhores avaliações. Em contrapartida, divulgação $(5,8 \%)$ e organização $(2,9 \%)$ tiveram avaliação de fraco e médio na divulgação e organização.

A segunda etapa foi desenvolvida na Unidade Básica de Saúde com o treinamento e aplicação do instrumento para a consulta no seguimento do recémnascido prematuro. Participaram do curso duas enfermeiras e dois residentes de enfermagem. 0 treinamento ocorreu no turno da manhã. 0 público foi constituído por $100 \%$ profissionais do sexo feminino, metade atuava na UBS há menos de um ano e a outa metade há mais de cinco anos. Todos participantes possuíam pósgraduação, porém consideravam se inseguros durante as consultas dos recémnascidos prematuros, como demonstra a Tabela 3.

Tabela 3 - Caracterização de enfermeiros acerca da assistência de enfermagem ao prematuro de risco, $(\mathrm{n}=04)$, Teresina-PI, 2018.

\begin{tabular}{|c|c|c|c|}
\cline { 3 - 4 } Variáveis & $\mathbf{N}$ & $\mathbf{\%}$ \\
\hline \multirow{2}{*}{ Sexo } & Masculino & 00 & $0 \%$ \\
\cline { 2 - 4 } & Feminino & 04 & $100 \%$ \\
\hline \multirow{2}{*}{ Faixa etária } & $20-29$ anos & 02 & $50 \%$ \\
\cline { 2 - 4 } & $30-49$ anos & 02 & $50 \%$ \\
\hline \multirow{2}{*}{ Tempo de atuação em UBS } & $<1$ ano & 02 & $50 \%$ \\
\cline { 2 - 4 } Pós-graduação & $>5$ anos & 02 & $50 \%$ \\
\hline $\begin{array}{c}\text { Segurança durante a consulta no } \\
\text { seguimento do prematuro de risco? }\end{array}$ & Sim & 04 & $100 \%$ \\
\cline { 2 - 4 } & Sim & 00 & $0 \%$ \\
\hline Total Não & 04 & $100 \%$ \\
\hline
\end{tabular}

Fonte: Autoria própria.

Como seguimento da intervenção na consulta de enfermagem do recémnascido prematuro de risco, após aplicação do instrumento de SAE na UBS, avaliouse este instrumento junto aos enfermeiros participantes. Quanto aos participantes, $100 \%$ afirmaram que o instrumento é importante para a consulta de enfermagem, sendo de fácil uso e aplicabilidade, como demonstra a tabela 4. 
Tabela 4 - Avaliação da aplicabilidade do Instrumento da SAE para consulta do prematuro de risco, $(n=04)$, Teresina-PI, 2018.

\begin{tabular}{|c|r|r|c|}
\hline Variáveis & & $\mathbf{N}$ & \multicolumn{1}{c|}{$\%$} \\
\hline $\begin{array}{c}\text { Você acha importante o Instrumento da } \\
\text { SAE para a Consulta de Enfermagem do } \\
\text { prematuro de risco? }\end{array}$ & Sim & $\mathbf{0 4}$ & $\mathbf{1 0 0 \%}$ \\
\hline $\begin{array}{c}\text { Você concorda que o instrumento da } \\
\text { SAE é de fácil entendimento e } \\
\text { aplicabilidade? }\end{array}$ & Sim & $\mathbf{0 4}$ & $\mathbf{1 0 0 \%}$ \\
\hline Total & & $\mathbf{0 4}$ & $\mathbf{1 0 0 \%}$ \\
\hline
\end{tabular}

Fonte: Autoria própria.

No presente estudo verificou-se o perfil dos profissionais que prestam assistência direta ao recém-nascido da instituição estudada e a participação deles por eixos temáticos.

O curso teve como tema principal a "Atenção humanizada ao recém-nascido", visto que nas últimas décadas a partir das políticas públicas desenvolvidas no Brasil, verificou-se um impacto significativo no atendimento à saúde e sobrevivência dos recém-nascidos. A implementação da humanização reflete profissionais com intervenções referentes à individualidade e integralidade do cuidado, com garantia de tecnologia para segurança do recém-nascido, acolhimento à família, incentivo ao vínculo e apego, entre outras (NOGUEIRA; RODRIGUES, 2015).

A participação dos profissionais durante o curso demonstrou o interesse em realizar atividades de atualização na área para aprimoramento das ações nos setores atuantes, assim como a minimização de riscos aos recém-nascidos. 0 interesse e envolvimento no curso podem despertar para a prática assistencial de enfermagem pautada na humanização, assim como o avanço na atenção neonatal, por meio de evidências científicas, inovações tecnológicas para condução clínica e cuidados ao bebê. Para qualidade no cuidado, torna-se necessária que a equipe de enfermagem busque aperfeiçoamento na perspectiva da humanização do cuidado (FERREIRA; LOPES, 2016).

No segundo dia do curso, com o tema principal assistência de enfermagem ao prematuro de risco, observou-se a participação de 44 (73,33\%) profissionais de enfermagem. Foi relatada a importância do seguimento do prematuro de risco, visto que a terceira etapa do método canguru consiste no acompanhamento da criança após a alta hospitalar no ambulatório e no domicílio com a participação da Atenção Básica. O Ministério da saúde propõe a vinculação da Atenção Básica com o 
ambulatório nessa etapa, no entanto, sabe-se que ainda é tímida a articulação dos diversos níveis de saúde (BRASIL, 2013).

As educações dos profissionais de saúde, principalmente os da área de enfermagem, necessitam de atualizações constantes. A educação permanente é uma exigência para os profissionais, visto que requer deles novas formas de conhecimento, entendida como a aprendizagem no trabalho. 0 cuidado não se embasa somente em equipamentos especiais, mas também em atitude particular da equipe, com orientações destas para as facilidades técnicas, com oferecimento de segurança e apoio emocional, tanto aos pacientes quanto aos acompanhantes e familiares (VIEIRA et al, 2014).

Sobre a avaliação do curso, divulgação e organização tiveram avaliação de fraco e médio, vale ressaltar que o NEEPS foi o responsável por divulgação, talvez por funcionar só no turno da manhã não houve uma maior divulgação entre os profissionais. $\mathrm{O}$ fato de o curso ter sido realizado só no turno da manhã, talvez contribuísse para a nota da organização, visto que alguns profissionais reclamaram de não ter acontecido em todos os turnos.

Por outro lado, os indicadores: organização, temas abordados e metodologia de ensino utilizada pelos ministrantes obtiveram as melhores avaliações. Os participantes apreciaram a atividade de intervenção por abordar temas em constante atualização e esclarecer as principais dúvidas durante a realização de procedimentos na prática. Assim, foi possível atingir os objetivos propostos, com repasse dos conteúdos de forma clara e objetiva.

$\mathrm{Na}$ pesquisa verificou-se também o perfil dos profissionais envolvidos no treinamento para implantação da consulta de enfermagem no seguimento do prematuro de risco na Unidade Básica de Saúde (UBS).

Os resultados demonstraram que a maioria dos profissionais de enfermagem possui o tempo de atuação na Atenção Básica maior que cinco anos, total de 2 (50\%) profissionais de enfermagem, dados significativos pois é recomendado ter profissionais com maior experiência profissional para trabalhar com o recémnascido de alto risco, uma vez que eles precisam de cuidados específicos. No tocante a qualificação, 4 (100\%) dos profissionais de enfermagem possui pós-graduação, o que reforça a busca pela atualização e busca de estratégias de humanização no atendimento ao RN de risco (SANTOS; CAMPELO, 2015). 
No início da capacitação dos profissionais foi questionado a eles quanto à segurança durante o atendimento do prematuro de risco, observou-se que todos responderam não ter segurança durante a consulta. Avaliou-se, em Santa Catarina, a percepção dos profissionais de saúde da Atenção Básica sobre o seguimento do prematuro com a interface da terceira etapa do método canguru, o que demonstrou a insegurança dos enfermeiros a esse público. Muitos encaminhavam o recém-nascido ao consultório médico com a justificativa de este profissional passar mais segurança aos pais e familiares (AIRES et al, 2015).

Nesta pesquisa, por meio de um questionário, os enfermeiros avaliaram o instrumento da Sistematização da Assistência de Enfermagem durante a consulta do prematuro de risco. Observaram que o instrumento era de fácil entendimento e aplicabilidade. A avaliação dos enfermeiros quanto ao uso do instrumento foi positiva, visto que estudos demonstram insegurança na sua aplicabilidade prática. No cenário da atenção primária, por muitas vezes priorizar o atendimento por demanda espontânea, os profissionais de enfermagem não aplicam a sistematização durante as consultas, ou pulam suas etapas. A operacionalização do processo de enfermagem através da SAE desenvolve o pensamento crítico durante a prática, gerenciamento, promoção do cuidado humanizado, desperta os profissionais para reavaliação de suas ações e decisões de qual melhor prática utilizar (SANTANA et al, 2013; KRAUZER et al, 2015; DINIZ et al., 2015).

A terceira etapa do método requer acompanhamento multiprofissional, pela Atenção Básica e ambulatório. Embora o Ministério da Saúde incentive a participação dos profissionais, ainda assim esta ainda não é a realidade na maioria dos municípios brasileiros. As dificuldades apresentadas pelos enfermeiros em atuar na consulta de enfermagem do recém-nascido prematuro, pode estar relacionada ao limitado conhecimento dos mesmos em conduzir uma consulta de um grupo tão específico. Torna-se necessária a capacitação profissional nos diversos níveis de atenção a saúde para efetivação de todas as etapas do método canguru (AIRES et al, 2015). 
Os dados do presente estudo indicam o interesse dos profissionais por atividades educativas para atualização e aprimoramento de seus conhecimentos nos setores atuantes. 0 envolvimento refletirá em uma melhor assistência de enfermagem aos prematuros de risco, assim como qualidade no cuidado humanizado. Torna-se importante o desenvolvimento de mais ações educativas sobre temas relevantes ao aprimoramento profissional, com esclarecimento de dúvidas, oportunidades de crescimento profissional.

Acredita-se que a atualização dos profissionais da Atenção Básica, quanto à consulta de enfermagem do prematuro de risco, trará práticas de saúde mais seguras, que possam contribuir e melhorar as possibilidades de um desenvolvimento mais saudável à criança nascida prematura.

A implantação da consulta de enfermagem no seguimento do prematuro de risco na atenção básica, com o instrumento da Sistematização da Assistência de Enfermagem, trouxe para as equipes um direcionamento e esclarecimento sobre esse público. Nota-se que mesmo com a obrigatoriedade da SAE em todos os serviços de saúde, ainda se encontra distante do cotidiano de muitos profissionais. Mas com o interesse dos profissionais e incentivos é possível chegar a um serviço de assistência sistematizado.

A atuação do enfermeiro no seguimento do prematuro de risco é de suma importância, visto que esse profissional é interlocutor entre a família e a equipe multiprofissional. Espera-se que a presente intervenção possa contribuir com subsídios da consulta de enfermagem e a sistematização no seguimento do prematuro de risco seja estabelecida em todos os níveis de atenção.

\section{REFERÊNCIAS}

AIRES, L.C.P., et al. Referência e contra referência do bebê egresso da unidade neonatal no sistema de saúde: percepção de profissionais de saúde da atenção primária. Esc Anna Nery, v.21, n.2, p. 1-7, 2017.

AIRES, L.C.P., et al. Seguimento do bebê na atenção básica: interface com a terceira etapa do método canguru. Rev Gaúcha Enferm, v.36, n.1, p.224-32, 2015. 
BRASIL. Ministério da Saúde. Atenção humanizada ao recém-nascido de baixo peso: Método Canguru: manual técnico. Brasília, DF, 2013.

DINIZ, I.A., et al. Percepção dos Enfermeiros Gestores da Atenção primária Sobre o Processo de Enfermagem. Rev Bras de Enf, v.68, n.2, p.206-13,2015.

FERREIRA, J.H.P; AMARAL, J.J.F; LOPES, M.M.C. Equipe de enfermagem e promoção do cuidado humanizado em unidade neonatal. Rev.Rene. v.6, n.17,p. 741-9, 2016.

GONTIJO, M.L., et al. Evasão em ambulatório de seguimento do desenvolvimento de pré-termos: taxas e causas. Cad. Bras. Ter Ocup, v. 26, n. 1, p.73-83, 2018.

KRAUZER, I.M, et al. Sistematização da assistência de enfermagem na Atenção básica: o que dizem os enfermeiros?. Ciencia y enfermeria, v.21, n.2, p.31$38,2015$.

LEITE, P.F.P, et al. Incidência de Aleitamento materno no momento da alta da terceira etapa do método canguru da maternidade Ana Braga. Rev de Ciências da saúde da Amazônia, v.1, n.1, p.45-68, 2016.

MARQUES, C.R.G., et al. Metodologia canguru: benefícios para o recém-nascido prétermo. Ciências biológicas e de saúde, v.3, n.3, p.65-78, 2016.

NOGUEIRA, J.W.S; RODRIGUES, M.C.S. Comunicação efetiva no trabalho em equipe em saúde: desafio para segurança do paciente. Cogitare Enfermagem, v.1, n.17, p.636-640, 2015.

OLIVEIRA, S.K.P., et al. Temas abordados na consulta de enfermagem: revisão integrativa da literatura. Rev Bras de Enf, v.1, n.65, p.155-61, 2012.

SALES, I.M.M. Contribuições da equipe enfermagem na segunda etapa do Método Canguru: Implicações para a alta hospitalar do recém-nascido. Esc Anna Nery, v.4, n.22, p.1-8, 2018.

SANTANA, J.C.B, et al. Percepção dos enfermeiros acerca da Sistematização da Assistência de Enfermagem na atenção básica de Belo Horizonte. Enf Rev, v. 16, n.1, p. 4-17, 2013.

SANTOS, F. C.; CAMPELO, S. H. O enfermeiro que atua em Unidades de Terapia Intensiva: Perfil e Capacitação Profissional. Cult. cuid, v.19, n. 43, p.127-140, 2015.

VIEIRA, G. B. et al. Primeiros passos da educação permanente em enfermagem de uma Unidade de Terapia Intensiva Neonatal. Rev Enferm UFPE, v. 8, n. 4, p.889-95, 2014. 


\section{REFLEXÕES SOBRE PRÁTICA ASSISTENCIAL INOVADORA E DE QUALIDADE DA GRAVIDEZ AO NASCIMENTO}
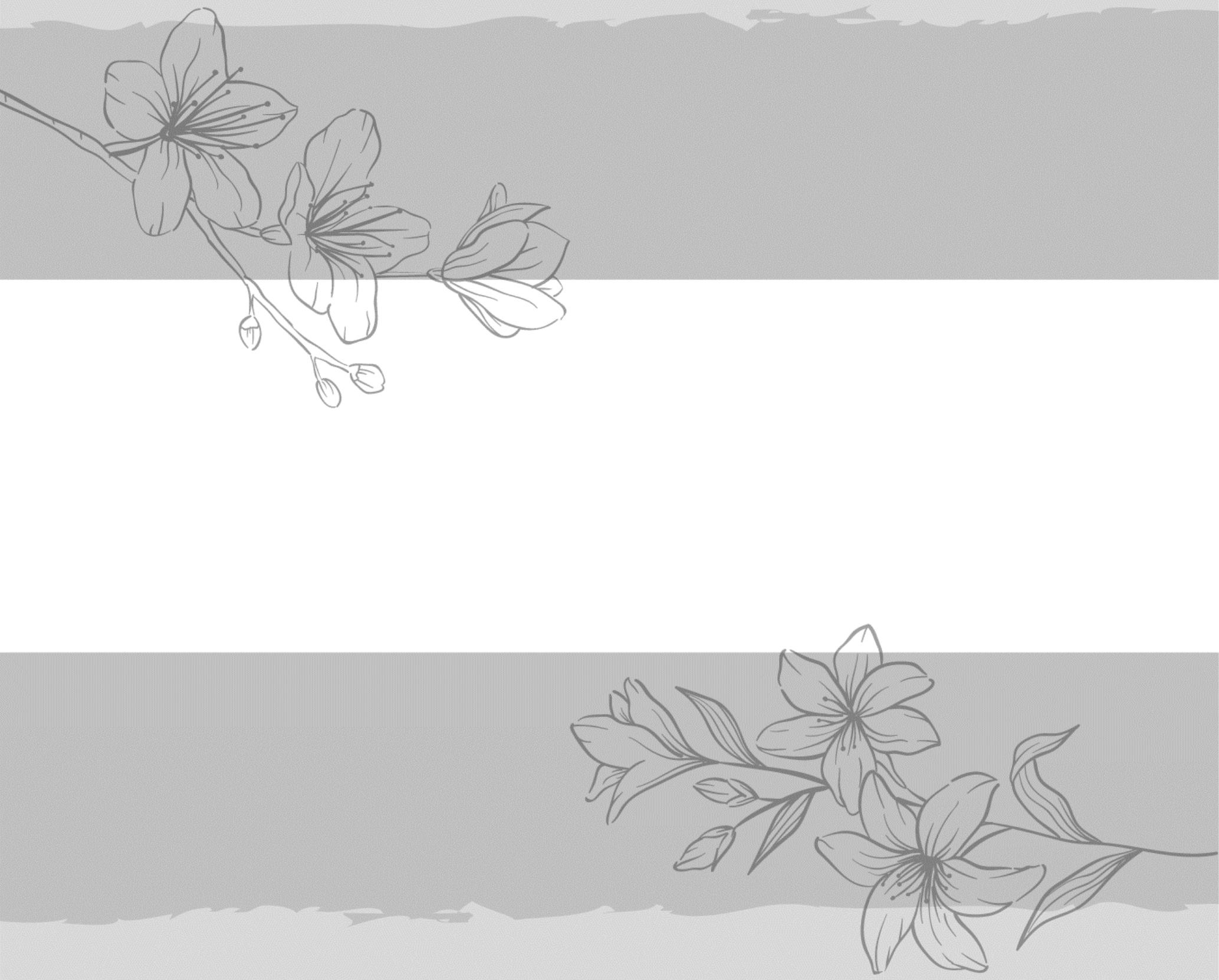

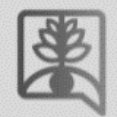




\section{REFLEXÕES SOBRE PRÁTICA ASSISTENCIAL INOVADORA E DE QUALIDADE DA GRAVIDEZ AO NASCIMENTO}
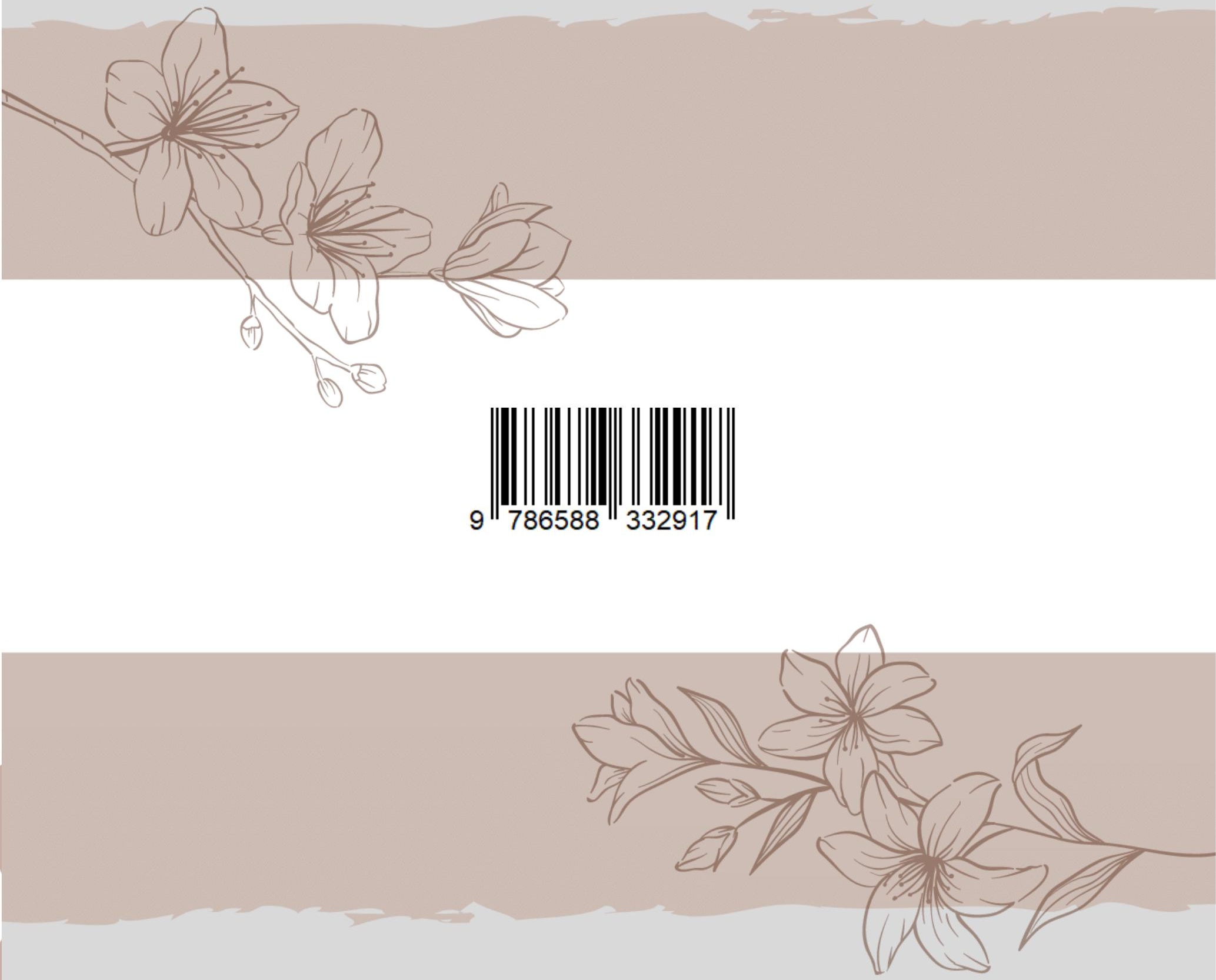